\title{
CROSS-SCALE INTERACTIONS BETWEEN ATMOSPHERIC AND HYDROLOGIC PROCESSES IN A TOPOGRAPHICALLY COMPLEX, SNOW-DOMINATED WATERSHED AS REVEALED THROUGH AN INTEGRATED HYDROLOGIC MODEL
}

\author{
by \\ Miguel A. Aguayo Arias
}

\author{
A dissertation \\ submitted in partial fulfillment \\ of the requirements for the degree of \\ Doctor of Philosophy in Geosciences \\ Boise State University
}

December 2018 
Miguel A. Aguayo Arias

SOME RIGHTS RESERVED

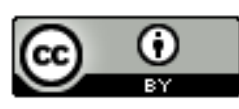

This work is licensed under a Creative

Commons Attribution 4.0 International

License 
BOISE STATE UNIVERSITY GRADUATE COLLEGE

\title{
DEFENSE COMMITTEE AND FINAL READING APPROVALS
}

of the dissertation submitted by

\author{
Miguel A. Aguayo Arias
}

\begin{abstract}
Dissertation Title: Cross-scale Interactions Between Atmospheric and Hydrologic Processes in a Topographically Complex, Snow-dominated Watershed as Revealed Through an Integrated Hydrologic Model
\end{abstract}

Date of Final Oral Examination: 02 May 2018

The following individuals read and discussed the dissertation submitted by student Miguel A. Aguayo Arias, and they evaluated the students presentation and response to questions during the final oral examination. They found that the student passed the final oral examination.

\author{
Alejandro Flores Ph.D. Chair, Supervisory Committee \\ James McNamara Ph.D. Member, Supervisory Committee \\ Hans-Peter Marshall Ph.D. Member, Supervisory Committee \\ Jodi Mead Ph.D. Member, Supervisory Committee \\ Daniele Tonina Ph.D. External Examiner
}

The final reading approval of the dissertation was granted by Alejandro Flores Ph.D., Chair of the Supervisory Committee. The dissertation was approved by the Graduate College. 


\section{DEDICATION}

To my wonderful family:

My wife Carmen,

and my children, Emilia and Mateo 


\section{ACKNOWLEDGMENT}

I would like to express my sincere gratitude and enormous appreciation to my advisor Dr. Alejandro Flores for all his support, generosity and time in guiding me throughout this journey.

I would also like to thank to my dissertation committee: Dr. James McNamara, Dr. Hans-Peter Marshall and Dr. Jodi Mead for all their support, constructive discussions and feedback during all my PhD program and my dissertation. Also special thanks to my external examiner Dr. Daniele Tonina for all his support and time.

I would like to thank all the funding agencies for their generous support: National Science Foundation IIA-1329513 Collaborative Research: Western Consortium for Watershed Analysis, Visualization, and Exploration (WC-WAVE); NASA award NNX15AD56G, "Multiple frequency active microwave remote sensing for snow wa-

ter equivalent retrieval from space: A data assimilation approach." and NASA award NNX14AN39A, "Monitoring Earths Hydrosphere: Integrating Remote Sensing, Modeling, and Verification".

I would like to thank all LEAF group members for their friendly support, generosity and kindness. Especially thanks to Katelyn Fitzgerald and Matt Masarik for 
their amazing support on WRF modeling and simulations.

I would like to thank Ben Nickell and Eric Whiting from Idaho National Laboratory for their remote support on high performance computing.

Finally, I wish to thank my wife Carmen and to our beloved children Emilia and Mateo, for all their support and encouragement throughout this journey. 


\begin{abstract}
In much of the world, water for agricultural, domestic, and hydroelectric power generation uses are derived from snow-dominated mountain basins. In these regions, water management requires accurate and timely knowledge of runoff generation by snowmelt. This information is used to plan reservoir releases for downstream users and is generated by models of biophysical processes associated with varying degrees of fidelity to physical processes and/or spatial heterogeneities. The large variability in the characteristic spatial and temporal scales of atmospheric forcings, land-surface water and energy balance, and groundwater flow contribute to significant uncertainties in resolved hydrologic states and fluxes. Underlying sources of uncertainty in these models include difficulties in parameterizing nonlinear or unresolved processes, associated uncertainties in meteorological forcing data and parameters, as well as the large variability in characteristic spatial and temporal scales of atmospheric forcing, surface energy balance, and subsurface hydrological processes. These sources of uncertainty can introduce systematic biases when performing integrated atmospheric and hydrologic modeling. Reconciling these discrepancies while maintaining computational tractability remains a fundamental challenge in hydrologic modeling. This work investigates and quantifies the impacts of discrepancies in scales between distributed meteorological forcing data and modeled land surface and subsurface water flow at hillslope scales. In particular, we are interested in assessing hydrologic state
\end{abstract}


variables and fluxes such as snow water equivalent, discharge, and soil water storage. Also, this work includes the evaluation of the outputs of integrated hydrologic models against observations for a particular set of environmental forcing data (i.e., spatially distributed, semi-distributed, and uniform). We also include an investigation of how the external forcings impact the estimation of snow prognostic and diagnostic variables, primarily snow water equivalent, by performing a global sensitivity analysis. Results of this work suggest that topography (e.g., slope, aspect and valley bottoms) is the primary physiographic variable that describes variations spatial patterns of snow water equivalent and soil water storage when hillslope-scale models are driven by atmospheric forcing characterized by a range of spatial resolutions. At the same time, simulations performed with spatially distributed and semi-distributed meteorological forcings revealed interesting interrelationships between different forcing variables during the snowmelt process. Of particular significance were relationships found between longwave radiation and other atmospheric forcings. Our global sensitivity analyses work allowed us to quantify the strength of first and second order interactions between forcing variables and the snowmelt process. This work has important implications for the use of atmospheric data and integrated hydrologic models in remote and ungauged areas and provides key insights regarding which forcing variables, if measured more precisely, may afford the most significant improvements in snowmelt predictions. In particular, this work has potential ramifications for the selection of forcing datasets for integrated hydrologic modeling experiment as well as for the design and development of observing system simulation experiments (OSSEs) in complex and snow-dominated landscapes. 


\section{TABLE OF CONTENTS}

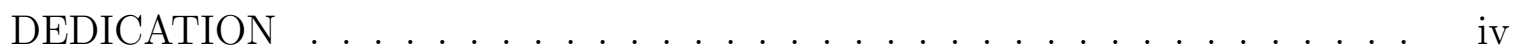

ACKNOWLEDGMENT . . . . . . . . . . . . . . . . . v v

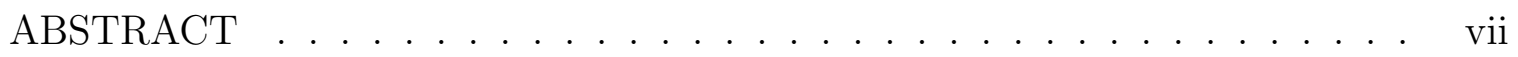

LIST OF FIGURES . . . . . . . . . . . . . . . . . . xiii

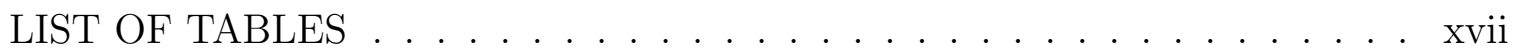

1 INTRODUCTION . . . . . . . . . . . . . . . . . 1

2 ASSESSING THE EFFECTS OF METEOROLOGICAL FORCING ON SNOWMELT PROCESSES BY PERFORMING A SNOW MODEL GLOBAL SENSITIV-

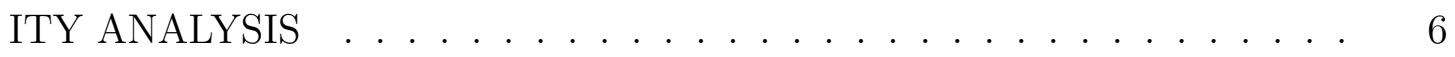

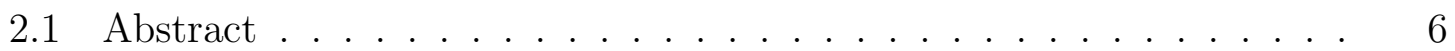

2.2 Introduction . . . . . . . . . . . . . . . . . . 7

2.3 Methods . . . . . . . . . . . . . . . . . . . . . . . 12

2.3.1 Sites ............................. 12

2.3.2 Model ......................... 14

2.3.3 Sensitivity Analysis . . . . . . . . . . . . . . 17 
2.3.4 Sensitivity Analysis Process, Algorithm and Experiments . . 20

2.4 Results........................... 22

2.4.1 Snow Model Capabilities . . . . . . . . . . . . . . 22

2.4.2 Distribution of Forcing Data . . . . . . . . . . . . . 24

2.4.3 Sensitivity Indices . . . . . . . . . . . . . . . . . . . . 30

2.5 Discussion . . . . . . . . . . . . . . . . . . . . . . . . . . 30

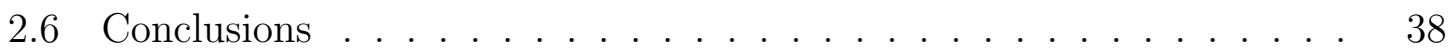

3 ASSESSING CROSS-SCALE INTERACTIONS BETWEEN ATMOSPHERIC AND HILLSLOPE-SCALE HYDROLOGY MODELS IN SNOW-DOMINATED COMPLEX WATERSHEDS USING MODELS . . . . . . . . . . . . 40

3.1 Abstract . . . . . . . . . . . . . . . . . 40

3.2 Introduction . . . . . . . . . . . . . . . . . . . . . . 42

3.3 Methods . . . . . . . . . . . . . . . . . . 47

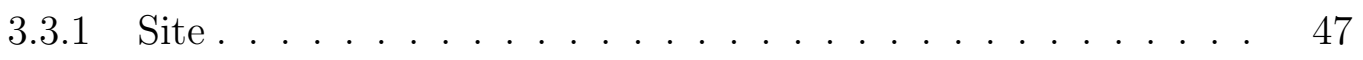

3.3.2 Modeling Framework . . . . . . . . . . . . . . . . . 47

3.3.3 Experimental setup ................ 50

3.3.4 Hydrologic variables assessed . . . . . . . . . . . 52

3.3.5 Data requirement and model configuration . . . . . . . . 55

3.4 Results.............................. 62

3.4.1 Spatially distributed RMSE for SWE and soil water storage . 63

3.4.2 Spatially distributed bias for SWE and soil water storage . . . 67

3.5 Discussion . . . . . . . . . . . . . . . . . . . 71

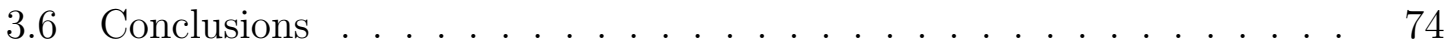


4 EXAMINING IMPACTS OF VARYING SPATIAL RESOLUTIONS OF ATMOSPHERIC FORCING DATA ON INTEGRATED HYDROLOGIC MODELING IN SNOW-DOMINATED, MOUNTAIN WATERSHEDS $\ldots . .76$

4.1 Abstract . . . . . . . . . . . . . . . . 76

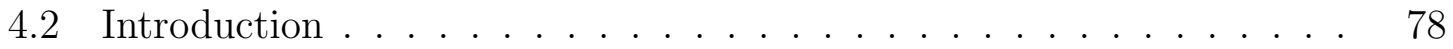

4.3 Methods . . . . . . . . . . . . . . . . . . . . . . 81

4.3 .1 Study area . . . . . . . . . . . . . . . . . . . 81

4.3.2 Experiments and modeling framework . . . . . . . . . 82

4.3 .3 Atmospheric data . . . . . . . . . . . . . . . . 86

4.3.4 Land surface and subsurface data . . . . . . . . . . . 88

4.3 .5 Initial condition data . . . . . . . . . . . . . . . . . . 89

4.3.6 Assessment of experiments . . . . . . . . . . . . . . . 990

4.4 Results . . . . . . . . . . . . . . . . . . . . . 91

4.4.1 Analysis on snow water equivalent . . . . . . . . . . . . 92

4.4 .2 Analysis on discharge . . . . . . . . . . . . . . . . 98

4.4 .3 Analysis on soil water storage . . . . . . . . . . . . 102

4.5 Discussion . . . . . . . . . . . . . . . . . . . . . . . . 108

4.6 Conclusions . . . . . . . . . . . . . . . . . . . . . . . . 113

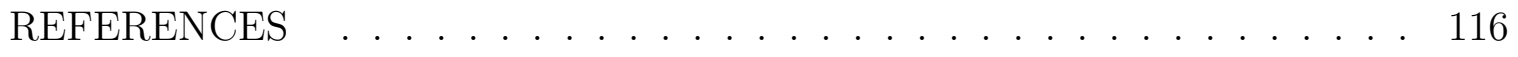

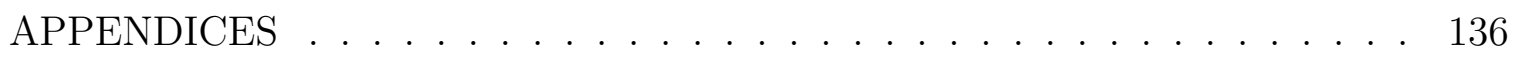

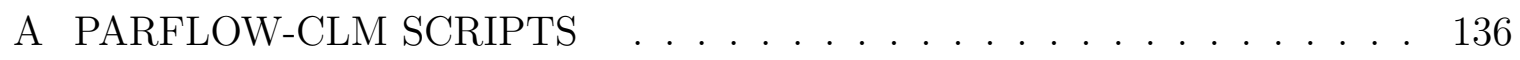

A.1 Parflow-clm scripts Repository . . . . . . . . . . . . . . 137 
B PARFLOW-CLM PREPROCESSING SCRIPTS . . . . . . . . 138

B.1 Python Parflow-CLM preprocessing functions for DEM, soil and land cover data . . . . . . . . . . . . . . . . . . . . . . 139

B.2 TCL script to process flat areas, fill pits and set slopes in Parflow domain . . . . . . . . . . . . . . . . . . 146

B.3 TCL script to set soil indicators . . . . . . . . . . . . . . 148

B.4 Bash script to run Python functions and TCL scripts . . . . . . . 149

C PARFLOW-CLM MODELING SCRIPTS . . . . . . . . . . . 151

C.1 TCL script to run Parflow-CLM model . . . . . . . . . . . . . 152

C.2 TCL script to distribute WRF forcing meteorological data . . . . . 164

D PARFLOW-CLM POSTPROCESSING SCRIPTS . . . . . . . 166

D.1 TCL script for streamfow estimation $\ldots \ldots \ldots \ldots \ldots \ldots$

D.2 TCL script to get SWE data at specific points . . . . . . . . . 169

D.3 Python script to convert spatially distributed outputs to vtk format . 170 


\section{LIST OF FIGURES}

1.1 Relationship between spatial and temporal hydrological process scales and atmospheric processes. (From Bronstert et. al., 2005. Extended from Blöschl (1996) by Niehoff $(2002))$. . . . . . . . . . . . . . 3

2.1 Weather and snow data stations. . . . . . . . . . . . . . . 14

2.2 Temperature balance in a multi-layer snowpack (A) and configuration of the energy balance model used by SNTHERM (B). . . . . . . . . 16

2.3 Sensitivity analysis workflow. Bordered boxes show GSA process steps. Dark boxes describe data and/or the procedure need in each step. . . 20

2.4 Sobols Sensitivity analysis process, from forcing data selection and sampling to Sobols indices computation. . . . . . . . . . . . .

2.5 Snow simulations performed by the snow energy balance model at Snoqualmie Pass (A); Treeline station (B) and Swamp Angel Study Plot (C) in water year 2014. . . . . . . . . . . . . . . .

2.6 Normalized frequencies of forcing magnitudes related to a snowmelt event at Snoqualmie Pass station and adjusted PDFs for each variable; Generalized logistic (A), Johnson $\mathrm{S}_{\mathrm{B}}(\mathrm{B})$, Gauss hypergeometric (C), Johnson $\mathrm{S}_{\mathrm{U}}(\mathrm{D})$, Johnson $\mathrm{S}_{\mathrm{B}}(\mathrm{E})$. . . . . . . . . . . . . . 27 
2.7 Normalized frequencies of forcing magnitudes related to a snowmelt event at Treeline station and adjusted PDFs for each variable; Generalized logistic (A), Gauss hypergeometric (B), Beta (C), Reciprocal Inverse Gaussian (D), Exponentially Modified Normal (E). . . . . . . 28

2.8 Normalized frequencies of forcing magnitudes related to a snowmelt event at Swamp Angel Study Plot station and adjusted PDFs for each variable; Generalized Logistic (A), Exponentiated Weibull (B), Johnson $S_{B}(C)$, Generalized Normal (D), Log-Laplace (E). . . . . . . .

2.9 Sensitivity variation of the snow model using 12 ensembles time series generated by Saltelli's extension of the Sobol sequence for the three sites: Snoqualmie Pass (A), Treeline (B) and Swamp Angel Study Plot

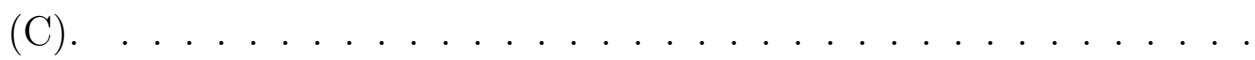

2.10 First order and second order or forcing interactions of sites: (A) Snoqualmie Pass, (B) Treeline and (C) Swamp Angel Study Plot. . . . .

3.1 Dry Creek Experimental Watershed study area with some relevant weather $(\triangle)$ and discharge $(\circ)$ stations. . . . . . . . . 48

3.2 Multiscale modeling assessment framework. . . . . . . . . . . . 53

3.3 Schematic cell representation of surface and subsurface layers in ParFlowCLM. Variables $q_{f}$ represent downward energy fluxes from forcings and $q_{L H}$ upward energy fluxes (sensible and latent) respectively, from snow

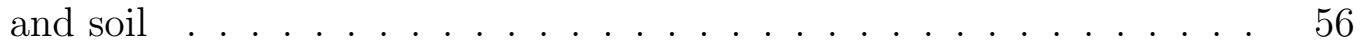

3.4 Detailed soil layers configuration for the modeling domain used in ParFlow-CLM simulations. . . . . . . . . . . . . . . . 59

3.5 Soil moisture initial conditions generation process. . . . . . . . . 61 
3.6 Soil moisture initial conditions and an example of distributed atmospheric data generated by WRF model. . . . . . . . . . . . . . . . . 61

3.7 Soil moisture at $2 \mathrm{~cm}$ observed simulated time series at lower south station in DCEW. Precipitation data is retrieved from Lower Weather station (see Figure 3.1). . . . . . . . . . . . . . . . . . . 63

3.8 Spatially distributed RMSEs for SWE in water year 2014. . . . . . . 64

3.9 Spatially distributed RMSEs for soil water storage in water year 2014. 66

3.10 Spatially distributed bias for SWE in water year 2014. . . . . . . . 68

3.11 Spatially distributed ME for soil water storage in water year 2014. . . 70

4.1 Study site (DCEW) with some relevant weather $(\triangle)$ and discharge (o) stations (right) and WRF domains used for forcing data in northwest United States (left). . . . . . . . . . . . . . .

4.2 Modeling framework diagram and corresponding prognostic and diagnostic variables. . . . . . . . . . . . . . . . . 85

4.3 Hydrologic modeling experiments and analysis diagram. . . . . . . . . 86

4.4 Soil texture and land cover classification on the study domain. Nomenclature for soil texture correspond to: SL for Sandy Loam; SCL for Sandy Clay Loam; LS for Loamy Sand; L for Loam and C for Clay. Nomenclature for IGBP classification correspond to: G for Grasslands; OS for Open Shrublands; ENF for Evergreen Needleleaf Forests DNF for Deciduous Needleleaf Forests and B for Barren. . . . . . . . . .

4.5 Snow depth and meteorological stations within DCEW modeling domain. Bogus Ridge station is used only to generate distributed data through spatial interpolation. . . . . . . . . . . . . . 
4.6 Modeling performance on SWE variable, using WRF outputs as forcing

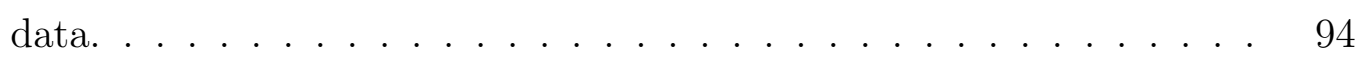

4.7 Modeling performance on SWE variable, using IMS data as forcing data. 95

4.8 Taylor diagram for simulated SWE. . . . . . . . . . . . . . . . . 96

4.9 Discharge gauges within DCEW modeling domain. . . . . . . . . . 100

4.10 Modeling performance on discharge variable, using WRF outputs as forcing data. . . . . . . . . . . . . . . . . . . 101

4.11 Modeling performance on discharge variable, using IMS data as forcing data. . . . . . . . . . . . . . . . . . . 102

4.12 Taylor diagram for simulated discharge. . . . . . . . . . . . . 103

4.13 Soil moisture stations within DCEW modeling domain. . . . . . . . . 106

4.14 Modeling performance on soil water storage variable, using WRF outputs as forcing data. . . . . . . . . . . . . . . . 107

4.15 Modeling performance on soil water storage variable, using IMS data as forcing data. . . . . . . . . . . . . . . . . . . . 108

4.16 Taylor diagram for simulated discharge. . . . . . . . . . . . . . . . 109 


\section{LIST OF TABLES}

2.1 Data summary of meteorological station. Superscript numbers indicate the corresponding historical periods of record. . . . . . . . . . . . . . 13

2.2 Snow depth initial condition internal parameters and number of samples for all the synthetic experiments performed in each site. . . . . . 22

2.3 SNTHERM performance in all stations. . . . . . . . . . . . . . . 24

2.4 Range of values for each forcing data, used to fit the probability density functions at each site. . . . . . . . . . . . . . . 26

2.5 First, total and second order index for Snoqualmie Pass site. . . . . . 33

2.6 First order index for Treeline (No second order interactions encountered in this site) . . . . . . . . . . . . . .

2.7 First order index for Swamp Angel Study Plot. (No second order interactions encountered in this site). . . . . . . . . . . . .

3.1 Simulation experiments and nomenclature. . . . . . . . . . . . 54

3.2 Summary of soil parameters selected from Leij (1996) and Simmers (2005) and applied to the DCEW study domain. . . . . . . . . 59

3.3 Summary of RMSEs for SWE $(\mathrm{mm}) . \ldots \ldots$. . . . . . . . . 65

3.4 Summary of RMSEs for soil water storage $(\mathrm{cm}) \ldots \ldots$. . . . . . . . 67

3.5 Summary of ME for SWE $(\mathrm{mm}) . \ldots \ldots \ldots$

3.6 Summary of ME for soil water storage $(\mathrm{cm}) \ldots \ldots$. . . . . . . . . 71 
4.1 Atmospheric data configurations and nomenclature for the simulation

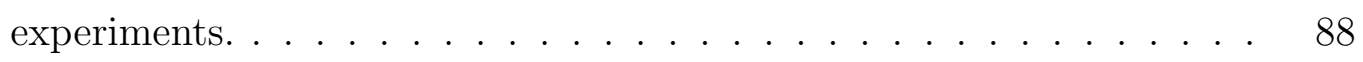

4.2 Summary of spatial average of normalized standard deviation, RMSE and Pearson correlation between simulated and observed data (reference) for SWE variable at Lower Weather (LW); Treeline (TL); Shingle Creek (SC) and Lower Deer Point (LD) stations. . . . . . . . . . . 97

4.3 Wilcoxon Rank-Sum statistic summary for Shingle Creek (SC) and Lower Deer $(\mathrm{LD})$ point. . . . . . . . . . . . . . . . .

4.4 Summary of spatial averaged of normalized standard deviation, RMSE and Pearson correlation between simulated and observed data (reference) for discharge variable at Lower Gauge (LG); Con2Main (C2M); Con2East (C2E); Con1West (C1W) stations. . . . . . . . . . . . . 104

4.5 Summary of spatial averaged of normalized standard deviation, RMSE and Pearson correlation between simulated and observed data (reference) for soil water storage variable at Low S-facing (LS); Mid-Low S-facing (MLS); Mid-High S-facing (MHS) and High N-facing (HN) stations. . . . . . . . . . . . . . . . . 110 


\section{CHAPTER 1: INTRODUCTION}

In snow-dominated watersheds throughout the world, snow accumulation and melt are the most critical factors to generate sufficient water supply for human and ecological systems. In order to quantify the amount of water released from watersheds, it is essential that snow distribution and ablation in space and time can be accurately estimated across these landscapes that exhibit complexity in key controlling

factors such as topographic elevation, slope, aspect, and vegetation. Ground-based and remote sensing observational data, distributed temperature index models, physically based mass and energy balance models, and data-assimilation processes are among the variety of tools employed often proposed for addressing these estimation at a specific spatiotemporal scale. However, many problems associated particularly on physically based models (such as difficulty of parameterization and validation), not only result from the nonlinearites of some hydrologic processes but also from the high variability of spatial and temporal scale (Seyfried \& Wilcox, 1995). Even though physical models and data-assimilation processes are able to reproduce snow cover and snow water equivalent reasonably, we are still facing scale discrepancies on land surface-subsurface modeling processes, that may result in different conclusions in monitoring and forecasting (Bronstert et al., 2005).

In many efforts to model the spatiotemporal distribution of snow at high spatial 
resolutions, small-scale hydrologic models are forced by large-scale meteorological forcing. This involves the exchange of information between scales through some sort of interpolation, extrapolation or equivalent that constitute a nonnegligible source of uncertainty (Blöschl \& Sivapalan, 1995). The wide range of spatial and temporal scales in hydrologic and atmospheric processes with which models must cope is underscored in Figure 1.1. The precipitation process for instance, varies across ranges of scale of several meters to more than $1000 \mathrm{~km}$ in space and from minutes to days in time. Subsurface flow, by contrast, varies across a range of several meters to thousands of meters in space and from hours to several years in time(Blöschl \& Sivapalan, 1995; Wu \& Li, 2009). On the other hand, hydrologists and atmospheric scientists often use remote sensing measurements to compare with model outputs, or to constrain the model outputs via data assimilation (Lahoz et al., 2010). However, remote sensing techniques are associated with scaling issues that can be independent of those scale issues associated with modeling. Those scale effects may restrict the accuracy of retrieval and also limit the improvement of remote sensing techniques (Bronstert et al., 2005). Retrieval models and algorithms are generally made at small scales (e.g., at the scale of a single tower footprint) that are then directly applied at regional scales without regard to issues of scale. For instance, an estimation of soil moisture content in a small area in a watershed is ill-suited as a drought index at regional scale information, despite the fact that the data is often used in this way ( $\mathrm{Wu} \& \mathrm{Li}, 2009)$. To take advantage of remote sensing data for modeling and data assimilation processes at different scales, upscaling or downscaling methods are required. In this manner, spatial scale choice in sensor design will be an important decision before putting them in production. 


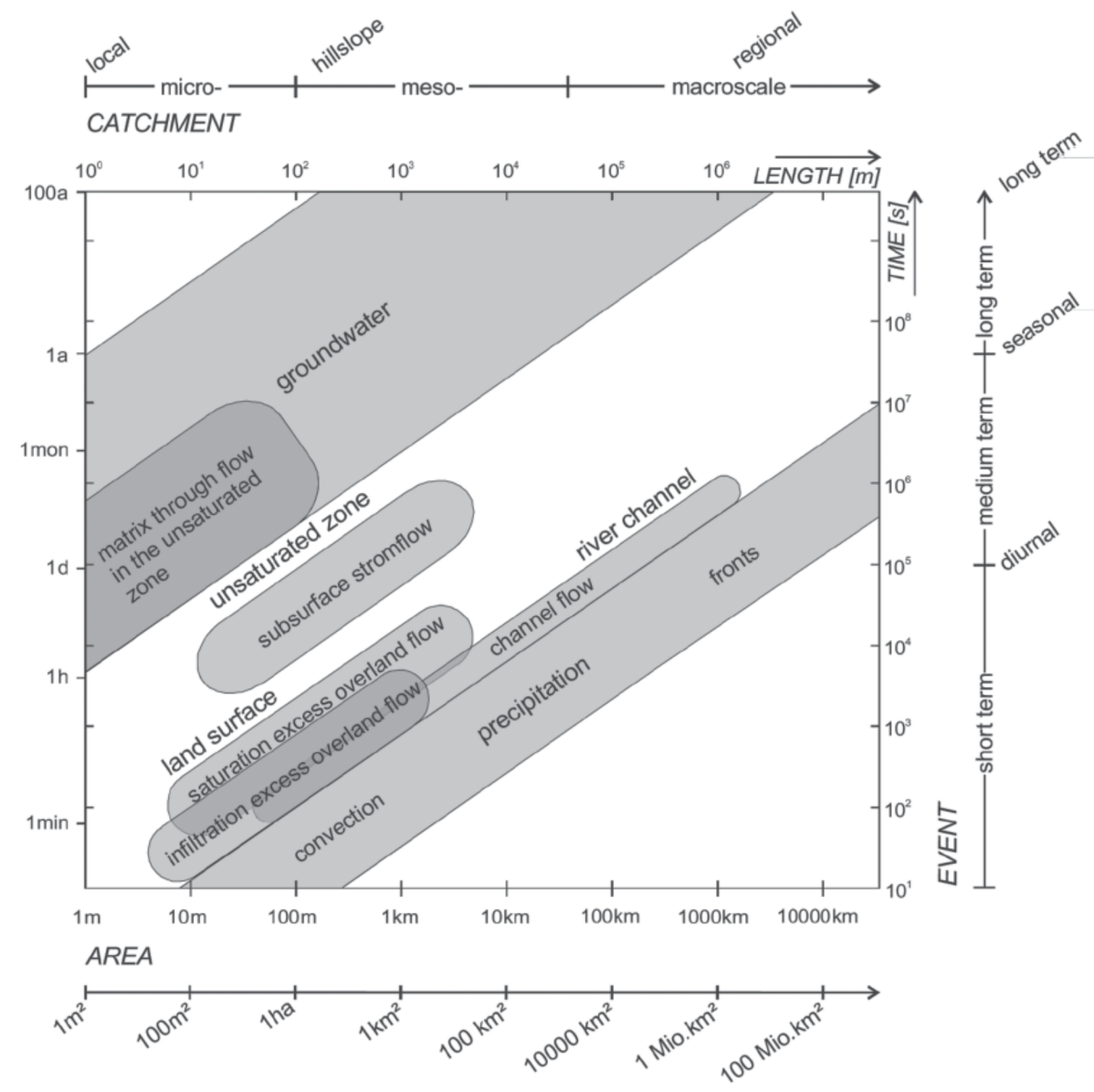

Figure 1.1: Relationship between spatial and temporal hydrological process scales and atmospheric processes. (From Bronstert et. al., 2005. Extended from Blöschl (1996) by Niehoff (2002)) 
Overall, scale discrepancies in hydrologic modeling and remote sensing applications may introduce systematic biases and remains a fundamental challenge in surface hydrology (Gentine et al., 2012). Such systematic biases can be propagated to water forecasting and future water decision management as well as to the optimization of the spatial and spectral resolution design in remote sensing instrumentation that imply high technology and cost. Gentine et al. (2012) indicates that scale issues can be addressed by considering some necessary steps such as identification of critical process scales, scale invariance and invariant scale parameters definition and also considering upscaling and downscaling based on rigorous mathematical methods and physical constrain.

This dissertation is meant to contribute to a better understanding of the issues associated to the variability in scales between the processes controlling precipitation, snow accumulation and melt, and soil water redistribution and discharge and the challenges involved in modeling and remote sensing of snow. To address this, we first present an investigation of how the atmospheric forcings impact the estimation of snow prognostic and diagnostic variables, primarily snow water equivalent, by performing a global sensitivity analysis, in which we quantify the strength of first and second order interactions between forcing variables and the snowmelt process (Chapter 2). Then, we investigate and quantify the impacts of discrepancies in scales between distributed meteorological forcing data and modeled land surface and subsurface water flow at hillslope scales by assessing hydrologic state variables and fluxes such as snow water equivalent and soil water storage (Chapter 3). Finally, we performed an evaluation of the outputs of integrated hydrologic models against observations for a particular set of environmental forcing data (i.e., spatially distributed, semi-distributed, and 
uniform) (Chapter 4). The specific objectives of this dissertation are:

(i) To show how sensitive the snowmelt processes are to atmospheric forcing variables and to determine which set of forcing variables have the largest effect over the snow-melting processes.

(ii) To explore and quantify the impact of multiple spatial scales of weather predictions used as input on hydrologic modeled state variables and also be able to see spatial error patterns due to these variations in spatial scale.

(iii) To evaluate the impact of meteorological forcings associated with different spatial distribution (i.e. spatially uniform, semi-distributed and fully distributed) as well as to see the most accurate hydrologic state variable simulated under certain atmospheric forcing setups.

This dissertation has important implications for the use of atmospheric data and integrated hydrologic models in remote and ungauged areas and provides key insights regarding which forcing variables, if measured more precisely, may afford the most significant improvements in snowmelt predictions. Also, this dissertation has potential ramifications for the selection of forcing datasets for integrated hydrologic modeling experiments as well as for the design and development of observing system simulation experiments (OSSEs) (Atlas et al., 1985a,b; Atlas, 1997) in complex and snow dominated landscapes. 


\section{CHAPTER 2:}

\section{ASSESSING THE EFFECTS OF METEOROLOGICAL FORCING ON SNOWMELT PROCESSES BY PERFORMING A SNOW MODEL GLOBAL SENSITIVITY}

\section{ANALYSIS}

\subsection{Abstract}

Seasonal snowpacks in mountain watersheds serve as natural and ephemeral reservoirs of water on which downstream populations depend for water supply and against which those populations also must mitigate flood risks. The processes of snow accumulation and ablation arise through complex exchanges and transformation of water mass and energy between the atmosphere-soil-vegetation system. Snowmelt processes, in particular, control the release of water from these snow reservoirs and estimating the onset and rate of snowmelt, often through the use of snow mass and energy balance models, is critical for accurate and timely forecasting of water supply and flood risk. These models require meteorological forcing data and parameters as input, but are often associated with significant uncertainties that lead to corresponding uncertain- 
ties in prognostic and diagnostic snow variable output by these models. In this work, we focus on understanding how the external forcings impact the estimation of snow prognostic and diagnostic variables, primarily snow water equivalent, by performing a global sensitivity analysis on the one-dimensional physically based multilayer snow model, SNTHERM. The global sensitivity analysis is based on Sobol's variance decomposition approach which is able to not only determine first order forcing effects over a particular dependent variable, but also the existence of interaction effects among those forcing variables. The results of this study indicate that forcing variables such as temperature, wind speed and incoming shortwave radiation have the largest first order impact over snowmelt. However, we find a higher order interaction occurring during the snowmelt processes related primarily to incoming longwave radiation. The study allows us to determine the atmospheric forcings that may cause the greatest effect over the snowmelt processes and also potentially suggests important physical interactions among complex snow processes. In doing so, we provide potentially key insights regarding which forcing variables, if measured more precisely, may afford the most significant improvements in snowmelt predictions.

\subsection{Introduction}

Mountain watersheds in the Western United States supply a considerable amount of water for ecosystems services and downstream communities. Half of the water on which the Western United States relies is provided by the seasonal snowpack that acts as a natural reservoir (Lundquist et al., 2009) and controls water release to soil and streams in the spring, exerting a fundamental role in the hydrologic cycle. However, significant changes in the interactions between and among hydrologic and ecosystem processes are expected in the future, which will challenge water management prac- 
tices (Brooks et al., 2012). In this context, accurate and timely knowledge of the onset, rate, and duration of the snowmelt process is critical for advancing both our understanding of the redistribution of water in mountain watersheds, as well as our ability to predict the transformation of snowpack storage into streamflow.

Snowmelt dynamics (i.e., the onset, rate, and duration of the snowmelt process) can be inferred from temporal observation in the spring of snow water equivalent (SWE). Increasingly, owing to the increased availability of hydrometeorologic data and out of a desire to better represent the process dynamics underlying the snowmelt process, estimation of snowmelt dynamics by researchers is achieved using physicallybased snow mass and energy balance models (Anderson, 1976; Jordan, 1991; Bartelt \& Lehning, 2002). Such models are not only useful in providing detailed temporal information about snow variables, but also in understanding the interactions between and among the energy and mass fluxes that occur within snowpack. A key limitation of these physically based snow models, however, is that they require large amounts of forcing data and predictions are sensitive to key parameterizations of variables like albedo and bulk turbulent transfer coefficients (Horne \& Kavvas, 1997). Most of the time these parameters are adjusted or fit such that the simulated snowpack dynamics from snow models fit measured data from, for example, USDA NRCS SNOTEL network sites. Accurate and precise estimation of both prognostic (e.g., snow water equivalent, density, depth) and diagnostic (e.g., latent heat flux, melt flux) snow variables is difficult to achieve when the parameters of the model to be calibrated, hydrometeorological inputs, and observational data used to assess model performance are all associated with significant uncertainty. Such difficulties can, in part, be addressed by performing a Global Sensitivity Analysis (GSA) on the model. 
GSA methods are advantageous because they consider both uncertainty arising from model parameters and model inputs (Saltelli et al., 2010).

Previous application of GSA methods in snow hydrology research have investigated the effects of perturbations of individual parameters corresponding to the model structure and only assessed a narrow set of other potential sources of uncertainty. Examples of these studies include He et al. (2011), which assessed parameter sensitivity and uncertainty for ten parameters in SNOW-17 (temperature index based model) (Anderson, 2006) with Generalized Sensitivity Analysis using the DiffeRential Evolution Adaptive Metropolis (DREAM) algorithm (Vrugt et al., 2008). The authors found that the major source of uncertainty to the model output is caused by parameters that mainly control the snowfall input. In a study using a coupled snow-runoff modeling framework, Tang et al. (2006) performed multiple parameter sensitivity techniques (i.e. local analysis using parameter estimation software (PEST), regional sensitivity analysis (RSA), analysis of variance (ANOVA), and Sobol's Method) on the lumped parameter Sacramento soil moisture accounting model (SAC-SMA), coupled to SNOW-17. In this study, the authors found that only the melt factor, which group all the energy balance components in a temperature index model, for non-rain periods has a significant effect (among other factors in SAC-SMA) on the outputs of this coupled modeling system. In addition, they suggest that Sobol's method provides the most detailed information of the effects of parameters and their interaction over the model output. Lastly, Houle et al. (2017) performed a GSA, as well as a temperature warming analysis, on two snow models, SNOW-17 and VIC (energy and mass balance based model) (Gao et al., 2010). The goal of this study was to inform model structure and temperature sensitivity to improve SWE projections in model- 
ing changing climate scenarios. Some sensitivity parameters such as albedo decay and melt factor in VIC and SNOW-17, respectively, were identified as parameters to which model outputs were particularly sensitive. The authors also discovered that SNOW-17 exhibits a lack of sensitivity to climate warming and suggest that it is less reliable for climate warming applications.

To our knowledge, only one study has performed a GSA of a snow model that explicitly investigates the role of uncertainties in atmospheric forcing inputs. Raleigh et al. (2015) conducted a complex forcing uncertainty study that quantified the sensitivity of the Utah Energy Balance (UEB) model (Tarboton et al., 1996) to atmospheric forcing uncertainty by adding error to the forcing variables. Their study found that forcing uncertainties contribute significantly to modeled snowpack dynamics (i.e. variations in snow water equivalent, ablation rates, snow disappearance, and sublimation variables) in five hypothetical scenarios applied to four study sites. That work suggests that model output uncertainty arising from forcing uncertainty can be comparable to and even more significant than the uncertainty produced by the associated parameters in the model structure. This work, in particular, highlights how the forcing data is among the most important factor contributing to uncertainties in model outputs.

Beyond the understanding of how some model parameters and forcing errors impact model outputs, there is a critical need to understand the actual sensitivities of snowmelt processes to environmental forcings in order to potentially prioritize efforts to constrain and better characterize the spatiotemporal distribution of those forcings. In this context, we consider that GSA is a potentially powerful tool to be used to identify the ways in which environmental forcings control a complex set of snowmelt 
processes, under the assumption that physically-based models provide an adequate description of those processes. In this study, we focus on advancing our understanding of how atmospheric forcing variables play an important role on the estimation of snow prognostic and diagnostic variables by performing a GSA using a physically based snow model, focusing principally on variations in snowmelt rates which are derived from temporary variation of snow water equivalent (SWE) (i.e., $d^{2} S W E / d t^{2}$ ). The physically based model chosen is the SNow THERmal Model, SNTHERM (Jordan, 1991) which simulates most snowpack properties and snow physical processes like snow depth, multilayer snow density, surface energy fluxes, snow surface temperature, snow grain size, and others. The global sensitivity analysis we apply here is based on Saltelli's extension of Sobol's variance decomposition approach (Sobol, 1993; Saltelli et al., 2010), which is able to identify first order effects of the model inputs (i.e., forcing variables) over a particular dependent variable (i.e., SWE, snow density, etc.) in the model output and also the existence of interaction effects among those model inputs (i.e., high-order effects).

The overarching goal of this study is to determine the forcing or set of forcing variables that have the largest effect over the snow-melting processes inferred from the decreasing of snow water equivalent in time in three different sites that represent different climates. The specific objectives are to: (1) identify forcing variables that have first order effect on the snow melting processes, and (2) find possible higher order effects that reveal the existence of interaction effects among forcing variables that may impact snowmelt processes at these sites. The paper is organized as follows: (1) a description of the methods and an overview of the GSA methods, model, and forcing data used and the associated treatment of forcing uncertainties, (2) a summary of the 
results and interpretation, and (3) discussion of the implications for understanding and modeling of snowmelt processes and associated conclusions. This study attempts to emphasize that a GSA can be used as a tool to determine not just the key parameters that give rise to uncertainties in model predictions of key snowmelt variables, but also the importance of the forcing variables that may influence the underlying complex processes.

\subsection{Methods}

\subsubsection{Sites}

Sites are selected according to the availability of coincident observations of environmental forcing variables to perform the sensitivity analysis, observation of key snowpack properties to assess model performance, records of sufficient length in time, and sites representing a range of snow-dominated systems that span maritime and continental climates. Snow measurements and forcing data used are retrieved from weather and hydrological databases of three well-instrumented sources as depicted in Figure 2.1. The stations that best satisfy these constraints are: (1) Swamp Angel Study Plot located in Senator Beck Basin Study Area, Colorado (Landry et al., 2014); (2) Treeline located in Dry Creek Experimental Watershed, Idaho (McNamara et al., 2018) and (3) Snoqualmie Pass located in Cascades, Washington (Wayand et al., 2015). All the meteorological stations provide hourly measured snow depth as well as hourly forcing data required for this work such as: air temperature, precipitation, incoming and outgoing shortwave and longwave radiation, wind speed, relative humidity and air pressure among others (see Table 2.1 for more details). 


\section{Table 2.1: Data summary of meteorological station. Superscript numbers} indicate the corresponding historical periods of record.

\begin{tabular}{|c|c|c|c|c|c|c|}
\hline Station & Climate & $\begin{array}{l}\text { Available } \\
\text { forcings }\end{array}$ & $\begin{array}{l}\text { Snow } \\
\text { variables }\end{array}$ & $\begin{array}{l}\text { Historical } \\
\text { periods }\end{array}$ & Intervals & $\begin{array}{l}\text { Period } \\
\text { used }\end{array}$ \\
\hline $\begin{array}{l}{ }^{*} \text { Snoqualmie } \\
\text { pass (WA) }\end{array}$ & Maritime & $\begin{array}{l}\text { Air temperature }{ }^{1} \text {, } \\
\text { precipitation }^{1}, \\
\text { incoming and } \\
\text { outgoing }_{\text {shortwave }^{2} \text { and }} \\
\text { longwave }^{2} \\
\text { radiation, wind } \\
\text { speed }^{3}, \text { relative } \\
\text { humidity }^{4} \text {, air } \\
\text { pressure }^{4}, \text { sensible } \\
\text { heat flux }^{2} \text { and } \\
\text { latent heat flux }\end{array}$ & $\begin{array}{l}\text { Snow depth, } \\
\text { Surface } \\
\text { temperature, } \\
\text { albedo }\end{array}$ & $\begin{array}{l}{ }^{1} 1989-2015 \\
{ }^{2} 2013-2015 \\
{ }^{3} 2003-2015 \\
{ }^{2} 2008-2015\end{array}$ & $\begin{array}{l}0.5 \text { hour } \\
(2013- \\
2015)-1 \\
\text { hour }\end{array}$ & 2013-2014 \\
\hline Treeline (ID) & $\begin{array}{l}\text { Steppe } \\
\text { summer } \\
\text { dry }\end{array}$ & $\begin{array}{l}\text { Air temperature, } \\
\text { precipitation, } \\
\text { incoming and } \\
\text { outgoing } \\
\text { shortwave and } \\
\text { longwave } \\
\text { radiation }{ }^{5} \text {, wind } \\
\text { speed and relative } \\
\text { humidity }\end{array}$ & Snow depth & $\begin{array}{c}{ }^{5} 2010-2017 \\
1999-2017\end{array}$ & $1 \mathrm{hr}$ & 2013-2014 \\
\hline $\begin{array}{l}\text { ** Swamp } \\
\text { Angel (CO) }\end{array}$ & Alpine & $\begin{array}{l}\text { Air temperature, } \\
\text { precipitation, } \\
\text { incoming and } \\
\text { outgoing } \\
\text { shortwave and } \\
\text { longwave } \\
\text { radiation, wind } \\
\text { speed, relative } \\
\text { humidity, air } \\
\text { pressure }\end{array}$ & $\begin{array}{l}\text { Snow depth } \\
\text { snow surface } \\
\text { temperature }\end{array}$ & $\begin{array}{c}{ }^{6} 2003-2017 \\
2005-2017\end{array}$ & $\begin{array}{l}1 \mathrm{hr}-3 \mathrm{hr} \\
-24 \mathrm{hr}\end{array}$ & 2013-2014 \\
\hline
\end{tabular}

\footnotetext{
${ }_{* *}^{*}$ A more complete list and details of this dataset can be found in Wayand et al. (2015).

** A more complete list and details of this dataset can be found in Landry et al. (2014).
} 


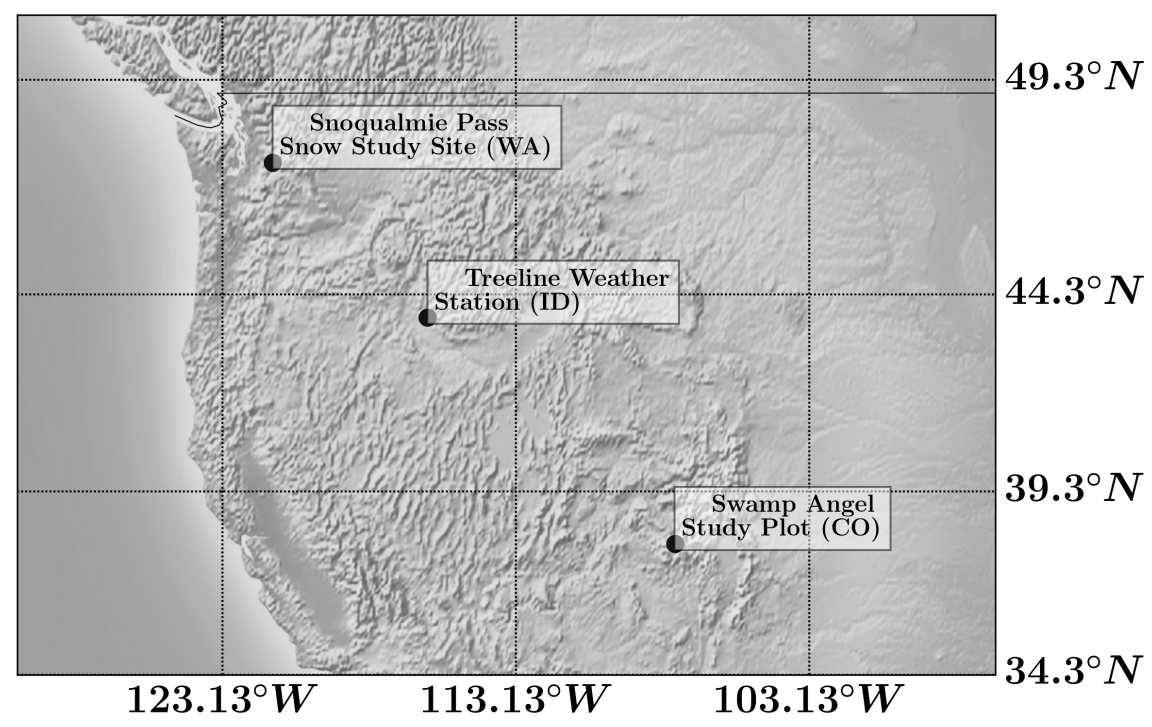

Figure 2.1: Weather and snow data stations.

\subsubsection{Model}

There are several physically based snow mass-energy balance models developed with different characteristics and multiple types of applications such as snow processes research, weather and runoff forecasting and global climate. Extensive lists of models can be found in Etchevers et al. (2004); Yang (2008) and Essery et al. (2013), in which they classify snow models according to complexity, characteristics and functionality.

For our study, we selected SNTHERM model which has been used extensively in civil and military snow research programs (Ge \& Gong, 2010) and more important, it has shown to predict accurately evolution of snowpack processes and properties (Etchevers et al., 2004; Ge \& Gong, 2010). SNTHERM, in contrast with other models used in previous GSA studies, is a more complex model (Etchevers et al., 2004; Lapo et al., 2015) that represents the physics of the energy balance involved in the snowmelt process in greater detail. Such complexity does not necessarily lead improved simula- 
tion outputs and/or uncertainty decreasing as noted in snow intercomparison studies (Etchevers et al., 2004; Essery et al., 2013). However, it gives us the assurance that the model structure is suited to the requirements of this study because it provides a more detailed depiction of the internal mass and energy dynamics of the simulated snowpack.

SNTHERM is a one-dimensional multilayered mass and energy balance snowpack model developed for predicting surface and profile temperatures in non-forested areas (Jordan, 1991; Frankenstein et al., 2008). The main objective of the model was to predict temperature profiles (Figure $2.2 \mathrm{~A}$ ) within snow layers and frozen soil, however, it can be used for predicting multiple properties that impact the optical and thermal properties of the snow (Jordan, 1991) as well as to predict energy fluxes such as latent and sensible heat that are always required for the snow energy balance (Figure 2.2 B).

The snowpack conservation of mass in SNTHERM is determined by the balance of fluxes on liquid water, diffuse water vapor and water released through phase change such as melting, sublimation and evaporation (Koivusalo \& Heikinheimo, 1999) and also by either rain or snow precipitation. The energy balance is subject primarily to external forcings such as temperature and radiation that act as boundary conditions, and also subject to turbulent energy exchanges which are estimated by stability functions defined mainly by bulk transfer coefficients.

Like many mass-energy balance models, SNTHERM tracks several state variables, such as snow depth, snow density, energy content, average temperature and liquid water for each layer (Barrett, 2003) that allow us to estimate variables of our interest such as: snow water equivalent and snowmelt rates. For this study, SNTHERM is 
(A)

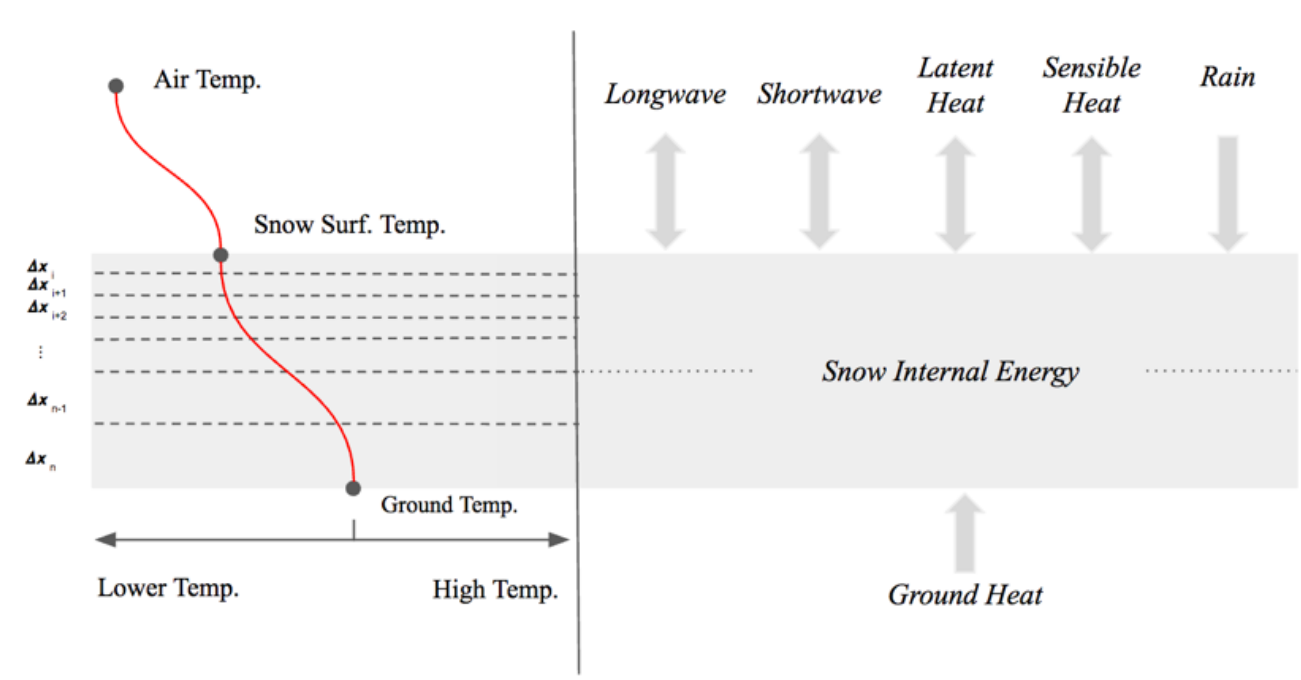

Figure 2.2: Temperature balance in a multi-layer snowpack (A) and configuration of the energy balance model used by SNTHERM (B).

driven by time series of the following forcing variables: precipitation, air temperature, relative humidity, wind speed, longwave and shortwave radiation. For all the simulation experiments performed in this study, we estimated the snow albedo by using the USACE method (US Army Corps of Engineers, 1956) as well as to estimate the precipitation partition information required by the model, we used the algorithm proposed by (Ding et al., 2014) which is based on site elevation, wet-bulb temperature and humidity. We run the model in a water year for all the stations selected in order to verify whether the model follows snow accumulation and depletion trends and also to verify the agreement with observed snow depth data by measuring the root mean square error (RMSE). The model also provided us snow density information for each layer, which is important to estimate SWE. 


\subsubsection{Sensitivity Analysis}

In this study, we select the Saltelli's extension of Sobol's variance decomposition approach, which offers a more expensive computational approach than the approach provided by Sobol (1993). However, it gives a more robust estimate of first, second, and total order effects of the inputs to the model outputs, and at the same time helps to reduce the error rates in the calculation of the sensitivity indices. This approach considers a model which can be viewed as a function:

$$
Y=f(X)
$$

Where $X=\left(X_{1}, X_{2}, X_{3}, \ldots, X_{K}\right)$ are model inputs with associated probability distribution function (PDF). $f(X)$ may be represented in a functional decomposition scheme (Sobol, 1993; Homma \& Saltelli, 1996; Saltelli et al., 2010) where is considered as an expansion of terms with increasing dimensions:

$$
Y=f(X)=f_{0}+\sum_{i} f_{i}+\sum_{i} \sum_{i>j} f_{i j}+\ldots+f_{12 \ldots k}
$$

Where $f_{i}$ are the model components driven by a single factor, $f_{i j}$ are the model components driven by the interaction of a pair of factors and $f_{i j \cdots k}$ are the model components driven by multiple factors. The above expansion is not unique and may have infinite choices for its terms (Saltelli et al., 2008) and can be calculated in terms of conditional expectations of the model output $Y$. The variance of $Y$ can be expressed as:

$$
V(Y)=\sum_{i} V_{i}+\sum_{i} \sum_{i>j} V_{i j}+\ldots+V_{12 \ldots k}
$$


where

$$
V_{i}=V_{X_{i}}\left(E_{X_{\sim i}}\left(Y \mid X_{i}\right)\right)
$$

and

$$
V_{i j}=V_{X_{i} X_{j}}\left(E_{X_{\sim i}}\left(Y \mid X_{i}, X_{j}\right)\right)-V_{X_{i}}\left(E_{X_{\sim i}}\left(Y \mid X_{i}\right)\right)-V_{X_{i}}\left(E_{X_{\sim i}}\left(Y \mid X_{j}\right)\right)
$$

The term $X_{i}$ is the $i^{\text {th }}$ factor or input variable and $X_{\sim i}$ denotes the matrix of all factors but $X_{\sim i}$ (Saltelli et al., 2008). The variance of the conditional expectation $E_{X_{\sim i}}\left(Y \mid X_{i}, X_{j}\right)$, is considered as a summary measure of sensitivity and the variance of $E_{X_{\sim i}}\left(Y \mid X_{i}, X_{j}\right)$ measures the joint effect of the pair variables $X_{i}, X_{j}$ (Saltelli et al., 2008). The first-order sensitivity indices correspond to the main effect of each input in equation (2.1) that impact $Y$. Such indices can be estimated by dividing equation (2.4) by

$$
S_{i}=\frac{V_{X_{i}}\left(E_{X_{\sim i}}\left(Y \mid X_{i}\right)\right)}{V(Y)}
$$

Second-order and higher-order sensitivity indices correspond to the amount of variance that contribute to the interaction of two or more variables in $Y$. These indices are significantly important to determine for sensitivity analysis in non-linear models (Homma \& Saltelli, 1996). These indices can be estimated dividing equation (2.3) by $V(Y)$ that yield the following expression: 


$$
\sum_{i} S_{i}+\sum_{i} \sum_{i>j} S_{i j}+\ldots+S_{12 \ldots k}=1
$$

Other indices to consider, are the total sensitivity indices, which represent the overall contribution of a variable on $Y$ and account for first and higher effects or interactions (Homma \& Saltelli, 1996; Saltelli et al., 2008). A total sensitivity index can be expressed as:

$$
S_{T_{i}}=\frac{E_{X_{\sim i}}\left(V_{X_{\sim i}}\left(Y \mid X_{\sim i}\right)\right)}{V(Y)}=1-\frac{V_{X_{i}}\left(E_{X_{\sim i}}\left(Y \mid X_{\sim i}\right)\right)}{V(Y)}
$$

Total indices are significantly important because they provide information about whether the model is purely additive by the single effect of each variable (i.e., $\sum S_{i}=1$ ) and also indicates if additional uncertainty is been accounted from interactions of the individual variables with other. Values of $V$ and $E$ can be estimated by a Monte Carlo integration approach:

$$
V_{X_{i}}\left(E_{X_{\sim i}}\left(Y \mid X_{\sim i}\right)\right) \approx \frac{1}{N} \sum_{j=1}^{N} f\left(B_{i}\right)\left(f\left(A_{B}^{i}\right)_{j}-f(A)_{j}\right)
$$

and

$$
E_{X_{i}}\left(V_{X_{i}}\left(Y \mid X_{\sim i}\right)\right) \approx \frac{1}{2 N} \sum_{j=1}^{N}\left(f(A)_{j}-f\left(A_{B}^{i}\right)_{j}\right)^{2}
$$

Where $A$ and $B$ are matrices part of a $N \times 2 d$ matrix (i.e. $N$ : number of samples and $d$ : number of factors or input variables) generated with respect to a probability distribution function that correspond to each input variable. 


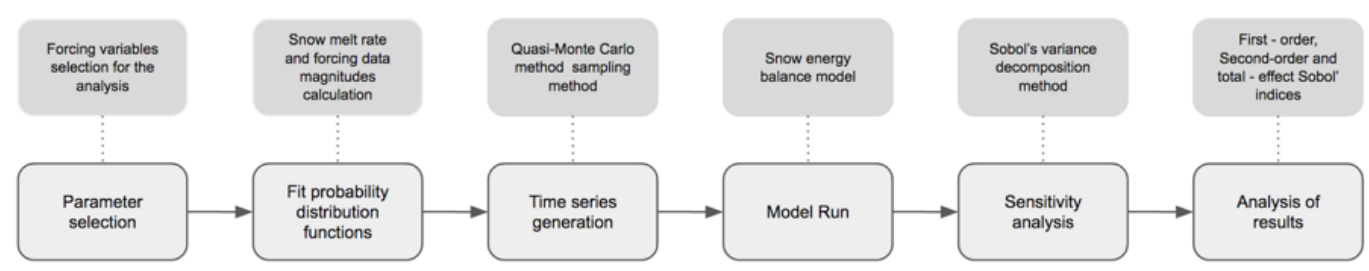

Figure 2.3: Sensitivity analysis workflow. Bordered boxes show GSA process steps. Dark boxes describe data and/or the procedure need in each step.

\subsubsection{Sensitivity Analysis Process, Algorithm and Experi- ments}

The process of the GSA variance decomposition applied to this study is subject to three major steps. (1) Atmospheric and snow measured data collection and probability distribution function adjustment based on snowmelt events to each atmospheric variable, (2) Atmospheric sampling generation and snow model simulations and (3) perform the GSA on simulation outputs and effect index analysis. The GSA process is depicted in more detail in Figure 2.3.

We selected snow data from each meteorological station in water year 2014 and identify hourly melt events as hourly occurrences of a negative increment to the SWE time series to posteriorly estimate snowmelt rates. All snowmelt events identified in each site are then attributed to the magnitude of the corresponding forcing variable. Parametric conditional probability distribution functions (PDFs) are constructed based on observed snowmelt rates associated with the corresponding magnitude of the forcings. Each distribution function shows the probability in which snowmelt occurs with certain frequency. These approximated distribution functions are then used as a Quasi Monte-Carlo low-discrepancy sampler that generates new 


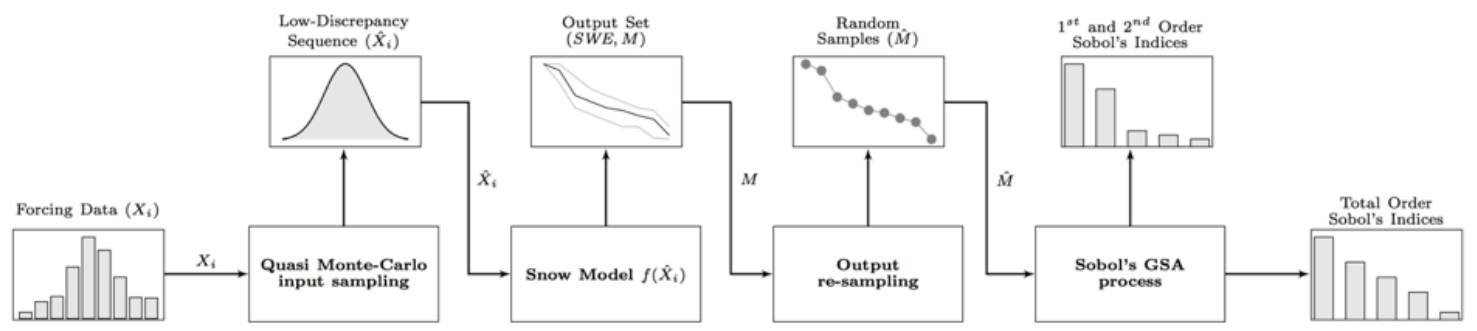

Figure 2.4: Sobols Sensitivity analysis process, from forcing data selection and sampling to Sobols indices computation.

input data to posteriorly perform the sensitivity analysis (see Figure 2.4).

The input data $(\hat{X})$ for the sensitivity analysis is generated using Saltelli's extension of Sobol's sequence (Saltelli, 2002) for all atmospheric variables required as input to SNTHERM . The atmospheric variables selected are: incoming longwave and shortwave radiation, relative humidity, wind speed and temperature. The data generation is performed by using the modified sampler function of the GSA open-source Python library SALib (Herman \& Usher, 2017), in which, additional conditional probability distribution functions are incorporated for data generation. Since our interest lies on snowmelt events associated with a decrease in SWE $(M)$, we assume precipitation to be zero and all synthetic experiments are performed with the rest of the atmospheric forcing variables with a sample size $N$ for each station. The size of samples was chosen according to the time that the initial snowpack for each site takes to melt completely. The initial state of the snowpack for each site, that includes the snow depth and all layers with their corresponding physical properties, were retrieved from the outputs of the runs performed previously by SNTHERM using the observed data, considering the last significant snow peak accumulation. Table 2.2 specified snowpack initial conditions and other structural model parameters for the experiments in each site. 
Table 2.2: Snow depth initial condition internal parameters and number of samples for all the synthetic experiments performed in each site.

\begin{tabular}{llllll}
\hline Site & $\begin{array}{l}\text { Snow depth initial } \\
\text { condition }\end{array}$ & $\begin{array}{l}\text { Roughness } \\
\text { length }\end{array}$ & Albedo formulation & $\begin{array}{l}N \\
\text { ples }\end{array}$ \\
\hline $\begin{array}{l}\text { Snoqualmie } \\
\text { pass } \\
\text { Treeline }\end{array}$ & $2.91 \mathrm{~m}$ & 0.002 & $\begin{array}{l}\text { Marshall \& Warren } \\
(1987) ; \text { Marks }(1988)\end{array}$ & 2800 \\
$\begin{array}{l}\text { Swamp Angel } \\
\text { Study Plot }\end{array}$ & $1.67 \mathrm{~m}$ & 0.002 & $\begin{array}{l}\text { Marshall \& Warren } \\
(1987) ; \text { Marks (1988) }\end{array}$ & \\
\hline
\end{tabular}

The SNTHERM model generates outputs that include snow depth, snow density, and SWE based on input time series of the meteorological forcings. The simulation of each time step correspondingly serves as an initial condition to estimate the snow state for the next time step, given the associated meteorological conditions provided as input during that period. As such, performing this GSA experiment requires many integrations of the SNTHERM model for one time step with given initial and atmospheric boundary conditions. As such, the experimental setup lends itself well to parallelizing the GSA. We, therefore, subdivided the entire dataset generated into 12 (i.e. $=2 k+2$ ) ensembles that were treated as independent hourly time series. After SNTHERM completes all the experiment runs, we performed a GSA algorithm based on Sobols' approach, in R (Pujol et al., 2017) by taking random samples $(\hat{M})$ for each site.

\subsection{Results}

\subsubsection{Snow Model Capabilities}

We performed model simulations with SNTHERM at the three stations selected, where data are collected in order to analyze the models capabilities. Simulations 
are performed in water year 2014, because of the data availability in all stations selected for this study. Values of precipitation (useful for snow accumulation) in Snoqualmie Pass were adopted from the North American Land Data Assimilation System (NLDAS) (Mitchell et al., 2004) due to inconsistencies in snow accumulation when observed precipitation are used as input to the model. On the other hand, precipitation data in Treeline and Swamp Angel sites are retrieved from their corresponding meteorological stations. All simulation results are depicted in Figure 2.5, discrepancies in snow depths in simulations can be seen in both the accumulation season and part of the melting season.

The discrepancies observed in Snoqualmie Pass, particularly at the snow melting season, are attributable to the difficulties on albedo parameterization since in this site the presence of new snow due to constant small snowfall events, helps to maintain the snow albedo with high values. Issues also seen in some snowmelt periods in Treeline station are attributable to the effects of underlying ground that affects radiative properties of snow (O'Neill \& Gray, 1972) to a shallow snowpack that dominates this station during the snow season in water year 2014. Discrepancies observed in the Swamp Angel site in the accumulation season can be attributed to the poor estimation of snow accumulation in the model due to the rain-snow partition algorithm used. On the other hand, during the melting season at this site, the model significantly underpredicts the snow depth. These errors can be attributable, in most part, to abrupt changes in albedo decay produced by dust events occurred during April 2014 (Landry, 2014) that cannot be captured by SNTHERM. In such dust events, the snow cover increased the absorption of solar energy and consequently accelerated snowmelt process (Landry, 2014). In general, we consider all simulations performed in all sites 


\section{Table 2.3: SNTHERM performance in all stations.}

\begin{tabular}{lll}
\hline Location & $\mathrm{R}^{2}$ & RMSE $(\mathrm{m})$ \\
\hline Snoqualmie Pass (WA) & 0.93 & 0.31 \\
Treeline (ID) & 0.92 & 0.03 \\
Swamp Angel (CO) & 0.99 & 0.17 \\
\hline
\end{tabular}

show an acceptable agreement with observed snow depth. Table 2.3 summarizes the root mean squared error (RMSE) between simulated and measured values of SNTHERM simulation in water year 2014. The 1:1 line (depicted in dashed black line) in Figure 2.5 shows the difference between under predicted and over predicted values of snow depth and the coefficient of determination $\left(\mathrm{R}^{2}\right)$ of the predicted versus observed values are also shown in Table 2.3.

\subsubsection{Distribution of Forcing Data}

To illustrate how forcing data are distributed according to the frequency of snowmelt occurrences, histograms are constructed for each variable using the Freedman-Diaconis rule (Freedman \& Diaconis, 1981) that allows optimization of the size of bins. Based on the shape of histograms, conditional probability density functions (PDFs) are fitted for each variable in each site. Figures 2.6, 2.7 and 2.8 illustrate the density (Solid lines) and corresponding PDF of snowmelt events for each atmospheric variable at Snoqualmie Pass, Treeline and Swamp Angel Study Plot station respectively. According to the shape of the histograms and quartile-quartile plots in these figures, distribution fitting of observations are in good agreement with the theoretical probability distribution functions proposed for each forcing variable, except for longwave at all the stations, air temperature at Snoqualmie Pass and Treeline and relative 

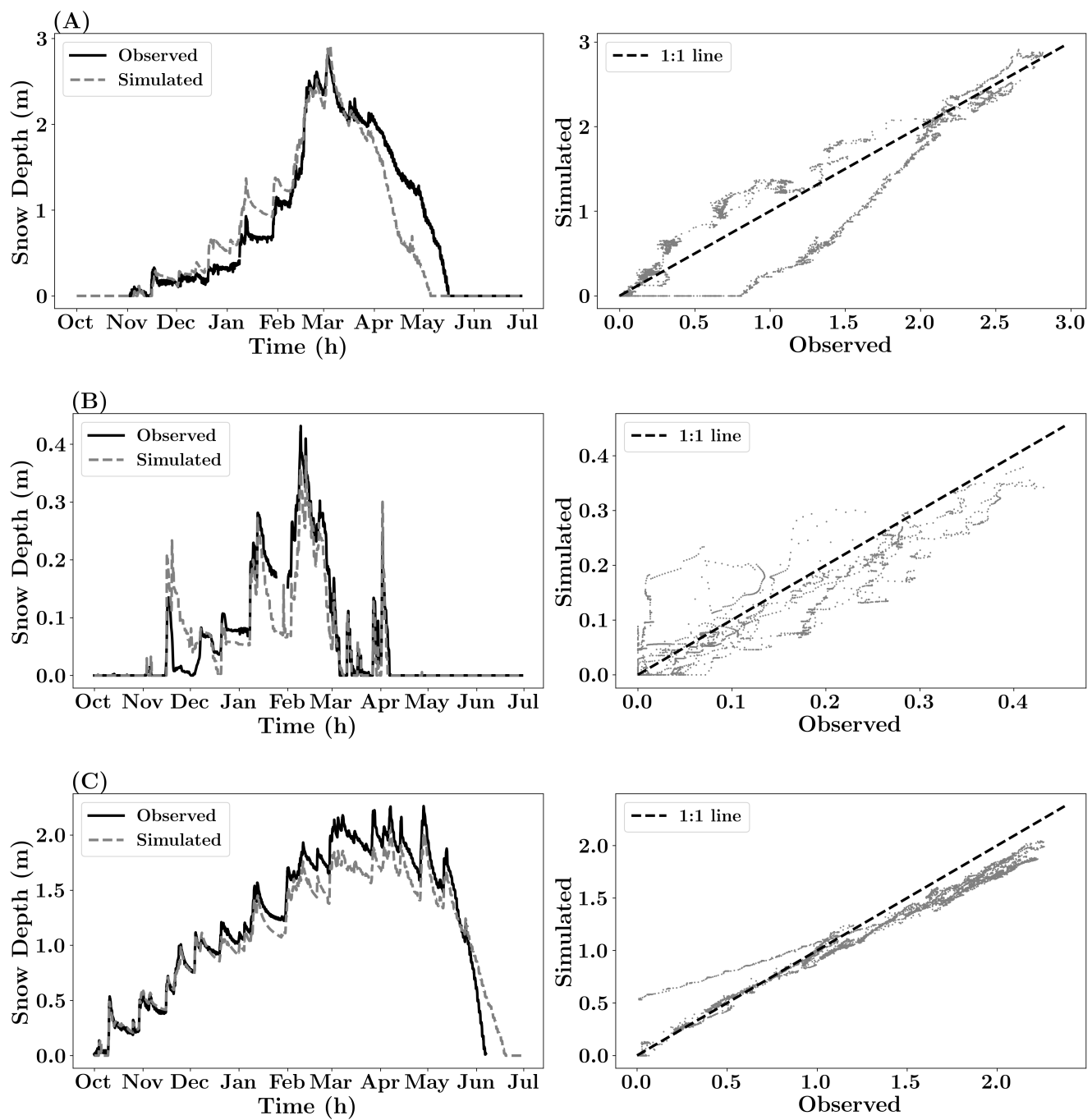

Figure 2.5: Snow simulations performed by the snow energy balance model at Snoqualmie Pass (A); Treeline station (B) and Swamp Angel Study Plot (C) in water year 2014 . 
Table 2.4: Range of values for each forcing data, used to fit the probability density functions at each site.

\begin{tabular}{llll}
\hline Site & Forcing variable & PDF & Range \\
\hline \multirow{3}{*}{ Snoqualmie } & Longwave & Generalized Logistic & $202.0-349.4\left(\mathrm{~W} / \mathrm{m}^{2}\right)$ \\
Pass & Relative Humidity & Johnson SB & $20.8-99.0 \%$ \\
& Shortwave & Gauss hypergeometric & $0.0-1031.0\left(\mathrm{~W} / \mathrm{m}^{2}\right)$ \\
& Temperature & Johnson SU & $-7.14-22.8\left({ }^{\circ} \mathrm{C}\right)$ \\
& Wind Speed & Johnson SB & $0.0-4.5(\mathrm{~m} / \mathrm{s})$ \\
\cline { 2 - 4 } Treeline & Longwave & Generalized logistic & $232.6-339.8\left(\mathrm{~W} / \mathrm{m}^{2}\right)$ \\
& Relative Humidity & Gauss hypergeometric & $29.7-100 \%$ \\
& Shortwave & Beta & $0.0-953.0\left(\mathrm{~W} / \mathrm{m}^{2}\right)$ \\
& Temperature & Reciprocal Inverse Gaussian & $-4.2-9.4\left({ }^{\circ} \mathrm{C}\right)$ \\
Swamp Angel & Wind Speed & Exponentially Modified Normal & $0.04-6.6(\mathrm{~m} / \mathrm{s})$ \\
\cline { 2 - 4 } Study Plot & Longwave & Generalized logistic & $171.2-332.0\left(\mathrm{~W} / \mathrm{m}^{2}\right)$ \\
& Relative Humidity & Exponentiated Weibull & $10.2-98.1 \%$ \\
& Temperature & Johnson SB & $0.0-837.9\left(\mathrm{~W} / \mathrm{m}^{2}\right)$ \\
& Wind Speed & Leneralized Normal & $-10.9-16.7\left({ }^{\circ} \mathrm{C}\right)$ \\
& & & $0.0-13.86(\mathrm{~m} / \mathrm{s})$ \\
\hline
\end{tabular}

humidity and wind speed at Swamp Angel Study plot, where the assumption of the respective conditional PDFs, slightly disagrees despite the small sum of square error. As seen in Figures 2.6, 2.7 and 2.8, each forcing variable has its own probability density functions and the corresponding range of values which are summarized in Table 2.4 .

Synthetic simulations are performed with input data generated for each forcing variable using Saltelli's extension of the Sobol's sequence. Figure 2.9 shows the sensitivity of the model performing snow depth calculations at the three stations. The shadow region corresponds to one standard deviation $( \pm \sigma)$ of the outputs, the solid line represents the average $\operatorname{SWE}(\mu)$ and dashed lines correspond to the maximum and minimum values of SWE of all the experiments at each time step. Major sensitivities in SWE are exhibited in Treeline (Figure 2.9 (B)), attributable to the effects of the random magnitudes of the forcing on a shallow snowpack, such effect can be 

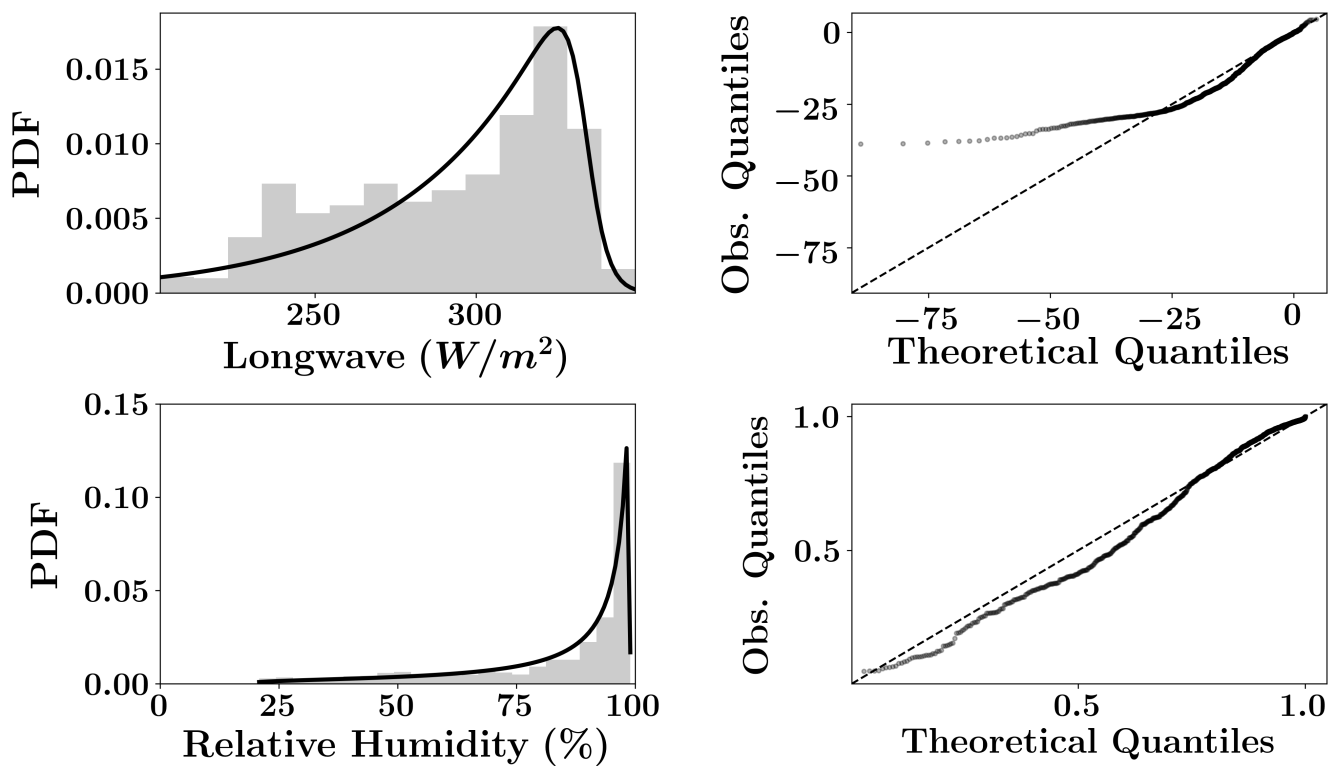

Theoretical Quantiles
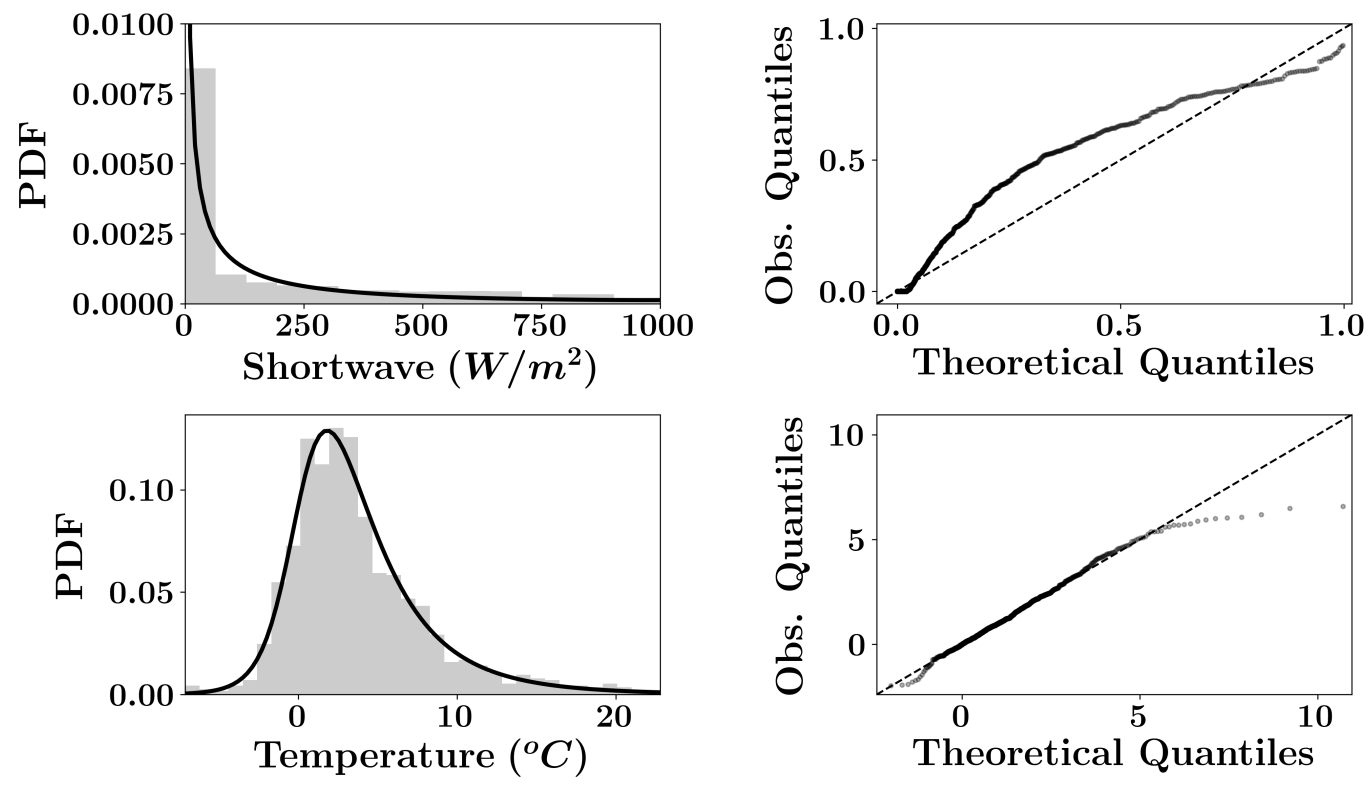

Theoretical Quantiles
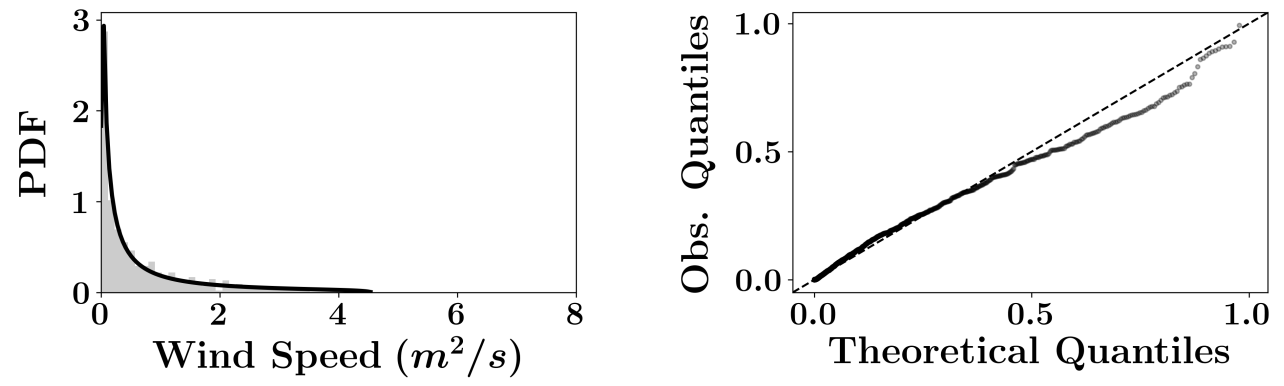

Figure 2.6: Normalized frequencies of forcing magnitudes related to a snowmelt event at Snoqualmie Pass station and adjusted PDFs for each variable; Generalized logistic (A), Johnson $\mathrm{S}_{\mathrm{B}}(\mathrm{B})$, Gauss hypergeometric (C), Johnson $\mathrm{S}_{\mathrm{U}}(\mathrm{D})$, Johnson $\mathrm{S}_{\mathrm{B}}(\mathrm{E})$. 

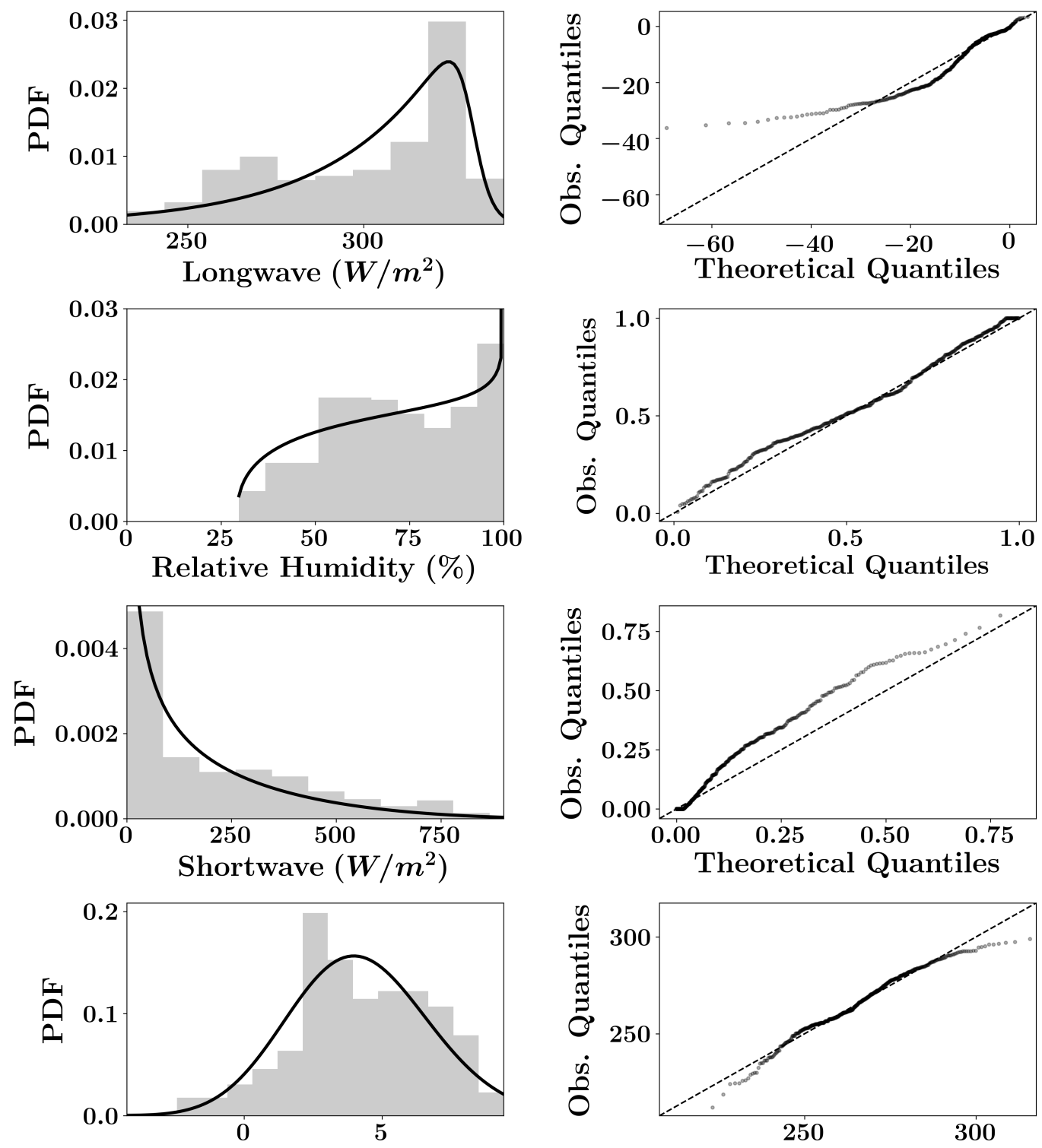

Temperature $\left({ }^{\circ} C\right)$
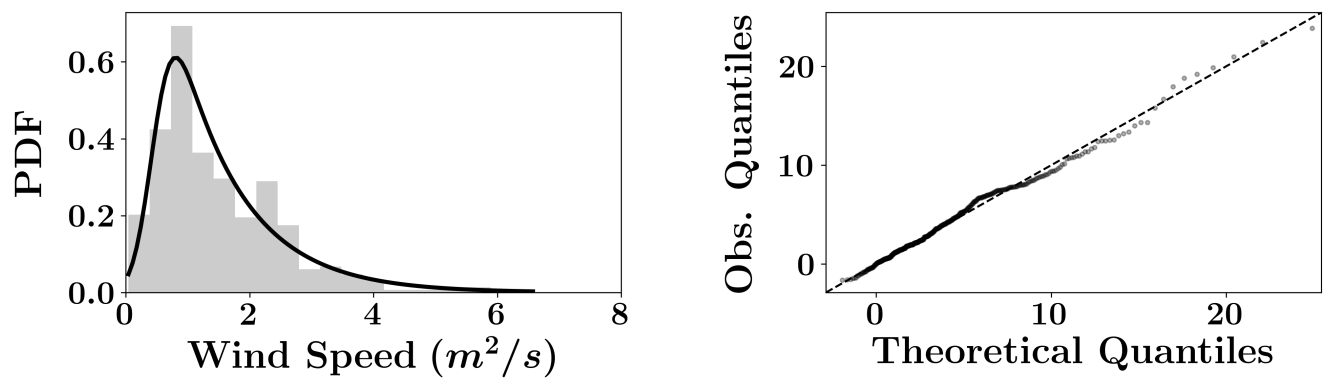

Figure 2.7: Normalized frequencies of forcing magnitudes related to a snowmelt event at Treeline station and adjusted PDFs for each variable; Generalized logistic (A), Gauss hypergeometric (B), Beta (C), Reciprocal Inverse Gaussian (D), Exponentially Modified Normal (E). 

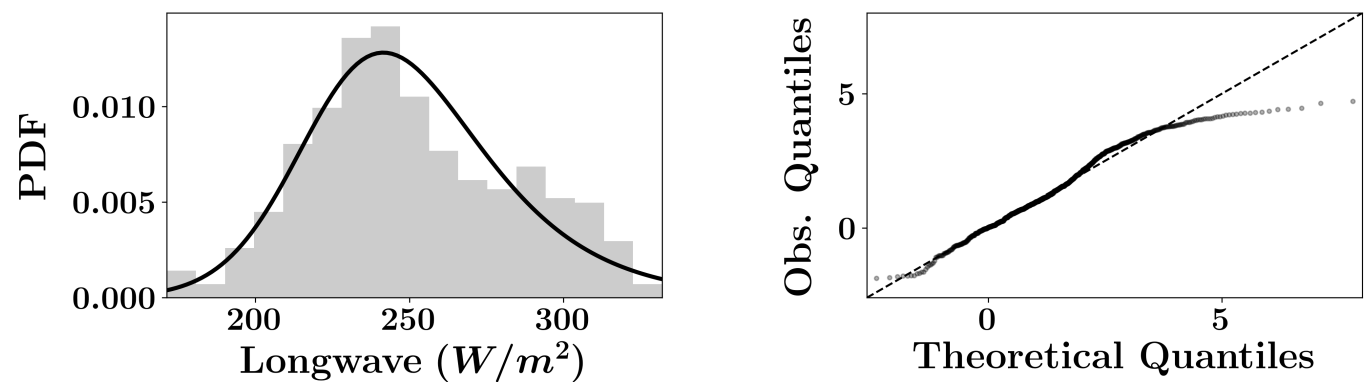

Theoretical Quantiles
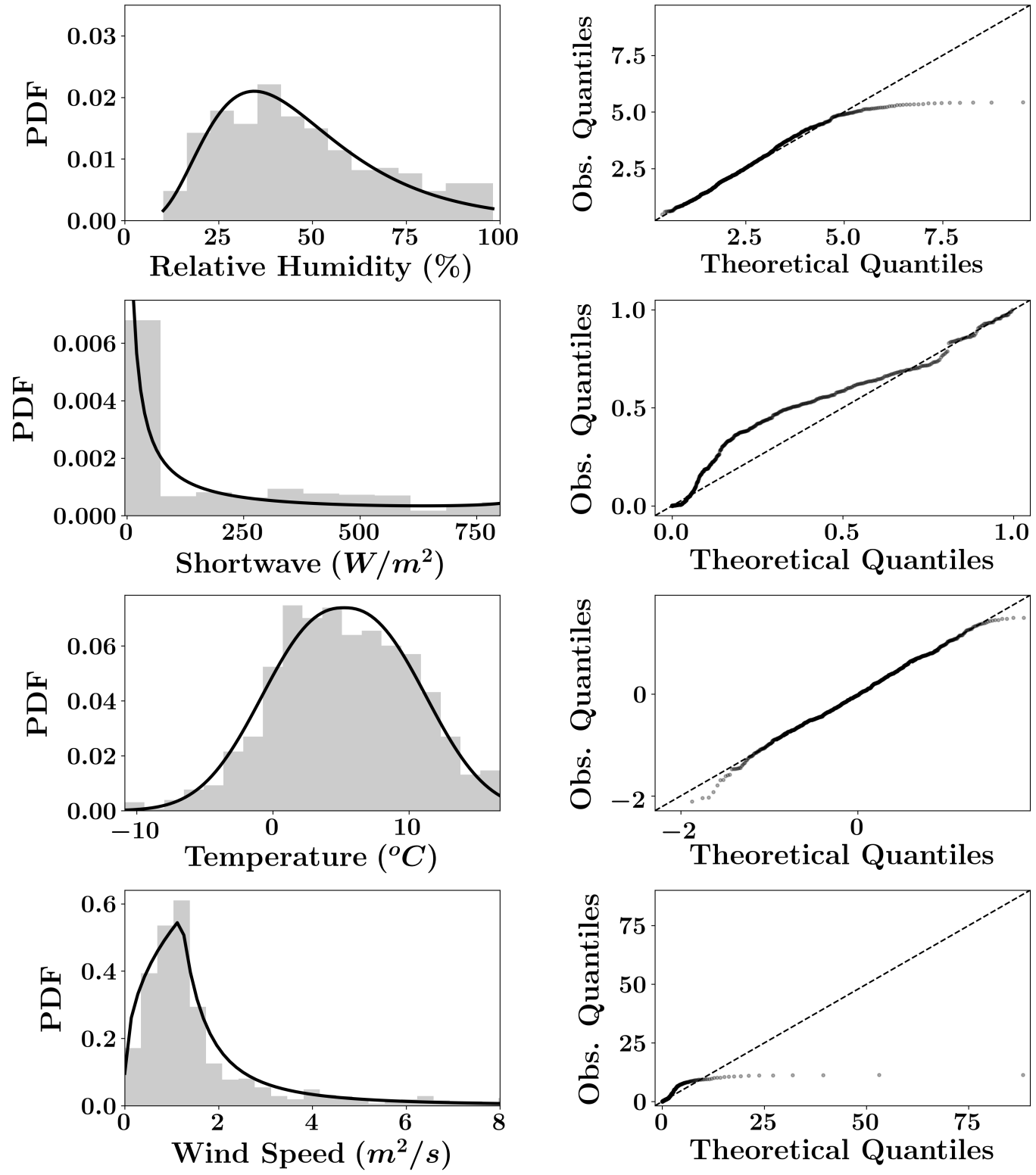

Figure 2.8: Normalized frequencies of forcing magnitudes related to a snowmelt event at Swamp Angel Study Plot station and adjusted PDFs for each variable; Generalized Logistic (A), Exponentiated Weibull (B), Johnson $\mathrm{S}_{\mathrm{B}}(\mathrm{C})$, Generalized Normal (D), Log-Laplace (E). 
observed at the three stations as their snowpack depth decreases.

\subsubsection{Sensitivity Indices}

The sensitivity analysis is performed using the second derivative of SWE with respect

to time, that corresponds to the changes of snowmelt rate (i.e., $d^{2} S W E / d t^{2}$ ). Figure 2.10(A), 2.10(B) and 2.10(C) present first order, and second order Sobol's indices for Snoqualmie Pass, Treeline and Swamp Angel Study Plot stations respectively. Tables 2.5, 2.6 and 2.7 illustrate for each site the first order indices that represent the relative variance explained by the effect of each single input variable on the output model, the total order indices that represent the relative variance explained by the first order effects and potential interactions of each variable with other input variables (Johannesson et al., 2014) and the second order indices, that represent the interactions between all pairs of input variables. Bars in figure 2.10(A) exhibit that shortwave forcing causes the highest single impact on snowmelt rates in Snoqualmie Pass station as well as exhibiting a second order interaction between longwave and shortwave radiation. Bars in figure 2.10(B) exhibit almost similar single effects of all forcing variables on the snowmelt process at Treeline station, and bars in figure 2.10(C) exhibit that shortwave forcing causes the highest single impact on snowmelt in Swamp Angel Study Plot station. Total effects $\left(S_{T}\right)$ values of the forcing variables are specified only for Snoqualmie Pass station, since a second order effect was detected (see Table 2.5).

\subsection{Discussion}

This study uses a sensitivity analysis based on variance-decomposition of a physicallybased snow model (SNTHERM), as a way to better understand the impact effects of atmospheric forcing variables on snowmelt process. We used an extension of Sobol's 

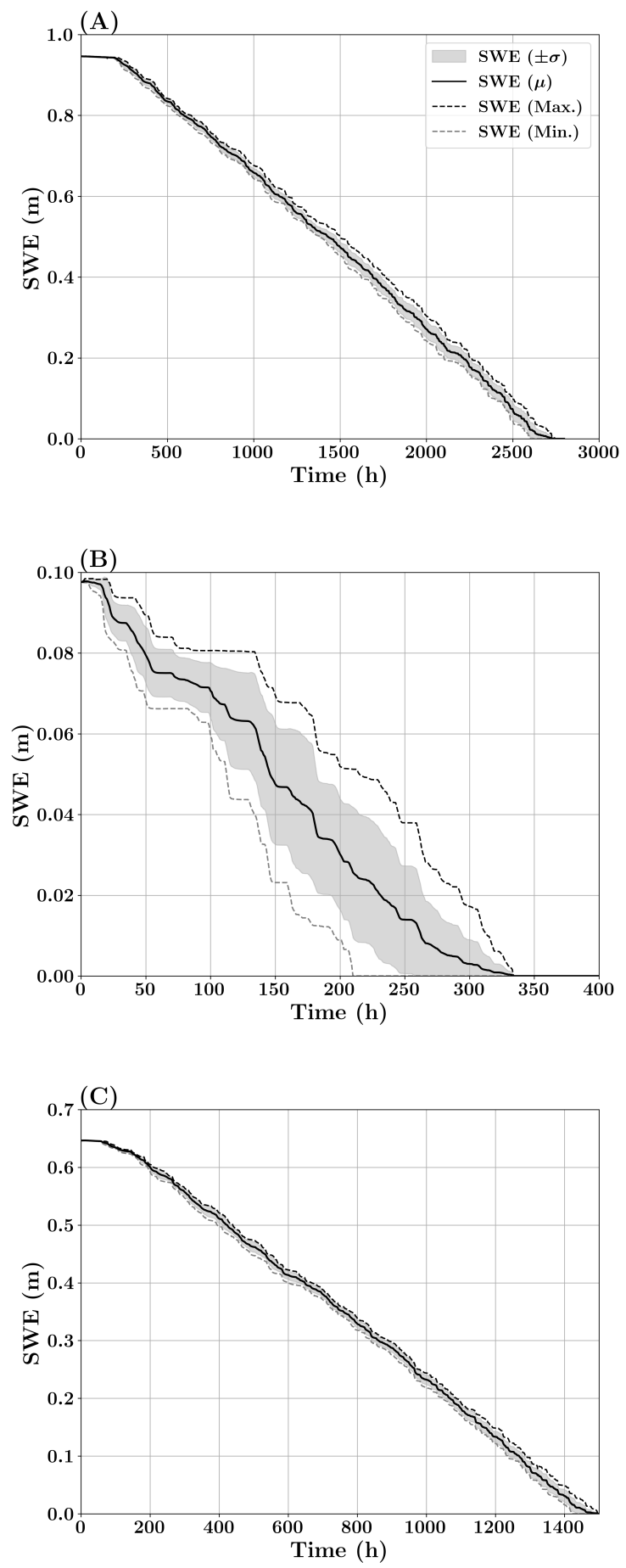

Figure 2.9: Sensitivity variation of the snow model using 12 ensembles time series generated by Saltelli's extension of the Sobol sequence for the three sites: Snoqualmie Pass (A), Treeline (B) and Swamp Angel Study Plot (C). 

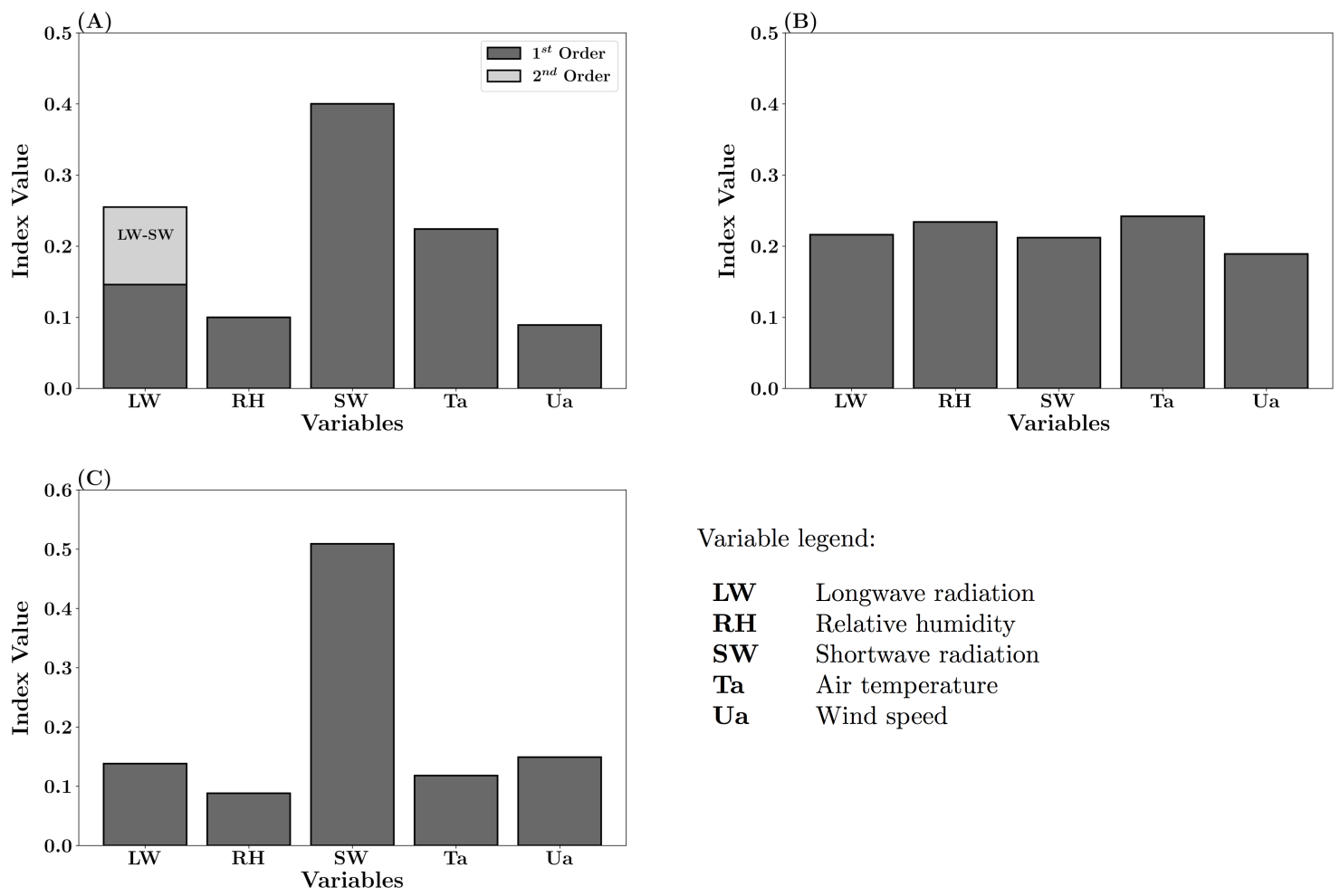

Variable legend:

LW Longwave radiation

RH Relative humidity

SW Shortwave radiation

Ta Air temperature

Ua Wind speed

Figure 2.10: First order and second order or forcing interactions of sites: (A) Snoqualmie Pass, (B) Treeline and (C) Swamp Angel Study Plot. 
Table 2.5: First, total and second order index for Snoqualmie Pass site.

\begin{tabular}{ll}
\hline Forcing Forcing variable and order index & Value \\
\hline First Order Index & \\
Longwave radiation & 0.146 \\
Relative humidity & 0.100 \\
Shortwave radiation & 0.400 \\
Air temperature & 0.224 \\
Wind speed & 0.089 \\
Total Index & \\
Longwave radiation & 0.455 \\
Relative humidity & 0.223 \\
Shortwave radiation & 0.787 \\
Air temperature & 0.439 \\
Wind speed & 0.186 \\
Second Order Index & \\
Longwave-Relative humidity & 0.000 \\
Longwave-Shortwave & 0.109 \\
Longwave-Air temperature & 0.000 \\
Longwave -Wind speed & 0.000 \\
Relative Humidity -Shortwave & 0.000 \\
Relative Humidity-Air temperature & 0.000 \\
Relative Humidity-Wind speed & 0.000 \\
Shortwave-Air Temperature & 0.000 \\
Shortwave-Wind speed & 0.000 \\
Air Temperature-Wind speed & 0.000 \\
\hline
\end{tabular}

Table 2.6: First order index for Treeline (No second order interactions encountered in this site).

\begin{tabular}{lc}
\hline Forcing Forcing variable and order index & Value \\
\hline First Order Index & \\
Longwave radiation & 0.216 \\
Relative humidity & 0.234 \\
Shortwave radiation & 0.212 \\
Air temperature & 0.242 \\
Wind speed & 0.189 \\
\hline
\end{tabular}


Table 2.7: First order index for Swamp Angel Study Plot. (No second order interactions encountered in this site).

\begin{tabular}{ll}
\hline Forcing Forcing variable and order index & Value \\
\hline First Order Index & \\
Longwave radiation & 0.138 \\
Relative humidity & 0.088 \\
Shortwave radiation & 0.509 \\
Air temperature & 0.118 \\
Wind speed & 0149 \\
\hline
\end{tabular}

(1993) method attributable to Saltelli (2002), which estimates first, second and total order effects of the input variables on the snowmelt process represented by the model. Such indices provide important information about how snowmelt is sensitive to meteorological forcing including possible interactions between such forcings (Homma \& Saltelli, 1996). We have found that the first order effects on snowmelt dominated at the three stations assessed except for Snoqualmie Pass station, where a second order effect was encountered.

In Snoqualmie Pass station, we found that shortwave has the major single effect on snowmelt process. However, since the station is located in a maritime climate, significant changes in snowmelt rates can occur by the addition of the effects of other single variables such as longwave, air temperature and relative humidity due to very cloudy conditions, and dense forest. In addition, we have found in this site that single effects of each variable are not sufficient to express the total variance of the diagnostic variable assessed (i.e., snowmelt rate) and suggest the existence of interactions effects (Saltelli et al., 2008) between atmospheric forcings that impact snowmelt rate magnitudes. This indicates that second-order indices can describe 
such interaction effects. In this site, we identified an interaction between atmospheric forcing, related primarily to both incoming shortwave and longwave radiation, which added to the first order effects of irradiance forcings, results in an influence of $65.5 \%$ of the total effect to the snowmelt process.

In Treeline station the single effects of each forcing variable on the snowmelt process are relatively the same. Air temperature and relative humidity have slightly higher indices' magnitudes and longwave exerts almost the same magnitude as shortwave. Since Dry Creek is located in a steppe dry summer climate, we expected to have a much larger sensitivity of snowmelt to shortwave radiation, evidenced by the extreme aspect dependence of snowpack in this site. However, this site is located at the rain-snow transition zone where the snow cover is generally warm and ephemeral and sensitive to climate warming trends (Kormos et al., 2014) with significant impact of the air temperature and humidity.

In Swamp Angel Study Plot station, shortwave radiation causes the major single effect on the changes of snowmelt rates in which, together with longwave radiation, exert more than $64 \%$ of the total first order effect on the snowmelt process. This alpine site has large continental dust influenced snowpacks, which can have a huge impact on shortwave fluxes due to increased albedo from the dust. However, even when the dust deposition processes occurred during the water year of 2014 were not represented in SNTHERM, the sensitivity analysis approach was able to capture the strong influence of shortwave radiation at this site.

We also found at Treeline and Swamp Angel sites that wind speed effect was not totally insignificant (i.e., more than 14 and $18 \%$ respectively) on the changes of snowmelt rates. In those cases where wind speed is present on snowmelt events, the 
influence of the turbulent fluxes of the energy balance snowmelt processes appear. The latent and sensible heat fluxes which are primarily driven by wind and temperature gradients between the snowpack surface and surrounding atmosphere. These fluxes, in conjunction to other parameters such as snow surface roughness and air stability, may play an important role in snow-melting process (Pohl et al., 2006). In addition, Marks et al. (1998), have demonstrated that increased turbulence (particularly in rainon-snow events) produced by a combination of high winds, warm temperatures and high humidity, significantly increases the snow condensation on the surface providing favorable conditions for rapid snowmelting.

In all stations, we found that the effects of irradiances can explain much of the variation in snowmelt (i.e., more than a $54 \%$ at Snoqualmie Pass, $42 \%$ at Treeline and a $64 \%$ at Swamp Angel site). This reinforces the evidence found by Zuzel \& Cox (1975) who emphasize the importance of meteorological variables in snowmelt. In their study (in which a principal component analysis and a regression analysis using meteorological variables and daily melt data was performed) suggests that snowmelt variation can be explained in a $40 \%$ by only considering all-wave radiation fluxes, which in addition considering more variables such as vapor pressure and wind the snowmelt variation can be explained in a $78 \%$.

It should be noted that all atmospheric forcing play a relatively important role in the snowmelt process and none of them should be neglected in the estimation of snowmelt. An example of this is that for many decades, in most snow energy balance research studies, solar or shortwave radiation received more attention since its flux magnitude is considerably higher with respect to other energy fluxes in clear skies (Juszak \& Pellicciotti, 2013). However, in the last twenty-five years, multiple efforts 
to parameterize longwave radiation in alpine snowpacks and glaciers (although for the sites in this study did not cause significant single effects), have emphasized the importance of longwave radiation, not only on the snowpack energy budget but also, on predicting evapotranspiration, surface temperature and frost (Flerchinger et al., 2009) and also in global warming (Philipona \& Dürr, 2004; Dufresne \& Bony, 2008).

In this study, second order index values which represent atmospheric forcing interaction on snowmelt process reveal the complexity of the system. Interpretation of the second order interactions (represented by combination of pairs of input variables) such as Longwave-Shortwave in our case, may have some caveats on interpretation. Such interactions represented by a pair of variables, are not necessarily correlated to make any effect on the system, but represent a synergic effect which contribute significantly to the systems variance. We have sufficient confidence that this method is a useful tool that help to identify input variables or variable interactions that account for most of snowmelt process variance and also make sure if such variable interaction(s) (if any) that influence on the key snowmelt output, have physical sense (Saltelli et al., 2000) according with the understanding of the snowmelt process.

Limitations of global sensitivity analysis most lie in the model selection for this type of study, if the model has a poor representation of the reality the sensitivity of the parameters will be meaningless (Pilkey \& Pilkey-Jarvis, 2007), however, the selection of highly detailed physically based snow models can mitigate these limitations and serve as valuable tools when studying complex processes on snowmelt. This study opens avenues for future research that investigate the effects of atmospheric forcing on snowmelt by using several other fully and semi physically based snow models such as: SNOWPACK (Bartelt \& Lehning, 2002; Lehning et al., 2002), iSnobal (Marks 
et al., 1999), Utah Energy Balance model (Tarboton et al., 1996) and CLM (Dai et al., 2003) among others. Future research will inform some differences and coincidences on snowmelt output sensitivities that might exist in snowmelting processes represented in those models, and also consider the relevance of model structure parameters that also play an important role in the snowpack energy balance such as albedo and snow surface roughness.

\subsection{Conclusions}

In this study, a sensitivity analysis based on variance-decomposition is performed to a physically-based snow model (SNTHERM) in order to investigate and quantify first and higher-order effects of the most common meteorological forcing variables used for snow modeling (i.e. wind speed, air temperature, relative humidity, incoming longwave and shortwave radiation) on prognostic and diagnostic variables related with snowmelt process in a snowpack, primarily snowmelt rates.

SNTHERM model simulations in all the sites, show good agreement with respect to measurements of snow depth in water year 2013-2014. Discrepancies found mainly in snowmelt delay in the melting season and snow accumulation at all the sites, can be attributable principally to the lack of structural model calibration, primarily in the snow albedo parameterization under other external conditions such as dust events as shown in Swamp Angel Study Plot.

First order effects in Snoqualmie Pass are dominated principally by irradiance forcings and air temperature. However, single effects that the forcing variables can exert over the snowmelt process in this station, are not sufficient to explain the total variance of such process. This suggests that second order interactions can give important information that needs to be considered and reveal a small but not insignificant 
role of interaction related primarily to incoming longwave radiation that may play in the snowmelt process.

All forcing variables in Treeline station show the same first-order indices over the snowmelt process and suggest the importance of these variables in radiative and turbulent fluxes between snowpack and the atmosphere, additionally to the importance on land surface thermodynamics caused by wind redistribution of the snow mass.

First order effects on snowmelt at the Swamp Angel site are principally dominated by shortwave radiation, which is characteristic of alpine snowpacks, even when the dust deposition processes happened in water year 2014, and was not represented in the snow model.

In this work we have emphasized the importance of the irradiance variables on the snowmelt process, suggesting that these variables need special attention in terms of measurement and/or parameterization for a better estimate of snowmelt and other land surface processes. The previous emphasis also suggests that the decision of using any irradiance parameterization scheme in snow modeling, must be carefully considered and always subject to corroboration with observations, since the uncertainties involved in such estimations can easily propagate and significantly impact the modeling outputs (Lapo et al., 2015; Raleigh et al., 2015) as well as to misunderstand important energy balance processes that occur in the snowpack. 


\section{CHAPTER 3:}

\section{ASSESSING CROSS-SCALE INTERACTIONS}

BETWEEN ATMOSPHERIC AND

\section{HILLSLOPE-SCALE HYDROLOGY MODELS IN SNOW-DOMINATED COMPLEX WATERSHEDS USING MODELS}

\subsection{Abstract}

Water management in semiarid regions of the western United States requires accurate and timely knowledge of runoff generated by snowmelt. This information is used to plan reservoir releases for downstream users and hydrologic models play an important role in estimating the volume of snow stored in mountain watersheds that serve as source waters for downstream reservoirs. Physically based, distributed hydrologic models are used to develop spatiotemporally dynamic estimates of hydrologic states and fluxes based on understanding of the underlying biophysics of hydrologic response. Yet this class of models are associated with many issues that give rise to significant uncertainties in key hydrologic variables of interest like snow water storage and streamflow. Underlying sources of uncertainty include difficulties in parameteriz- 
ing processes associated with nonlinearities of some processes, as well as from the large variability in the characteristic spatial and temporal scale of atmospheric forcing and land-surface water and energy balance and groundwater processes. Scale issues, in particular, can introduce systematic biases in integrated atmospheric and hydrologic modeling. Reconciling these discrepancies while maintaining computational tractability remains a fundamental challenge in integrated hydrologic modeling. Here we investigate the hydrologic impact of discrepancies between distributed meteorological forcing data exhibiting a range of spatial scales consistent with a variety of numerical weather prediction models when used to force an integrated hydrologic model associated with a corresponding range of spatial resolutions characteristic of distributed hydrologic modeling. To achieve this, we design and conduct a total of twelve numerical modeling experiments that seek to quantify the impact of applied resolution of atmospheric forcings on simulated hillslope-scale hydrologic state variables. The experiments are arranged in such a way to assess the impact of four different atmospheric forcing resolutions (i.e., interpolated $30 \mathrm{~m}, 1 \mathrm{~km}, 3 \mathrm{~km}$ and $9 \mathrm{~km}$ ) on two hydrologic variables, snow water equivalent and soil water storage, arranged in three hydrologic spatial resolutions (i.e., $30 \mathrm{~m}, 90 \mathrm{~m}$ and $250 \mathrm{~m}$ ). Results show spatial patterns in snow water equivalent driven by atmospheric forcing in hillslope-scale simulations and patterns mostly driven by topographical characteristics (i.e., slope and aspect) on coarser simulations. Similar patterns are observed in soil water storage however, in addition to that, large errors are encountered primarily in riparian areas of the watershed on coarser simulations. The Weather Research Forecasting (WRF) model is used to develop the environmental forcing variables required as input to the integrated hydrologic model. WRF is an open source, community supported 
coupled land-atmosphere model capable of capturing spatial scales that permit convection. The integrated hydrologic modeling framework used in this work coincides with the ParFlow open-source surface-subsurface hydrology model. This work has important implications for the use of atmospheric and integrated hydrologic models in remote and ungauged areas. In particular, this work has potential ramifications for the design and development of observing system simulation experiments (OSSEs) in complex and snow-dominated landscapes. OSSEs are critical in constraining the performance characteristics of Earth-observing satellites.

\subsection{Introduction}

In semi-arid mountain areas of the western United States, snow accumulation and melt are the most critical factors to generate sufficient water supply for human and ecological systems. Water resources management in these areas requires accurate and timely knowledge of runoff generation by snowmelt (Dettinger, 2005; Stewart et al., 2005). Generally, those management strategies are based on the use of lumped hydrologic models (Burnash et al., 1973; Brunner, 2010; Havnø et al., 1995; Mishra \& Singh, 2002) because of their simplicity in data needs, historically proven performance, and computational efficiency. The parameterized nature of key watershed processes and properties in these models, however, necessitates data records of significant length for calibration and cannot respond to disturbances internal to the watershed such as land use change, or changes in vegetative cover associated with climate change or other drivers. Because these models require sufficiently long periods of observed precipitation and streamflow it is also impossible to validate predictions in ungauged basins.

Physically based models, on the other hand (Abbott et al., 1986; Beven \& Kirkby, 
1979; Kollet \& Maxwell, 2006; Šimůnek et al., 2006; Qu \& Duffy, 2007; Markstrom et al., 2008), are more sophisticated in their representation of processes and, in principle, provide predictions of observable parameters (e.g., snow water equivalent, soil moisture, etc.) throughout the watershed rather than only at the watershed outlet. Even though physically based models represent most hydrologic processes with more fidelity to hydrologic processes than lumped parameter models, they suffer from a number of other issues that has made their general use for hydrologic forecasting difficult. First, nonlinearities and closure problems in the underlying processes ultimately necessitate empirical parameterization (e.g., constitutive relationships between soil water content and matric potential). Second, these models require a correspondingly complex and large amount of spatiotemporally varying data related to atmospheric, surface, and subsurface variables as input. In topographically complex watersheds, observations characterizing the environmental forcings required as input to these models (e.g., precipitation, temperature, wind speed, etc.) are sparse and often not representative. The complexity of the terrain, moreover, leads to gaps in or unavailability of radar-retrieved precipitation. As a result, in these watersheds data input to hydrologic models is increasingly derived from the output of numerical weather prediction (NWP) models. The key advantage of these models is that they provide environmental forcings that are internally and physically consistent, and spatiotemporally continuous during the period of interest.

Challenges in the use of NWP models to derive hydrologic forcings include, however, the computational expense required to run these models and the discrepancies in spatial scales resolved by the atmospheric, versus land surface hydrology models (Blöschl \& Sivapalan, 1995; Wu \& Li, 2009). Such discrepancies lead to significant 
uncertainties because the characteristic scales of processes and errors can be many orders of magnitude different between atmospheric and hydrologic models. Stated differently, a highly accurate weather prediction within a large region (e.g., the position of key synoptic phenomena is captured to within a few kilometers) can nevertheless lead to highly inaccurate hillslope-scape predictions when used to force a hydrologic model.

A fundamental challenge within the hydrologic sciences, therefore, is to characterize the relationship between the spatial resolution of numerical weather predictions used as input to hillslope-scale resolving models and the corresponding errors in predictions of quantities like SWE and soil moisture. Improving knowledge of the sensitivities of hydrologic predictions to the spatial resolution of weather prediction used as input to hydrologic models is of particular importance in the arid regions of the world that depend on snowmelt in upland mountain watersheds. In these regions, increasing precipitation variability and warming temperatures associated with climate change, coupled with increasing demands on water resources necessitate more accurate predictions of the spatiotemporal evolution of key hydrologic variables.

Only few studies have been conducted to assess directly or indirectly the sensitivity of atmospheric and hydrologic variables to spatial scale. Shao et al. (2001), for example, assessed the influence of the grid scales on both land surface and atmospheric processes. They suggest that surface-energy fluxes in areas where land surface heterogeneity is greatest exhibit the highest uncertainty. By contrast, Mölders \& Raabe (1996) assessed the influence of aggregated land surface grid scale on atmospheric processes (e.g. evapotranspiration representing a key bottom boundary condition to atmospheric models) and suggest that the method used in aggregating land surface 
scale can reduce significantly the impact on atmospheric simulation results at coarse scale. Considering only the land surface, Maxwell et al. (2007, as cited in Gentine et al., 2012) found that coarse scale representation of the surface hydrological processes in land surface modeling may have a significant effect on the area-averaged soil moisture estimates and introduce important biases because of scale. To our knowledge, only one study has performed a distributed spatial scale assessment that explicitly investigate the role of the forcing data resolution on snow modeling. Winstral et al. (2014) performed several modeling experiments in the Dobson Creek catchment within the Reynolds Creek Experimental Watershed by degrading $10 \mathrm{~m}$ forcing data, derived by geostatistically interpolating station data, progressively to a spatial resolution of $1500 \mathrm{~m}$, while maintaining a snow model grid at $10 \mathrm{~m}$ resolution. The study suggests that significant effects on snow accumulation and melt occur due to the resolution of model forcing data, particularly when decreasing spatial forcing resolution. They postulate that topographic smoothness increases as the forcing resolution is degraded in complex terrain leading to increased snow accumulation in high-energy zones and less snow accumulation in low-energy zones. This correspondingly led to earlier melt and increased late-season water deficits and also suggest that in snow simulations performed with forcing scales of $250 \mathrm{~m}$ and larger, the errors increase. In summary, all these studies have identified multiple discrepancies on the estimations of hydrologic states and fluxes by applying combined scale modeling representations in either atmosphere and/or land surface and introduce systematic biases in integrated atmospheric and hydrologic modeling. Reconciling these discrepancies in scale while maintaining computational tractability, remains a fundamental challenge in surface hydrology. 
In this study, we continue with the idea of the work introduced by Winstral et al. (2014) that through a series of carefully designed numerical modeling experiments, seek to advance fundamental understanding of the spatiotemporal expressions of coupled land-atmosphere processes in complex, snow-dominated watersheds. In our case, we introduce a framework that also incorporates the variability of the land surface scale as well as we extend the analysis to soil water storage which allow us to quantify the impact of the spatial resolution of the atmospheric forcings on simulated hillslope-scale hydrologic states and fluxes in a more integrated way. This multi scale assessing framework, in consideration to the time and cost associated in developing new modeling and observing systems at certain scale, is developed based on the observing system simulation experiment (OSSE) approach (Atlas et al., 1985a,b; Atlas, 1997) that takes advantage of already developed atmospheric and hydrologic modeling systems.

The overarching goal of this study is to assess the impact of the atmospheric forcing scales on hydrologic state variables such as snow water equivalent and soil moisture to potentially establish requirements for hydrologic modeling and observation system design. The paper is organized as follows: (1) a description of the methods and an overview of the atmospheric and hydrologic modeling framework, (2) a summary of the results and interpretation, (3) Discussion and conclusion. This study attempts to emphasize the importance of the spatial and temporal meteorological scale to be used in any hydrology forecasting and data assimilation in compensating for coarse resolution atmospheric forcing data, that also may potentially help to reduce the computational and instrumentation cost, and at the same time attempt to improve the accuracy of surface and subsurface hydrologic outputs. 


\subsection{Methods}

\subsubsection{Site}

The study site was conducted in Dry Creek Experimental Watershed (DCEW) which is used as a high-resolution testbed (Figure 3.1). DCEW is a hydrologic experimental site established in 1999. It is located $16 \mathrm{~km}$ northeast of the city of Boise, Idaho with elevation ranging from $950 \mathrm{~m}$ to $2130 \mathrm{~m}$. It is a semi-arid mountain front watershed, facing predominantly southwest. Precipitation is dominated by snow in the upper basin and by rain in the lower elevations. Soil in Dry Creek is composed primarily by coarse, sandy soil derived from in-situ weathering of granite (Gribb et al., 2009). Vegetation communities at lower elevations are composed primarily of sagebrush, bitterbrush, mixed grasses and riparian vegetation, while at higher elevations vegetation is dominated by coniferous evergreen trees, including Douglas Fir and Ponderosa Pine (Anderson et al., 2014).

\subsubsection{Modeling Framework}

The main components for the model execution within the area defined above are: (1) atmospheric processes represented by weather research forecast model (WRF), a mesoscale numerical weather prediction model and (2) an open-source integrated surface-subsurface hydrology model represented by ParFlow-CLM.

\section{Atmospheric Model}

The weather research forecast model (WRF) (Skamarock et al., 2005) with its advanced forecasting system version ARW (advanced research WRF) is a numerical weather prediction (NWP) and atmospheric simulation system designed for research 


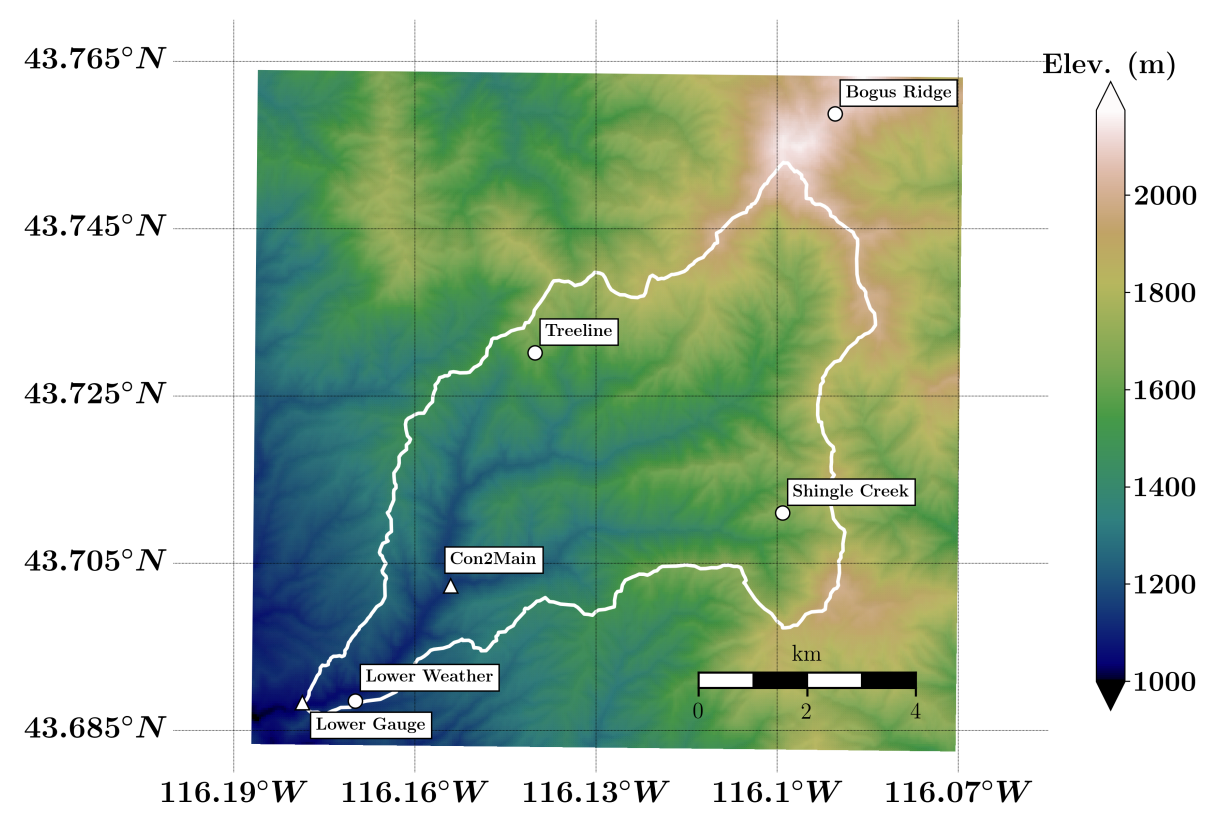

Figure 3.1: Dry Creek Experimental Watershed study area with some relevant weather $(\triangle)$ and discharge $(\circ)$ stations.

and operational purposes. WRF is a community model developed and supported mainly by the National Center of Atmospheric Research (NCAR). WRF-ARW integrates the compressible, nonhydrostatic Euler equations in order to deal with atmospheric motion on a finer spatial scale. Those equations (which involve the equations of momentum and thermodynamic equation) are written in flux form, in order to work either on the sphere by using geographical latitude-longitude coordinates or on a conformal projection of the sphere by using Cartesian coordinates on a Mercator, Lambert or polar stereographic. An important characteristic of WRF for our purposes is that it can be used in mesoscale regional atmospheric research as a ConvectionPermitting Model $(\mathrm{CPM})$ (horizontal scale $<4 \mathrm{~km}$ ) that can explicitly resolve deep convection, which is a significant source of precipitation, in a fine orographic scale (Prein et al., 2015). Within this context WRF simulations have been performed in 
several studies as summarized in (Prein et al., 2015) for periods ranging from months to several years at horizontal scales ranging from $4 \mathrm{~km}$ to $0.8 \mathrm{~km}$. In addition, WRF has been used with spatial domains that include complex terrain (e.g. mountain landscapes) in a high-resolution scale such as Colorado Front Range at $1.3 \mathrm{~km}$ resolution (Mahoney et al., 2013), Idaho mountain ranges spanning Owyhee mountains and Sawtooth mountains at $1 \mathrm{~km}$ resolution (Flores et al., 2016), and even at kilometer and sub-kilometer scales (i.e., $333 \mathrm{~m}$ ) on west-central Nevada (Horvath et al., 2012). All these studies have showed accurate results and also allowed to obtain more detailed spatial representation of simulation outputs that serve as forcing for hydrologic modeling.

\section{Hydrologic Model}

For hydrologic modeling purposes, we selected the ParFlow-CLM model that is able to simulate both surface and subsurface hydrologic processes in an integrated way. ParFlow (Maxwell, 2013; Kollet \& Maxwell, 2006; Jones \& Woodward, 2001; Ashby \& Falgout, 1996) is an open-source high spatial resolution surface-subsurface hydrology model which solves simultaneously the three-dimensional Richards equation and the kinematic wave equation for isothermal, transient and variably saturated flow using a Newton-Krylov method coupled to a multigrid preconditioned solver (Maxwell \& Miller, 2005). ParFlow has the advantage of an advance octree data structure which facilitates the watershed topography representation using digital elevation models and geologic modeling of the subsurface. ParFlow also, is coupled with Common Land Model (CLM) (Dai et al., 2003) where ParFlow computes the mass balance in the subsurface and CLM computes the mass and energy balance at the land surface. 
Both models work simultaneously, by exchanging information of water fluxes between models at every time step (Maxwell \& Miller, 2005). More details of this coupled modeling system can be found in Maxwell \& Miller (2005) and (Kollet \& Maxwell, 2008). ParFlow has been applied to several projects within the US as well as Europe and West Africa ranging from local and regional watersheds applications (e.g., Gilbert et al., 2017; Fang et al., 2016; Maxwell et al., 2007) to large scale continental (e.g., Condon \& Maxwell, 2015; Keune et al., 2016), providing an excellent scalability of its solver in distributed systems along with computationally accurate and efficient surface and subsurface flow solutions (Maxwell \& Miller, 2005).

\subsubsection{Experimental setup}

For this study we design and conduct a total of twelve numerical modeling experiments that seek to quantify the impact of applied resolution of atmospheric forcings on simulated hillslope-scale hydrologic state variables that include two hydrologic variables, Snow Water Equivalent and Soil Water Storage. The simulation experiments are arranged in such way to assess the impact of four different atmospheric forcing resolutions (i.e., interpolated $30 \mathrm{~m}, 1 \mathrm{~km}, 3 \mathrm{~km}$ and $9 \mathrm{~km}$ ) on three hydrologic spatial resolutions commonly used for land surface modeling (i.e., 30 m, 90 m and 250

m). Table 3.1 illustrates the set of simulation experiments performed in this study. In order to setup all the experiments two major phases were needed: (1) the atmospheric forcing generation (input data to Parflow) and hydrologic model parameter adjustment and (2) Scale assessing framework development and implementation for the atmospheric and land surface multiscale modeling. 


\section{Atmospheric forcing generation and hydrologic model parameter adjust- ment}

Surface hydrometeorological data required as input to the hydrologic model are obtained from the WRF model. The model produces distributed meteorological forcing data at several scales to feed the land surface-subsurface component represented by ParFlow and CLM, incorporating consistent environmental forcing data distributed over the landscape that consider remote and ungauged areas. After synthesizing the hydrometerological forcings to ParFlow using WRF, we adjusted the Manning roughness value on the study site, using the finest land surface spatial scale, in order that the model outputs match acceptably the observed data. This process was manually performed and the outputs targeted were soil moisture and streamflow, and they were compared with observational soil moisture and streamflow data obtained by sensors and gauges distributed within Dry Creek Experimental Watershed. The value suggested was $0.000094 \mathrm{~h} / \mathrm{m}^{1 / 3}$. Initial conditions for Parflow were obtained by performing a set of drainage experiments that allow us to find an initial moisture state for a particular time that matches a real condition in the dry season.

\section{Scale assessing framework development and implementation for the atmo- spheric and land surface multiscale modeling}

A scale assessing framework based on OSSE's methodology was developed by using the previous atmospheric input generation and hydrologic model parameter adjustment. Figure 3.2 describes the overarching process of scale assessing framework adapted to our case. This framework consists on the generation of a reference hydrologic state focusing primarily on snow water equivalent and soil water storage for a certain 
period. This state reference is often referred to in OSSE methodology as a Nature Run or Truth and for this study the experimental simulation performed with highest spatial resolution (i.e., interpolated $1 \mathrm{~km}$ to $30 \mathrm{~m}$ atmospheric forcing scale and 30 $\mathrm{m}$ hydrologic scale) is considered as nature run. Then, several experiments were run, maintaining constant spatial resolution of the land-surface and using multiple meteorological forcing resolutions decided arbitrarily (see Table 3.1). These types of runs are often called perturbation runs which then are compared to the nature run. The impact of the scale resolution was measured by estimating the mean error (ME) and the root mean square error (RMSE) between the nature (observations) and perturbation (simulated) runs. The bias, or mean error is computed as,

$$
M E=\frac{1}{N} \sum_{i=1}^{N}\left(\delta_{E, i, j}-\delta_{T, i, j}\right)
$$

and the root mean squared error is computed as,

$$
R M S E=\sqrt{\frac{1}{N} \sum_{i=1}^{N}\left(\delta_{E, i, j}-\delta_{T, i, j}\right)^{2}}
$$

where $\delta_{E, i, j}$ is the hydrologic variable to assess for each experiment at the coordinates $(i, j)$ in the modeling grid and $\delta_{T, i, j}$ represent the hydrologic variable to assess for the control run, $N$ represents the number of samples in time (time series length) assessed.

\subsubsection{Hydrologic variables assessed}

In this study, we assessed two hydrologic variables of importance that represent surface and subsurface processes: total soil water storage and snow water equivalent. These processes and corresponding mass and energy fluxes within model grid cells 


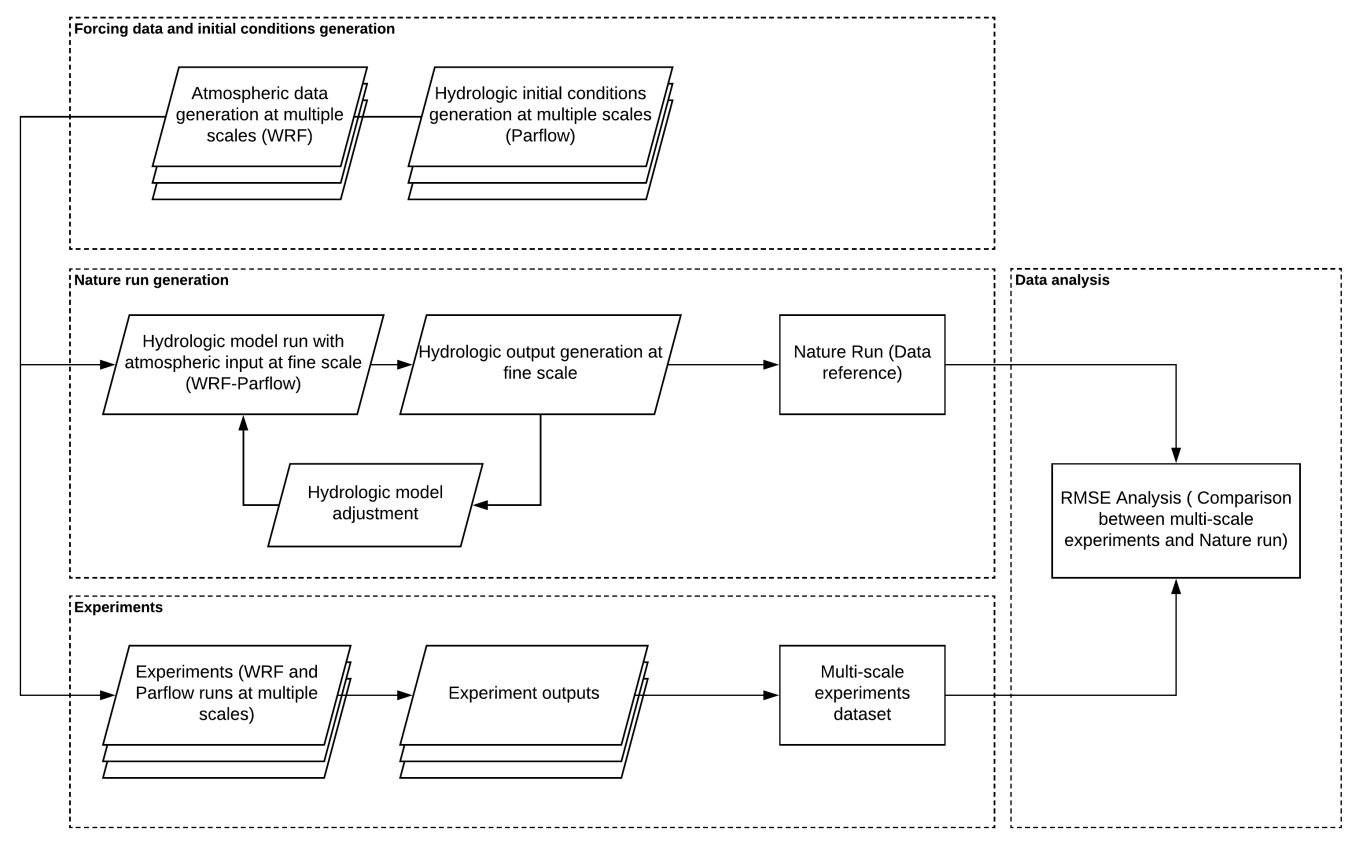

Figure 3.2: Multiscale modeling assessment framework.

and external forcings are depicted in Figure 3.3. The total soil water storage in a soil column is represented by the sum of the product of saturation, porosity and the layer thickness as,

$$
\Theta=\sum_{k=1}^{L} S_{i, j, k} \phi_{i, j, k} \Delta z
$$

where $\Theta$ represents soil water storage, $S$ is the water saturation in layer located at coordinates $(i, j, k), \phi$ is the porosity in layer $k$ and $\Delta z$ corresponds to the layer thickness. The water saturation in ParFlow model is estimated from the pressure field (equation 3.2), using the mixed form of the Richards equation (Maxwell and Miller, 2005) as, 
Table 3.1: Simulation experiments and nomenclature.

\begin{tabular}{lllll}
\hline \multirow{2}{*}{ Hydrologic Resolution } & \multicolumn{4}{c}{ Atmospheric Forcing Resolution } \\
\cline { 2 - 5 } & A1 $(\mathrm{H} \mathrm{m})^{\mathrm{a}}$ & A2 $(1 \mathrm{~km})$ & A3 $(3 \mathrm{~km})$ & A4 $(9 \mathrm{~km})$ \\
\hline H1 $(30 \mathrm{~m})$ & A1-H1 & A2-H1 & A3-H1 & A4-H1 \\
H2 $(90 \mathrm{~m})$ & A1-H2 & A2-H2 & A3-H2 & A4-H2 \\
H3 $(250 \mathrm{~m})$ & A1-H3 & A2-H3 & A3-H3 & A4-H3 \\
\hline
\end{tabular}

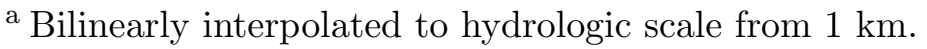

b Simulation reference (Nature run).

$$
\frac{\partial(s(p)) \rho \theta)}{\partial t}-\nabla\left[\frac{k(x) k_{r}(p) \rho}{\mu}(\nabla p-\rho g \nabla z)\right]=q
$$

the variable $s(p)$ is the water saturation at a hydraulic pressure $p$ while the variables $\theta, k(x)$ and $k_{r}(p)$ are the effective porosity, the absolute permeability and the relative permeability of the medium, $\rho$ and $\mu$ represent the density and dynamic viscosity of the water. Snow water equivalent, represents the amount of water that results if snowpack is melted by unit of area (DeWalle \& Rango, 2008; Armstrong \& Brun, 2008). It can be simply expressed as the measurement of snow depth $h_{s}$ and the density ratio between snow $\rho_{s}$ and liquid water $\rho_{w}$ as,

$$
S W E=h_{s} \frac{\rho_{s}}{\rho_{w}}
$$

However, in CLM model the amount of water in a snowpack is determined by the conservation of mass and energy of the snowpack within a control volume, neglecting horizontal fluxes but considering vertical neighbors (i.e., snow layers). The mass balance is represented in terms of mass of water $w_{l i q}$ and mass of ice $w_{i c e}$ which the temporal variation of mass of water in such control volume is driven by liquid phase, ice phase water fluxes and changes in water phase $M_{i l}$ due to melt (melting rate) as 
follows,

$$
\begin{gathered}
\frac{\partial w_{l i q, k}}{\partial t}=\left(q_{l i q, k-1}-q_{l i q, k}\right)+\left(M_{i l} \Delta z\right)_{k} \\
\frac{\partial w_{i c e, k}}{\partial t}=\left(q_{i c e, k-1}-q_{i c e, k}\right)-\left(M_{i l} \Delta z\right)_{k}
\end{gathered}
$$

The energy balance in snowpack is represented by the conservation of energy equation which is defined as the change in stored energy within a control volume (snow layer) equal to the net energy flux across the volume surface as follows,

$$
\sum_{m=i, l}\left[\rho z_{m} c_{m} \theta_{m}\right]_{k} \Delta z_{k} \frac{\partial T_{k}}{\partial t}=R_{n, k}-\left[L_{f} M_{i l} \Delta z\right]_{k}-H-L_{v} E+\left[\lambda \frac{\partial T}{\partial t}\right]_{z_{h, k-1}}^{z_{h, k}}
$$

where $t$ is the time, $T_{k}$ is the average temperature of the layer $k, \rho_{m}, c_{m}$ and $\theta_{m}$ are the density, specific heat and the partial volume of the water $l$ and ice $i . L_{f}$ and $L_{v}$ latent heat of fusion for ice and latent heat of evaporation, $\lambda$ is the is the thermal conductivity of snow, and $R_{n, k}, H$ and $L_{v} E$ are radiative, latent and sensible heat fluxes. The snow component in CLM is represented by up to five snow layers and the momentum, latent heat and sensitive heat fluxes between the atmosphere at reference height (i.e., $10 \mathrm{~m}$ ) and snow surface, are derived from Monin-Obukhov similarity theory (Monin \& Obukhov, 1954).

\subsubsection{Data requirement and model configuration}

The ParFlow-CLM model requires hourly forcing inputs of precipitation, temperature, pressure, wind speed, incoming short and longwave radiation, and specific humidity. The forcing input data are generated by WRF models and retrieved as 


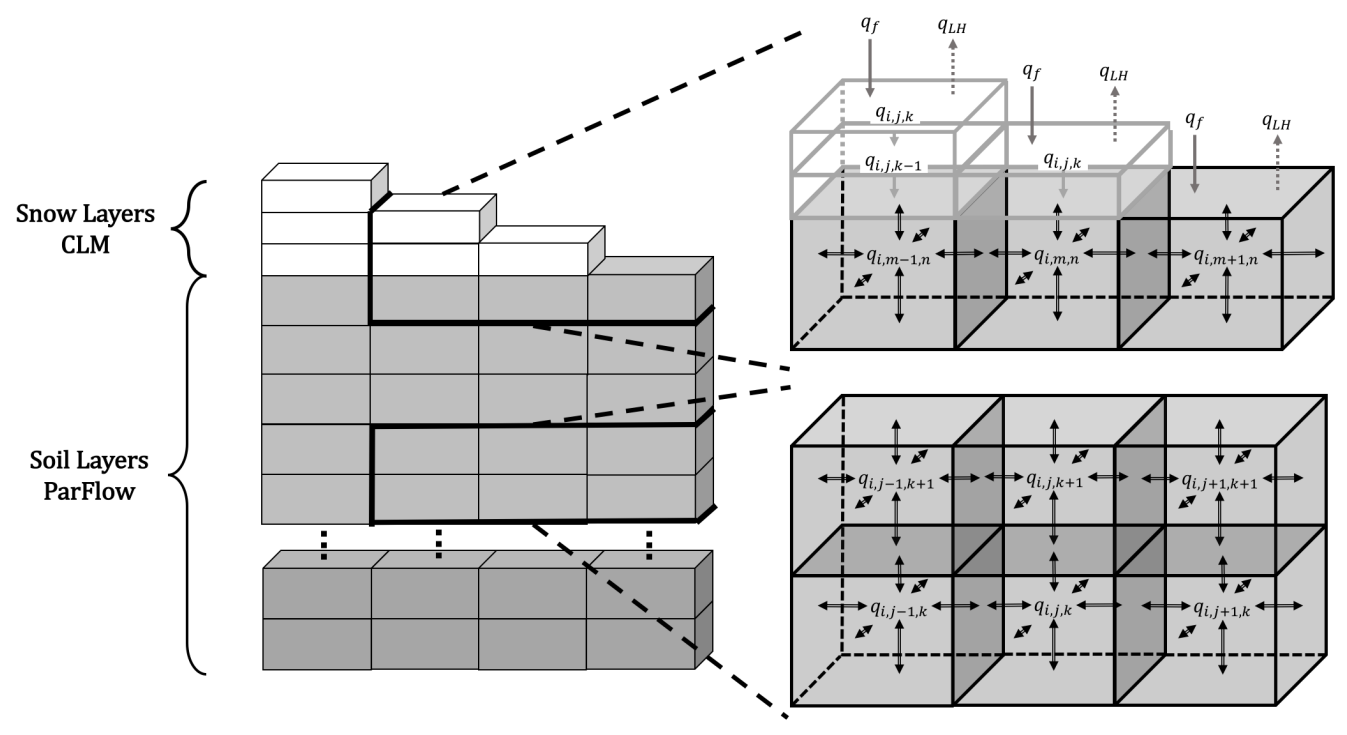

Figure 3.3: Schematic cell representation of surface and subsurface layers in ParFlow-CLM. Variables $q_{f}$ represent downward energy fluxes from forcings and $q_{L H}$ upward energy fluxes (sensible and latent) respectively, from snow and soil 
a data-subset from the 30-Year, Multi-Domain High-Resolution Climate Simulation Dataset for the Interior Pacific Northwest and Southern Idaho project (Flores et al., 2016). Data used to verify model outputs include observations of hourly and daily average discharge, soil moisture, and snow water equivalent are located at multiple sites in DCEW. Such observation data were retrieved from DCEW in water year 2009 at https://earth.boisestate.edu/drycreek/data/.

To develop the computational grid for the ParFlow-CLM model the following data were needed: (1) digital elevation data defining watershed topography, (2) the spatial distribution of soil types (e.g., surface texture), and (3) the spatial distribution of land cover data. The digital elevation data for the domain area was retrieved from the National Elevation Dataset (Gesch et al., 2002) data source at 1/9 arc-second spatial resolution $(30 \mathrm{~m})$, while other domain spatial scales (i.e., $90 \mathrm{~m}$ and $250 \mathrm{~m}$ ) were retrieved by upscaling such data sources using QGIS raster alignments tools (QGIS Development Team et al., 2014) with a bilinear resampling method. Soil types were retrieved from Soil Survey Geographic Database (SSURGO)(Soil Survey Staff, 2014) and the soil texture classifications were determined based on the percent of sand and clay by using NRCAs soil texture calculator (Natural Resources Conservation Service, 2014). Hydraulic and soil moisture characteristic parameters (i.e., Van Genuchten parameters) were retrieved from Leij (1996) and Simmers (2005) while land cover datasets, were retrieved from the National Land Cover Database (NLDAS) (Homer et al., 2015). Since CLM model requires the International Geosphere-Biosphere Programme (IGBP) land cover classification, primarily retrieved from $500 \mathrm{~m}$ spatial resolution MODIS data, each NLCD classification is approximated to the corresponding IGBP classification required by CLM model. This approach takes advantage of using 
a finer resolution of NLDAS land cover dataset and the similitude existing between MODIS and NLDAS datasets.

The computational soil grid in ParFlow uses terrain following grid formulation (Maxwell, 2013), which has the advantage of solving all the governing equations in a near ground complex terrain and fine spatial discretization, more efficiently. The soil profile and layer thicknesses are selected according to the ParFlow-CLM modeling requirements. Figure 3.4 illustrates the soil layers configuration as well as the thickness value for each layer and total soil depth for the modeling domain. The top soil layer was set to $1 \mathrm{~m}$ depth for the entire domain followed by $19 \mathrm{~m}$ of bedrock. The first two top soil layers in ParFlow are set with small values (i.e., $0.05 \mathrm{~m}$ each) of thickness to allow efficient flux exchange with CLM model. The subsequent soil layers are distributed by equal valued thicknesses (i.e., $0.1 \mathrm{~m}$ ) up to reach $0.8 \mathrm{~m}$ depth. The transition between soil and bedrock are set as $0.2 \mathrm{~m}$ from the soil part and $1 \mathrm{~m}$ from the bedrock part followed by 9 layers of $2 \mathrm{~m}$ each up to reach $20 \mathrm{~m}$ depth. The set of hydraulic and soil moisture characteristic parameters selected for each soil texture are shown in Table 3.2 and are used for all the simulation experiments.

\section{Forcing data and initial condition generation}

The atmospheric forcing data generated by the WRF model, are spatially distributed (9 km, $3 \mathrm{~km}, 1 \mathrm{~km}$ and $30 \mathrm{~m}$ interpolated from $1 \mathrm{~km}$ ) and available at hourly resolutions during water year 2009. Since we performed different experiments at $30 \mathrm{~m}, 90 \mathrm{~m}$ and $250 \mathrm{~m}$ land surface spatial resolution, the forcing data are rescaled to the corresponding land surface model grid using a nearest neighbor interpolation algorithm to maintain the atmospheric spatial scale of the original data output of WRF. Another 
Table 3.2: Summary of soil parameters selected from Leij (1996) and Simmers (2005) and applied to the DCEW study domain.

\begin{tabular}{llllll}
\hline \multirow{2}{*}{ Soil Texture } & \multicolumn{5}{c}{ Parameters } \\
\cline { 2 - 6 } & $\theta_{r}\left(\mathrm{~m}^{3} / \mathrm{m}^{3}\right)^{\mathrm{a}}$ & $\theta_{s}\left(\mathrm{~m}^{3} / \mathrm{m}^{3}\right)^{\mathrm{b}}$ & $\alpha\left(m^{-1}\right)^{\mathrm{c}}$ & $n(-)$ & $K_{s}(\mathrm{~m} / \mathrm{hr})^{\mathrm{e}}$ \\
\hline Loamy sand & 0.057 & 0.41 & 12.4 & 2.28 & 0.1459 \\
Sandy loam & 0.065 & 0.41 & 7.5 & 1.89 & 0.0442 \\
Sandy clay loam & 0.1 & 0.39 & 5.9 & 1.48 & 0.0131 \\
Loam & 0.078 & 0.43 & 3.6 & 1.56 & 0.0104 \\
Clay & 0.068 & 0.38 & 0.8 & 1.09 & 0.002 \\
\hline
\end{tabular}

a Saturation residual.

b Saturated water content.

${ }^{\mathrm{c}}$ Parameter inversely related to the air entry value.

${ }^{\mathrm{d}}$ Parameter that determine the water retention curve shape.

e Saturated hydraulic conductivity.

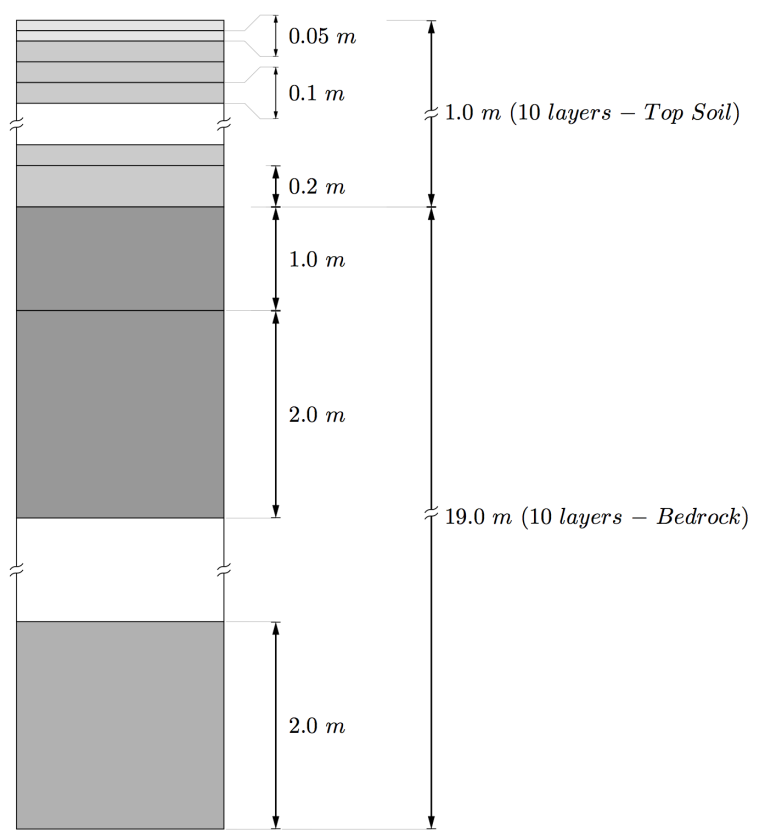

Figure 3.4: Detailed soil layers configuration for the modeling domain used in ParFlow-CLM simulations. 
set of three experiments are rescaled from $1 \mathrm{~km}$ WRF grid to the $30 \mathrm{~m}$ ParFlow grid using bilinear interpolation in order to provide a set of meteorological forcings that are smooth in space at the scale of the ParFlow model.

Drainage experiments are performed for all land surface scales in order to find a reasonable initial condition of water pressure to initialize the model (Figure 3.5). The drainage experiment consisted of dampening the domain with a small and constant value of recharge in order to reach groundwater equilibrium (Figure 3.5A). At this stage, the lateral flows on each cell are turned off to avoid formation of streams and ponds. Afterwards, we allowed the watershed to drain by turning on the lateral flows. This drainage experiment allows us to estimate continuous pressure head and saturation fields for all the cells in the domain and also allows groundwater to converge and discharge through the valleys and form streams (Figure 3.5B). During drainage, we allow groundwater storage and streamflow to decrease until the streamflow matches a reference value of observed streamflow at the watershed outlet in the dry season. The value to match was $0.0031 \mathrm{~m}^{3} / \mathrm{s}$ which corresponds to the streamflow value obtained at the end of September 2008 (Figure 3.5C). The states of the ParFlow model, pressure head and saturation, at this discharge during the drainage experiment are then retained. We use these retained states as the initial conditions for the complete set of experiments depicted in Figure 3.6. The top layer of head pressure for land surface domains at $30 \mathrm{~m}, 90 \mathrm{~m}$ and $250 \mathrm{~m}$ spatial scale are shown in Figure 3.6 with a sample of distributed atmospheric forcing at scale of $30 \mathrm{~m}, 1 \mathrm{~km}, 3 \mathrm{~km}$ and $9 \mathrm{~km}$. 
(A)

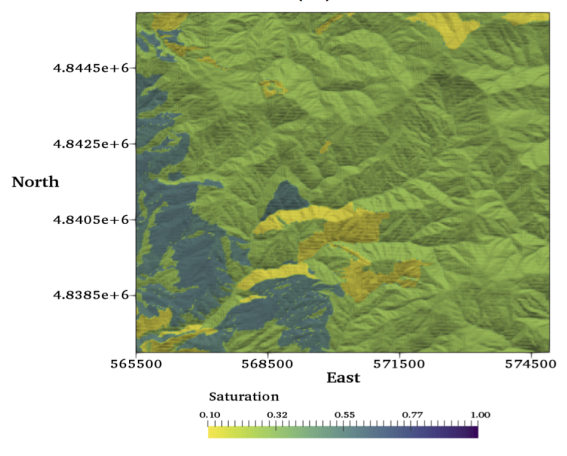

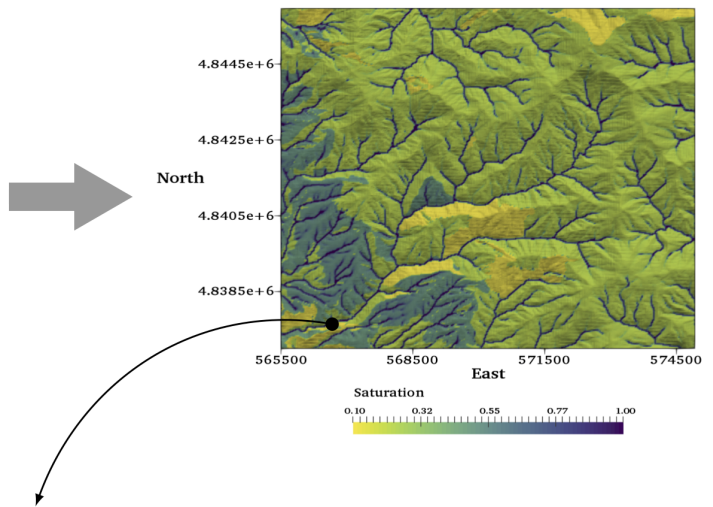

(C)

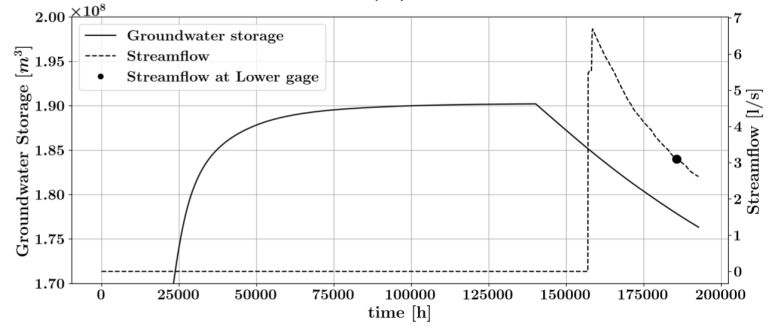

Figure 3.5: Soil moisture initial conditions generation process.

(A1) 1km-bilinear

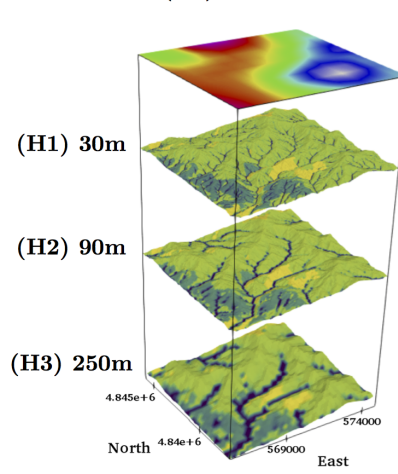

(A2) $1 \mathrm{~km}$

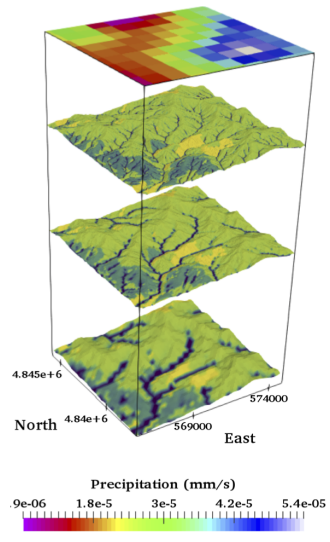

(A3) $3 \mathrm{~km}$

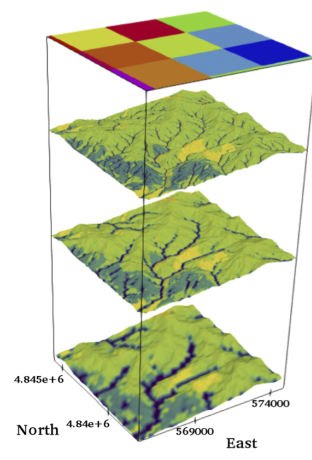

Saturation (-)
(B)

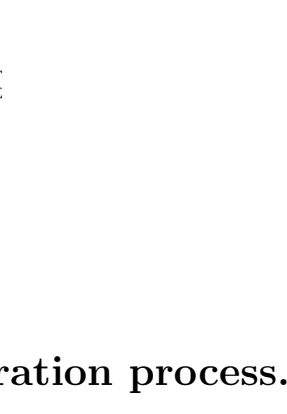




\section{Baseline run}

A baseline run (Nature Run) is obtained by performing a short-term simulation, comparing simulated streamflow, soil moisture, and snow water equivalent to observed values in DCEW, and a set of parameters principally in the soil component of the model, were selected from Leij (1996) to try to match the simulated and observed values. The nature run coincided with the experiment with the finest hydrologic resolution and the finest interpolated atmospheric forcing scale (i.e., $30 \mathrm{~m}$ hydrologic resolution and $30 \mathrm{~m}$ bilinear interpolated forcing resolution).

Once Parflow and CLM finish their simulations, the model performance is assessed where data variables are available for verification. Figure 3.7 shows for example the model performance of soil moisture with respect to observed data. Simulated values of soil moisture are either underestimated and/or overestimated in some periods during 2009 water year. These discrepencies arise primarily due to effects of rainfall events simulated by WRF that do not coincide in time with the observations, as well as uncalibrated hydraulics parameters in the soil component. However, calibration to improve model predictability in the baseline run is not the main purpose of this study, but rather to use it as a reference to compare with the other experiments and determine the impact of applied resolution of atmospheric forcings on simulated hillslope-scale hydrologic state variables.

\subsection{Results}

Once all of the numerical modeling experiments are performed according to the modeling assessment framework developed, all the experiments were compared to the baseline run in order to verify spatial error patterns due to variations in spatial scale. 


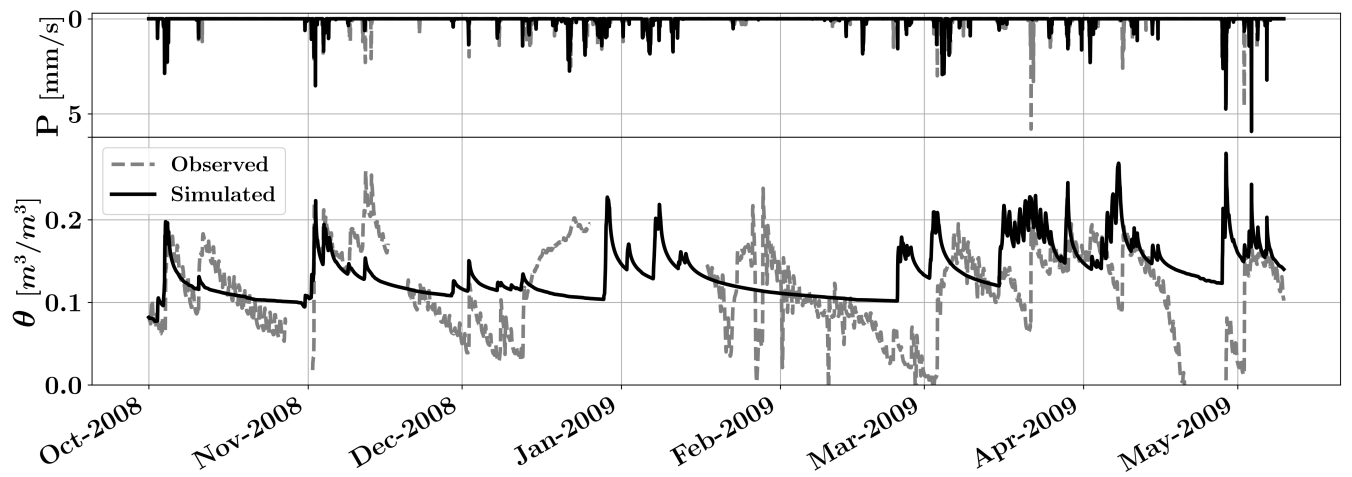

Figure 3.7: Soil moisture at $2 \mathrm{~cm}$ observed simulated time series at lower south station in DCEW. Precipitation data is retrieved from Lower Weather station (see Figure 3.1).

The spatially distributed results for all the experiments are presented in terms of soil water storage integrated vertically in the soil column (i.e., $1 \mathrm{~m}$ soil column), and SWE, which allows us to assess the subsurface and surface water balance sensitivity to changes in atmospheric forcing scales.

\subsubsection{Spatially distributed RMSE for SWE and soil water storage}

Analysis of Figure 3.8 shows the effects of variation in the spatial resolution of atmospheric forcing inputs on SWE across a corresponding range of ParFlow spatial resolutions in DCEW. For all land surface resolutions, the RMSE increases with decreasing resolution in the atmospheric forcing. In terms of magnitude of the RMSE, correspondingly, increasing land surface scale and atmospheric scale increases the magnitude of errors in SWE. Local effects of forcing data are particularly pronounced in simulations at $30 \mathrm{~m}$ land surface spatial resolution in which high magnitudes of RMSE are located in borders and/or corners defined by the corresponding atmospheric grid resolution. These patterns are due to the comparison of the effects of 


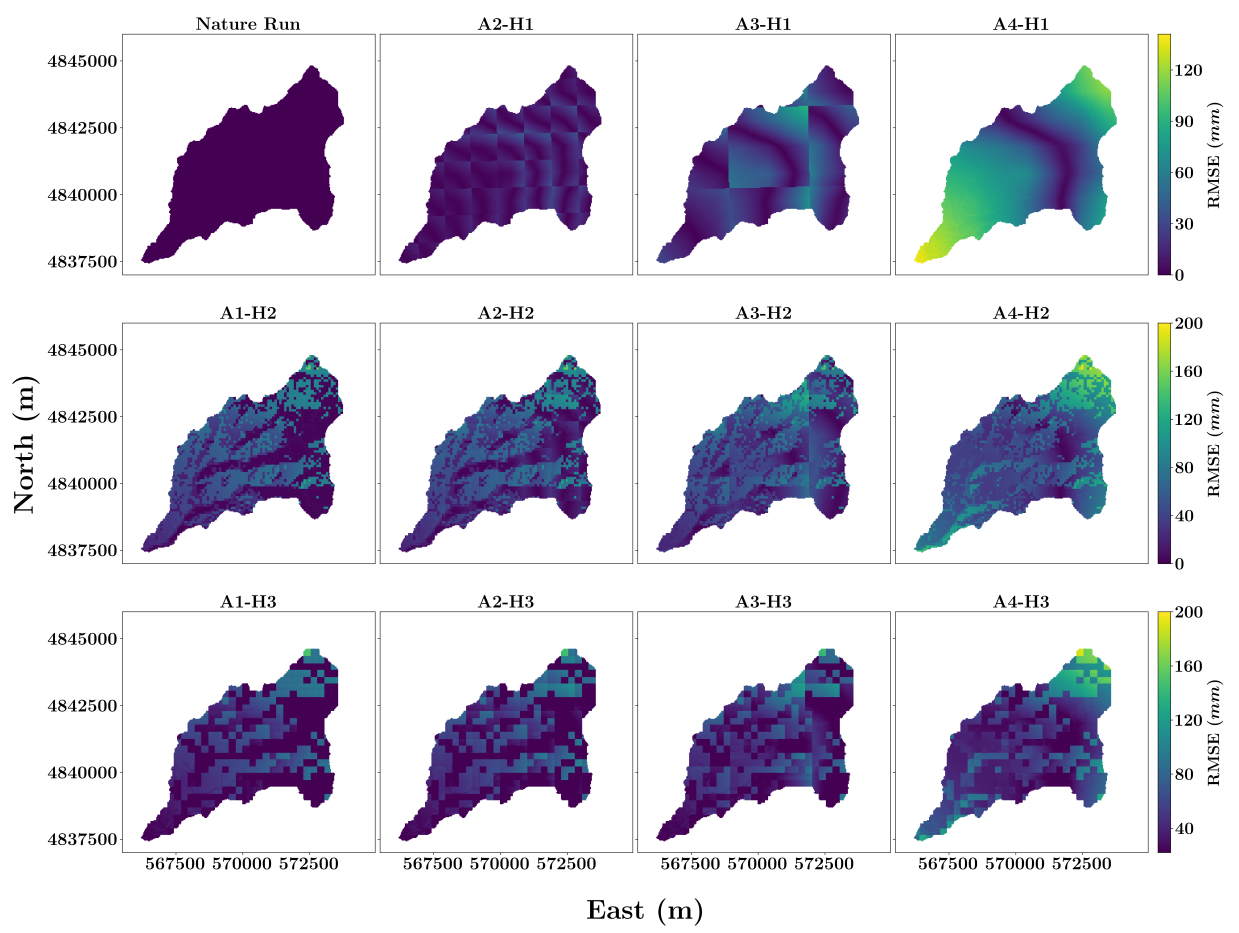

Figure 3.8: Spatially distributed RMSEs for SWE in water year 2014.

coarse atmospheric forcing resolution and finest ones to simulated SWE. High spatial resolution modeling (i.e., nature run) produce of high gradients of SWE across in the modeling domain and when it is compared to effects caused for aggregated forcing (i.e., $1 \mathrm{~km}, 3 \mathrm{~m}$ and $9 \mathrm{~km}$ ) on $\mathrm{SWE}$, these types of artifacts are generated concentrating less error around the middle of the coarse grid cell and larger along the boundaries.

On the other hand, the errors in the soil water storage shown in Figure 9, shows slightly different RMSE patterns at $30 \mathrm{~m}$ land surface model resolution in contrast to SWE cases. In these cases, the atmospheric patterns caused particularly in SWE as 
shown in Figure 3.8, are now combined to topographic effects on streamflow in which higher moisture converge to lower elevated areas. On the other hand, comparisons of $90 \mathrm{~m}$ and $250 \mathrm{~m}$ land surface spatial resolution to the nature run show significant topography and aspect patterns on the spatial pattern in RMSE of soil water storage. Specifically, there are significant topographic effects on soil water storage patterns and large effects on flat areas, such as riparian areas. More general statistics that show RMSE variability expressed above between experiments and the nature run are also illustrated in tables 3.2 and 3.3 in which minimum, maximum, mean and standard deviation of RMSE measurements for SWE and soil water storage variables are shown respectively. These global statistics, particularly the mean of the spatial RMSE, indicate the drastic incremental changes in magnitude, specially for SWE, when degrading the hydrologic scale (i.e., from $\mathrm{H} 1$ to H2) as well as indicate the incremental change when degrading the atmospheric scale while maintaining the hydrologic scale.

Table 3.3: Summary of RMSEs for SWE (mm).

\begin{tabular}{lllll}
\hline \multirow{2}{*}{ Experiment } & \multicolumn{4}{c}{ Metrics } \\
\cline { 2 - 5 } & Min & Max & Mean & SD \\
\hline A2-H1 & 0.50 & 44.55 & 9.04 & 6.84 \\
A3-H1 & 0.36 & 91.38 & 22.97 & 16.33 \\
A4-H1 & 1.75 & 140.69 & 60.64 & 33.14 \\
A1-H2 & 0.43 & 153.92 & 33.60 & 30.18 \\
A2-H2 & 0.53 & 161.90 & 36.48 & 28.12 \\
A3-H2 & 0.40 & 147.63 & 42.03 & 25.26 \\
A4-H2 & 1.64 & 196.09 & 57.26 & 33.12 \\
A1-H3 & 0.51 & 152.97 & 34.40 & 29.82 \\
A2-H3 & 0.55 & 149.28 & 37.30 & 27.88 \\
A3-H3 & 0.83 & 144.61 & 41.61 & 25.38 \\
A4-H3 & 1.28 & 192.16 & 56.53 & 32.99 \\
\hline
\end{tabular}




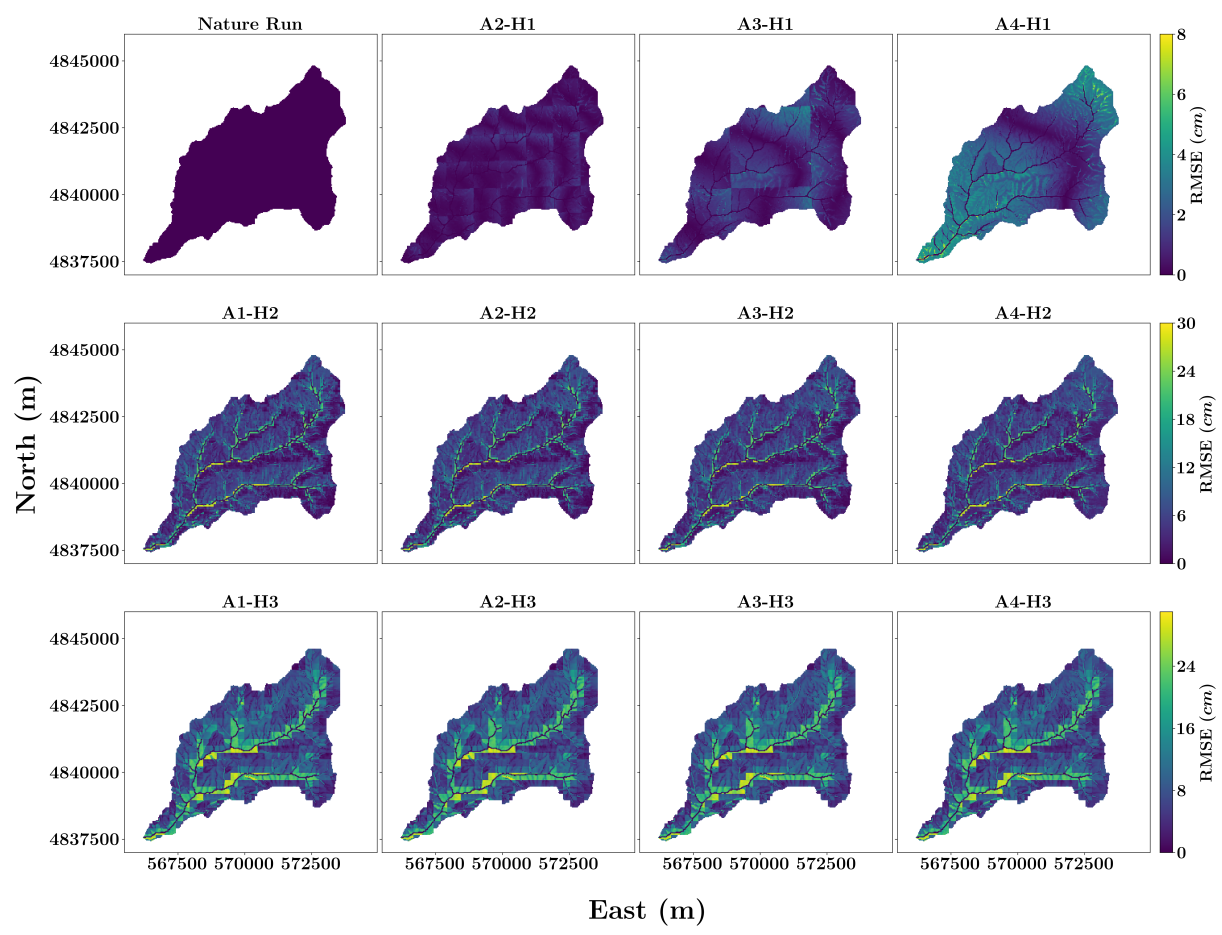

Figure 3.9: Spatially distributed RMSEs for soil water storage in water year 2014. 
Table 3.4: Summary of RMSEs for soil water storage $(\mathrm{cm})$.

\begin{tabular}{lllll}
\hline \multirow{2}{*}{ Experiment } & \multicolumn{4}{c}{ Metrics } \\
\cline { 2 - 5 } & Min & Max & Mean & SD \\
\hline A2-H1 & 0.00 & 1.99 & 0.41 & 0.31 \\
A3-H1 & 0.00 & 5.64 & 0.95 & 0.69 \\
A4-H1 & 0.00 & 10.71 & 2.13 & 1.26 \\
A1-H2 & 0.00 & 29.46 & 6.08 & 5.01 \\
A2-H2 & 0.00 & 29.46 & 6.10 & 5.00 \\
A3-H2 & 0.00 & 29.46 & 6.15 & 4.96 \\
A4-H2 & 0.00 & 29.46 & 6.22 & 4.89 \\
A1-H3 & 0.00 & 30.08 & 9.50 & 6.42 \\
A2-H3 & 0.00 & 30.08 & 9.53 & 6.40 \\
A3-H3 & 0.00 & 30.08 & 9.56 & 6.39 \\
A4-H3 & 0.00 & 30.09 & 9.54 & 6.37 \\
\hline
\end{tabular}

\subsubsection{Spatially distributed bias for SWE and soil water stor-} age

Analysis of bias for SWE as shown in Figure 3.10 reveals (similar to RMSE analysis) that the most positive biases are found around the borders of the associated forcing grid at $30 \mathrm{~m}$ land surface resolution. Also, decreasing in both atmospheric and land surface spatial resolutions, it is revealed that topography and slope aspect have significant impact on simulated SWE. Visual inspection on simulations over 90 $\mathrm{m}$ land surface resolution shows that the most positive biases are associated with north aspects and lower elevation areas (case of land surface simulated with $9 \mathrm{~km}$ atmospheric resolution). Conversely, negative biases are mostly associated with south facing aspects and higher elevations.

Visual inspection of biases for soil water storage (Figure 3.11) reveals that most positive biases are associated with the borders of the associated forcing grid in the 


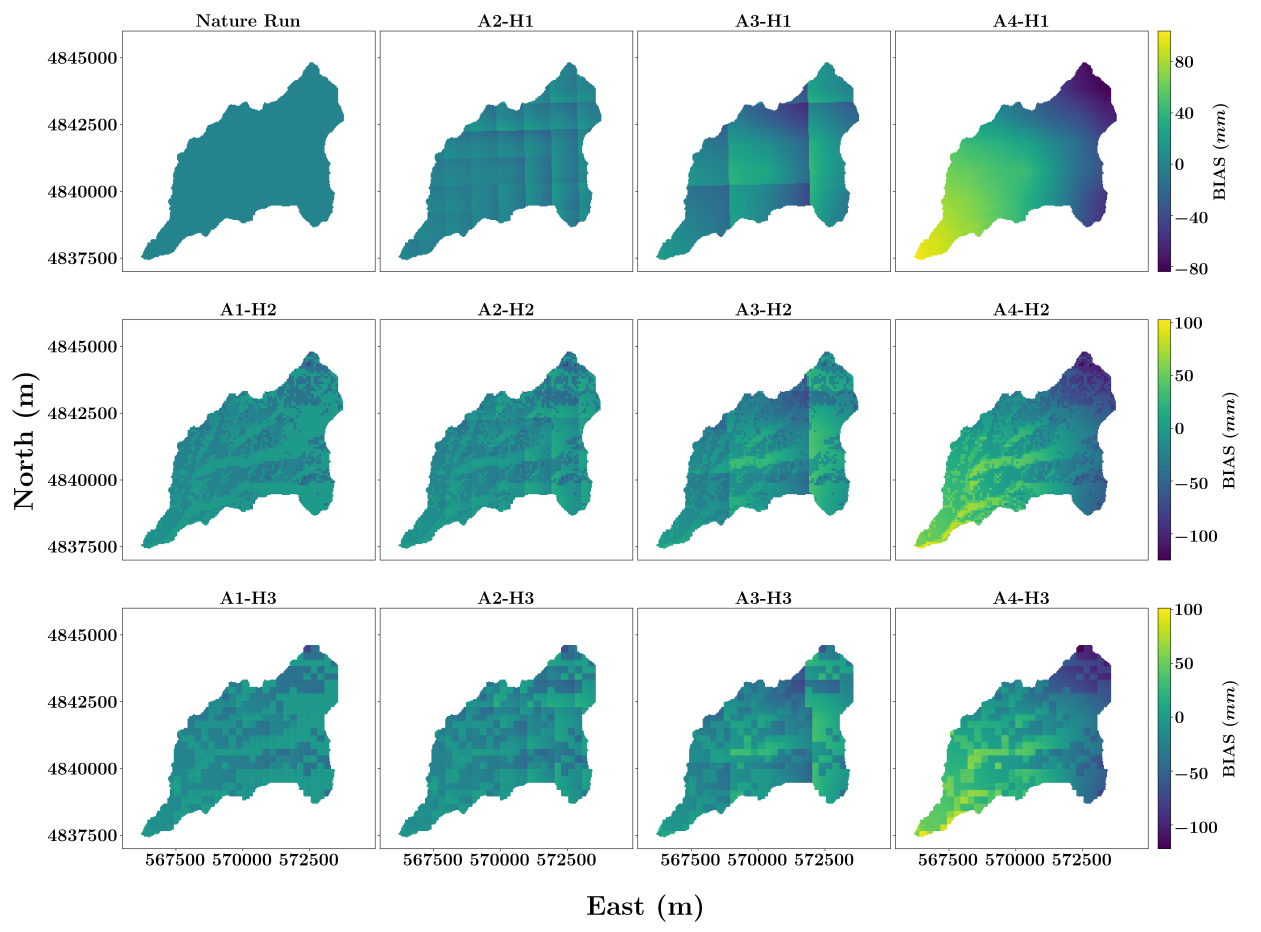

Figure 3.10: Spatially distributed bias for SWE in water year 2014. 
$30 \mathrm{~m}$ land surface resolution simulation. However, for atmospheric resolutions over $3 \mathrm{~km}$, both positive and negative biases are associated with valley bottoms. On the other hand, decreasing both atmospheric and land surface spatial resolution, shows that topography has significant impact on the spatial distribution of bias in soil water storage. On simulations performed with $90 \mathrm{~m}$ land surface resolution and above, it is found that the mean of negative and positive biases are associated with stream and riparian areas respectively. More general statistics that show ME variability expressed above between experiments and nature run are also illustrated in tables 3.4 and 3.5 in which minimum, maximum, mean and standard deviation of ME measurements for SWE and soil water storage variables are shown respectively. Similarly as RMSE analysis in the previous subsection, drastic changes can be visible in the mean of the $\mathrm{ME}$, specially when degrading the hydrologic scale (i.e., from $\mathrm{H} 1$ to $\mathrm{H} 2$ ).

Table 3.5: Summary of ME for SWE (mm).

\begin{tabular}{lllll}
\hline \multirow{2}{*}{ Experiment } & \multicolumn{4}{c}{ Metrics } \\
\cline { 2 - 5 } & Min & Max & Mean & SD \\
\hline A2-H1 & -28.84 & 24.08 & -1.11 & 7.38 \\
A3-H1 & -62.19 & 43.10 & 1.38 & 19.10 \\
A4-H1 & -83.82 & 104.52 & 12.85 & 46.35 \\
A1-H2 & -75.61 & 10.19 & -14.00 & 13.90 \\
A2-H2 & -85.53 & 21.56 & -14.12 & 15.20 \\
A3-H2 & -77.82 & 43.84 & -11.89 & 21.43 \\
A4-H2 & -125.01 & 103.13 & -8.75 & 39.69 \\
A1-H3 & -75.70 & 12.73 & -14.24 & 13.98 \\
A2-H3 & -72.39 & 23.73 & -14.94 & 15.00 \\
A3-H3 & -75.60 & 38.29 & -12.47 & 20.65 \\
A4-H3 & -121.53 & 101.34 & -8.47 & 39.22 \\
\hline
\end{tabular}




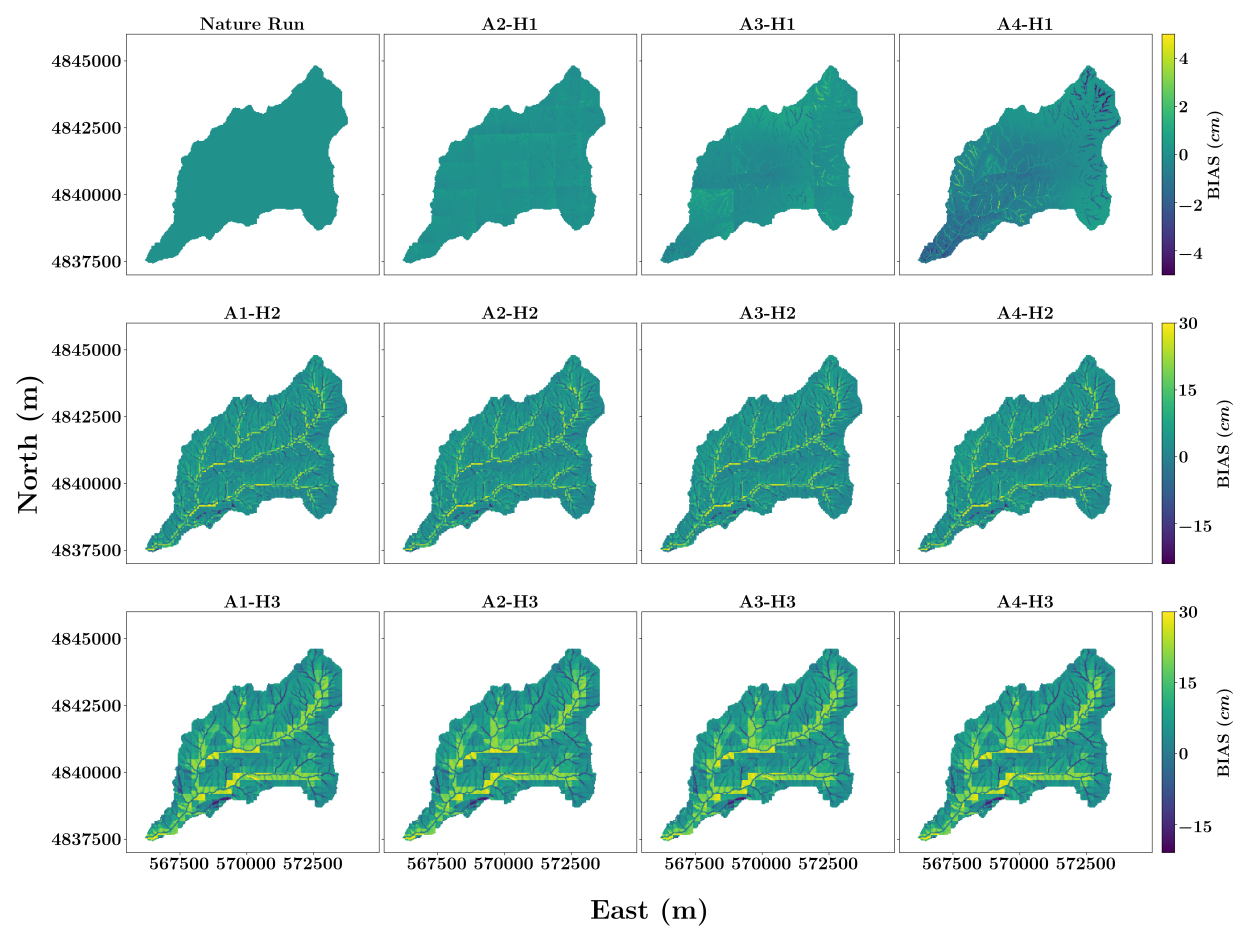

Figure 3.11: Spatially distributed ME for soil water storage in water year 2014. 
Table 3.6: Summary of ME for soil water storage $(\mathrm{cm})$.

\begin{tabular}{lllll}
\hline \multirow{2}{*}{ Experiment } & \multicolumn{4}{c}{ Metrics } \\
\cline { 2 - 5 } & Min & Max & Mean & SD \\
\hline A2-H1 & -0.91 & 1.35 & 0.07 & 0.16 \\
A3-H1 & -2.84 & 3.64 & 0.06 & 0.41 \\
A4-H1 & -5.89 & 4.95 & -0.39 & 0.77 \\
A1-H2 & -22.85 & 29.12 & 3.95 & 5.77 \\
A2-H2 & -22.99 & 29.12 & 3.96 & 5.77 \\
A3-H2 & -23.09 & 29.12 & 3.99 & 5.77 \\
A4-H2 & -24.31 & 29.12 & 3.89 & 5.82 \\
A1-H3 & -22.80 & 29.88 & 7.51 & 7.71 \\
A2-H3 & -22.93 & 29.88 & 7.53 & 7.70 \\
A3-H3 & -22.74 & 29.88 & 7.57 & 7.69 \\
A4-H3 & -21.84 & 29.88 & 7.45 & 7.76 \\
\hline
\end{tabular}

\subsection{Discussion}

This study is meant to develop a spatial scale assessment framework that can be used to inform the discrepancies on hydrologic modeling outputs due to the use of coarse scale atmospheric forcing data. By performing a set of synthetic experiments, this study has revealed the importance of choosing a specific spatial scale in both atmospheric and land surface to maintain consistency of the modeling outputs in comparison to observations as well as computational tractability. We found that modeling at high resolution land surface scales, the processes assessed are locally driven by atmospheric forcings downscaled to the corresponding land surface scale. However, as decreasing in land surface resolution (i.e., coarser spatial resolution) the effects of the topography are more influential on the variables assessed.

As seen in figures 3.8 and 3.10, simulations for snow variables (i.e., SWE) at high resolution land surface scale of (i.e., $30 \mathrm{~m}$.), the variability of bias and RMSEs are 
particularly controlled by the atmospheric grid, revealing more local effects over the spatially distributed variable modeled. This leads to large errors in SWE, concentrated on opposite sides or corners of the atmospheric grid cells produced by gradients of magnitude of SWE existent on the base resolution of the nature run or reference, where atmospheric scale is interpolated from $1 \mathrm{~km}$ to $30 \mathrm{~m}$. The scale artifacts as depicted might demonstrate that snow processes are not only dependent on orographic characteristics at that specific spatial scale, but also are highly dependent on the complex interaction between mass and energy inputs coming from the atmospheric processes and local topography (Grünewald et al., 2014). Bias and RMSEs in simulations at coarse land surface scales (i.e., $90 \mathrm{~m}$. and $250 \mathrm{~m}$.) are controlled more by the topography than the atmospheric grid and clearly reveal the effects of the topography on snow processes at these scales in which larger errors in SWE estimation in the entire time series simulation, occur in upper areas of the watershed where naturally snow precipitation and accumulation are considerable. Looking at slope aspects it is observed that most north-facing slope areas show less error compared to south-facing slope areas. This can be attributable to the fact that thermal forcings are more significant in south-facing slopes, particularly in the snow ablation process (Pomeroy et al., 2003) which is also becoming even more sensitive to the climate warming (López-Moreno et al., 2014).

In simulations for soil water storage at high land surface model resolutions (i.e., 30 $\mathrm{m})$, the RMSEs are primarily controlled by atmospheric grid in a similar manner to SWE. Since snow is one of the main sources of soil moisture in mountain environments (Marks et al., 1999), spatial patterns in soil water storage become highly dependent of inputs of water controlled by snow melting processes (Williams et al., 2009). These 
are, in turn, controlled by atmospheric forcing effects and therefore, such effects can be propagated directly to the soil moisture. On the other hand, at land surface model resolutions of $90 \mathrm{~m}$ and $250 \mathrm{~m}$, larger errors in soil water storage occur in riparian areas of the watershed where accumulation of moisture due to topography and vegetation are considerable. Particularly on north facing slopes there is less error compared with south facing slopes due to large radiation effects on snowmelt dynamics, which are also propagated to the water inputs to the soil. Such coarse scale atmospheric effects on soil water storage reinforce some previous studies focused in hydrologic responses performed by Wood et al. (1988) in which a watershed domain is represented in a catchment scale or Representative Elementary Areas (REA). The authors found that REA are strongly influenced by topography in which increases in the variability of rainfall input and soil between sub-catchments, causing significant changes in surface runoff between sub-catchments.

On the other hand, Molnar \& Julien (2000) state that finer land surface spatial scales are important for short duration events and coarser spatial land surface spatial scales are suitable for long precipitation events. A similar study performed by Bormann (2006) suggests that aggregating input (atmosphere) as well as decreasing spatial scale at land surface (increasing grid size) may cause effects in streamflow simulation results. Additionally, coarse land surface spatial scales must preserve important information of land use classes since they are determinant in vertical processes such as evapotranspiration. His study suggests that the statistics of the water balance are not significantly dependent on the land surface spatial resolution. However, this requires high quality input data and posteriorly optimized to the best resolution. Finally, Vivoni et al. (2005) suggest that domain resolution is a critical step for a mod- 
eling application. Decreases in terrain resolution may lead to potential increments of uncertainty in the hydrologic response. In addition, their study suggests that saturation dynamics are better captured at high resolutions, particularly in the vicinity of streams (riparian areas) since these areas contribute directly and significantly to runoff and evapotranspiration processes.

Limitations of this study lie in the type of atmospheric and hydrologic modeling platform selected as well as the climatological and topographic characteristic study area. In addition, the selection of highly detailed physically based atmospheric and hydrologic models is of great importance in this type of assessment. The selection of physical parameterizations in both the atmospheric and hydrologic models must give enough confidence that coupled complex land surface and subsurface processes are well represented and consistent to changes in spatial scale. This study opens avenues for future research that investigate the effects of atmospheric forcing scales by using several other coupled atmospheric-land surface and subsurface models. Potential pairs of models of interest include the coupled version of WRF-hydro, ParFlow-ARPS, ParFlow-Cosmo, and others. This study also suggests potential value in investigating scale effects in modeling systems applied to different types of climate and/or topography

\subsection{Conclusions}

In this study, we introduce a multi scale modeling assessment framework which was useful to investigate and quantify the impact of the spatial resolution of the atmospheric forcings (i.e., wind speed, air temperature, relative humidity, incoming longwave and shortwave radiation) on simulated hillslope-scale hydrologic states and fluxes such as snow water equivalent and soil water storage of coupled land-atmosphere 
processes in complex, snow-dominated watersheds.

The spatial distributions of errors (i.e., MEs and RMSEs) found in simulations for SWE at high resolution land surface scale (i.e., $30 \mathrm{~m}$ ) are particularly driven by the atmospheric grid, revealing local effects over the spatially distributed variable modeled. Simulations performed with coarse land surface scales (i.e., $90 \mathrm{~m}$ and 250 m) as well as with coarse atmospheric spatial scales, has errors that are driven more by topography than the atmospheric grid and clearly reveal the effects of topography and slope aspect on snow processes. However, both play an important role on the effect of the spatial SWE magnitude across the watershed.

The spatially distributed errors found in simulations for soil water storage at the high resolution land surface scale are driven by the atmospheric grid scale, similar to corresponding patterns in SWE errors. However, simulations performed for land surface scales at $90 \mathrm{~m}$ and $250 \mathrm{~m}$ as well as with coarse atmospheric spatial scales, larger errors in the entire time series simulations occur in riparian areas of the watershed, where accumulation of moisture due to flat areas in the topography is significant.

In this study, we have emphasized the importance of the effects caused by atmospheric forcing scales on simulated hydrologic state variables such as snow water equivalent and soil moisture in the regions that depend on snowmelt. The study has also improved the knowledge of the sensitivities of hydrologic predictions to the spatial resolution of weather prediction data used as input to hydrologic models and helped to characterize the relationship between the spatial resolution of numerical weather predictions used as input to hillslope-scale resolving models. 


\title{
CHAPTER 4:
}

\author{
EXAMINING IMPACTS OF VARYING \\ SPATIAL RESOLUTIONS OF ATMOSPHERIC \\ FORCING DATA ON INTEGRATED \\ HYDROLOGIC MODELING IN \\ SNOW-DOMINATED, MOUNTAIN \\ WATERSHEDS
}

\begin{abstract}
4.1 Abstract
Integrated weather and climate models combined with process ecohydrology models is increasingly an important methodological approach for improving understanding of watershed dynamics and predictions of the complex responses of watersheds to climate and hydrologic change. However, the large amount of distributed forcing data required, particularly in sparsely gaged or ungaged basins associated with significant gradients in topography that are needed as input to these models, are often not available. As a result, modelers are often required to use coarse spatial resolution data from regional reanalysis and/or spatiotemporally interpolated point-scale surface weather observations. Either of these options for model inputs are associated
\end{abstract}


with significant uncertainties because these products often do not capture important characteristic scales in environmental forcings. In this work, we assess the impact of meteorological forcings associated with different spatial distribution characteristics (i.e., spatially uniform, semi-distributed and fully distributed) on the complex hydrologic response as simulated by an integrated hydrologic model. Spatiotemporal hydrologic variables of interest include snow water storage, streamflow, and soil moisture. To achieve this objective we perform a set of simulation experiments involving a high spatial resolution surface-subsurface hydrology model (ParFlow) and two forcing data sources: (a) simulated data from Weather Research and Forecasting model (WRF) and (b) interpolated meteorological station data from different points located at the experimental watershed. The integrated hydrologic impacts of these alternative sources of environmental forcing data were assessed based on the accuracy of simulated streamflow, soil water storage, and snow water equivalent with respect to four observation stations for each simulated variable. With respect to streamflow, results show that simulated outputs performed better when all forcing data were spatially distributed. By comparison, soil water storage simulations were most accurate in the case of spatially distributed or semi-distributed forcings. At the same time we encountered interesting discrepancies with respect to simulated snow water equivalent. Specifically, when distributed forcing data from both, WRF and spatially interpolated, are used, simulation performance in snow water equivalent in the points that correspond to meteorological stations were affected, causing significant overestimation of snow accumulation and reduced predisposition to ablation. This suite of numerical experiments were useful for evaluating tradeoffs in simulated hydrologic states from an integrated hydrologic model under a variety of assumptions about the underlying 
characteristics of the spatial distribution of environmental forcings. This work has important ramifications for both the selection of forcing datasets for integrated hydrologic modeling experiments, as well as the evaluation of the outputs of integrated hydrologic models against observations for a particular set of environmental forcing data.

\subsection{Introduction}

Water demands in the western United States and many other arid regions of the world are highly dependent on seasonal snowpacks. In many water limited systems mountain snowpacks are one of the largest and most dynamic components of water storage. Frozen water is delivered to mountain watersheds during cold, wet winters, accumulates in a seasonal snowpack, and subsequently melts in the late spring and summer to supply water for critical ecosystem services and downstream human uses. These snowpacks are highly susceptible to changes in temperature and turbulent fluxes, which are expected to change significantly due to global warming. Changes to hydrologic regimes in mountain watersheds are already well documented as patterns in decreased snow accumulation in winter seasons, earlier snowmelt-driven streamflows, and incresing frequency of rain-on-snow events in spring seasons continue to change. It is likely these changes are more evident in mountain areas because they span the rain-snow transition zone (Kormos et al., 2014; Barros, 2013) where changes in precipitation phase can significantly alter hydrologic regimes. Significant changes in hydrologic processes in these high sensitive areas may cause snowmelting shifts in space and time that consequently impact the paths of surface and subsurface flow, having numerous implications for water management on reservoirs, flood risk, wildfire severity and forest ecology (Clow, 2010; Hinckley et al., 2014). 
Modeling snowpack and surface-subsurface water dynamics in these areas is challenging without a framework that includes sophisticated coupled surface-subsurface exchanges of water (Maxwell \& Miller, 2005; Kollet \& Maxwell, 2006; Rihani et al., 2010; Maxwell et al., 2014) as well as the exchange of water between snowpack and vegetation. Snowpack and soil control the surface-subsurface water flow and water storage (Pederson et al., 2011; Miller \& White, 1998) and also the response to a particular climate perturbation that can potentially propagate toward the watershed system. The complexity of obtaining or measuring snow water equivalent (SWE) and/or surface water inputs (SWI) in a spatiotemporally distributed manner has led hydrologists to use hydrologic models. These models require surface hydrometeorological forcing data as input. These data typically come from weather or climate models, or via geostatistical interpolation of surface meteorological stations. These required input hydrometeorological data are often not available at spatiotemporal resolutions sufficient to capture important spatial gradients in variables like precipitation and temperature. As a result, modelers often resort to using coarse spatial resolution data and/or uniform data based on one representative meteorological station near to study area, often not explicitly accounting for uncertainties in those data.

The effects of the use of these suboptimal forcing datasets have been investigated in previous studies, with particular attention paid to precipitation as the key driver of land surface hydrologic dynamics and, therefore, the main source of uncertainty on hydrologic simulations. Most of those studies, furthermore, have focused only on assessing the impacts of the degree of spatial support in precipitation data primarily. Few studies have been performed that use multiple atmospheric and land surface modeling configurations, or that have also assessed other prognostic and diagnostic 
variables simulated by the hydrologic model. One notable counterexample is found in Essery (2003), who assessed peak snow accumulation and runoff using different modeling configurations (i.e., uniform and distributed forcings) and concluded that aggregated versions of both atmospheric forcing and land surface models overestimate the peak snow accumulation. They further find that significant improvements are made even in the case where precipitation is not fully distributed in space, but when elevation bands are used to capture orographic variability in precipitation. On the other hand, Melsen et al. (2016) evaluated the transferability across temporal and spatial scale of seven sensitive parameters required in the Variable Infiltration Capacity (VIC) model. They examined outputs of the VIC model with four different spatial resolutions of the model, three relevant temporal resolutions, and comparing uniform to distributed forcing. The authors suggest that VIC model performance is improved with using distributed forcing, while also finding that parameter transferability is more sensitive to temporal scales.

In this study, we assess the impact of meteorological forcing associated with varying spatial support (spatially uniform, semi-distributed, and fully distributed) on snowmelt, streamflow, and soil water storage simulated by a process-based, integrated hydrologic model. We perform a set of numerical experiments using two forcing data sources: (a) simulated data from Weather Research and Forecasting (WRF) model and (b) geostatistically interpolated point scale data from different meteorological stations located along an elevation gradient in an experimental mountain watershed. The simulation experiments are configured combining both uniform and distributed thermodynamic forcings (i.e., temperature, wind speed, and radiative components) and mass (i.e., precipitation) forcing data in the Dry Creek Experimental Watershed 
(DCEW). The assessment is conducted using a hillslope scale hydrologic model by performing several experiments that consider simulated and observed meteorological forcing. The numerical experiments performed consider the following three particular setups: a) hourly distributed precipitation and hourly distributed thermodynamic variables, b) hourly distributed precipitation and hourly uniform thermodynamics variables and c) hourly uniform precipitation and hourly uniform thermodynamic variables.

The objective of this study is to determine and explore the characteristics of the atmospheric components that drive surface hydrology in order to understand how variations in the spatial support in the hydrometeorologic data required as input to an integrated hydrologic model impact the spatiotemporal distribution of water and energy cycling. We conduct these experiments in a particular modeling domain that exhibits large spatial gradients in several of the driving environmental forcing variables. This work has important ramifications for both the selection of forcing datasets for integrated hydrologic modeling experiments, as well as the evaluation of the outputs of integrated hydrologic models against observations for a particular set of environmental forcing data.

\subsection{Methods}

\subsubsection{Study area}

The Dry Creek Experimental Watershed (DCEW) is an experimental site established in 1999 (Figure 4.1). It is located $16 \mathrm{~km}$ northeast of the city of Boise, Idaho with an elevation that ranges from $950 \mathrm{~m}$ to $2130 \mathrm{~m}$. It is a semiarid mountain front watershed that is predominantly southwest facing. The mean annual precipitation in the 

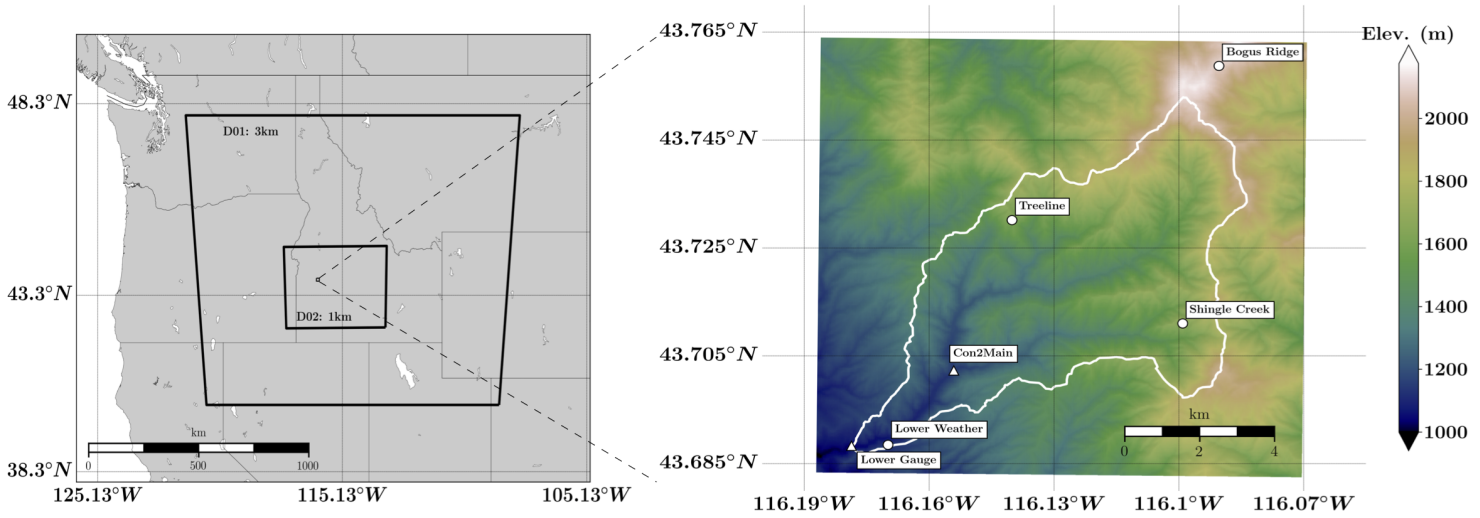

Figure 4.1: Study site (DCEW) with some relevant weather $(\triangle)$ and discharge (o) stations (right) and WRF domains used for forcing data in northwest United States (left).

watershed is approximately $37 \mathrm{~cm}$ at lower elevations and $57 \mathrm{~cm}$ at higher elevations (Tesfa et al., 2009). Precipitation phase is primarily snow in the upper elevations with approximately $77 \%$ of the annual precipitation falling as snow and rain in the lower elevations with less than 33\% falling as snow (Smith et al., 2011). Soils in Dry Creek are primarily composed of coarse, sandy soil derived from in-situ weathering of granite (Gribb et al., 2009). Vegetation type is predominantly sagebrush, bitterbrush, mixed grasses, and riparian vegetation at lower elevations, and forested areas composed mainly of Douglas Fir and Ponderosa Pine at higher elevations (Anderson et al., 2014). There is a variety of instrumentation within DCEW that provides data for seven stream gauging stations and five meteorological stations. These stations are located at different elevations ranging from $1100 \mathrm{~m}$ to $2114 \mathrm{~m}$.

\subsubsection{Experiments and modeling framework}

The modeling framework adopted in this study consists of a coupled land-atmosphere model and an integrated hydrologic model. The coupled land-atmosphere model is used to derive a suite of physically consistent, spatiotemporally complete sets of hy- 
drometeorological forcings for the integrated hydrologic model across a range of spatial resolutions. The atmospheric component for a set of experiments, is represented by the Weather Research Forecasting model (WRF) which resolves the spatiotemporal exchanges of mass, energy, and momentum between the land surface and atmosphere. The land surface and subsurface components represented by the hydrologic model ParFlow-CLM which resolves most of the physical processes and interactions between land surface and the subsurface. The surface hydrometeorological monitoring network within DCEW also allows us to derive observationally based forcings for the ParFlow model, which we refer to as the Interpolated Meteorological Stations (IMS) data in the study area.

The Weather Research Forecasting model (WRF) is a numerical weather prediction (NWP) and atmospheric simulation system designed for research and operational purposes (Skamarock et al., 2005). WRF is a community model developed and supported principally by the National Center of Atmospheric Research (NCAR) suitable for varying across scales applications. WRF's advanced forecasting system version (advanced research WRF; ARW) integrates the compressible, non-hydrostatic Euler equations in order to deal with atmospheric motions at spatial scales that explicitly permit convection. The system of equations consituting WRF's dynamical core are posed in flux form, such that they are applicable either on a sphere using geographical latitude-longitude coordinates or in a conformal Cartesian coordinates system on a Mercator, Lambert, or Polar Stereographic projection. The WRF model can be used as a powerful tool to dynamically downscale coarse meteorological data (i.e., NARR (Mesinger et al., 2006), GFS (Saha et al., 2010), among others). The outputs generated are physically consistent and intelligible with the corresponding landscape and 
usually serve as a rich source of forcing data for use as input into hydrologic models.

The integrated hydrologic model used, ParFlow-CLM, represents the physical processes and interactions between the land surface and the subsurface. ParFlow-CLM (Maxwell, 2013; Kollet \& Maxwell, 2006; Jones \& Woodward, 2001; Ashby \& Falgout, 1996) is an open-source, high spatial resolution surface-subsurface hydrologic model which solves simultaneously the three dimensional Richards' equation and the kinematic wave equation using a Newton-Krylov method with multigrid preconditioning. ParFlow has the advantage of an advanced octree data structure that facilitates representation of watershed topography using digital elevation models and geologic modeling of the subsurface. ParFlow is coupled with Common Land Model (CLM) (Dai et al., 2003) where ParFlow computes the mass balance in the subsurface and CLM computes the mass and energy balance at the land surface. Both models exchange information of fluxes such as evapotranspiration and infiltration from precipitation via input and output files.

Figure 4.2 illustrates a schematic of the modeling framework used, including the exchange of fluxes between models as well as the prognostic and diagnostic variables generated for each model. The atmospheric component (i.e., WRF outputs or IMS data) provides forcing data to the land surface model CLM, which is responsible for all the energy and water dynamics at the land surface. CLM solves the water and energy dynamics present in the vegetation, water bodies and snow, such as water sublimation, evapotranspiration, canopy interception, snow melting and outgoing longwave radiation (Maxwell \& Miller, 2005). The output variables generated by WRF that serve as input to CLM are precipitation, air temperature, atmospheric pressure, specific humidity, U-wind component (zonal) and V-wind component (meridional). 


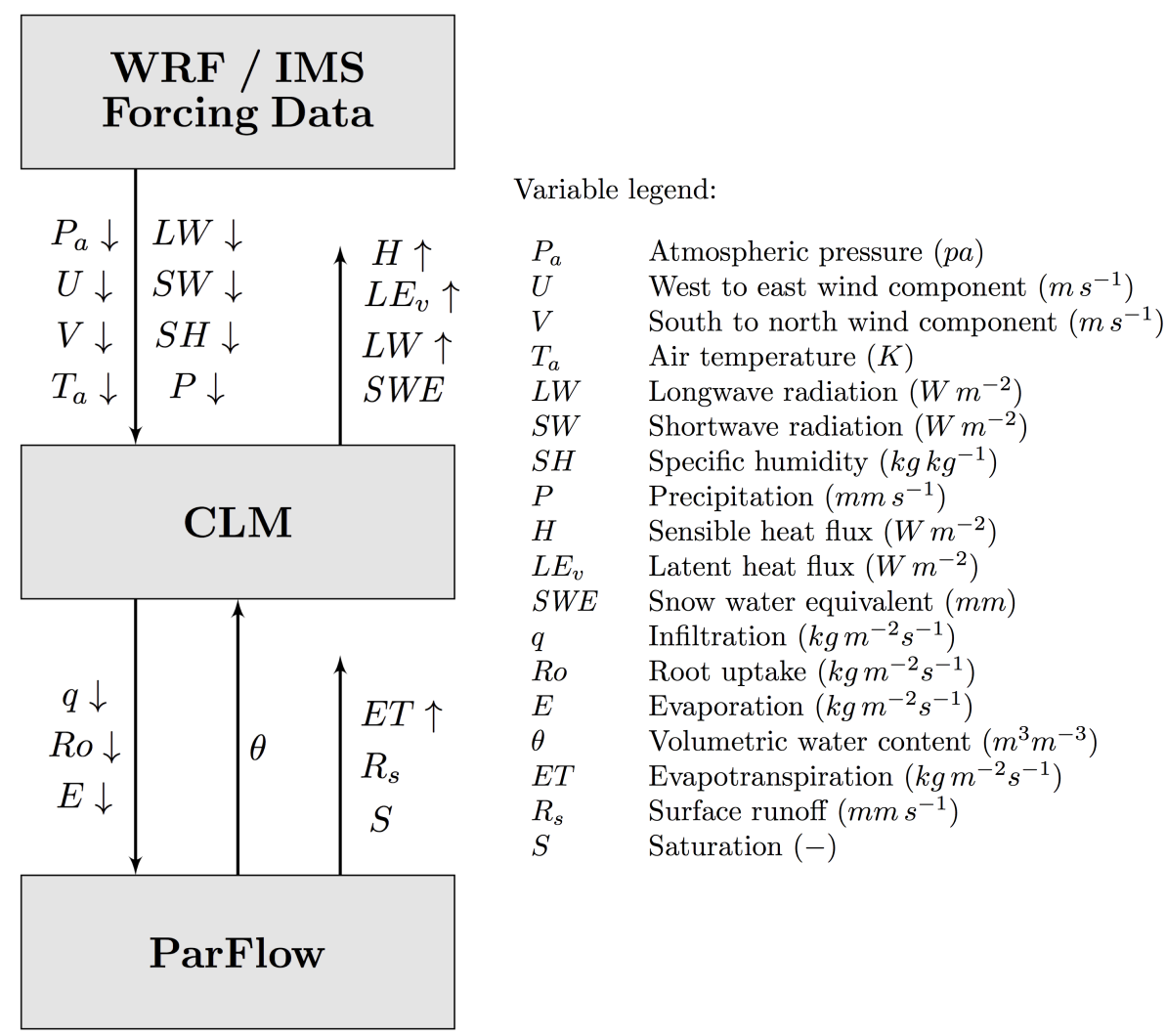

Figure 4.2: Modeling framework diagram and corresponding prognostic and diagnostic variables.

CLM provides fluxes to the ParFlow model such as infiltration, evaporation, and root uptake fluxes and receives moisture information from ParFlow. At the same time, ParFlow solves for all subsurface water dynamics and also is responsible for solving the surface runoff and channel routing in an integrated way.

The numerical experiments performed in this study and corresponding analysis of model results are depicted in Figure 4.3. The first set of experiments uses WRF model outputs as forcing data and the second set of experiments uses IMS data from different stations located within DCEW for the water year 2014. To assess the impact of the spatially distributed forcing data on the hydrologic simulations, 


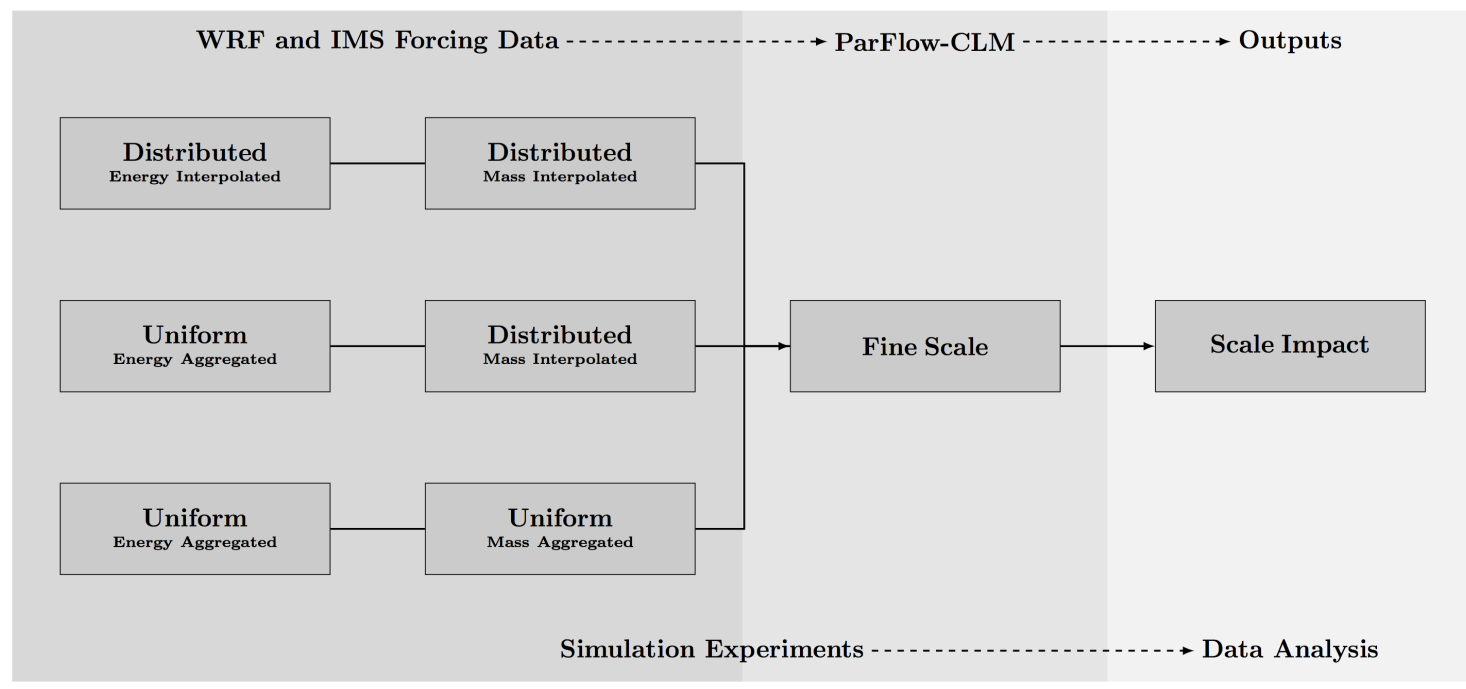

Figure 4.3: Hydrologic modeling experiments and analysis diagram.

the experiments are performed using the following configurations: (a) aggregated thermodynamics and mass, (b) aggregated thermodynamics and distributed mass and (c) fully distributed thermodynamics and mass forcing data, each using both WRF and IMS data, resulting in six simulation experiments. All these configurations give important information about the relative importance of how different forcing distribution configurations can affect the hydrologic modeling procedures.

\subsubsection{Atmospheric data}

The atmospheric data generated by WRF model is part of a 30-Year, Multi-Domain High-Resolution Climate Simulation Dataset for the Interior Pacific Northwest and Southern Idaho project performed by Flores et al. (2016). This dataset is hourly distributed in time and spatially distributed at $3 \mathrm{~km}$ and $1 \mathrm{~km}$ grid resolution, depending on the WRF nested domain. The $3 \mathrm{~km}$ grid resolution corresponds to the outer domain that covers an extensive region of the northwest of the United States (Figure 4.1). The $1 \mathrm{~km}$ spatial resolution correspond to the inner domain that covers 
a more local area that includes most of southwest Idaho (Figure 4.1).

The atmospheric data generated by interpolation of meteorological stations are hourly distributed in time and retrieved from five stations located at different elevations and hillslope aspects across DCEW (McNamara et al., 2018). Most of these stations have been operating since 1999 providing high quality meteorological data for different hydrometeorological variables such as: precipitation, air temperature, incoming and outgoing longwave and shortwave radiation, wind speed and direction, and relative humidity among others.

Forcing data preprocessing was necessary to perform this study. Table 1 shows all the atmospheric data configurations and nomenclature needed the perform the experiments illustrated in Figure 3. For the experiments performed using WRF data, uniform forcing data (i.e., WRF-AU) was obtained by spatial averaging of the 3 $\mathrm{km}$ grid within the modeling domain. The data needed in a distributed form (i.e., WRF-AD) was downscaled from the $1 \mathrm{~km}$ grid data to $30 \mathrm{~m}$, by using a bilinear interpolation. For the experiments performed using IMS forcing data, uniform forcing data (i.e., IMS-AU) was obtained by spatial averaging all the stations available in DCEW for all forcing variables. For IMS-AD and the data needed in a distributed form was generated by using a Gaussian stochastic process using a distance grid information and assuming a Gaussian autocorrelation model of the form:

$$
R(\theta, d)=\exp \left(\sum_{i=1}^{n}-\theta_{i} d_{i}^{2}\right)
$$

where $d_{i}$ is the distance between points in the field and $\theta$ are parameters of correlation model which are optimized by using maximum likelihood estimation to obtain a $\theta^{*}$ for every forcing dataset (i.e., forcing data for each time step). Such optimization 
uses box constraints optimal coefficient $\theta_{l}<\theta_{i}<\theta_{u}$ ( $l$ and $u$ correspond to lower and upper bounds for $\theta$ ) that for all our cases $\theta_{l}=0.01, \theta_{u}=1.0$ and a $\theta_{0}=0.1$ which is a starting point for the maximum likelihood estimation between $\theta_{l}$ and $\theta_{u}$. For more information refer to Lophaven et al. (2002)

Precipitation data from WRF-AD and IMS-AD and thermodynamic data from WRF-AU and IMS-AU are used in WRF-PD and IMS-PD experiments.

Table 4.1: Atmospheric data configurations and nomenclature for the simulation experiments.

\begin{tabular}{llll}
\hline Data source & \multicolumn{3}{c}{ Atmospheric distribution configuration } \\
\cline { 2 - 4 } & $\mathrm{AD}^{\mathrm{a}}$ & $\mathrm{PD}^{\mathrm{b}}$ & $\mathrm{AU}^{\mathrm{c}}$ \\
\hline WRF (Simulated) & WRF-AD & WRF-PD & WRF-AU \\
IMS (Observed) & IMS-AD & IMS-PD & IMS-AU \\
\hline
\end{tabular}

a All forcings distributed.

b Precipitation forcing distributed.

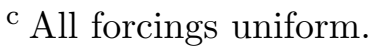

\subsubsection{Land surface and subsurface data}

The surface and the subsurface model domain is spatially distributed by $30 \mathrm{~m}$ cells equally spaced. All topographic data is obtained from standard digital elevation models, provided by the National Elevation Dataset (Gesch et al., 2002). Land cover data and soil data (Figure 4.4) are provided from the national land cover dataset (Homer et al., 2015) and SSURGO (Soil Survey Staff, 2014), respectively. Soil profiles and corresponding percent of sand and clay data is provided by SSURGO and soil texture data is assigned using the USDA soil texture calculator (Natural Resources Conservation Service, 2014). The total soil depth across the watershed is set to 1.0 $\mathrm{m}$ as well as bedrock is set below these layers up to $20 \mathrm{~m}$. The soil has 10 layers distributed equally spaced, except for the first 2 layers which are set to $5 \mathrm{~cm}$ each. 


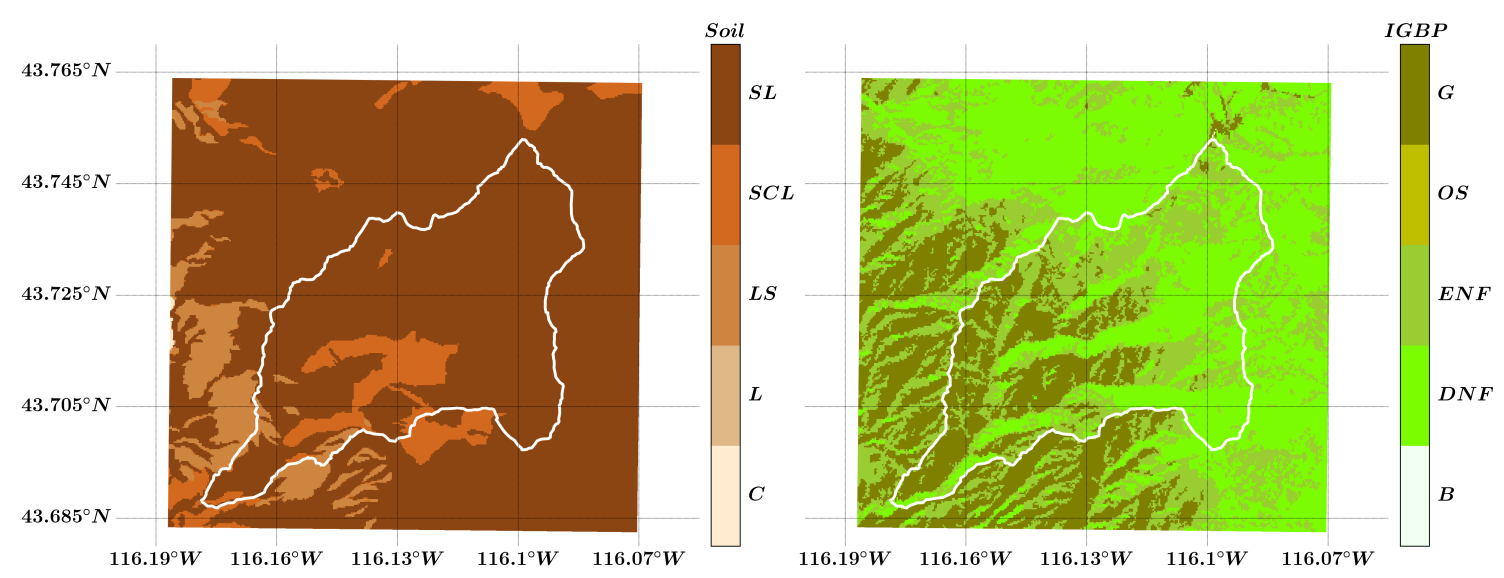

Figure 4.4: Soil texture and land cover classification on the study domain. Nomenclature for soil texture correspond to: SL for Sandy Loam; SCL for Sandy Clay Loam; LS for Loamy Sand; L for Loam and C for Clay. Nomenclature for IGBP classification correspond to: $G$ for Grasslands; OS for Open Shrublands; ENF for Evergreen Needleleaf Forests DNF for Deciduous Needleleaf Forests and B for Barren.

The bedrock layers have 10 uniformly spaced layers from depths of 1.0 to $20 \mathrm{~m}$.

\subsubsection{Initial condition data}

Drainage experiments were conducted to obtain the initial condition of pressure head required by ParFlow in the entire domain. These experiments consist of wetting the domain with a spatiotemporally constant recharge rate with no surface and subsurface lateral flows until the amount of water storage reached a steady state. Surface and subsurface lateral flows are then turned on and the domain starts to drain forced only by gravity until streams are well-defined. Afterwards, we allow groundwater storage and streamflow to decrease until the streamflow matches a reference value of observed streamflow at the watershed outlet in the dry season. The value to match was $0.018 \mathrm{~m}^{3} / \mathrm{s}$ which corresponds to the streamflow value obtained at the end of September 2014. Once streamflow matched the observed value, that state of the model is saved and used as an initial condition. The soil parameters for unsaturated 
and saturated flow such as soil water retention and hydraulic conductivity parameters represented by Van Genuchten (1980) relationships are taken from the unsaturated soil hydraulic database (Leij, 1996) and (Simmers, 2005). These parameters are saved to be used in all the experiments. The in-channel Manning roughness required adjustment through comparison between streamflow data and streamflow output from drainage experiments. Values of Manning roughness for overland flow can be obtained from (Engman, 1986) based on land cover type. The value assumed for these set of simulations for the entire domain was $0.34 \mathrm{~s} / \mathrm{m}^{1 / 3}$ associated to native grass.

\subsubsection{Assessment of experiments}

All experiment results above are assessed by comparison with observed soil water storage, streamflow, and snow water equivalent as reference. The snow water equivalent observations are directly provided by snow depth sensors located in DCEW. Since snow depth is not sufficient to determine SWE, a snow bulk density method based on a statistical model (Sturm et al., 2010) is used. Using snow bulk density parameters from Sturm's model, SWE can be estimated with DCEW snow depth observations. This empirical method estimates SWE by using a statistical model based on a Bayesian analysis of several thousand of snow depth data collected in three countries and also considers densification parameters for depth, the day of the year and the climate class of the snow at the selected locations (Sturm et al., 2010). The statistical model was developed for different snow classes which depends primarily of the type of climate existing in the site and offers different parameterization options for each climate. The model is described as follows:

$$
\rho\left(h_{i}, D O Y_{i}\right)=\left(\rho_{\max }-\rho_{0}\right)\left[1-\exp \left(k_{1} * h_{i}-k_{2} * D O Y_{i}\right)\right]+\rho_{0}
$$


where $k_{1}, k_{2}$ are densification parameters and $\rho_{0}, \rho_{\max }$ are initial and maximum density for a snow class that correspond to a particular climate. $D O Y_{i}$ correspond to the day of the year which is numbered from -92 (1 October) to +181(30 June), and $i$ indicates the $i$ th observation (Sturm et al., 2010).

For our experiments, all parameters selected to estimate SWE correspond to praire regions (Sturm et al., 2010) in which values assumed are: $k_{1}=0.0016, k_{2}=0.0031$, $\rho_{0}=0.2232$ and $\rho_{\max }=0.5940$. The experiments are assessed through visual inspection of time series plots and the use of Taylor Diagrams (Taylor, 2001). Such diagrams are able to detect similarities between two time series patterns and graphically summarize how closely a set of patterns match observed data. Patterns are quantified with reference to their centered root mean square difference, correlation and the amplitude of their variations (Taylor, 2005)

\subsection{Results}

We performed simulation experiments with the modeling framework shown in section 4.3.2 in order to analyze the impact of spatially distributed and uniform forcing data arrangements on hillslope hydrologic simulations. All simulations are performed in water year 2014, because of the data availability in all stations selected for this study particularly for irradiance variables. Especially for simulations performed by using ISM data, pressure values were not available in all the meteorological stations in DCEW in water year 2014. Due to the latter, values of pressure for all meteorological stations were adopted from the North American Land Data Assimilation System (NLDAS) (Mitchell et al., 2004). 


\subsubsection{Analysis on snow water equivalent}

Simulations of snow water equivalent (SWE) using simulated forcing data in stations selected in DCEW are depicted in Figure 4.5 and 4.6. Stations ordered by elevation as shown in Figure 4.5 include: (A) Lower Weather - 1151 m a.s.l. ; (B) Treeline 1610 m a.s.l.; (C) Shingle Creek - 1720 m a.s.l. and (D) Lower Deer Point - 1850 m a.s.l. All the observations originally correspond to snow depth which subsequently are converted to SWE by using a statistical model based on a Bayesian analysis (Sturm et al., 2010). Particularly, for the IMS experiment, we used the snow measurements located at the weather stations to assess the performance of simulated versus observed SWE and in this case, the performance analysis only corresponded to assess the performance of point scale simulated SWE at each station. However, the distributed data generated from IMS, was used to estimate the other two variables, streamflow and soil moisture, in which the stations are located at other points of the area of interest.

Significant differences on simulations particularly using WRF-AD, data are observed in all stations (Figure 4.6). For Lower Weather station, values of SWE are highly impacted by WRF-AU data, showing high values of SWE and consequently RMSE on snow accumulation period and posterior snow melting period. RMSE values decrease as the forcing data is spatially distributed in Lower Weather station however, increasing in altitude, SWE simulations show an opposite trend in which the values of SWEs increase and RMSEs increase. These patterns reveal important information about the impact of the thermodynamics forcing on the snowmelt process in these sites without considering a suitable calibration of the model structure. Similar behavior can be observed for experiments performed with IMS data. Figure 


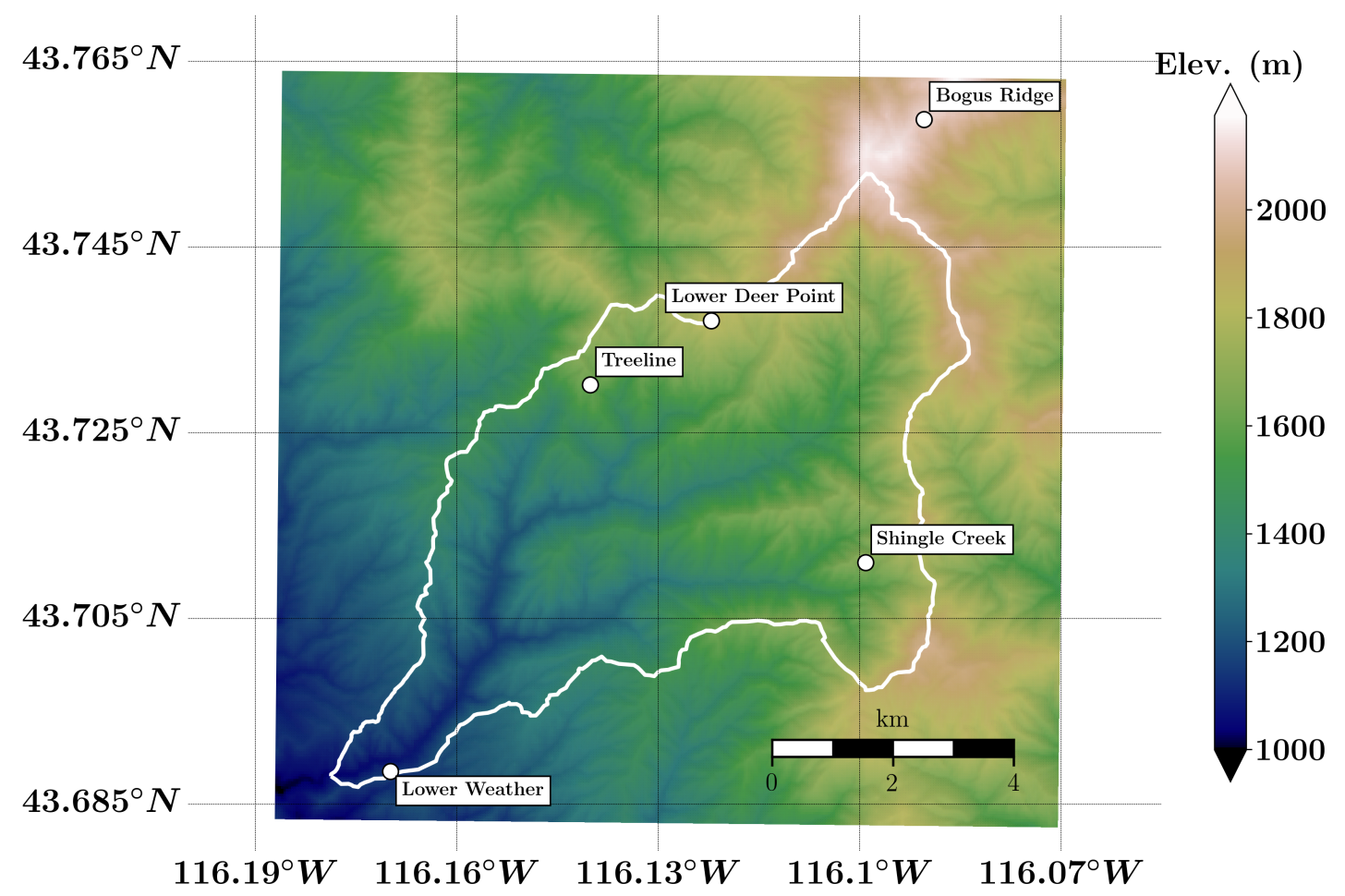

Figure 4.5: Snow depth and meteorological stations within DCEW modeling domain. Bogus Ridge station is used only to generate distributed data through spatial interpolation. 

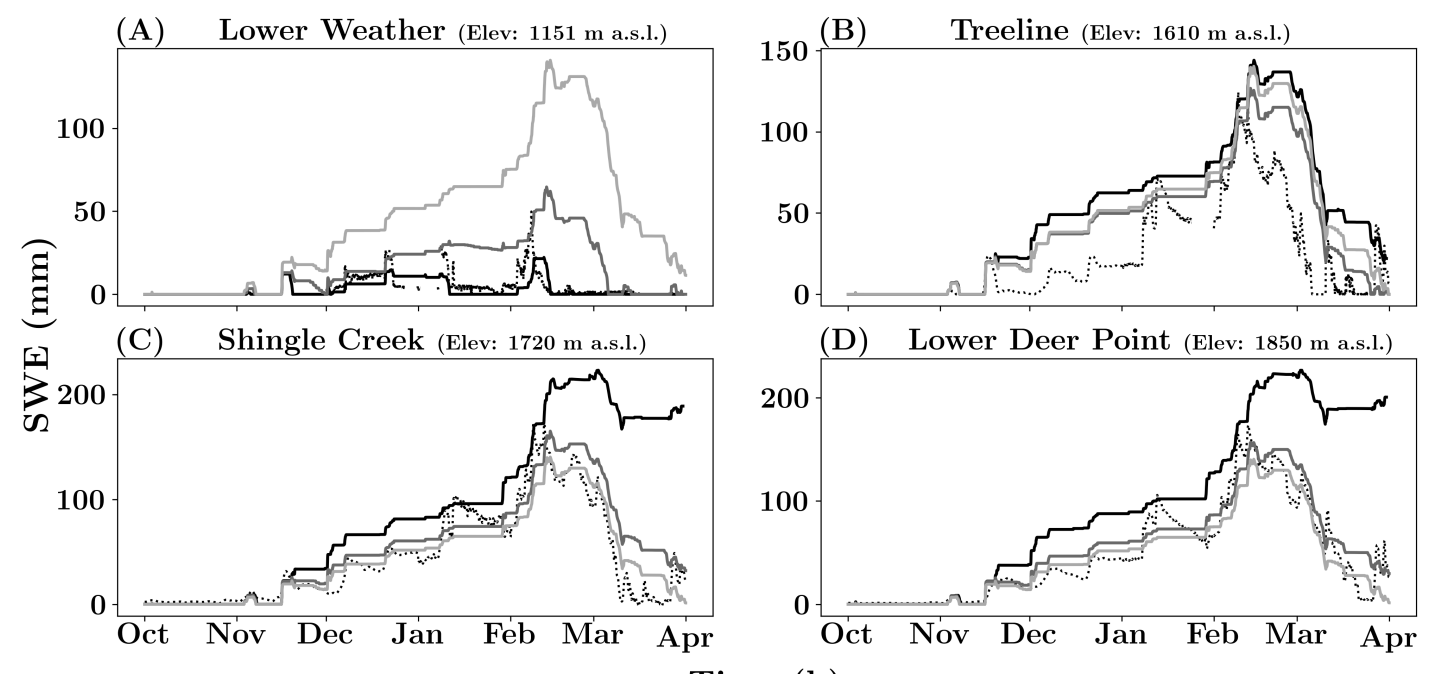

Time (h)

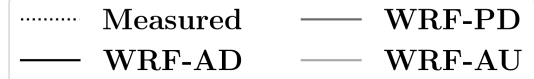

Figure 4.6: Modeling performance on SWE variable, using WRF outputs as forcing data.

4.7 shows the impact of uniform data on Lower Weather station and the opposite pattern in Treeline and Shingle Creek however, Lower Deer station this time shows similar behavior as Lower Weather.

Figure 4.8 shows a Taylor diagram that reflects the performance of the SWE simulations compared to the reference dataset (i.e., observed data). In this diagram every point represents the statistics of one experiment (i.e., simulated time series) at a particular observational site. In order to visualize the statistics of all the control stations for all experiments in one graph, the variables RMSE and simulated standard deviations, were plotted on the diagram in a normalized manner by dividing all the variables by the standard deviation of the corresponding observed field (i.e., $R M S E / \sigma_{o b s}, \sigma_{s i m} / \sigma_{o b s}$ and $\sigma_{o b s} / \sigma_{o b s}=1$ ) (Taylor, 2005).

Closer radial distance to the reference indicates less centered root mean squared 

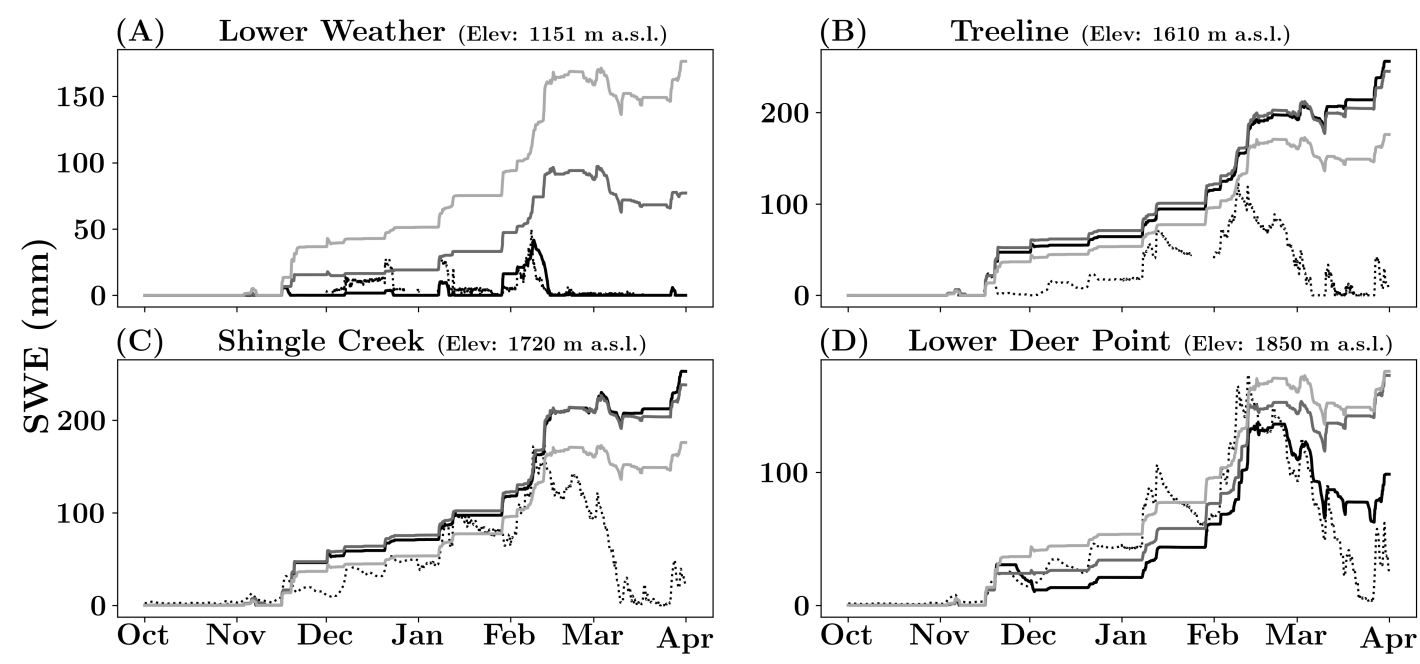

(D) Lower Deer Point (Elev: $1850 \mathrm{~m}$ a.s.l.)

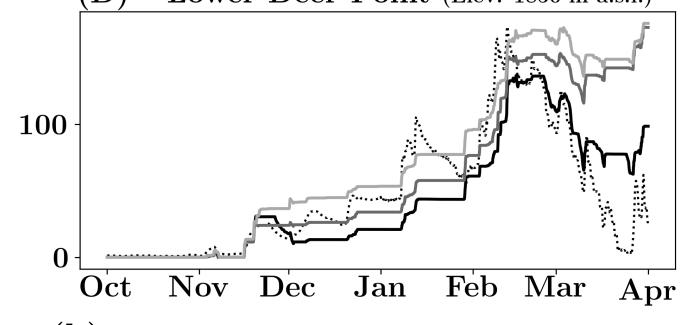

Time (h)

Measured

IMS-PD

IMS-AD

IMS-AU

Figure 4.7: Modeling performance on SWE variable, using IMS data as forcing data.

error and therefore a better accuracy of the simulation experiments with respect to the observations. In Figure 4.7 the experiments performed primarily with WRFPD and WRF-AU, show a good fit in some places such as Shingle Creek and Lower Deer, while experiments performed with WRF-AD and IMS-AD, performed better in Lower Weather and Lower Deer point respectively. Unfortunately we cannot visualize a clear pattern in the Taylor diagram that suggests the need of using fully or partially distributed data or fully aggregated data particularly for the land surface component of these modeling experiments. A summary of all statistics shown in this Taylor diagram for simulated snow water equivalent is displayed in Table 4.2.

We paid particular attention to the snowmelt process on spring season 2014 as shown in figures 4.6 B,C,D and 4.7 B,C,D. We have found, primarily for AD cases from both sources of input data (i.e., WRF and IMS), snow depletion discrepancies 


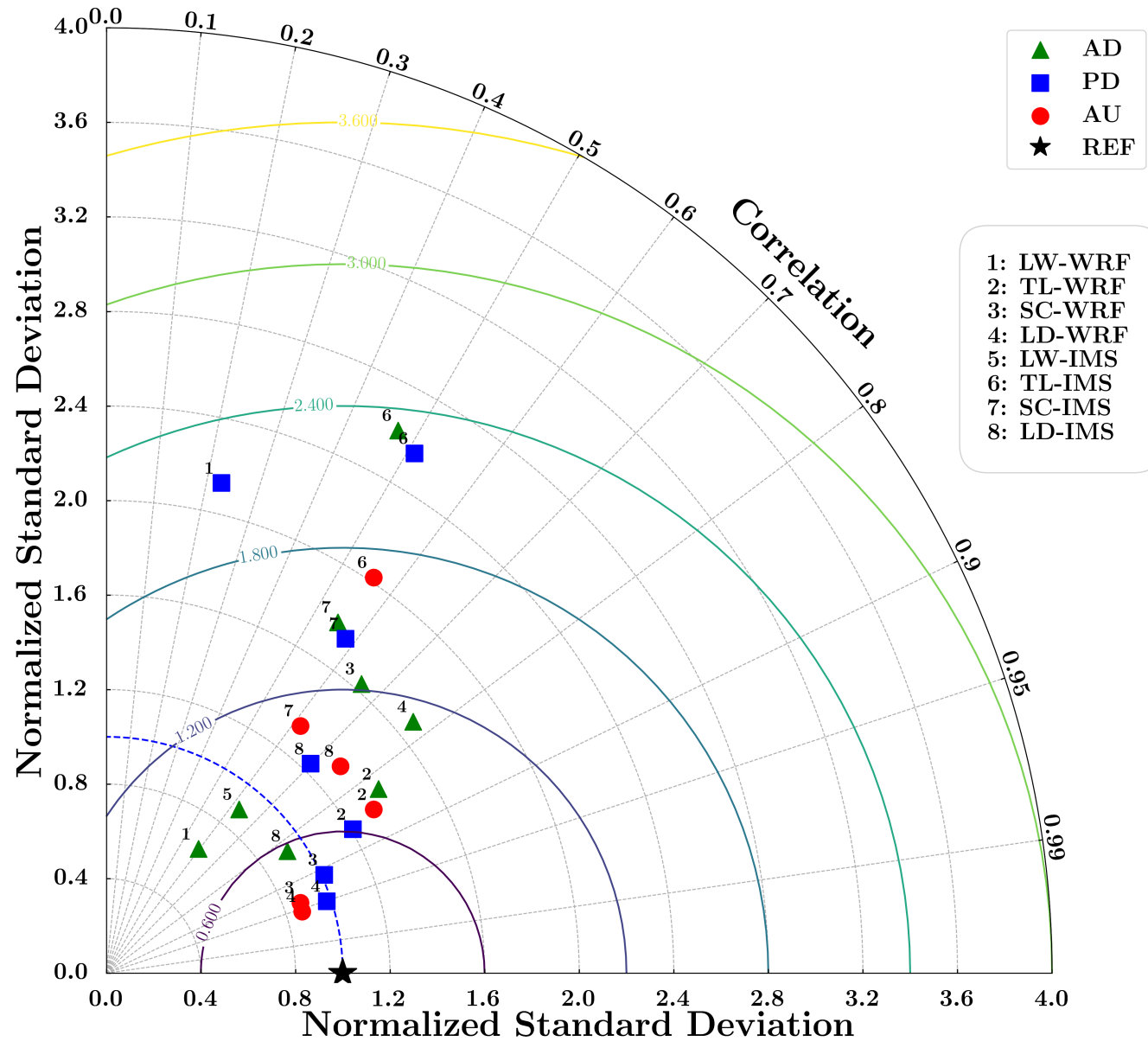

Figure 4.8: Taylor diagram for simulated SWE. 
Table 4.2: Summary of spatial average of normalized standard deviation, RMSE and Pearson correlation between simulated and observed data (reference) for SWE variable at Lower Weather (LW); Treeline (TL); Shingle Creek (SC) and Lower Deer Point (LD) stations.

\begin{tabular}{|c|c|c|c|c|c|}
\hline Data Source & Experiment Set & Site & NSTD $^{a}$ & $\mathrm{PC}^{\mathrm{b}}$ & $\mathrm{RMSE}^{\mathrm{c}}$ \\
\hline \multirow{12}{*}{ WRF } & \multirow{4}{*}{$\mathrm{AD}$} & $\mathrm{LW}$ & 0.655 & 0.595 & 0.806 \\
\hline & & $\mathrm{TL}$ & 1.390 & 0.828 & 0.794 \\
\hline & & $\mathrm{SC}$ & 1.631 & 0.661 & 1.226 \\
\hline & & $\mathrm{LD}$ & 1.678 & 0.773 & 1.105 \\
\hline & \multirow{4}{*}{$\mathrm{PD}$} & LW & 2.130 & 0.229 & 2.136 \\
\hline & & TL & 1.207 & 0.864 & 0.610 \\
\hline & & $\mathrm{SC}$ & 1.012 & 0.911 & 0.423 \\
\hline & & $\mathrm{LD}$ & 0.980 & 0.951 & 0.312 \\
\hline & \multirow{4}{*}{$\mathrm{AU}$} & LW & 5.245 & -0.007 & 5.347 \\
\hline & & $\mathrm{TL}$ & 1.326 & 0.852 & 0.706 \\
\hline & & $\mathrm{SC}$ & 0.873 & 0.940 & 0.347 \\
\hline & & $\mathrm{LD}$ & 0.868 & 0.954 & 0.312 \\
\hline \multirow{12}{*}{ IMS } & \multirow{4}{*}{$\mathrm{AD}$} & LW & 0.892 & 0.629 & 0.820 \\
\hline & & TL & 2.607 & 0.473 & 2.308 \\
\hline & & $\mathrm{SC}$ & 1.779 & 0.550 & 1.485 \\
\hline & & $\mathrm{LD}$ & 0.923 & 0.829 & 0.568 \\
\hline & \multirow{4}{*}{ PD } & LW & 4.238 & -0.380 & 4.709 \\
\hline & & TL & 2.557 & 0.510 & 2.220 \\
\hline & & $\mathrm{SC}$ & 1.740 & 0.582 & 1.415 \\
\hline & & $\mathrm{LD}$ & 1.238 & 0.698 & 0.896 \\
\hline & \multirow{4}{*}{$\mathrm{AU}$} & LW & 7.942 & -0.445 & 8.435 \\
\hline & & TL & 2.020 & 0.560 & 1.679 \\
\hline & & $\mathrm{SC}$ & 1.330 & 0.617 & 1.062 \\
\hline & & LD & 1.321 & 0.749 & 0.875 \\
\hline
\end{tabular}

a Normalized Standard Deviation.

b Pearson Correlation.

c Root Mean Squared Error. 
in comparison with observed SWE data in those stations. However, if we look at the AU and PD cases, those discrepancies are solved particularly where aggregated WRF input data is used. The aggregated data, that comes from the averaged $3 \mathrm{~km}$ spatial resolution (domain D01 in Figure 4.1) of WRF, offers some correction that allows the CLM's snow model to simulate snowmelt more correctly. This particular case opened an opportunity to find some clues to explain what forcing variable or what group of forcing variables have more influence to the snow model primarily on snow melting processes. For these cases we assume that there are some significant differences in magnitudes between some aggregated and distributed forcing variables that when applied to the modeling framework cause such snowmelt modeling perturbations. Our approach to detect such differences was by computing a Wilcoxon rank-sum statistic for two samples which hypothesized that the two set of measurements are originated from the same distribution. Based on this assumption, we can infer dissimilarities between the two data sets by rejecting the null hypothesis. The Wilcoxon ranksum statistic performs similar to t-test statistic with the difference that it is a free distribution test and there is no need of normal distributed data. Table 4.2 shows the values of the test in two sites, Shingle Creek and Lower Deer point. The data indicate that observed and simulated time series in variables such as Downward Longwave Radiation, Air Temperature and Wind Speed have larger differences and suggest us to perform a more deepest study such as a sensitivity analysis of the model focused primarily on snowmelting process.

\subsubsection{Analysis on discharge}

Simulations of discharge using simulated forcing data in stations selected in DCEW are depicted in Figure 4.10 and 4.11. Stations ordered by elevation as shown in Figure 
Table 4.3: Wilcoxon Rank-Sum statistic summary for Shingle Creek (SC) and Lower Deer (LD) point.

\begin{tabular}{llll}
\hline Variable & Site & $\begin{array}{l}\text { Test } \\
\text { p-value }\end{array}$ & $\begin{array}{l}\text { Rejected } \\
\text { Null hypothesis }\end{array}$ \\
\hline Downward Longwave & SC & 0.002 & yes \\
Radiation & LD & 0.001 & yes \\
\cline { 2 - 4 } Downward Shortwave & SC & 0.618 & no \\
Radiation & LD & 0.108 & no \\
\cline { 2 - 4 } Air Temperature & SC & 0.617 & no \\
\multirow{3}{*}{ Wind Speed } & LD & 0.001 & yes \\
\cline { 2 - 4 } Specific Humidity & SC & 0.839 & no \\
\cline { 2 - 4 } Precipitation & LD & 0.001 & yes \\
\hline
\end{tabular}

4.9 include: A) Lower Gauge; B) Con2Main; C) Con2East; D) Con1West. All the observations originally correspond to hourly observed discharge. However, all hourly rates were converted to hourly cumulative discharge in order to better observe differences among simulated and observed time series. In this way, the curves represent the cumulative release of water from the watershed as simulated with different configurations of input hydrometeorological data. The discharge in Parflow-CLM model is estimated by using the Mannings formula which is extensively used for surface flow (Kollet \& Maxwell, 2006; Tian \& Liu, 2011). The discharge defined in terms of overland flow at a point can be expressed as,

$$
Q=\frac{d x}{n} S^{1 / 2} h^{5 / 3}
$$




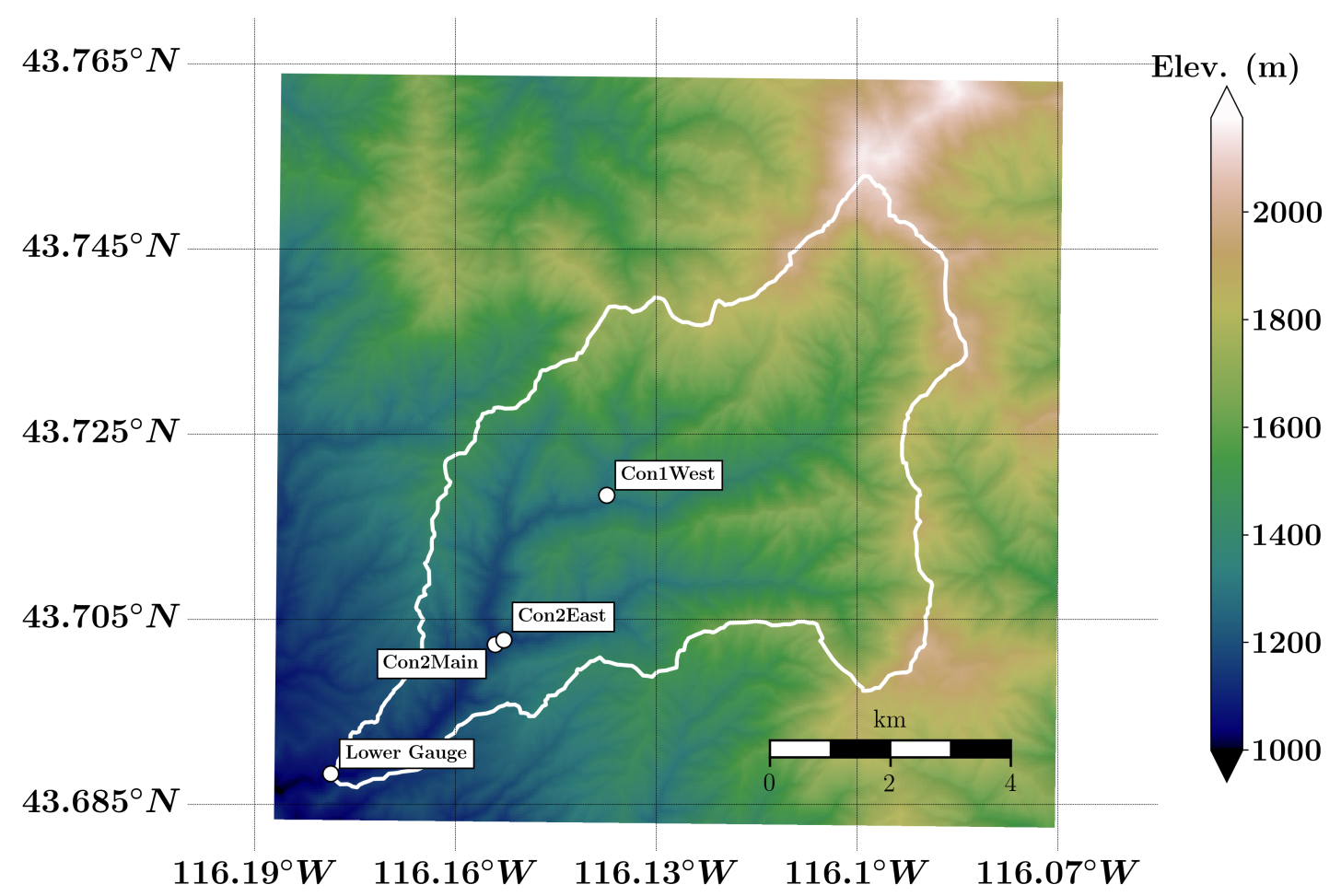

Figure 4.9: Discharge gauges within DCEW modeling domain.

Where $Q$ is the flow rate at a point in $m^{3} / s, S$ is the bed slope, $n$ is the Manning coefficient and $h$ is the head pressure at a specific point.

Significant impacts of computed discharge using WRF-PD and WRF-AU modeling configurations for discharge stations assessed is depicted in Figure 4.10. It is clearly observed that overestimation of discharge in most the stations occurs particularly in spring season when the snowmelt process predominates. Meanwhile, we can observe that simulations performed under WRF-AU reasonably approximate discharge observations at most of the stations in this water year. On the other hand, 

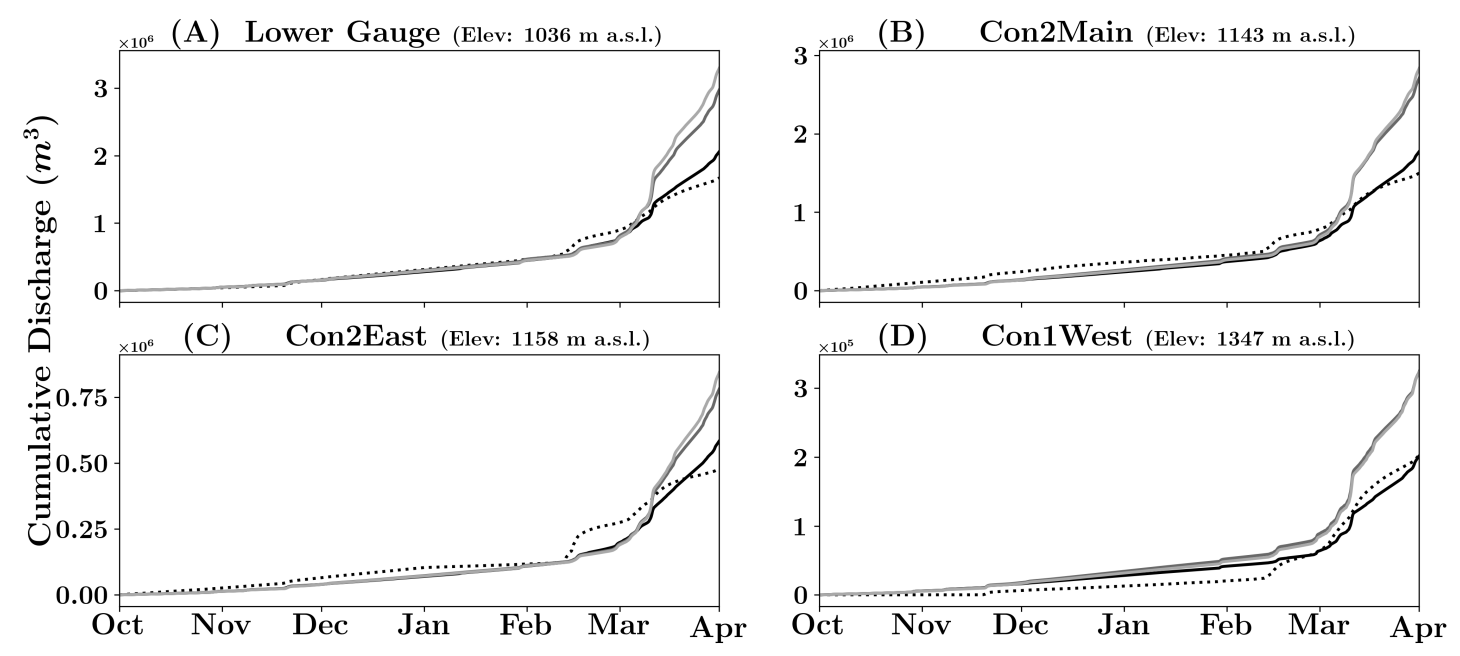

Time (h)

$\begin{array}{lll}\text { Measured } & \text { WRF-PD } \\ \text { WRF-AD } & \text { WRF-AU }\end{array}$

\section{Figure 4.10: Modeling performance on discharge variable, using WRF outputs as forcing data.}

Figure 4.11 shows some underestimation by the use of IMS-PD and IMS-AU on simulations particularly in sites Lower Gage, Con2Main and Con2East and significant overestimation by the use of IMS-AD in Con1West (start to occur during the first two months of the water year) causing mismatches of simulated discharge with respect to the observed one. One possible reason for this can be the misestimation of magnitudes of the forcing data due to the spatial interpolation method is distributed on the associated Con1West catchment, where the topographical features, such as elevation gradients that dominates this area, were not accounted.

A Taylor diagram for simulated discharge compared to a reference dataset shown in Figure 4.12, depicts that the experiments performed primarily with WRF-AD and IMS-AD, show the better fit with the exception of Con1West performed with IMSAD. Some experiments performed with IMS-PD and IMS-AU particularly at Lower 

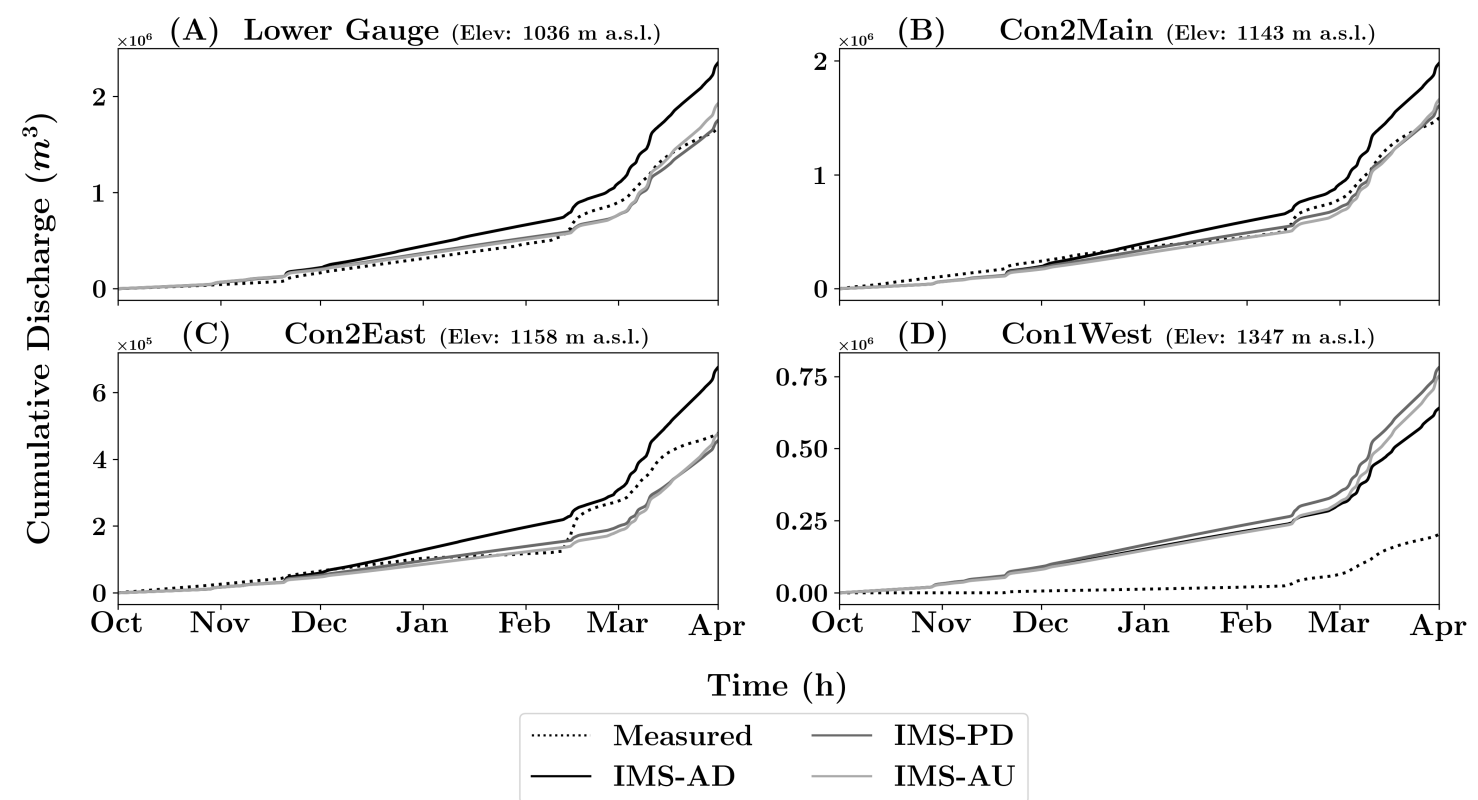

Figure 4.11: Modeling performance on discharge variable, using IMS data as forcing data.

Gage and Con2Main show good agreement with respect to the observation, and they are placed in the diagram where the experiments performed with AD are grouped. By looking at the $\mathrm{AD}$ grouping, we can infer that there is a trend of these experiments toward the reference which involve lower RMSE and reasonable correlation coefficient and allow us to deduce that the distribution of the forcing is important when assessing modeled discharge. A summary of all statistics shown in this Taylor diagram for simulated discharge is displayed in Table 4.4.

\subsubsection{Analysis on soil water storage}

Simulations of soil moisture (in terms of soil water storage) using simulated forcing data in stations selected in DCEW are depicted in Figure 4.14 and 4.15. Stations to assess are ordered by elevation and most of them are placed in south aspects. 


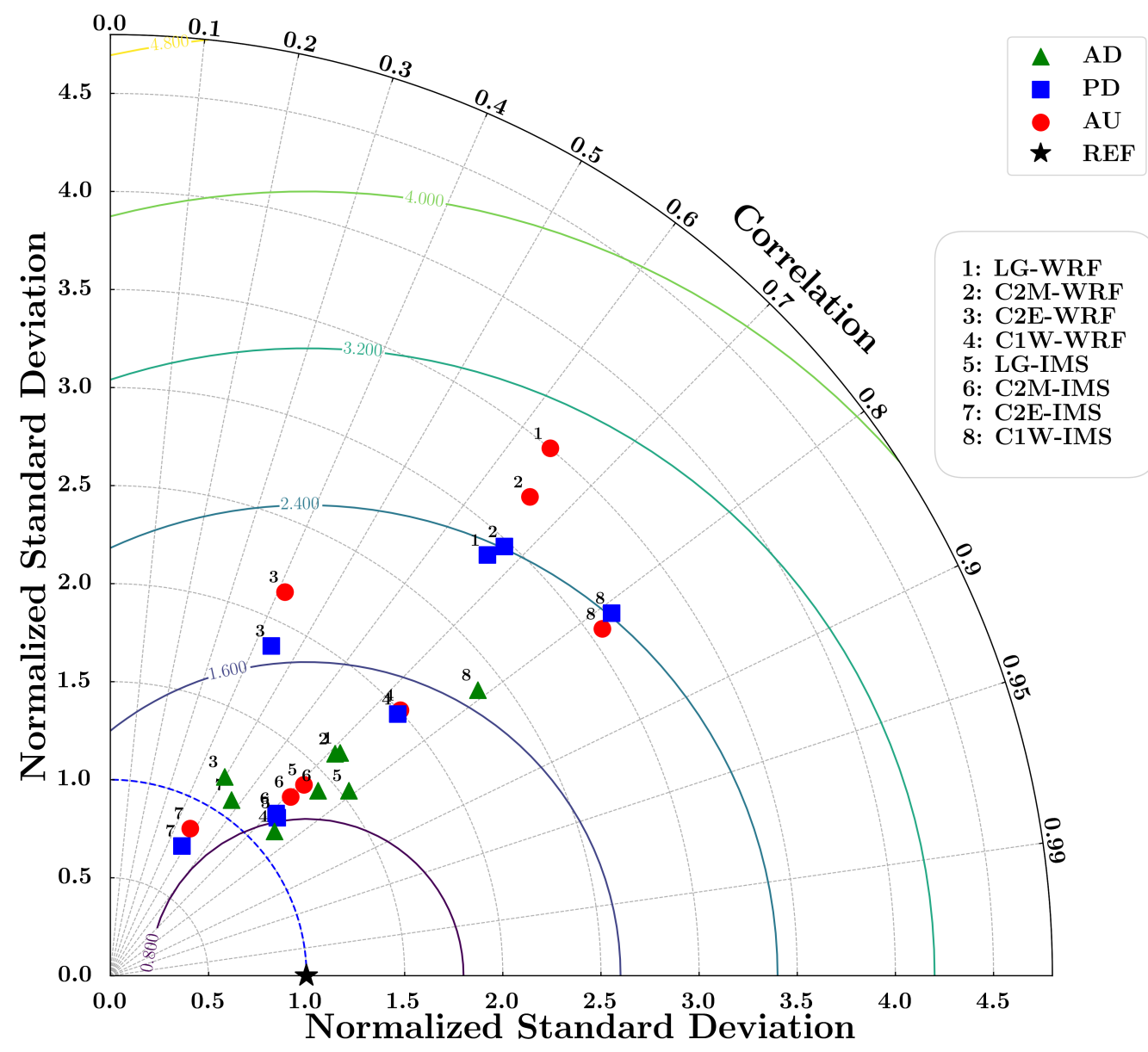

Figure 4.12: Taylor diagram for simulated discharge. 
Table 4.4: Summary of spatial averaged of normalized standard deviation, RMSE and Pearson correlation between simulated and observed data (reference) for discharge variable at Lower Gauge (LG); Con2Main (C2M); Con2East (C2E); Con1West (C1W) stations.

\begin{tabular}{|c|c|c|c|c|c|}
\hline Data Source & Experiment Set & Site & NSTD $^{a}$ & $\mathrm{PC}^{\mathrm{b}}$ & RMSE $^{b}$ \\
\hline \multirow{12}{*}{ WRF } & \multirow{4}{*}{$\mathrm{AD}$} & LG & 1.633 & 0.717 & 1.151 \\
\hline & & $\mathrm{C} 2 \mathrm{M}$ & 1.611 & 0.711 & 1.143 \\
\hline & & $\mathrm{C} 2 \mathrm{E}$ & 1.170 & 0.498 & 1.097 \\
\hline & & $\mathrm{C} 1 \mathrm{~W}$ & 0.489 & 0.481 & 0.877 \\
\hline & \multirow{4}{*}{$\mathrm{PD}$} & $\mathrm{LG}$ & 2.880 & 0.667 & 2.335 \\
\hline & & $\mathrm{C} 2 \mathrm{M}$ & 2.971 & 0.676 & 2.411 \\
\hline & & $\mathrm{C} 2 \mathrm{E}$ & 1.872 & 0.439 & 1.692 \\
\hline & & $\mathrm{C} 1 \mathrm{~W}$ & 6.122 & 0.656 & 1.413 \\
\hline & \multirow{4}{*}{$\mathrm{AU}$} & LG & 3.503 & 0.640 & 2.964 \\
\hline & & $\mathrm{C} 2 \mathrm{M}$ & 3.246 & 0.659 & 2.695 \\
\hline & & $\mathrm{C} 2 \mathrm{E}$ & 2.150 & 0.414 & 1.960 \\
\hline & & $\mathrm{C} 1 \mathrm{~W}$ & 5.067 & 0.704 & 1.437 \\
\hline \multirow{12}{*}{ IMS } & \multirow{4}{*}{$\mathrm{AD}$} & $\mathrm{LG}$ & 1.539 & 0.790 & 0.968 \\
\hline & & $\mathrm{C} 2 \mathrm{M}$ & 1.418 & 0.746 & 0.945 \\
\hline & & $\mathrm{C} 2 \mathrm{E}$ & 1.089 & 0.567 & 0.975 \\
\hline & & $\mathrm{C} 1 \mathrm{~W}$ & 0.432 & 0.408 & 1.699 \\
\hline & \multirow{4}{*}{$\mathrm{PD}$} & $\mathrm{LG}$ & 1.171 & 0.726 & 0.819 \\
\hline & & $\mathrm{C} 2 \mathrm{M}$ & 1.183 & 0.714 & 0.842 \\
\hline & & $\mathrm{C} 2 \mathrm{E}$ & 0.756 & 0.484 & 0.917 \\
\hline & & $\mathrm{C} 1 \mathrm{~W}$ & 2.187 & 0.645 & 2.416 \\
\hline & \multirow{4}{*}{$\mathrm{AU}$} & $\mathrm{LG}$ & 1.387 & 0.711 & 0.975 \\
\hline & & $\mathrm{C} 2 \mathrm{M}$ & 1.295 & 0.709 & 0.917 \\
\hline & & $\mathrm{C} 2 \mathrm{E}$ & 0.855 & 0.477 & 0.957 \\
\hline & & C1W & 1.598 & 0.712 & 2.324 \\
\hline
\end{tabular}

${ }^{a}$ Normalized Standard Deviation.

b Pearson Correlation.

c Root Mean Squared Error. 
The stations selected as shown in Figure 4.13 include: A) Low S-facing ; B) MidLow S-facing; C) Mid-High S-facing and D) High N-facing. All the observations originally correspond to hourly saturation, however all hourly rates were converted and represented in terms of total soil water storage. In a soil column the total soil water storage is the sum, over all layers, of the product of saturation, porosity and the layer thickness as,

$$
\Theta=\sum_{k=1}^{L} S_{i, j, k} \phi_{i, j, k} \Delta z
$$

where $\Theta$ represents soil water storage, $S$ is the water saturation (0-1, unitless) in layer located at coordinates $(i, j, k), \phi$ is the porosity in layer $k(0-1$, unitless) and $\Delta z$ corresponds to the layer thickness. The water saturation in ParFlow model, is estimated from the pressure field as described in section 3.3.4, equation 3.2. The soil water storage at the observation points were calculated based on soil depth and data availability. Because there are not soil moisture sensor data at all soil depths at all observation sites in DCEW, we were not able to estimate soil water storage for the entire soil column at some of the stations. The soil thicknesses used for this assessment were: $20 \mathrm{~cm}$ for Low S-facing and Mid-Low S-facing stations, $50 \mathrm{~cm}$ for Mid-High S-facing and $10 \mathrm{~cm}$ for High $\mathrm{N}$-facing station. Soil thicknesses and observation data were retrieved from DCEW in water year 2014 at https://earth.boisestate.edu/drycreek/data/.

Discrepancies in computed soil water storage at some periods of all the experiments (as shown in Figure 4.14 and 4.15) performed with WRF and IMS forcing data can be observed in all station assessed. We assert that this is primarily due to the fact that an exhaustive calibration of hydraulic soil properties was not performed and is outside of the scope of the present investigation. Simulations at the Mid-High S-facing 


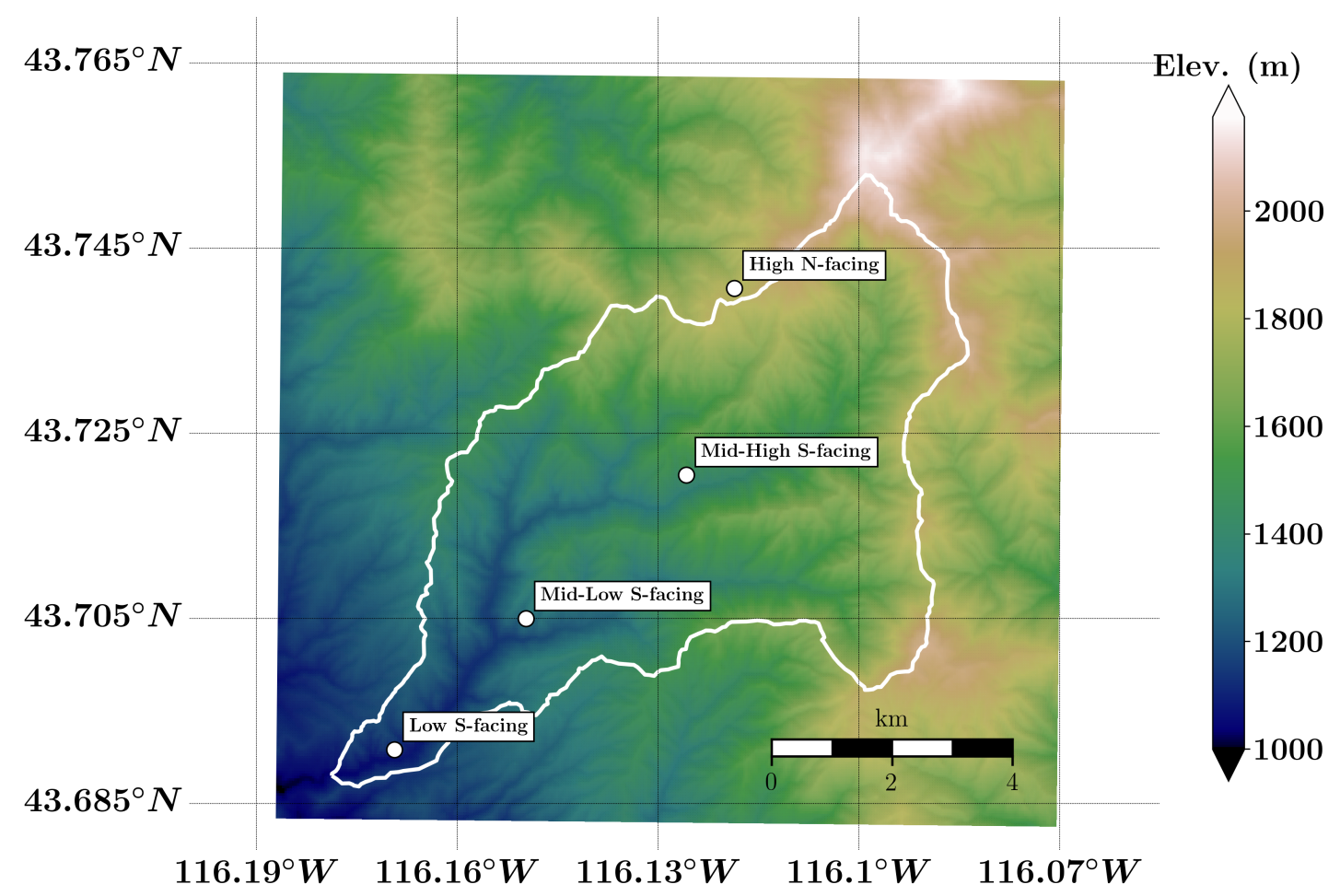

Figure 4.13: Soil moisture stations within DCEW modeling domain. 

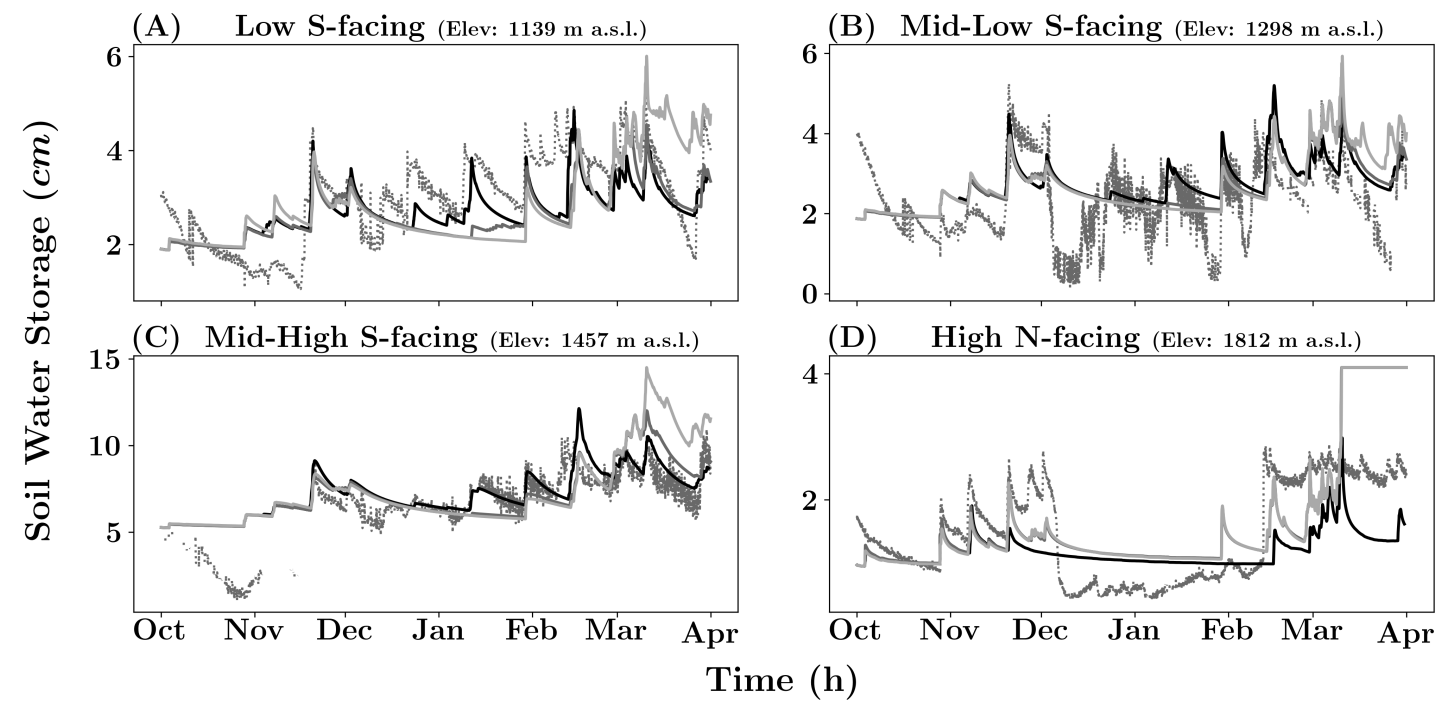

Time (h)

$\begin{array}{ll}\text { Measured } & \text { WRF-PD } \\ \text { WRF-AD } & \text { WRF-AU }\end{array}$

Figure 4.14: Modeling performance on soil water storage variable, using WRF outputs as forcing data.

performed using WRF-AD exhibit the best fit to the observation data particularly in the period of the end of November 2013 to April 2014. However, it does not reproduce correctly the period of October to the end of November 2013. By contrast, soil water storage at the High $\mathrm{N}$-facing is reproduced reasonably well during the period of October to the end of November 2013, but largely does not reproduce observed soil water storage for much of the rest of the water year.

Despite the fact that we did not undertake an exhaustive effort to calibrate soil parameters in the ParFlow model, simulations still produce reasonably good correlations between observed and modeled soil water storage when distributed forcing data are used. Taylor diagram for simulated soil water storage compared to a reference dataset shown in Figure 4.16, depicts that most of the experiments performed primarily with WRF-AD and IMS-AD have the better fit with the exception of Mid-High 

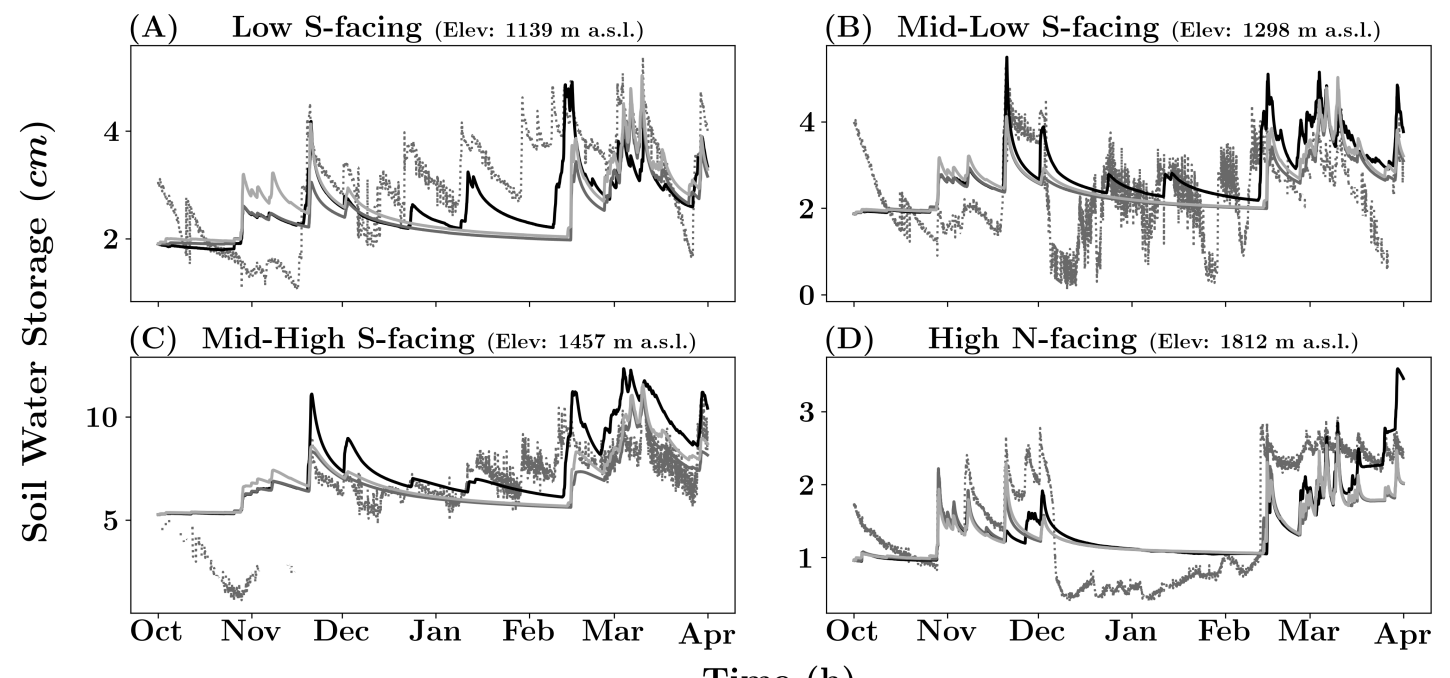

Time (h)

$\begin{array}{ll}\text { Measured } & - \text { IMS-PD } \\ \text { IMS-AD } & \text { IMS-AU }\end{array}$

Figure 4.15: Modeling performance on soil water storage variable, using IMS data as forcing data.

S-facing performed with WRF-AD and MLS performed with IMS-AD. Some experiments performed with IMS-PD and IMS-AU specifically at Low S-facing, Mid-Low S-facing and High N-facing show a good fit as well and are placed where the experiments performed with $\mathrm{AD}$ are grouped, similar to discharge analysis there is a trend of these experiments toward the reference which involves lower RMSE and reasonable correlation coefficients, deducting that the distribution of the forcing is important when assessing modeled soil water storage. A summary of all statistics in this Taylor diagram for simulated soil water storage is displayed in Table 4.5.

\subsection{Discussion}

In this study we examined the impact of spatially distributed and uniform forcing data configurations on snow water equivalent, soil water storage, and discharge. We ob- 


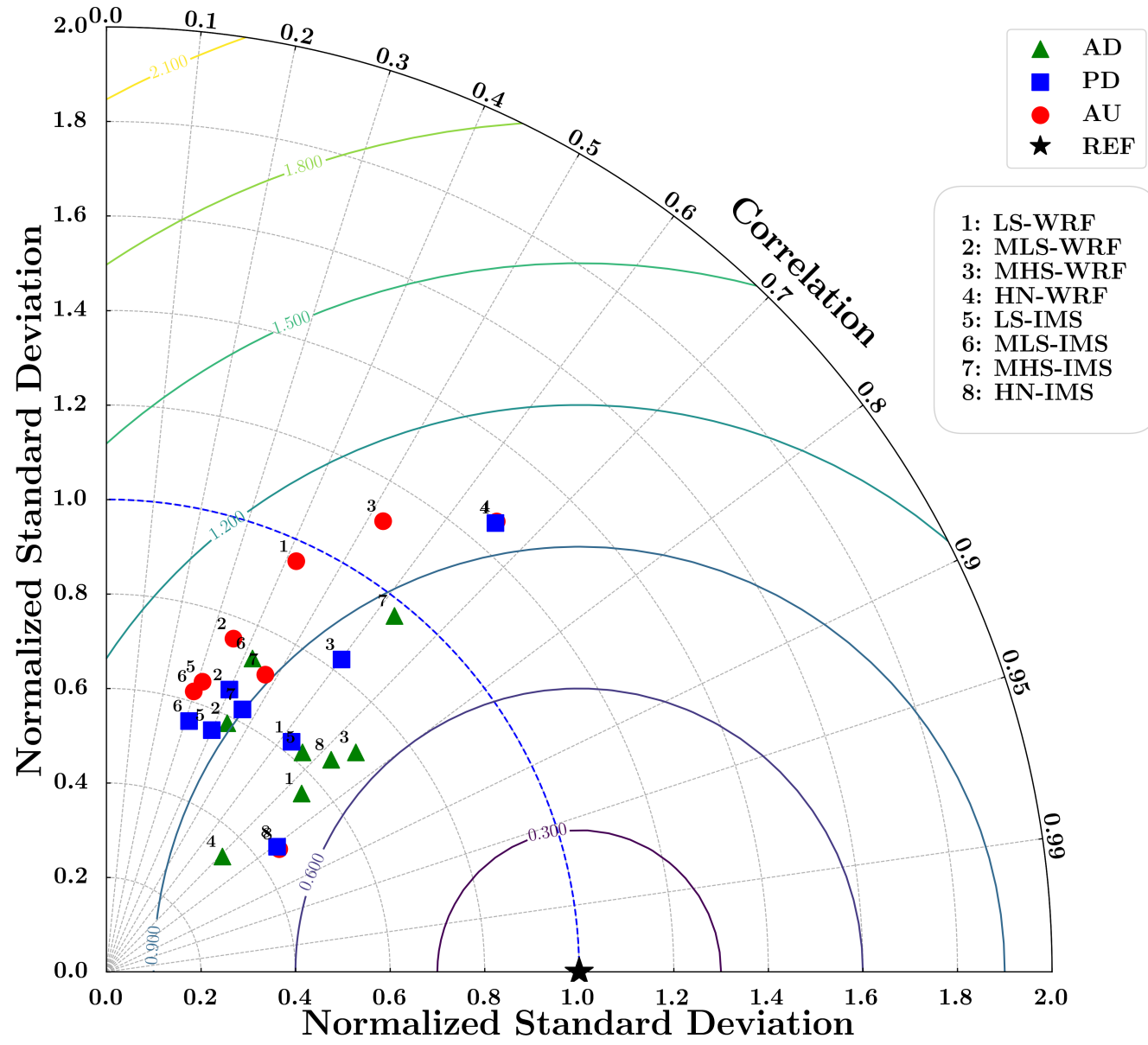

Figure 4.16: Taylor diagram for simulated discharge. 
Table 4.5: Summary of spatial averaged of normalized standard deviation, RMSE and Pearson correlation between simulated and observed data (reference) for soil water storage variable at Low S-facing (LS); Mid-Low Sfacing (MLS); Mid-High S-facing (MHS) and High N-facing (HN) stations.

\begin{tabular}{|c|c|c|c|c|c|}
\hline Data Source & Experiment Set & Site & NSTD $^{a}$ & $\mathrm{PC}^{\mathrm{b}}$ & RMSE $^{b}$ \\
\hline \multirow{12}{*}{ WRF } & \multirow{4}{*}{$\mathrm{AD}$} & LS & 0.560 & 0.738 & 0.698 \\
\hline & & MLS & 0.585 & 0.437 & 0.912 \\
\hline & & MHS & 0.703 & 0.750 & 0.663 \\
\hline & & $\mathrm{HN}$ & 0.346 & 0.709 & 0.793 \\
\hline & \multirow{4}{*}{$\mathrm{PD}$} & LS & 0.625 & 0.627 & 0.779 \\
\hline & & MLS & 0.652 & 0.399 & 0.951 \\
\hline & & MHS & 0.827 & 0.601 & 0.831 \\
\hline & & $\mathrm{HN}$ & 1.257 & 0.655 & 0.966 \\
\hline & \multirow{4}{*}{$\mathrm{AU}$} & $\mathrm{LS}$ & 0.958 & 0.419 & 1.056 \\
\hline & & MLS & 0.755 & 0.355 & 1.017 \\
\hline & & MHS & 1.119 & 0.523 & 1.040 \\
\hline & & $\mathrm{HN}$ & 1.261 & 0.654 & 0.970 \\
\hline \multirow{12}{*}{ IMS } & \multirow{4}{*}{$\mathrm{AD}$} & LS & 0.623 & 0.666 & 0.748 \\
\hline & & MLS & 0.732 & 0.422 & 0.958 \\
\hline & & MHS & 0.969 & 0.629 & 0.849 \\
\hline & & $\mathrm{HN}$ & 0.654 & 0.727 & 0.691 \\
\hline & \multirow{4}{*}{$\mathrm{PD}$} & LS & 0.558 & 0.400 & 0.930 \\
\hline & & MLS & 0.559 & 0.313 & 0.981 \\
\hline & & MHS & 0.625 & 0.460 & 0.903 \\
\hline & & $\mathrm{HN}$ & 0.448 & 0.807 & 0.691 \\
\hline & \multirow{4}{*}{$\mathrm{AU}$} & $\mathrm{LS}$ & 0.647 & 0.314 & 1.006 \\
\hline & & MLS & 0.622 & 0.297 & 1.009 \\
\hline & & MHS & 0.714 & 0.471 & 0.915 \\
\hline & & $\mathrm{HN}$ & 0.448 & 0.815 & 0.686 \\
\hline
\end{tabular}

${ }^{a}$ Normalized Standard Deviation.

b Pearson Correlation.

${ }^{\mathrm{c}}$ Root Mean Squared Error. 
served the sensitivity of a physically based hydrologic modeling framework to changes in forcing distribution configurations, and to the source of forcing data. Even with the selected soil parameters with no calibration on the hydrologic model, this study reveals the relative importance of choosing a particular forcing configuration. General findings show that modeling with $\mathrm{AD}$ and $\mathrm{PD}$ tend to have minimum distances to observational data when compared to simulations that use uniform forcing data. This is particularly true for streamflow and soil moisture, although there are some exceptions to this trend in which AU proved more accurate.

In a general context, this modeling exercise revealed the important role of both mass and energy distributed forcing data particularly on streamflow and soil moisture. This finding largely confirms previous studies that consider distributed precipitation as a key variable in hydrologic cycles. Those works also found that distributing configurations (i.e., distributed or uniform) large uncertainties in runoff estimations have been demonstrated when using uniform precipitation assumption. In addition, those works have demonstrated that knowledge of precipitation variability is needed at same or even smaller spatial scale in catchment modeling (Faurès et al., 1995). At the same time, the important role is revealed of distributed thermodynamics forcing data radiation and temperature forcing on all hydrologic variables assessed. Solar radiation is also a key variable for the hydrologic cycle. At hillslopes scales in mountain watersheds, the high variability of slope and aspect may lead to high gradients in solar radiation with corresponding impacts on the snow distribution and its evolution, which correspondingly impacts the water balance at the top of the soil layer (Aguilar et al., 2010).

Particular attention has been given to SWE simulations performed with AD that 
led to large uncertainty during snow melting season (i.e., March - April) and low uncertainty where PD or AU configurations were used. The spatiotemporal organization of SWE arises due to multiple factors that affect snowmelt processes like slope, aspect, elevation, vegetation and energy exchanges between snow and the surrounding atmosphere (Elder et al., 1991; Seyfried et al., 2009; Winstral et al., 2014). In addition, the assumption of AU, particularly in radiation forcings, does not consider the effects of slope and aspect and can potentially result in either an acceleration or deceleration of the snowmelt process (Dornes et al., 2008) resulting in inappropriate snow model predictions. In our case such non-consideration of the topographic effects in the radiative forcings led to satisfactory modeling performances in stations like Shingle Creek and Lower Deer Point and unsatisfactory performances in Lower Weather and Treeline. On the other hand, unsatisfactory modeling performances by using AD configurations suggest that other factors such as albedo parameterization, precipitation overestimation and uncertainty in radiative forcing estimations played an important role in snow melting process.

Due to the latter we performed a statistical test in order to detect the forcing configuration that together with the lack of snow models structure calibration, caused a significant overestimation on simulated SWE in some of the sites as shown in Figure 4.6 and 4.7. In this context, numerous studies have indicated that snowmelt is highly sensitive to albedo (Blöschl et al., 1991; Etchevers et al., 2004; Bales et al., 2004) increasing even more in high altitudes. For this case, the albedo parameterization in CLM, was adopted from BATS (Dickinson et al., 1993) and needs further exploration and analysis. On the other hand, several studies have indicated the significant effect caused by the interaction between radiation fluxes and turbulent energy fluxes existent 
between snowpack and the atmosphere (e.g., Zuzel \& Cox, 1975; Ohmura, 2001; Sicart et al., 2006) in which is suggested that variations in snowmelt is produced largely by interaction between all-wave radiation, vapor pressure, and wind forcings. (Ohmura, 2001), in particular, suggest that three quarters of the total energy needed for snowmelting is provided by incoming longwave radiation and sensible heat flux, both primarily controlled by the air temperature.

Limitations of this study lie in the type of atmospheric and hydrologic modeling platform selected as well as the climatological and topographic characteristics of the study area that need to be considered for instance, in the spatial interpolation method used. This study opens avenues for future research that investigates effects of atmospheric forcing scales and configurations on hydrologic state and fluxes as simulated by an integrated hydrologic model. It may be worthwhile, for instance, to consider other combinations of atmospheric-land surface-subsurface modeling workflows such as WRF-hydro, ParFlow-ARPS, or ParFlow-COSMO, to name a few. It is also important to investigate the role of scale effects and configurations of hydrologic model forcing data on regions that exhibit different physiographic controls on landatmosphere interactions (e.g., topographically flat regions, areas where precipitation is primarily through convective storms).

\subsection{Conclusions}

In this study we conducted a distributed forcing data assessment that considered different forcing arrangements applied to a hillslope-scale integrated hydrologic model. This study reveals, through comparisons of simulated hydrologic variables with observations at several ground stations, the extent to which spatiotemporally distributed (or uniform) precipitation and thermodynamic forcings control the integrated hydro- 
logic response of a watershed.

Assessment of snow water equivalents show that it is significantly sensitive to different mass and thermodynamics forcing configurations (i.e., distribution and or uniform forcing data). Unexpectedly, results suggest that some areas within the model are associated with behavior in which uniform forcing improves SWE simulations when compared to ground measurements. On the other hand, forcing distribution may affect the simulation performance causing significant overestimation of snow accumulation and reduced predisposition to ablation. We assert that these errors might arise from both the underlying forcing data particularly on the thermodynamics forcings, which may cause inappropriate simulation results and also from the parameterization of albedo within the snow model in CLM.

Assessment of soil water storage shows that in most simulations, using any spatially distributed configuration in the forcing data, does not reproduce well the observed soil water storage. However, most AD simulations show a better correlation and less error with respect to observations. Discharge shows similar behavior to soil moisture with the highest performance associated with the AD case, despite the fact that the AD simulations do a poorer job of simulating the melting season (i.e., middle of February forward) at the stations assessed. This suggests the relative importance of distributing all forcing data for better discharge estimations.

In general, experiments with $\mathrm{AU}$ and $\mathrm{PD}$ forcing data configurations cause the most error on simulated streamflow and soil moisture outputs. Uniform and distributed precipitation forcing setups are particularly helpful in estimating snow accumulation and depletion at Shingle Creek and Lower Deer Point by using WRF data and Lower Weather by using IMS data. Conversely, the AU configuration causes less 
error in simulated snow accumulation and depletion in Lower Weather by using both WRF and IMS data. 


\section{REFERENCES}

Abbott, Michael B, Bathurst, James C, Cunge, Jean A, O'Connell, Patrick E, \& Rasmussen, Jorn. 1986. An introduction to the European Hydrological SystemSysteme Hydrologique Europeen, "SHE", 1: History and philosophy of a physicallybased, distributed modelling system. Journal of hydrology, 87(1-2), 45-59.

Aguilar, C, Herrero, J, \& Polo, MJ. 2010. Topographic effects on solar radiation distribution in mountainous watersheds and their influence on reference evapotranspiration estimates at watershed scale. Hydrology and Earth System Sciences, 14(12), 2479.

Anderson, Brian T, McNamara, James P, Marshall, Hans-Peter, \& Flores, Alejandro N. 2014. Insights into the physical processes controlling correlations between snow distribution and terrain properties. Water Resources Research, 50(6), 45454563.

Anderson, EA. 2006. Snow accumulation and ablation model-SNOW-17. US National Weather Service, Silver Spring, MD.

Anderson, Eric A. 1976. A point energy and mass balance model of a snow cover.

Armstrong, R, \& Brun, E. 2008. Snow and climate: physical processes, surface energy exchange and modeling, Cambridge Univ. Pr., UK, 2366, 2367. 
Ashby, Steven F, \& Falgout, Robert D. 1996. A parallel multigrid preconditioned conjugate gradient algorithm for groundwater flow simulations. Nuclear Science and Engineering, 124(1), 145-159.

Atlas, R-, Kalnay, E, \& Halem, M. 1985a. Impact of satellite temperature sounding and wind data on numerical weather prediction. Optical Engineering, 24(2), 242341.

Atlas, R, Kalnay, E, Baker, WE, Susskind, J, Reuter, D, \& Halem, M. 1985b. Simulation studies of the impact of future observing systems on weather prediction.

Atlas, Robert. 1997. Atmospheric Observations and Experiments to Assess Their Usefulness in Data Assimilation (gtSpecial IssueltData Assimilation in Meteology and Oceanography: Theory and Practice). Journal of the Meteorological Society of Japan. Ser. II, 75(1B), 111-130.

Bales, Roger, Dozier, Jeff, Molotch, Noah, Painter, Tom, \& Rice, Bob. 2004. Mountain hydrology of the semi-arid western US: Research needs, opportunities \& challenges. Eos, Transactions American Geophysical Union, 85, 47.

Barrett, Andrew P. 2003. National operational hydrologic remote sensing center snow data assimilation system (SNODAS) products at NSIDC. National Snow and Ice Data Center, Cooperative Institute for Research in Environmental Sciences Boulder, CO.

Barros, A.P. 2013. 5.04 - Orographic Precipitation, Freshwater Resources, and Climate Vulnerabilities in Mountainous Regions. Pages 57 - 78 of: Pielke, Roger A. (ed), Climate Vulnerability. Oxford: Academic Press. 
Bartelt, Perry, \& Lehning, Michael. 2002. A physical SNOWPACK model for the Swiss avalanche warning: Part I: numerical model. Cold Regions Science and Technology, 35(3), 123-145.

Beven, Keith J, \& Kirkby, Michael J. 1979. A physically based, variable contributing area model of basin hydrology/Un modèle à base physique de zone d'appel variable de l'hydrologie du bassin versant. Hydrological Sciences Journal, 24(1), 43-69.

Blöschl, G, Gutknecht, D, \& Kirnbauer, R. 1991. Distributed snowmelt simulations in an alpine catchment: 2. Parameter study and model predictions. Water Resources Research, 27(12), 3181-3188.

Blöschl, Günter, \& Sivapalan, Murugesu. 1995. Scale issues in hydrological modelling: a review. Hydrological processes, 9(3-4), 251-290.

Bormann, H. 2006. Impact of spatial data resolution on simulated catchment water balances and model performance of the multi-scale TOPLATS model. Hydrology and Earth System Sciences Discussions, 10(2), 165-179.

Bronstert, A., Carrera, J., Kabat, P., \& Lütkemeier, S. 2005. Coupled Models for the Hydrological Cycle: Integrating Atmosphere, Biosphere and Pedosphere. Springer Berlin Heidelberg.

Brooks, Kenneth N, Ffolliott, Peter F, \& Magner, Joseph A. 2012. Hydrology and the Management of Watersheds. John Wiley \& Sons.

Brunner, Gary W. 2010. HEC-RAS river analysis system: hydraulic reference manual. US Army Corps of Engineers, Institute for Water Resources, Hydrologic Engineering Center. 
Burnash, Robert JC, Ferral, R Larry, \& McGuire, Robert A. 1973. A generalized streamflow simulation system, conceptual modeling for digital computers.

Clow, David W. 2010. Changes in the timing of snowmelt and streamflow in Colorado: a response to recent warming. Journal of Climate, 23(9), 2293-2306.

Condon, Laura E, \& Maxwell, Reed M. 2015. Evaluating the relationship between topography and groundwater using outputs from a continental-scale integrated hydrology model. Water Resources Research, 51(8), 6602-6621.

Dai, Yongjiu, Zeng, Xubin, Dickinson, Robert E, Baker, Ian, Bonan, Gordon B, Bosilovich, Michael G, Denning, A Scott, Dirmeyer, Paul A, Houser, Paul R, Niu, Guoyue, et al. 2003. The common land model. Bulletin of the American Meteorological Society, 84(8), 1013-1023.

Dettinger, Mike. 2005. Changes in streamflow timing in the western United States in recent decades... from the National Streamflow Information Program. Tech. rept. Geological Survey (US).

DeWalle, David R, \& Rango, Albert. 2008. Principles of snow hydrology. Cambridge University Press.

Dickinson, E, Henderson-Sellers, Anne, \& Kennedy, J. 1993. Biosphere-atmosphere transfer scheme (BATS) version 1e as coupled to the NCAR community climate model.

Ding, Baohong, Yang, Kun, Qin, Jun, Wang, Lei, Chen, Yingying, \& He, Xiaobo. 2014. The dependence of precipitation types on surface elevation and meteorological conditions and its parameterization. Journal of hydrology, 513, 154-163. 
Dornes, Pablo F, Pomeroy, John W, Pietroniro, Alain, \& Verseghy, Diana L. 2008. Effects of spatial aggregation of initial conditions and forcing data on modeling snowmelt using a land surface scheme. Journal of Hydrometeorology, 9(4), 789803.

Dufresne, Jean-Louis, \& Bony, Sandrine. 2008. An assessment of the primary sources of spread of global warming estimates from coupled atmosphere-ocean models. Journal of Climate, 21(19), 5135-5144.

Elder, Kelly, Dozier, Jeff, \& Michaelsen, Joel. 1991. Snow accumulation and distribution in an alpine watershed. Water Resources Research, 27(7), 1541-1552.

Engman, Edwin T. 1986. Roughness coefficients for routing surface runoff. Journal of Irrigation and Drainage Engineering, 112(1), 39-53.

Essery, Richard. 2003. Aggregated and distributed modelling of snow cover for a high-latitude basin. Global and Planetary Change, 38(1-2), 115-120.

Essery, Richard, Morin, Samuel, Lejeune, Yves, \& Ménard, Cécile B. 2013. A comparison of 1701 snow models using observations from an alpine site. Advances in water resources, 55, 131-148.

Etchevers, Pierre, Martin, Eric, Brown, Ross, Fierz, Charles, Lejeune, Yves, Bazile, Eric, Boone, Aaron, Dai, Yong-Jiu, Essery, Richard, Fernandez, Alberto, et al. 2004. Validation of the energy budget of an alpine snowpack simulated by several snow models (Snow MIP project). Annals of Glaciology, 38, 150-158.

Fang, Zhufeng, Bogena, Heye, Kollet, Stefan, \& Vereecken, Harry. 2016. Scale dependent parameterization of soil hydraulic conductivity in 3D simulation of hydro- 
logical processes in a forested headwater catchment. Journal of hydrology, 536, 365-375.

Faurès, Jean-Marc, Goodrich, DC, Woolhiser, David A, \& Sorooshian, Soroosh. 1995. Impact of small-scale spatial rainfall variability on runoff modeling. Journal of Hydrology, 173(1-4), 309-326.

Flerchinger, GN, Xaio, Wei, Marks, Danny, Sauer, TJ, \& Yu, Qiang. 2009. Comparison of algorithms for incoming atmospheric long-wave radiation. Water Resources Research, 45(3).

Flores, Alejandro, Masarik, Matt, \& Watson, Katelyn. 2016. A 30-Year, MultiDomain High-Resolution Climate Simulation Dataset for the Interior Pacific Northwest and Southern Idaho.

Frankenstein, Susan, Sawyer, Anne, \& Koeberle, Julie. 2008. Comparison of FASST and SNTHERM in three snow accumulation regimes. Journal of Hydrometeorology, $\mathbf{9}(6), 1443-1463$.

Freedman, David, \& Diaconis, Persi. 1981. On the histogram as a density estimator: L 2 theory. Zeitschrift für Wahrscheinlichkeitstheorie und verwandte Gebiete, 57(4), 453-476.

Gao, Huilin, Tang, Qiuhong, Shi, Xiaogang, Zhu, Chunmei, Bohn, Ted, Su, Fengge, Pan, Ming, Sheffield, Justin, Lettenmaier, Dennis, \& Wood, Eric. 2010. Water budget record from Variable Infiltration Capacity (VIC) model.

Ge, Yan, \& Gong, Gavin. 2010. Land surface insulation response to snow depth variability. Journal of Geophysical Research: Atmospheres, 115(D8). 
Gentine, Pierre, Troy, Tara J, Lintner, Benjamin R, \& Findell, Kirsten L. 2012. Scaling in surface hydrology: Progress and challenges. Journal of Contemporary Water research \& education, 147(1), 28-40.

Gesch, Dean, Oimoen, Michael, Greenlee, Susan, Nelson, Charles, Steuck, Michael, \& Tyler, Dean. 2002. The national elevation dataset. Photogrammetric engineering and remote sensing, 68(1), 5-32.

Gilbert, James M, Maxwell, Reed M, \& Gochis, David J. 2017. Effects of water-table configuration on the planetary boundary layer over the san joaquin river watershed, california. Journal of Hydrometeorology, 18(5), 1471-1488.

Gribb, Molly M, Forkutsa, Irina, Hansen, Aleshia, Chandler, David G, \& McNamara, James P. 2009. The effect of various soil hydraulic property estimates on soil moisture simulations. Vadose Zone Journal, 8(2), 321-331.

Grünewald, Thomas, Bühler, Yves, \& Lehning, Michael. 2014. Elevation dependency of mountain snow depth. The Cryosphere, 8(6), 2381-2394.

Havnø, K, Madsen, MN, \& Dørge, J. 1995. MIKE 11-a generalized river modelling package. Computer models of watershed hydrology, 733-782.

He, Minxue, Hogue, Terri S, Franz, Kristie J, Margulis, Steven A, \& Vrugt, Jasper A. 2011. Characterizing parameter sensitivity and uncertainty for a snow model across hydroclimatic regimes. Advances in Water Resources, 34(1), 114-127.

Herman, Jon, \& Usher, Will. 2017. SALib: an open-source Python library for sensitivity analysis. The Journal of Open Source Software, 2(9). 
Hinckley, Eve-Lyn S, Ebel, Brian A, Barnes, Rebecca T, Anderson, Robert S, Williams, Mark W, \& Anderson, Suzanne P. 2014. Aspect control of water movement on hillslopes near the rain-snow transition of the Colorado Front Range. Hydrological Processes, 28(1), 74-85.

Homer, Collin, Dewitz, Jon, Yang, Limin, Jin, Suming, Danielson, Patrick, Xian, George, Coulston, John, Herold, Nathaniel, Wickham, James, \& Megown, Kevin. 2015. Completion of the 2011 National Land Cover Database for the conterminous United States-representing a decade of land cover change information. Photogrammetric Engineering $\&$ Remote Sensing, 81(5), 345-354.

Homma, Toshimitsu, \& Saltelli, Andrea. 1996. Importance measures in global sensitivity analysis of nonlinear models. Reliability Engineering $\&$ System Safety, 52(1), $1-17$.

Horne, Federico E, \& Kavvas, M Levent. 1997. Physics of the spatially averaged snowmelt process. Journal of Hydrology, 191(1-4), 179-207.

Horvath, Kristian, Koracin, Darko, Vellore, Ramesh, Jiang, Jinhua, \& Belu, Radian. 2012. Sub-kilometer dynamical downscaling of near-surface winds in complex terrain using WRF and MM5 mesoscale models. Journal of Geophysical Research: Atmospheres, 117(D11).

Houle, Elizabeth S, Livneh, Ben, \& Kasprzyk, Joseph R. 2017. Exploring snow model parameter sensitivity using Sobol'variance decomposition. Environmental Modelling \& Software, 89, 144-158.

Johannesson, Gardar, Lucas, Donald, Qian, Yun, Swile, LP, \& Wildey, Timothy M. 
2014. Sensitivity of precipitation to parameter values in the Community Atmosphere Model Version 5. Sandia report SAND2014-0829. Sandia National Laboratories: Albuquerque, New Mexico.

Jones, Jim E, \& Woodward, Carol S. 2001. Newton-Krylov-multigrid solvers for large-scale, highly heterogeneous, variably saturated flow problems. Advances in Water Resources, 24(7), 763-774.

Jordan, Rachel. 1991. A one-dimensional temperature model for a snow cover: Technical documentation for SNTHERM. 89. Tech. rept. COLD REGIONS RESEARCH AND ENGINEERING LAB HANOVER NH.

Juszak, I, \& Pellicciotti, F. 2013. A comparison of parameterizations of incoming longwave radiation over melting glaciers: model robustness and seasonal variability. Journal of Geophysical Research: Atmospheres, 118(8), 3066-3084.

Keune, Jessica, Gasper, Fabian, Goergen, Klaus, Hense, Andreas, Shrestha, Prabhakar, Sulis, Mauro, \& Kollet, Stefan. 2016. Studying the influence of groundwater representations on land surface-atmosphere feedbacks during the European heat wave in 2003. Journal of Geophysical Research: Atmospheres, 121(22).

Koivusalo, H, \& Heikinheimo, M. 1999. Surface energy exchange over a boreal snowpack: Comparison of two snow energy balance models. Hydrological processes, 13(14-15), 2395-2408.

Kollet, Stefan J, \& Maxwell, Reed M. 2006. Integrated surface-groundwater flow modeling: A free-surface overland flow boundary condition in a parallel groundwater flow model. Advances in Water Resources, 29(7), 945-958. 
Kollet, Stefan J, \& Maxwell, Reed M. 2008. Capturing the influence of groundwater dynamics on land surface processes using an integrated, distributed watershed model. Water Resources Research, 44(2).

Kormos, Patrick R, Marks, Danny, McNamara, James P, Marshall, HP, Winstral, Adam, \& Flores, Alejandro N. 2014. Snow distribution, melt and surface water inputs to the soil in the mountain rain-snow transition zone. Journal of hydrology, 519, 190-204.

Lahoz, W., Khattatov, B., \& Menard, R. 2010. Data Assimilation: Making Sense of Observations. Springer Berlin Heidelberg.

Landry, Christopher C. 2014. Desert dust and snow stability. In: International Snow Science Workshops (ISSW) Proceedings of Professional Papers and Poster Talks.

Landry, Christopher C, Buck, Kimberly A, Raleigh, Mark S, \& Clark, Martyn P. 2014. Mountain system monitoring at Senator Beck Basin, San Juan Mountains, Colorado: A new integrative data source to develop and evaluate models of snow and hydrologic processes. Water Resources Research, 50(2), 1773-1788.

Lapo, Karl E, Hinkelman, Laura M, Raleigh, Mark S, \& Lundquist, Jessica D. 2015. Impact of errors in the downwelling irradiances on simulations of snow water equivalent, snow surface temperature, and the snow energy balance. Water Resources Research, 51(3), 1649-1670.

Lehning, Michael, Bartelt, Perry, Brown, Bob, Fierz, Charles, \& Satyawali, Pramod. 2002. A physical SNOWPACK model for the Swiss avalanche warning: Part II. Snow microstructure. Cold regions science and technology, 35(3), 147-167. 
Leij, Feike J. 1996. The UNSODA unsaturated soil hydraulic database: user's manual. Vol. 96. National Risk Management Research Laboratory, Office of Research and Development, US Environmental Protection Agency.

López-Moreno, JI, Revuelto, J, Gilaberte, M, Morán-Tejeda, E, Pons, M, Jover, E, Esteban, P, García, C, \& Pomeroy, JW. 2014. The effect of slope aspect on the response of snowpack to climate warming in the Pyrenees. Theoretical and applied climatology, 117(1-2), 207-219.

Lophaven, Søren Nymand, Nielsen, Hans Bruun, \& Søndergaard, Jacob. 2002. DACE: a Matlab kriging toolbox. Vol. 2. Citeseer.

Lundquist, Jessica D, Dettinger, Michael D, Stewart, Iris T, \& Cayan, Daniel R. 2009. Variability and trends in spring runoff in the western United States. Climate warming in western North America: evidence and environmental effects. University of Utah Press, Salt Lake City, Utah, USA, 63-76.

Mahoney, Kelly, Alexander, Michael, Scott, James D, \& Barsugli, Joseph. 2013. Highresolution downscaled simulations of warm-season extreme precipitation events in the Colorado Front Range under past and future climates. Journal of Climate, 26(21), 8671-8689.

Marks, Danny. 1988. Climate, energy exchange, and snowmelt in Emerald Lake watershed, Sierra Nevada. Ph.D. thesis, University of California, Santa Barbara.

Marks, Danny, Kimball, John, Tingey, Dave, \& Link, Tim. 1998. The sensitivity of snowmelt processes to climate conditions and forest cover during rain-on-snow: 
a case study of the 1996 Pacific Northwest flood. Hydrological Processes, 12(10), 1569-1587.

Marks, Danny, Domingo, James, Susong, Dave, Link, Tim, \& Garen, David. 1999. A spatially distributed energy balance snowmelt model for application in mountain basins. Hydrological processes, 13(12-13), 1935-1959.

Markstrom, Steven L, Niswonger, Richard G, Regan, R Steven, Prudic, David E, \& Barlow, Paul M. 2008. GSFLOW-Coupled Ground-water and Surface-water FLOW model based on the integration of the Precipitation-Runoff Modeling System (PRMS) and the Modular Ground-Water Flow Model (MODFLOW-2005). Tech. rept. Geological Survey (US).

Marshall, SE, \& Warren, SG. 1987. Parameterization of snow albedo for climate models. Pages 43-50 of: Large Scale Effects of Seasonal Snow Cover (Proceedings of the Vancouver Symposium, August 1987), vol. 166. IAHS Publ.

Maxwell, Reed M. 2013. A terrain-following grid transform and preconditioner for parallel, large-scale, integrated hydrologic modeling. Advances in Water Resources, 53, 109-117.

Maxwell, Reed M, \& Miller, Norman L. 2005. Development of a coupled land surface and groundwater model. Journal of Hydrometeorology, 6(3), 233-247.

Maxwell, Reed M, Chow, Fotini Katopodes, \& Kollet, Stefan J. 2007. The groundwater-land-surface-atmosphere connection: Soil moisture effects on the atmospheric boundary layer in fully-coupled simulations. Advances in Water Resources, 30(12), 2447-2466. 
Maxwell, Reed M, Putti, Mario, Meyerhoff, Steven, Delfs, Jens-Olaf, Ferguson, Ian M, Ivanov, Valeriy, Kim, Jongho, Kolditz, Olaf, Kollet, Stefan J, Kumar, Mukesh, et al. 2014. Surface-subsurface model intercomparison: A first set of benchmark results to diagnose integrated hydrology and feedbacks. Water resources research, 50(2), $1531-1549$.

McNamara, James P, Benner, Shawn G, Poulos, Michael J, Pierce, Jennifer L, Chandler, David G, Kormos, Patrick R, Marshall, Hans-Peter, Flores, Alejandro N, Seyfried, Mark, Glenn, Nancy F, et al. 2018. Form and function relationships revealed by long-term research in a semiarid mountain catchment. Wiley Interdisciplinary Reviews: Water, 5(2), e1267.

Melsen, Lieke, Teuling, Adriaan, Torfs, Paul, Zappa, Massimiliano, Mizukami, Naoki, Clark, Martyn, \& Uijlenhoet, Remko. 2016. Representation of spatial and temporal variability in large-domain hydrological models: case study for a mesoscale preAlpine basin. Hydrology and Earth System Sciences, 20(6), 2207-2226.

Mesinger, Fedor, DiMego, Geoff, Kalnay, Eugenia, Mitchell, Kenneth, Shafran, Perry C, Ebisuzaki, Wesley, Jović, Dušan, Woollen, Jack, Rogers, Eric, Berbery, Ernesto H, et al. 2006. North American regional reanalysis. Bulletin of the American Meteorological Society, 87(3), 343-360.

Miller, Douglas A, \& White, Richard A. 1998. A conterminous United States multilayer soil characteristics dataset for regional climate and hydrology modeling. Earth interactions, 2(2), 1-26.

Mishra, SK, \& Singh, VP. 2002. SCS-CN-based hydrologic simulation package. Mathematical models in small watershed hydrology and applications, 2841, 391-464. 
Mitchell, Kenneth E, Lohmann, Dag, Houser, Paul R, Wood, Eric F, Schaake, John C, Robock, Alan, Cosgrove, Brian A, Sheffield, Justin, Duan, Qingyun, Luo, Lifeng, et al. 2004. The multi-institution North American Land Data Assimilation System (NLDAS): Utilizing multiple GCIP products and partners in a continental distributed hydrological modeling system. Journal of Geophysical Research: Atmospheres, $\mathbf{1 0 9}(\mathrm{D} 7)$.

Mölders, Nicole, \& Raabe, Armin. 1996. Numerical investigations on the influence of subgrid-scale surface heterogeneity on evapotranspiration and cloud processes. Journal of Applied Meteorology, 35(6), 782-795.

Molnar, DK, \& Julien, PY. 2000. Grid-size effects on surface runoff modeling. Journal of Hydrologic Engineering, 5(1), 8-16.

Monin, AS, \& Obukhov, AMF. 1954. Basic laws of turbulent mixing in the surface layer of the atmosphere. Contrib. Geophys. Inst. Acad. Sci. USSR, 151(163), e187.

Natural Resources Conservation Service, United States Department of Agriculture. 2014. Soil texture calculator. https://www.nrcs. usda.gov/wps/portal/ nrcs/detail/soils/survey/?cid=nrcs142p2_054167. Accessed June, 2014.

Ohmura, Atsumu. 2001. Physical basis for the temperature-based melt-index method. Journal of applied meteorology, 40(4), 753-761.

O’Neill, ADJ, \& Gray, Don M. 1972. Solar radiation penetration through snow. Pages 227-240 of: The Role of Snow and Ice in Hydrology, Proceedings of the Banff Symposium, Int. Assoc. Hydrol. Sci, vol. 107. 
Pederson, Gregory T, Gray, Stephen T, Woodhouse, Connie A, Betancourt, Julio L, Fagre, Daniel B, Littell, Jeremy S, Watson, Emma, Luckman, Brian H, \& Graumlich, Lisa J. 2011. The unusual nature of recent snowpack declines in the North American Cordillera. science, 333(6040), 332-335.

Philipona, Rolf, \& Dürr, Bruno. 2004. Greenhouse forcing outweighs decreasing solar radiation driving rapid temperature rise over land. Geophysical research letters, $\mathbf{3 1}(22)$.

Pilkey, Orrin H, \& Pilkey-Jarvis, Linda. 2007. Useless arithmetic: why environmental scientists can't predict the future. Columbia University Press.

Pohl, S, Marsh, P, \& Liston, GE. 2006. Spatial-temporal variability in turbulent fluxes during spring snowmelt. Arctic, Antarctic, and Alpine Research, 38(1), 136-146.

Pomeroy, JW, Toth, B, Granger, RJ, Hedstrom, NR, \& Essery, RLH. 2003. Variation in surface energetics during snowmelt in a subarctic mountain catchment. Journal of Hydrometeorology, 4(4), 702-719.

Prein, Andreas F, Langhans, Wolfgang, Fosser, Giorgia, Ferrone, Andrew, Ban, Nikolina, Goergen, Klaus, Keller, Michael, Tölle, Merja, Gutjahr, Oliver, Feser, Frauke, et al. 2015. A review on regional convection-permitting climate modeling: Demonstrations, prospects, and challenges. Reviews of geophysics, 53(2), 323-361.

Pujol, Gilles, Iooss, Bertrand, \& Iooss, Maintainer Bertrand. 2017. Package 'sensitivity'. URL: https://cran.r-project.org/web/packages/sensitivity/ sensitivity.pdf. 
QGIS Development Team, et al. 2014. QGIS Geographic Information System, Version 2.6. 1. Open Source Geospatial Foundation. URL: http://qgis. osgeo. org.

Qu, Yizhong, \& Duffy, Christopher J. 2007. A semidiscrete finite volume formulation for multiprocess watershed simulation. Water Resources Research, 43(8).

Raleigh, MS, Lundquist, JD, \& Clark, MP. 2015. Exploring the impact of forcing error characteristics on physically based snow simulations within a global sensitivity analysis framework. Hydrology and Earth System Sciences, 19(7), 3153.

Rihani, Jehan F, Maxwell, Reed M, \& Chow, Fotini K. 2010. Coupling groundwater and land surface processes: Idealized simulations to identify effects of terrain and subsurface heterogeneity on land surface energy fluxes. Water Resources Research, 46(12).

Saha, Suranjana, Moorthi, Shrinivas, Pan, Hua-Lu, Wu, Xingren, Wang, Jiande, Nadiga, Sudhir, Tripp, Patrick, Kistler, Robert, Woollen, John, Behringer, David, et al. 2010. The NCEP climate forecast system reanalysis. Bulletin of the American Meteorological Society, 91(8), 1015-1058.

Saltelli, Andrea. 2002. Making best use of model evaluations to compute sensitivity indices. Computer physics communications, 145(2), 280-297.

Saltelli, Andrea, Tarantola, Stefano, \& Campolongo, Francesca. 2000. Sensitivity analysis as an ingredient of modeling. Statistical Science, 377-395.

Saltelli, Andrea, Ratto, Marco, Andres, Terry, Campolongo, Francesca, Cariboni, Jessica, Gatelli, Debora, Saisana, Michaela, \& Tarantola, Stefano. 2008. Global sensitivity analysis: the primer. John Wiley \& Sons. 
Saltelli, Andrea, Annoni, Paola, Azzini, Ivano, Campolongo, Francesca, Ratto, Marco, \& Tarantola, Stefano. 2010. Variance based sensitivity analysis of model output. Design and estimator for the total sensitivity index. Computer Physics Communications, 181(2), 259-270.

Seyfried, MS, \& Wilcox, BP. 1995. Scale and the nature of spatial variability: Field examples having implications for hydrologic modeling. Water Resources Research, 31(1), 173-184.

Seyfried, MS, Grant, LE, Marks, Daniel, Winstral, Adam, \& McNamara, James. 2009. Simulated soil water storage effects on streamflow generation in a mountainous snowmelt environment, Idaho, USA. Hydrological Processes: An International Journal, 23(6), 858-873.

Shao, Y, Sogalla, M, Kerschgens, M, \& Brücher, W. 2001. Effects of land-surface heterogeneity upon surface fluxes and turbulent conditions. Meteorology and Atmospheric Physics, 78(3-4), 157-181.

Sicart, Jean-Emmanuel, Pomeroy, JW, Essery, RLH, \& Bewley, D. 2006. Incoming longwave radiation to melting snow: observations, sensitivity and estimation in northern environments. Hydrological processes, 20(17), 3697-3708.

Simmers, Ian. 2005. Understanding water in a dry environment: IAH International Contributions to Hydrogeology 23. Taylor \& Francis.

Šimůnek, J, Van Genuchten, M Th, \& Šejna, M. 2006. The HYDRUS software package for simulating two-and three-dimensional movement of water, heat, and multiple solutes in variably-saturated media. Technical manual, version, 1, 241. 
Skamarock, William C, Klemp, Joseph B, Dudhia, Jimy, Gill, David O, Barker, Dale M, Wang, Wei, \& Powers, Jordan G. 2005. A description of the advanced research WRF version 2. Tech. rept. National Center For Atmospheric Research Boulder Co Mesoscale and Microscale Meteorology Div.

Smith, TJ, McNamara, James P, Flores, Alejandro N, Gribb, Molly M, Aishlin, PS, \& Benner, Shawn G. 2011. Small soil storage capacity limits benefit of winter snowpack to upland vegetation. Hydrological Processes, 25(25), 3858-3865.

Sobol, Ilya M. 1993. Sensitivity estimates for nonlinear mathematical models. Mathematical modelling and computational experiments, 1(4), 407-414.

Soil Survey Staff, Natural Resources Conservation Service, United States Department of Agriculture. 2014. Soil Survey Geographic (SSURGO) database. https:// websoilsurvey. sc. egov. usda. gov/. Accessed June, 2014.

Stewart, Iris T, Cayan, Daniel R, \& Dettinger, Michael D. 2005. Changes toward earlier streamflow timing across western North America. Journal of climate, 18(8), $1136-1155$.

Sturm, Matthew, Taras, Brian, Liston, Glen E, Derksen, Chris, Jonas, Tobias, \& Lea, Jon. 2010. Estimating snow water equivalent using snow depth data and climate classes. Journal of Hydrometeorology, 11(6), 1380-1394.

Tang, T, Reed, P, Wagener, T, \& Van Werkhoven, K. 2006. Comparing sensitivity analysis methods to advance lumped watershed model identification and evaluation. Hydrology and Earth System Sciences Discussions, 3(6), 3333-3395. 
Tarboton, David G, Luce, Charles H, et al. 1996. Utah energy balance snow accumulation and melt model (UEB). Utah Water Research Laboratory.

Taylor, Karl E. 2001. Summarizing multiple aspects of model performance in a single diagram. Journal of Geophysical Research: Atmospheres, 106(D7), 7183-7192.

Taylor, KE. 2005. Taylor diagram primer. Program for Climate Model Diagnosis and Intercomparison. https://pcmdi. llnl.gov/staff/taylor/CV/Taylor_ diagram_primer. $p d f$ ? $i d=87$. Accessed July, 2016.

Tesfa, Teklu K, Tarboton, David G, Chandler, David G, \& McNamara, James P. 2009. Modeling soil depth from topographic and land cover attributes. Water Resources Research, 45(10).

Tian, Dongfang, \& Liu, Defu. 2011. A new integrated surface and subsurface flows model and its verification. Applied mathematical modelling, 35(7), 3574-3586.

US Army Corps of Engineers. 1956. Snow hydrology: Summary report of the snow investigations.

Van Genuchten, M Th. 1980. A closed-form equation for predicting the hydraulic conductivity of unsaturated soils 1. Soil science society of America journal, 44(5), 892-898.

Vivoni, Enrique R, Ivanov, Valeriy Y, Bras, Rafael L, \& Entekhabi, Dara. 2005. On the effects of triangulated terrain resolution on distributed hydrologic model response. Hydrological Processes, 19(11), 2101-2122.

Vrugt, Jasper A, Ter Braak, Cajo JF, Clark, Martyn P, Hyman, James M, \& Robinson, Bruce A. 2008. Treatment of input uncertainty in hydrologic modeling: Doing 
hydrology backward with Markov chain Monte Carlo simulation. Water Resources Research, 44(12).

Wayand, Nicholas E, Massmann, Adam, Butler, Colin, Keenan, Eric, Stimberis, John, \& Lundquist, Jessica D. 2015. A meteorological and snow observational data set from Snoqualmie Pass (921 m), Washington Cascades, USA. Water Resources Research, 51(12), 10092-10103.

Williams, CJ, McNamara, JP, \& Chandler, DG. 2009. Controls on the temporal and spatial variability of soil moisture in a mountainous landscape: the signature of snow and complex terrain. Hydrology and Earth System Sciences, 13(7), 1325.

Winstral, Adam, Marks, Danny, \& Gurney, Robert. 2014. Assessing the sensitivities of a distributed snow model to forcing data resolution. Journal of Hydrometeorology, 15(4), 1366-1383.

Wood, Eric F, Sivapalan, Murugesu, Beven, Keith, \& Band, Larry. 1988. Effects of spatial variability and scale with implications to hydrologic modeling. Journal of hydrology, 102(1-4), 29-47.

Wu, Hua, \& Li, Zhao-Liang. 2009. Scale issues in remote sensing: A review on analysis, processing and modeling. Sensors, 9(3), 1768-1793.

Yang, Zong-Liang. 2008. Snow and climate: physical processes, surface energy exchange and modeling. Cambridge, UK: Cambridge University Press. Chap. Description of recent snow models, pages 129-136.

Zuzel, John F, \& Cox, Lloyd M. 1975. Relative importance of meteorological variables in snowmelt. Water Resources Research, 11(1), 174-176. 
APPENDIX A:

\section{PARFLOW-CLM SCRIPTS}




\section{A.1 Parflow-clm scripts Repository}

Parflow-CLM scripts used in this dissertation, can be found in the public GitHub repository at: https://github.com/miguelaguayo/ParFlow-CLM-Scripts/

In the following appendices, we present detailed Python, TCL and Bash preprocessing, modeling and postprocessing scripts for ParFlow simulations, applied in Dry Creek Experimental Watershed domain. 


\section{APPENDIX B:}

\section{PARFLOW-CLM PREPROCESSING SCRIPTS}




\section{B.1 Python Parflow-CLM preprocessing functions for DEM, soil and land cover data}

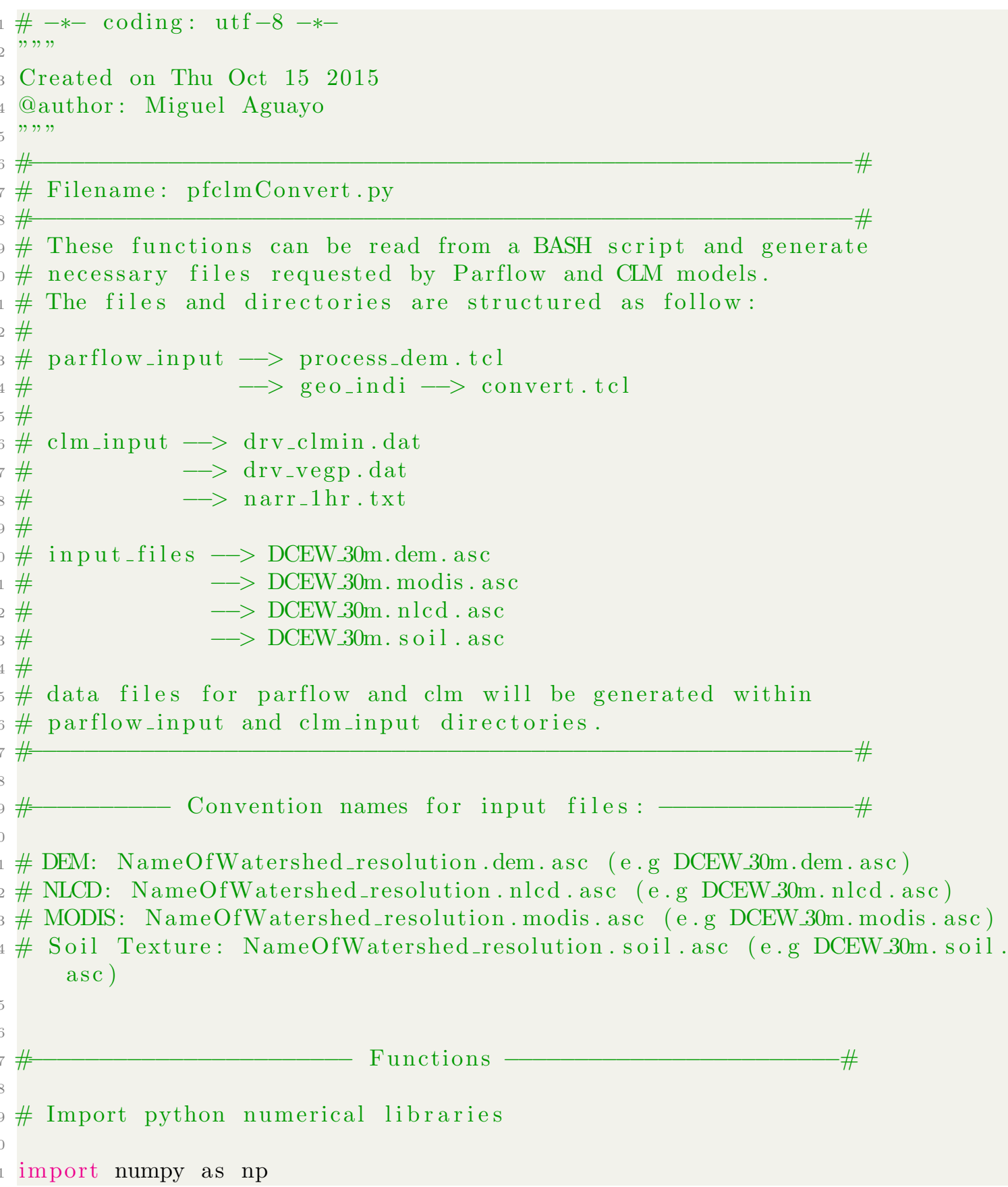




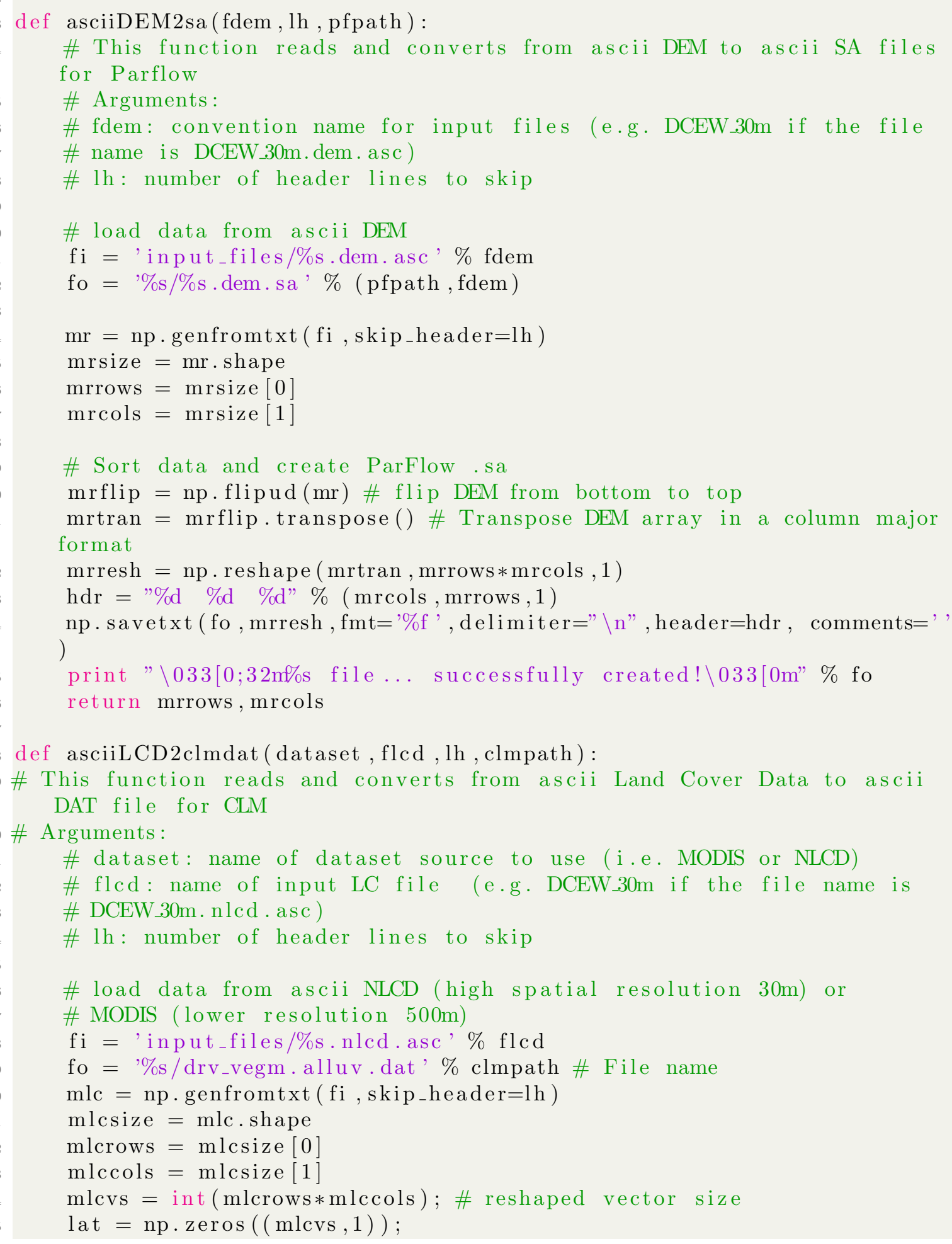




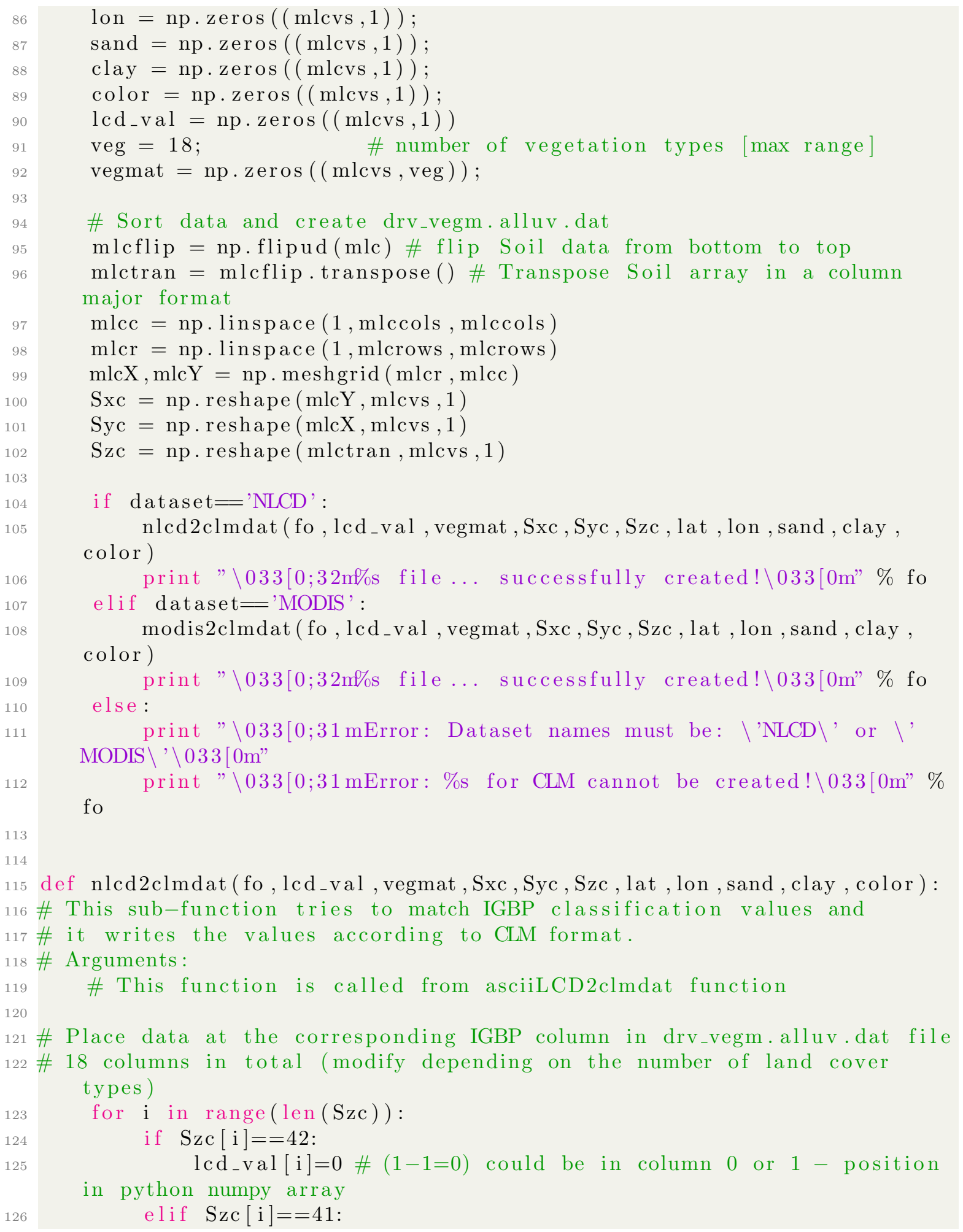




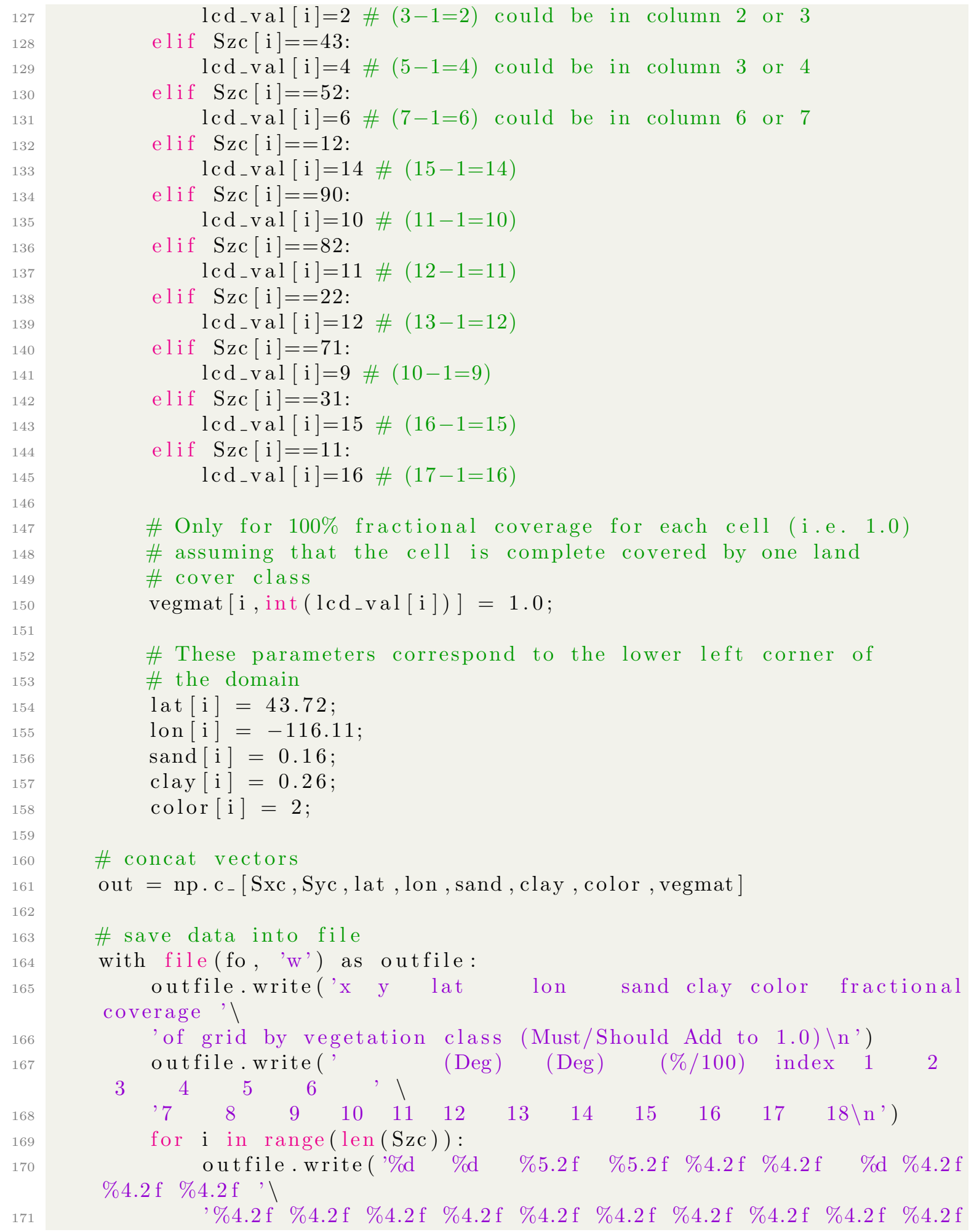




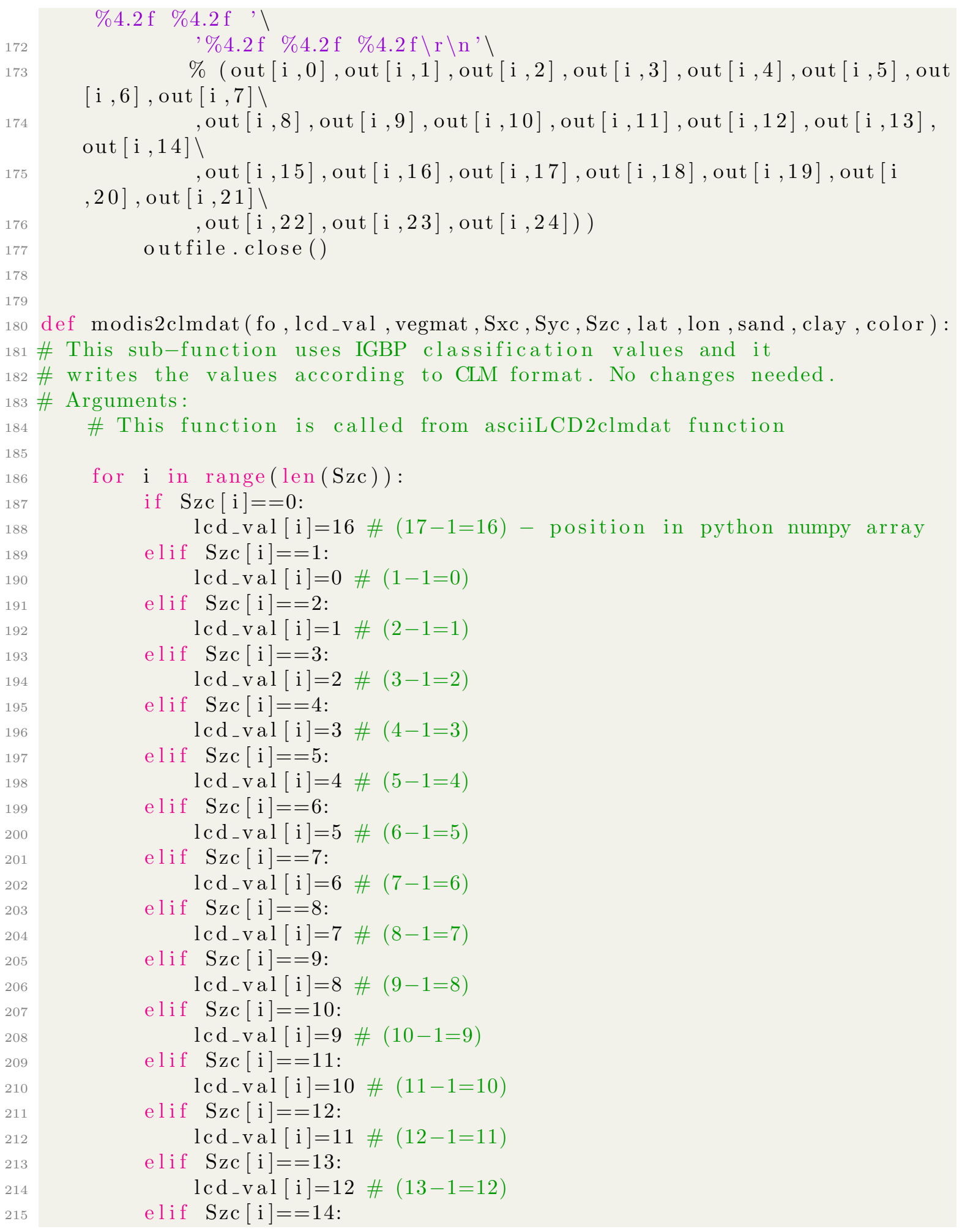




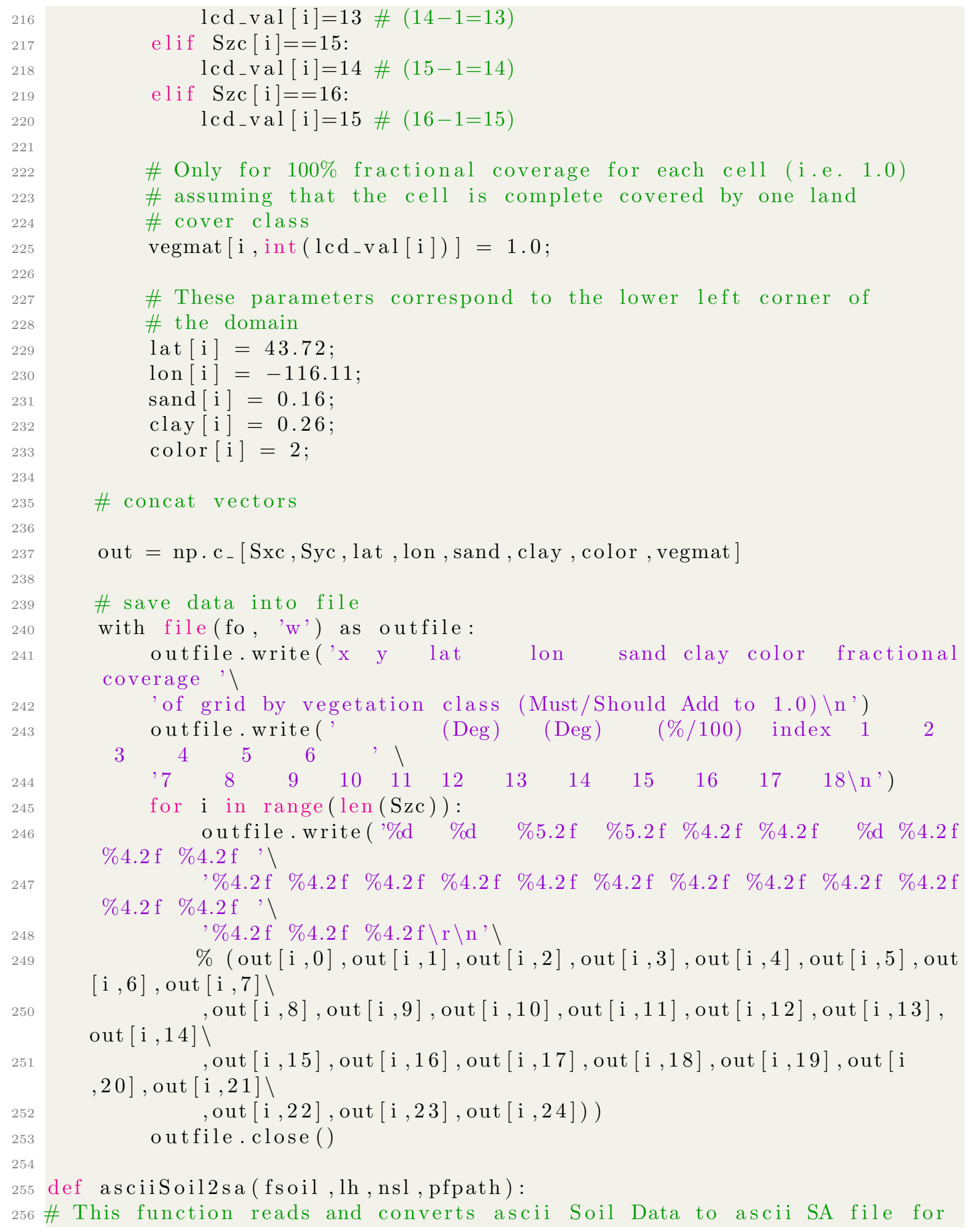




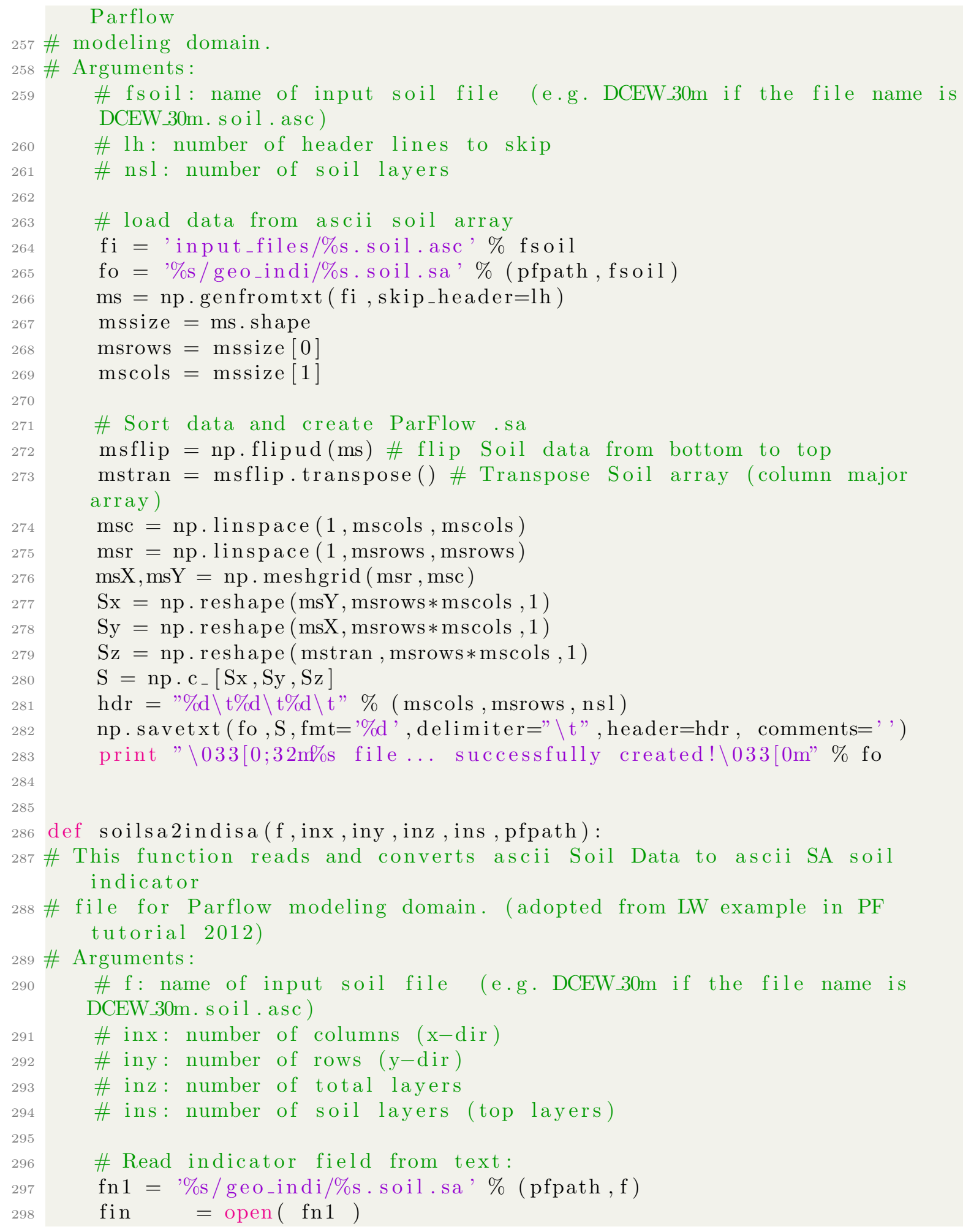




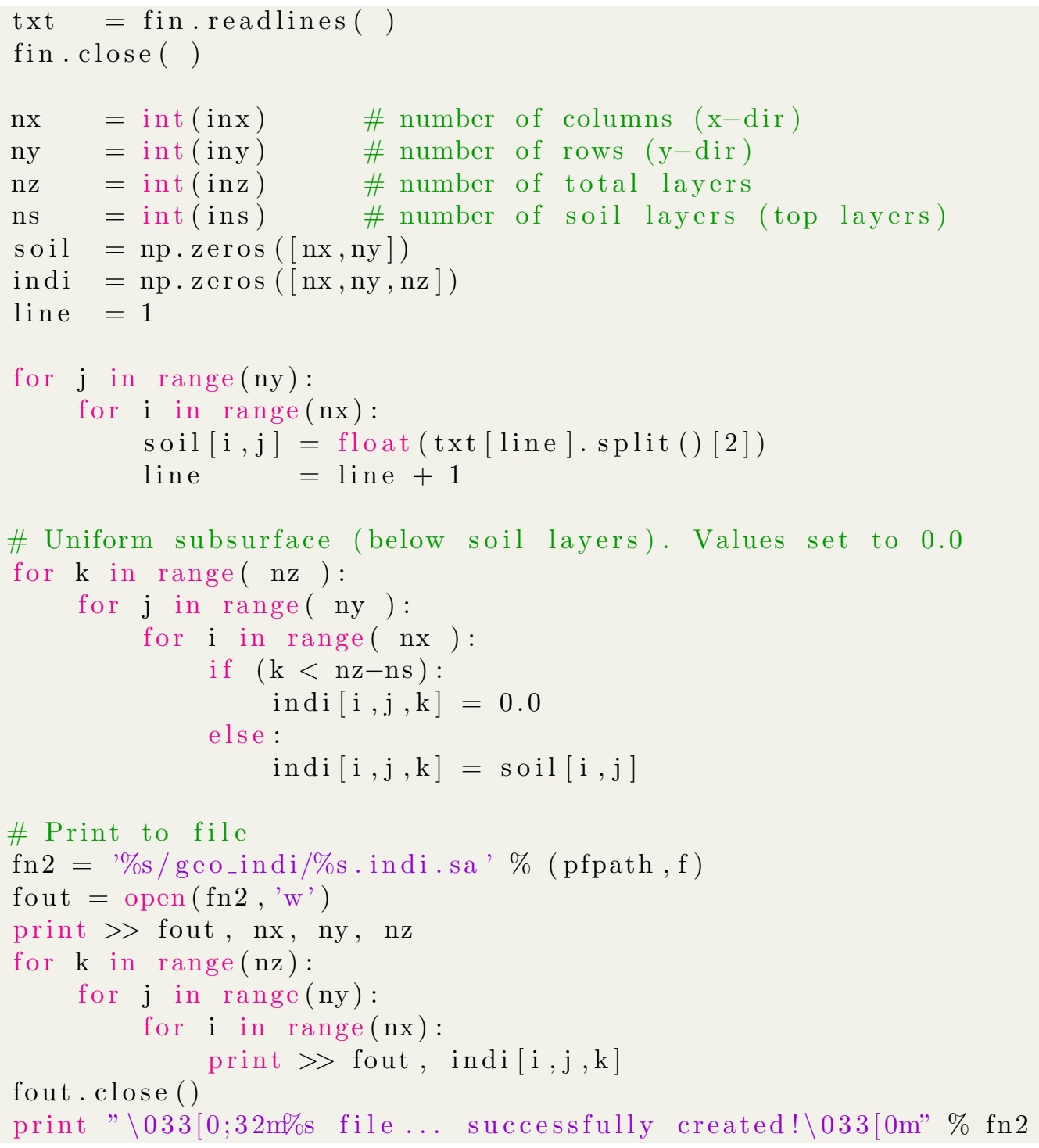

\section{B.2 TCL script to process flat areas, fill pits and set slopes in Parflow domain}

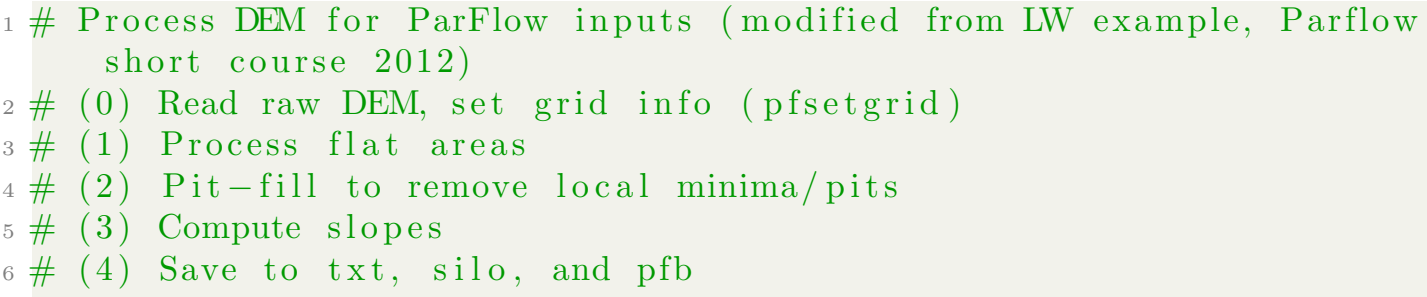




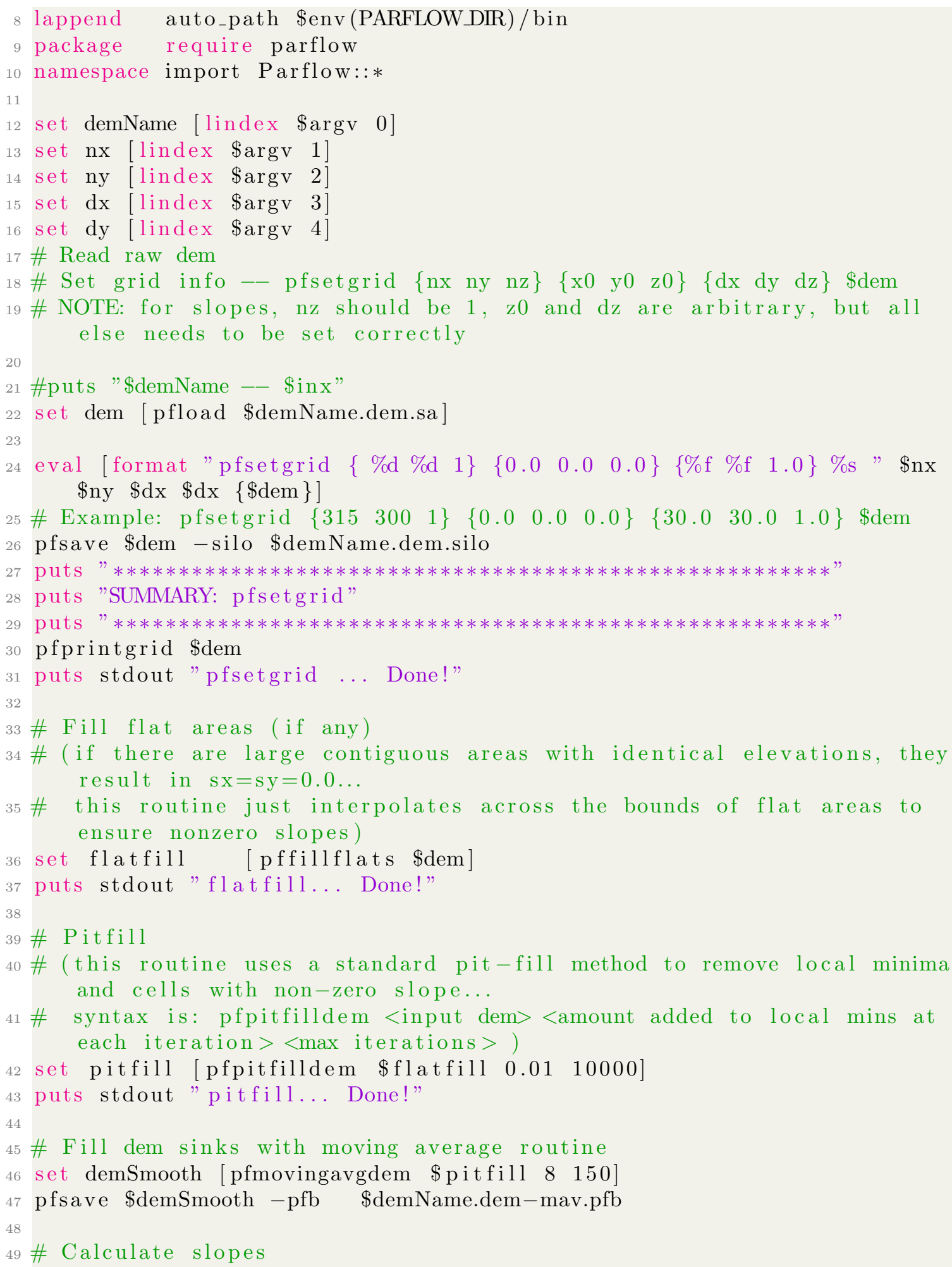




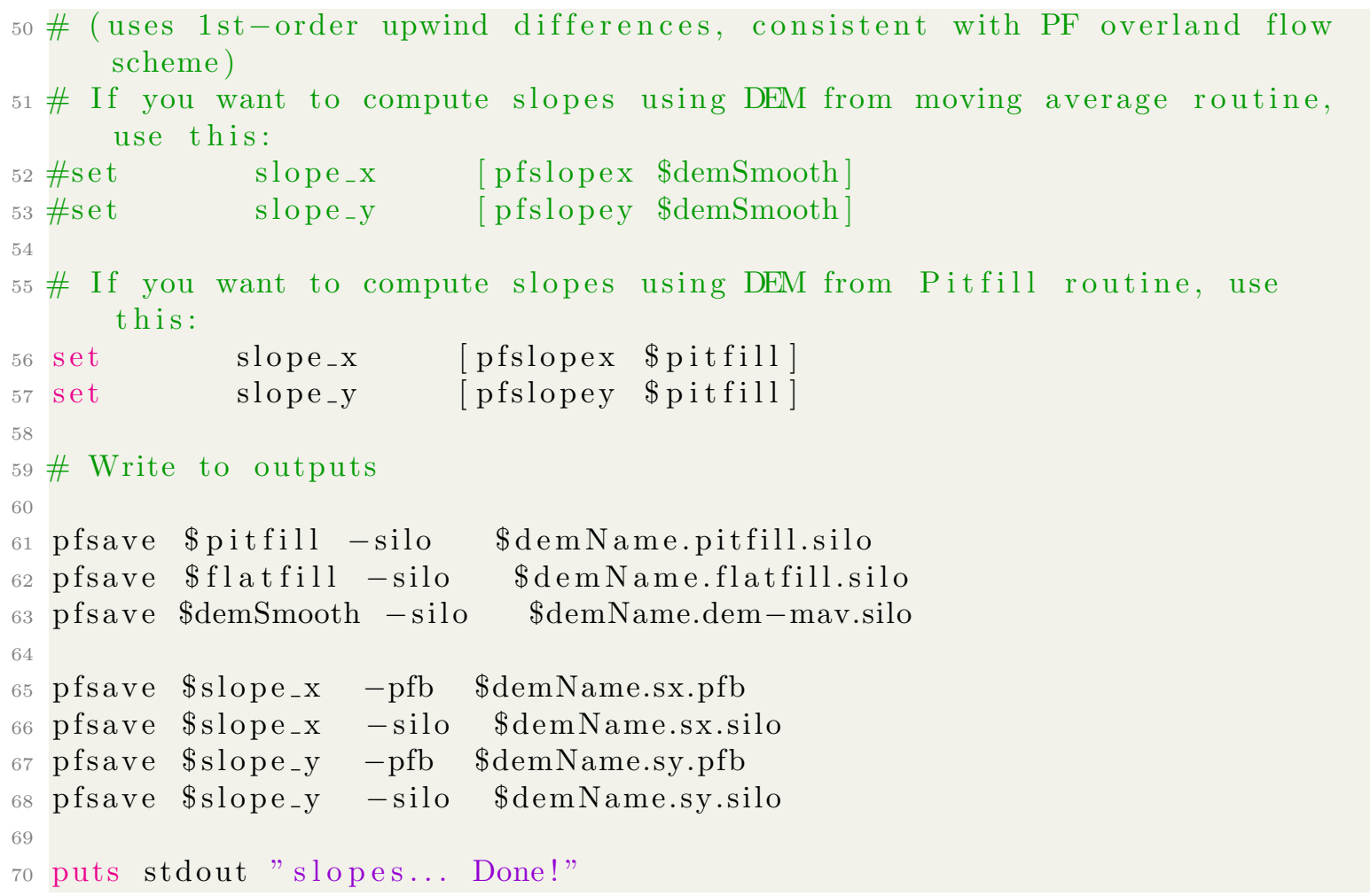

\section{B.3 TCL script to set soil indicators}

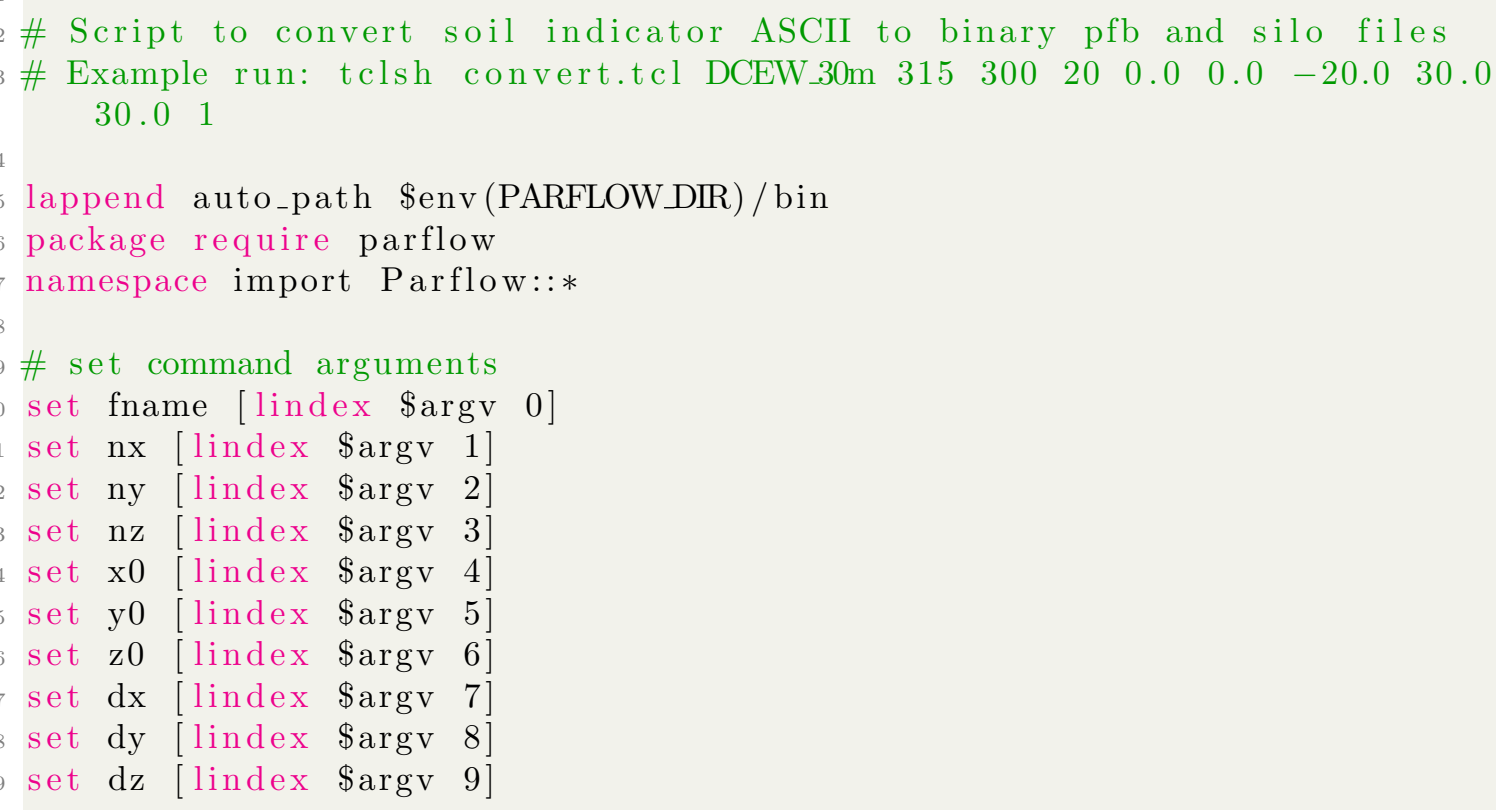




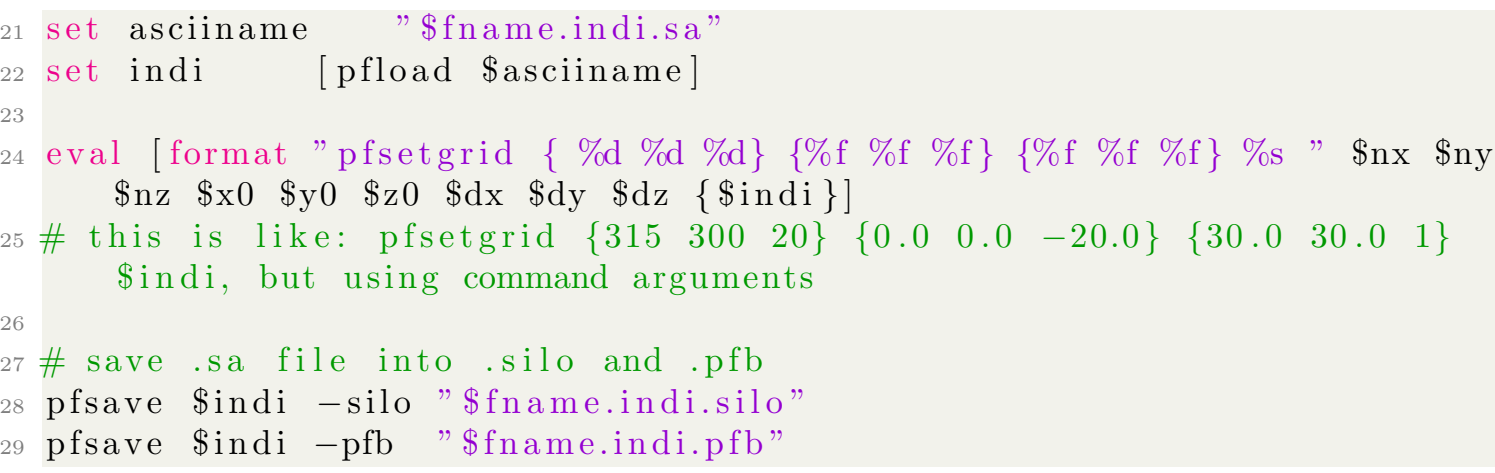

\section{B.4 Bash script to run Python functions and TCL scripts}

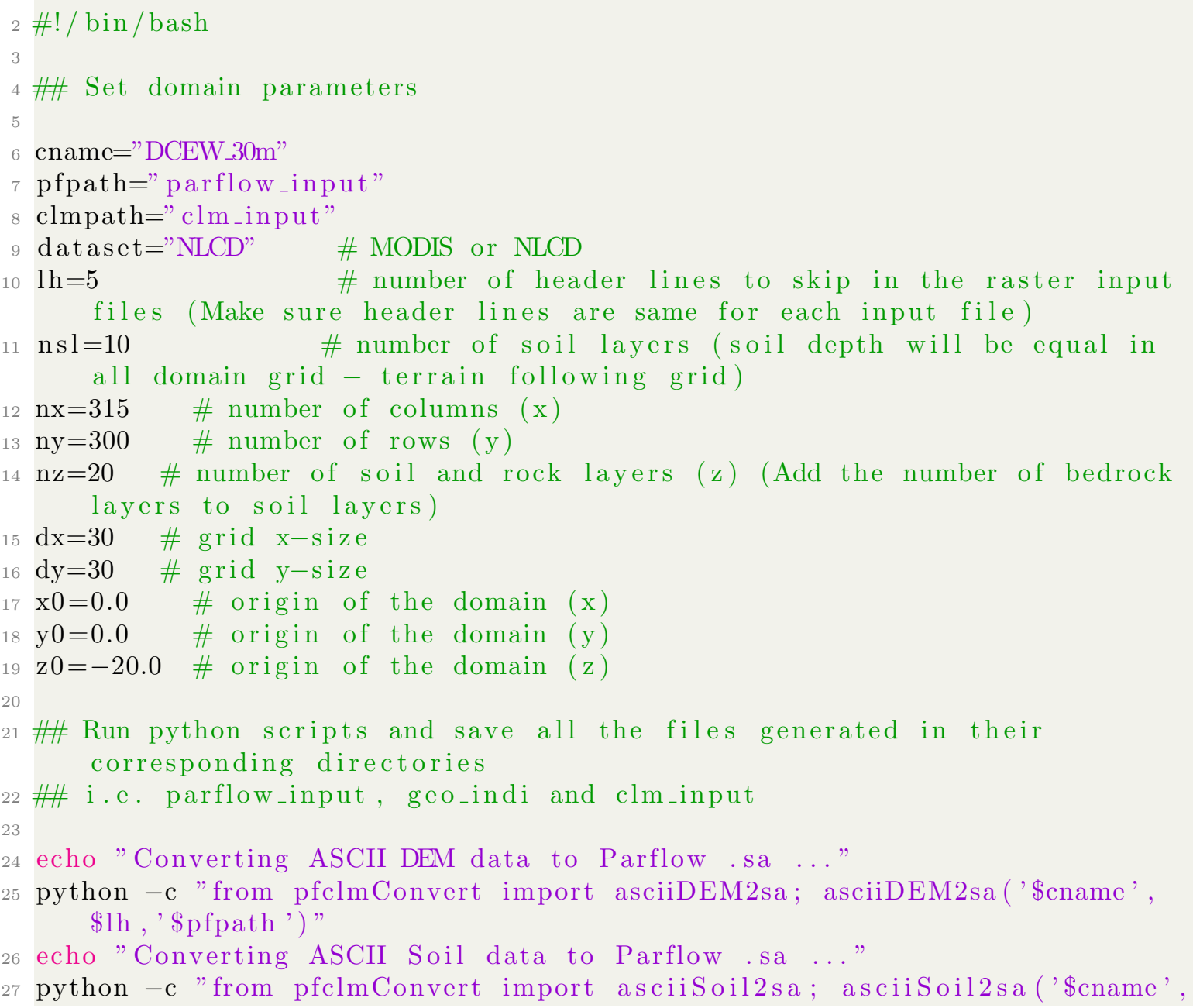




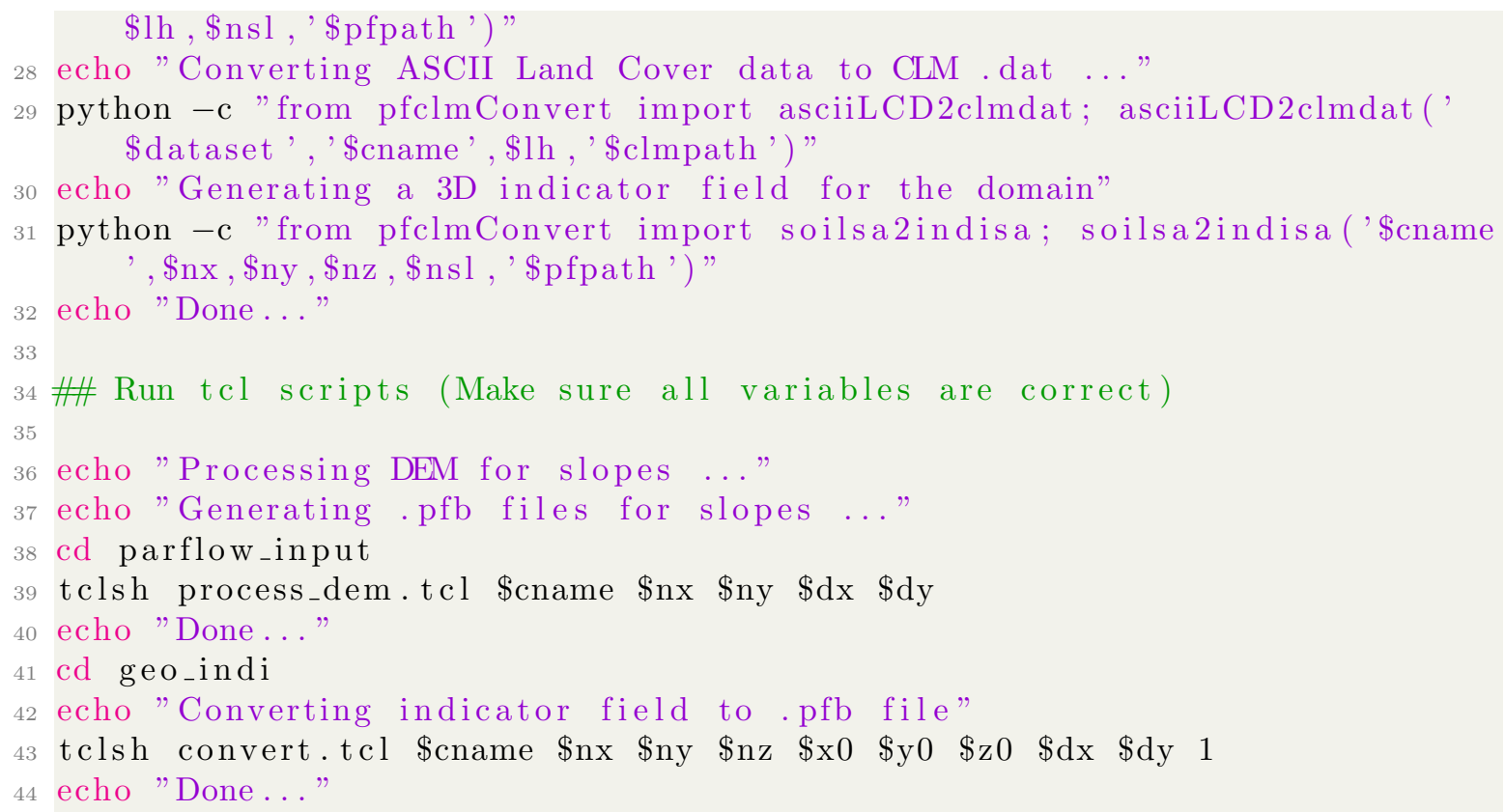




\section{APPENDIX C:}

\section{PARFLOW-CLM MODELING SCRIPTS}




\section{C.1 TCL script to run Parflow-CLM model}

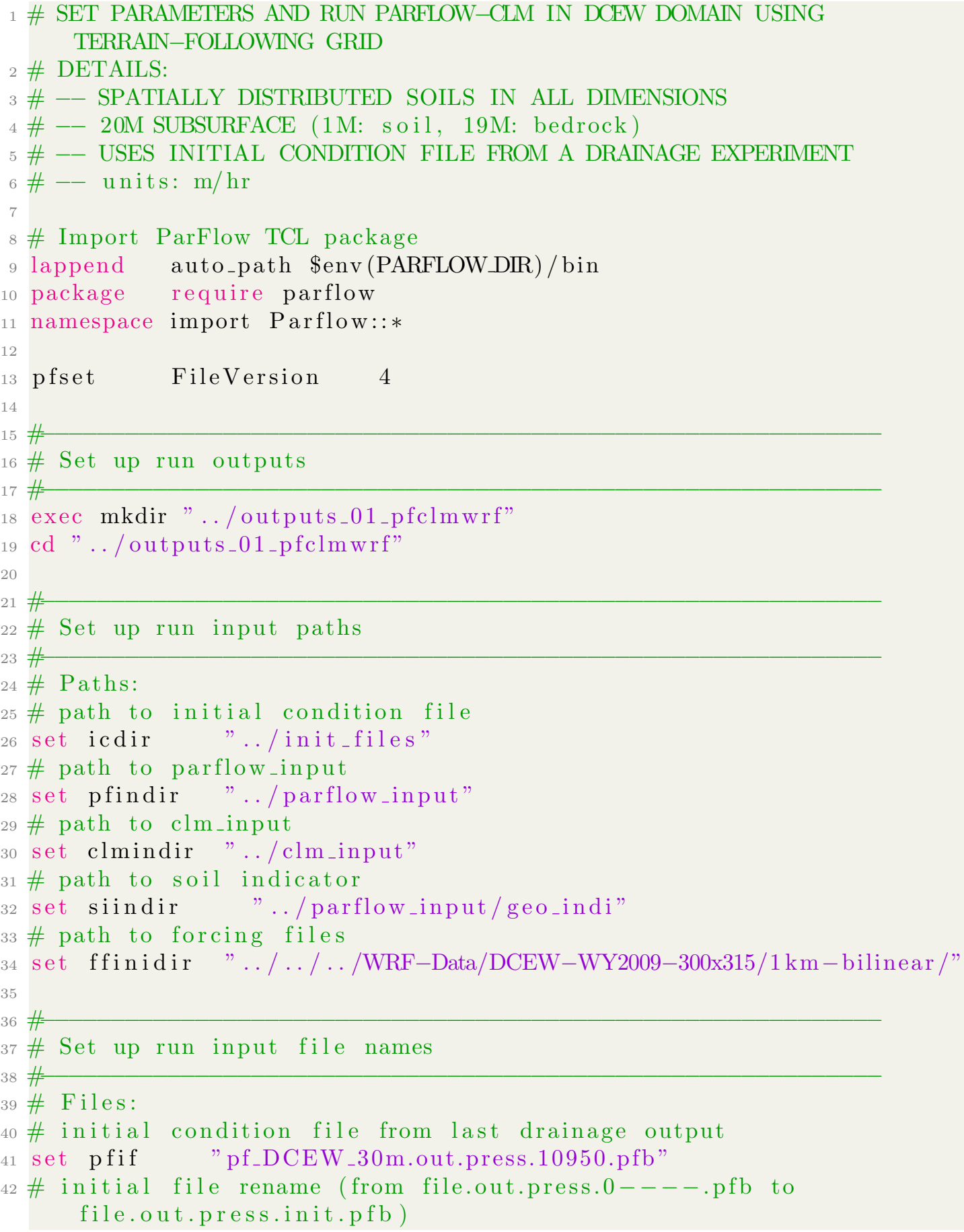




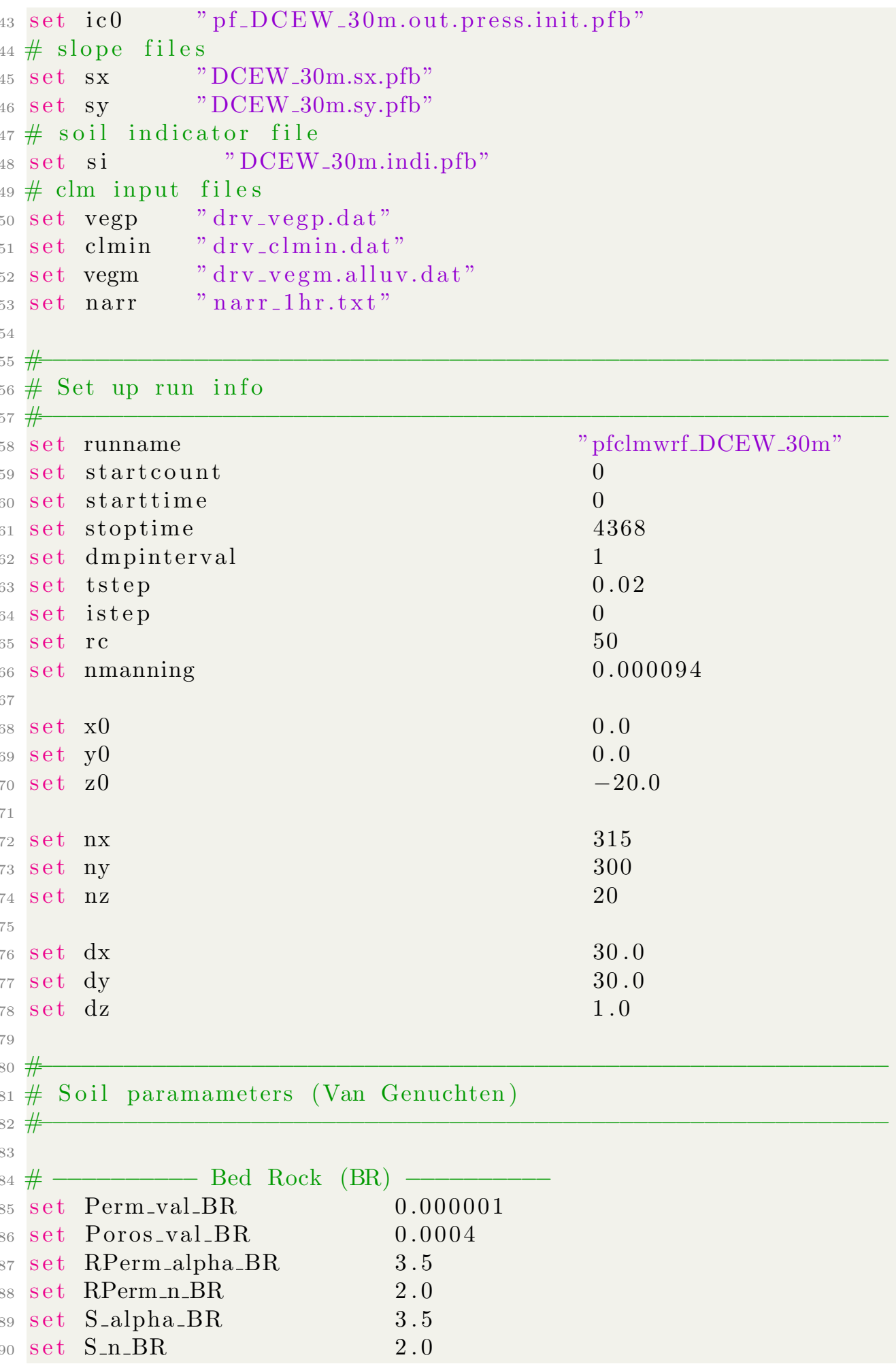




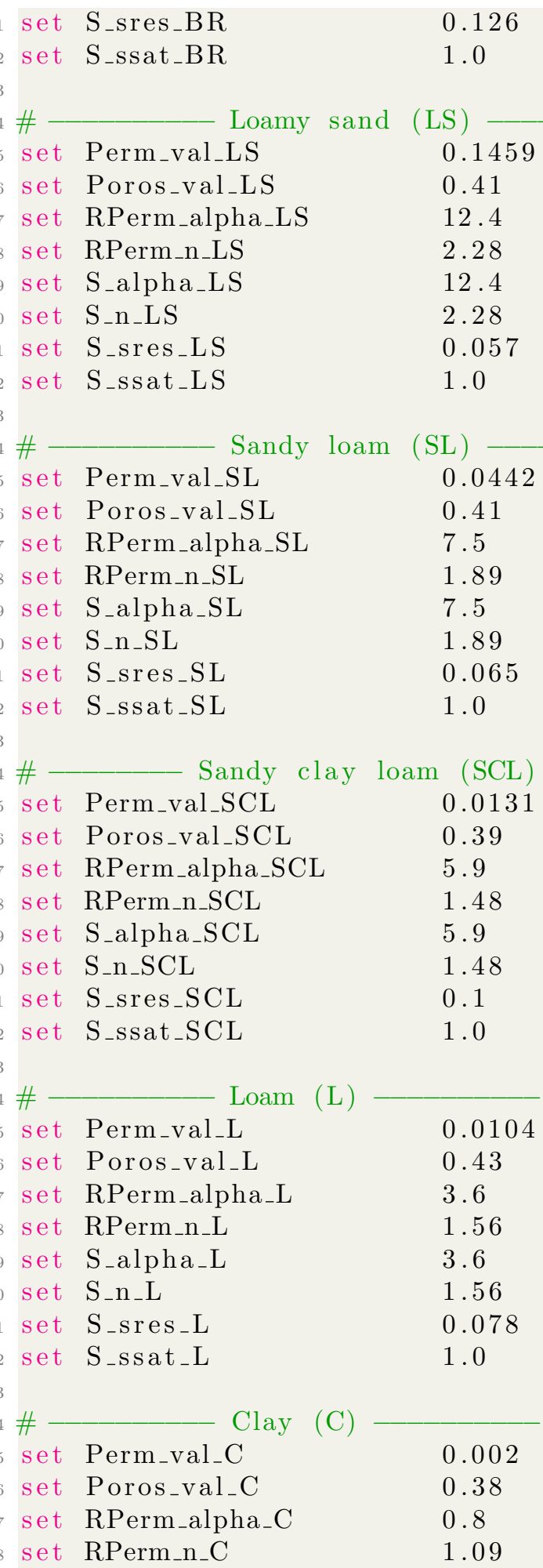




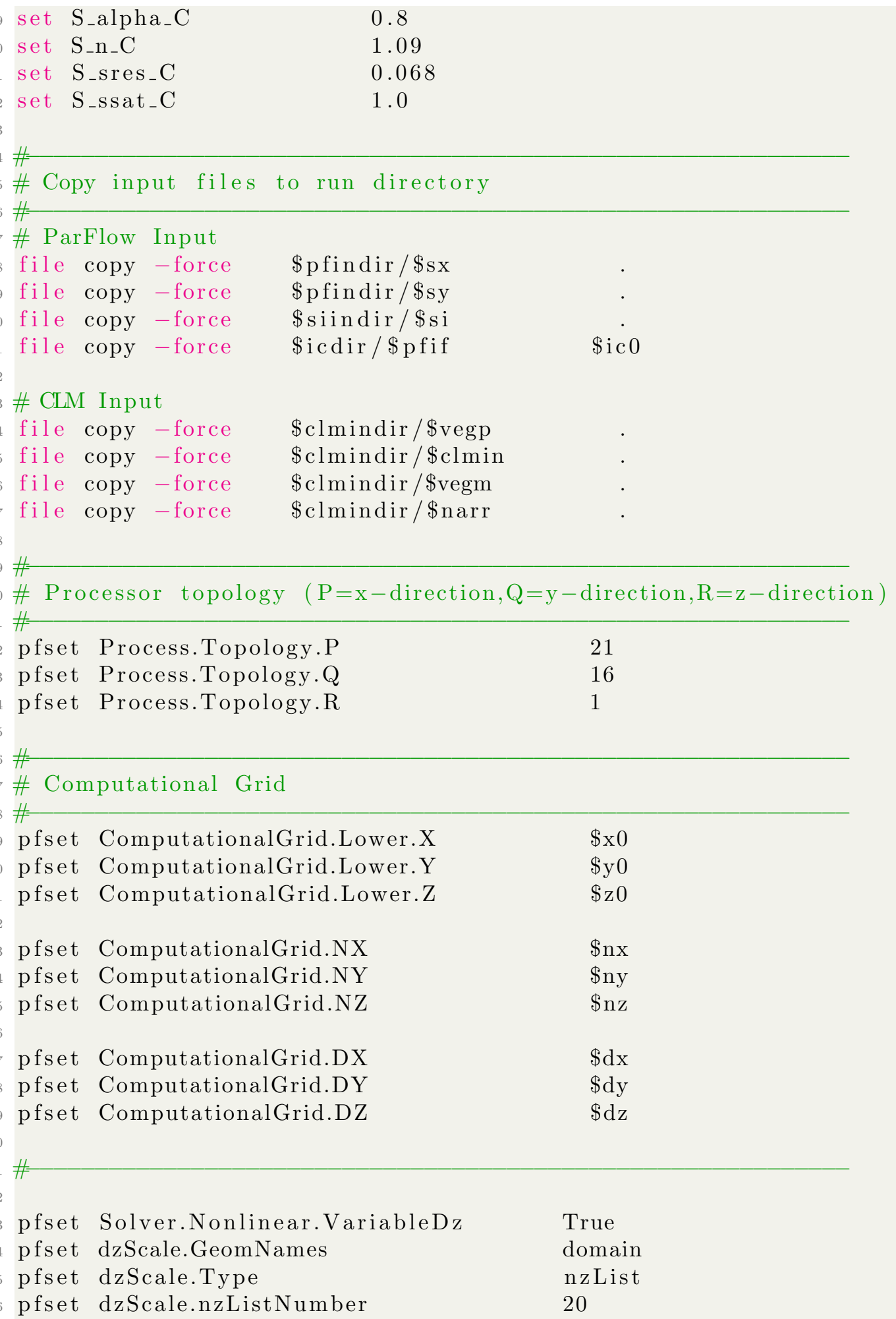




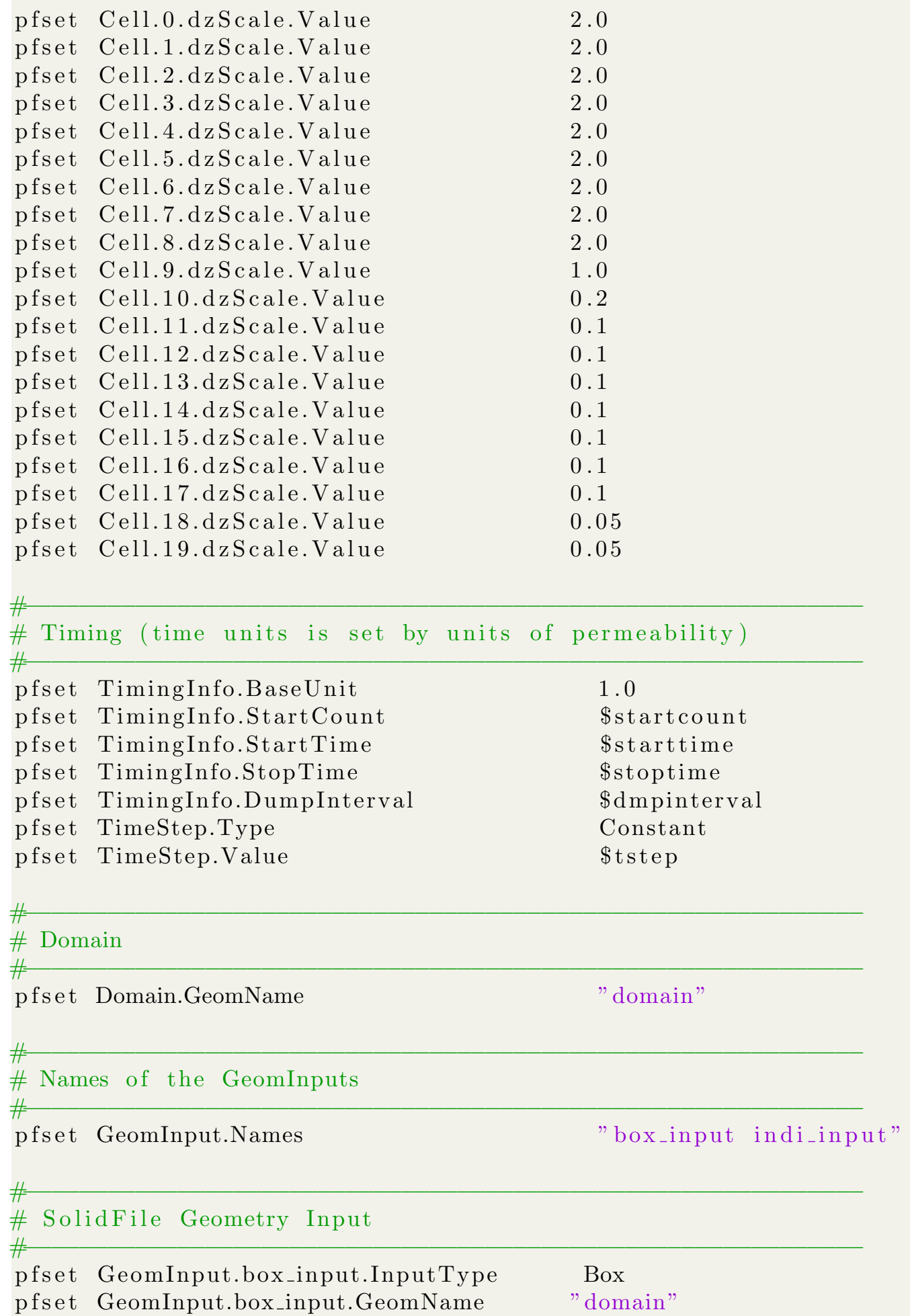




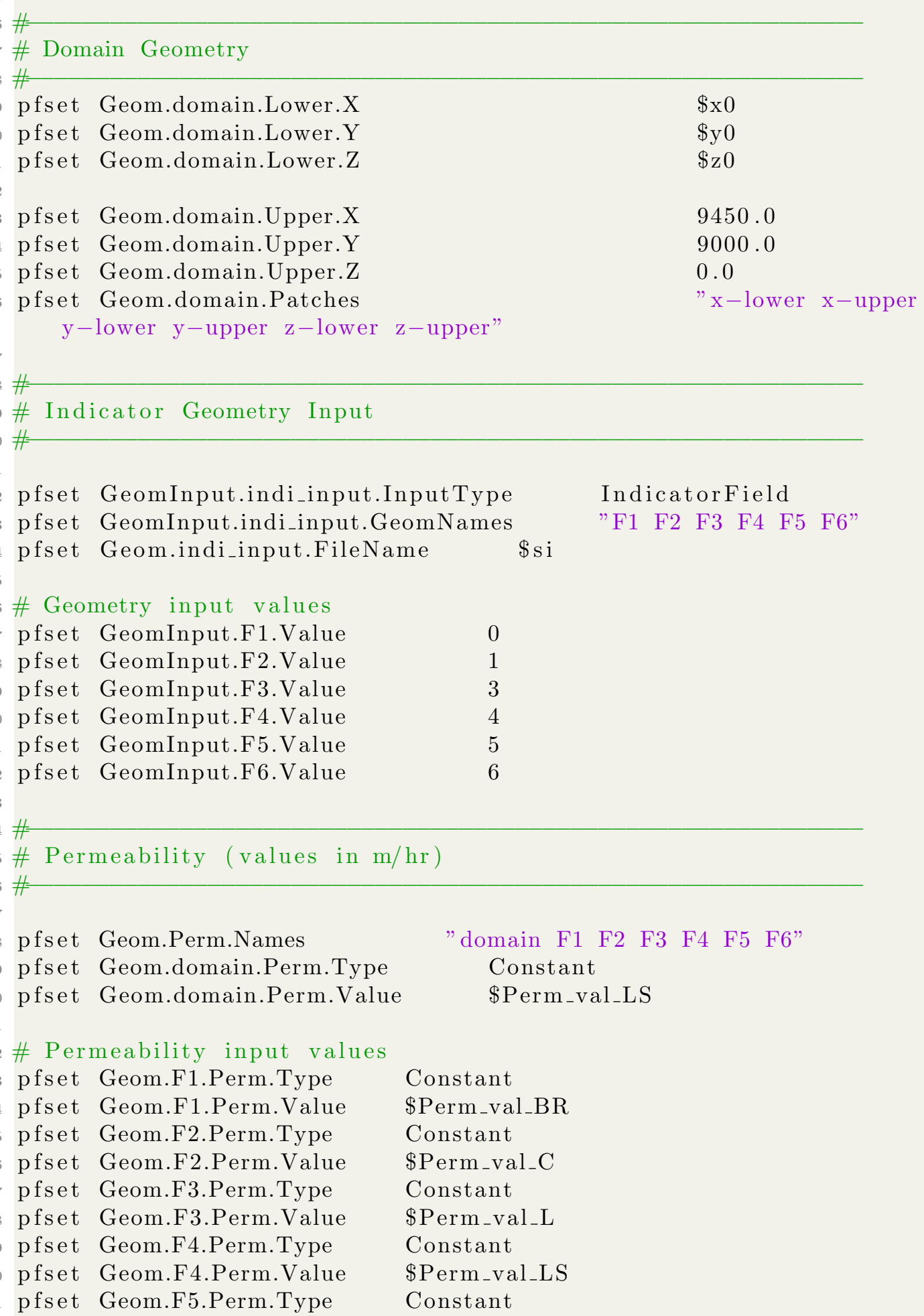




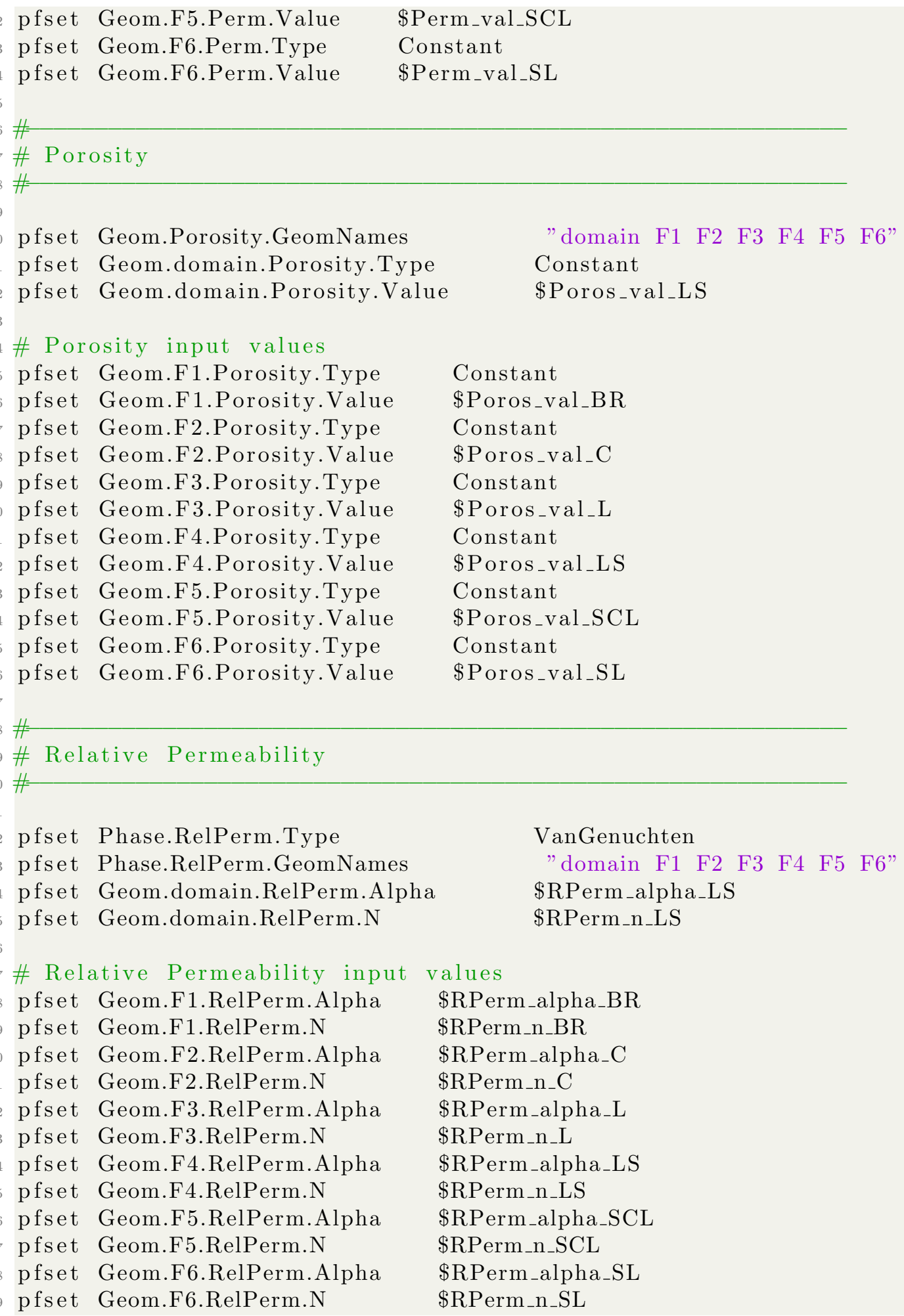

VanGenuchten "domain F1 F2 F3 F4 F5 F6" $\$ R P e r m \_a l p h a \_L S$ \$RPerm_n_LS

\$RPerm_alpha_C

\$RPerm_n_C

\$RPerm_alpha_L

\$RPerm_n_L

\$RPerm_alpha_LS

\$RPerm_n_LS

\$RPerm_alpha_SCL

\$RPerm_n_SCL

$\$$ RPerm_alpha_SL

\$RPerm_n_SL 


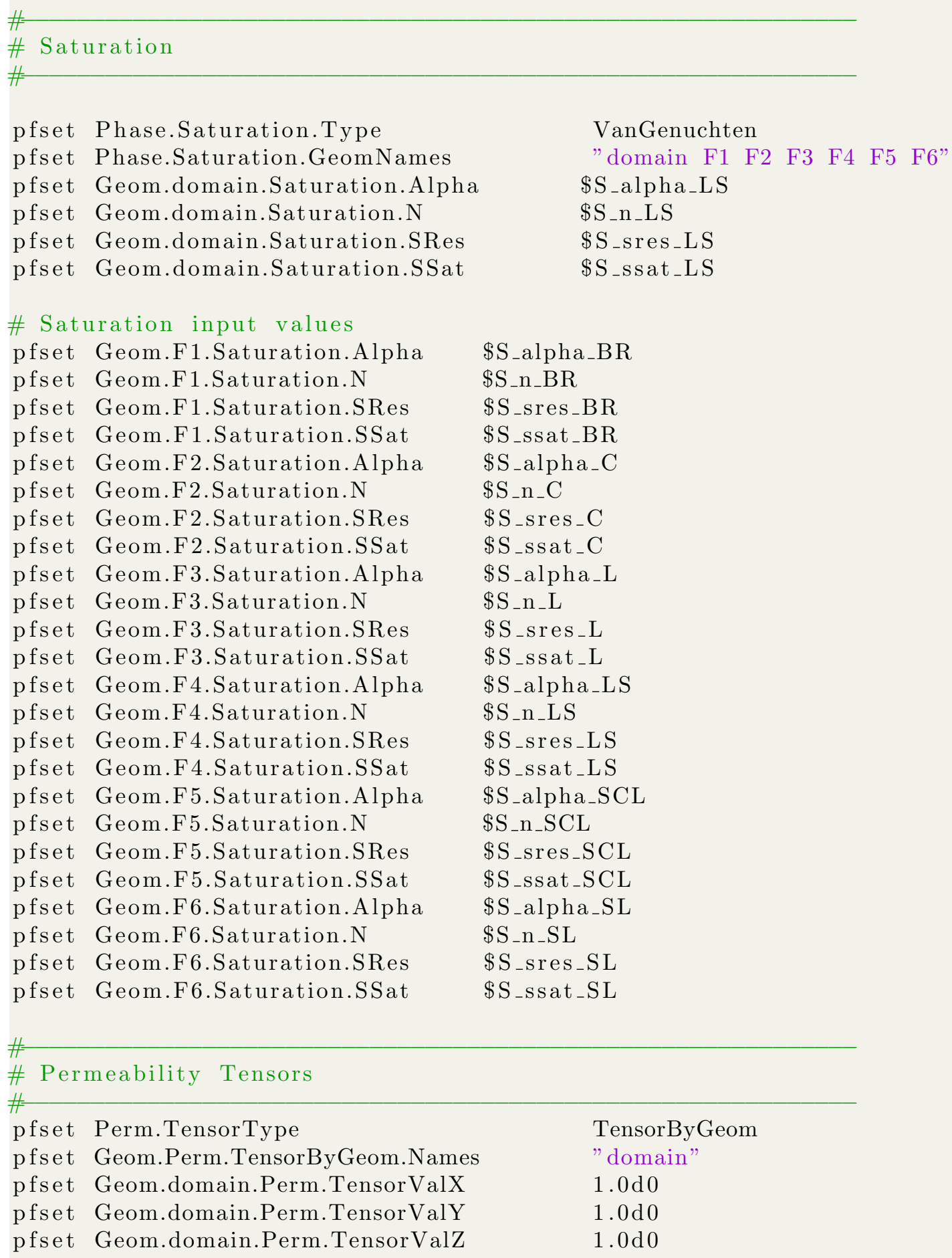




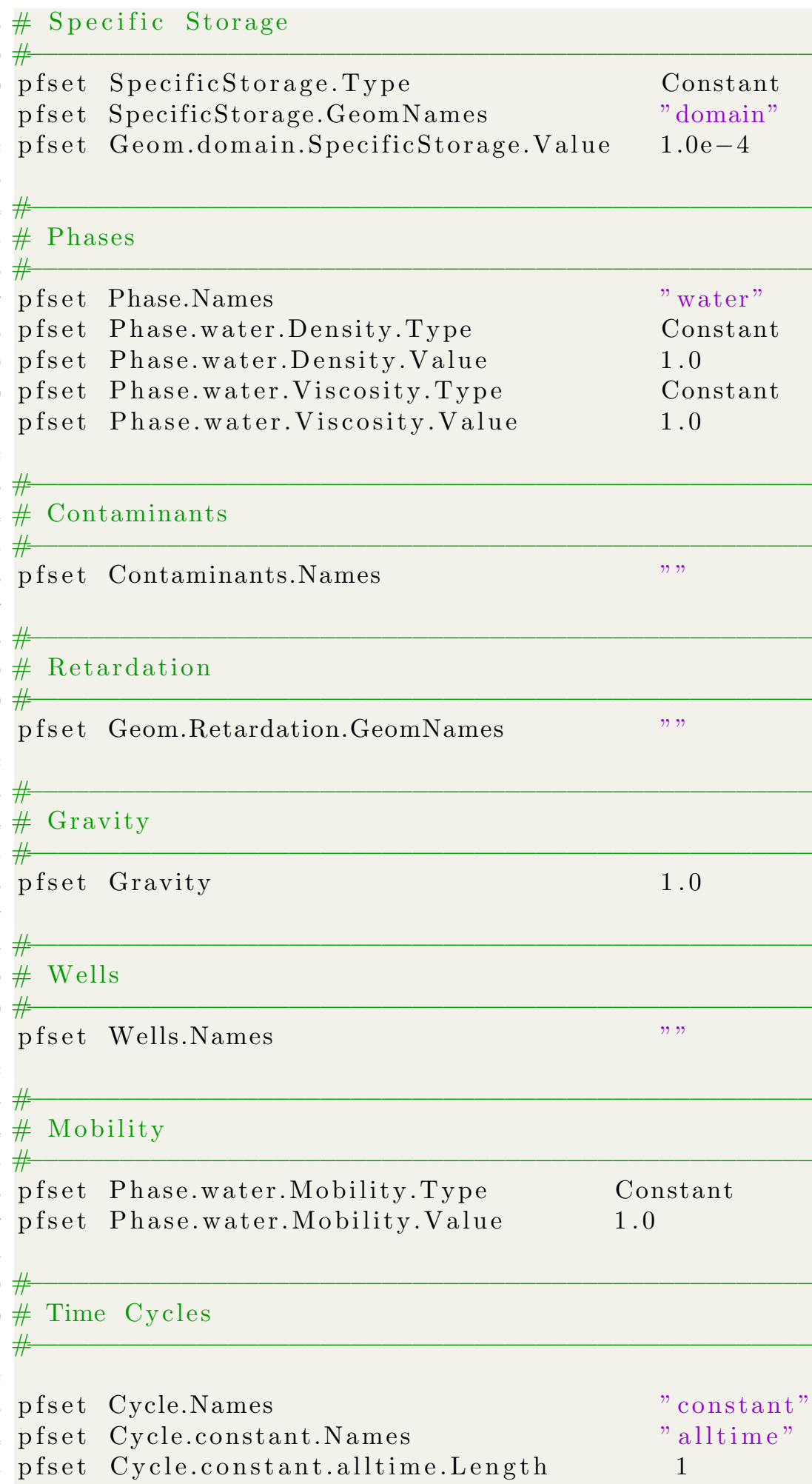


457 \#

458 \#

$$
\begin{aligned}
& 459 \\
& 460
\end{aligned}
$$

473 \#
$-1$

[pfget Geom.domain.Patches]

FluxConst

"constant"

0.0

FluxConst

"constant"

0.0

FluxConst

"constant"

0.0

FluxConst

"constant"

0.0

FluxConst

"constant"

0.0

OverlandFlow

"constant"

0.0

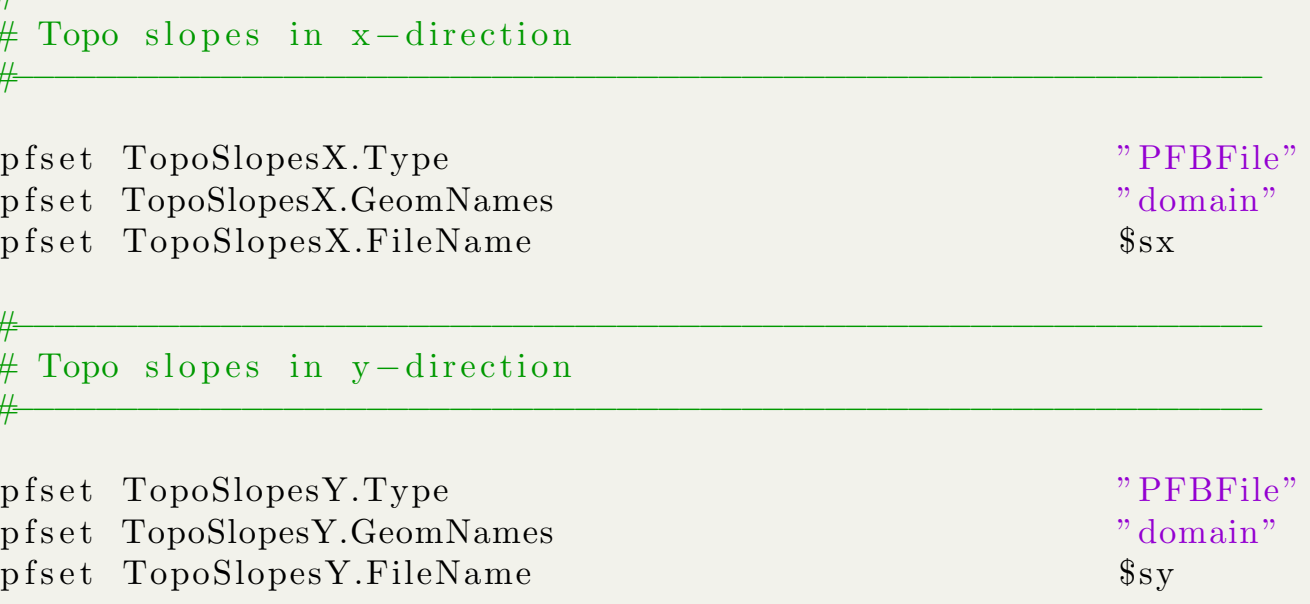




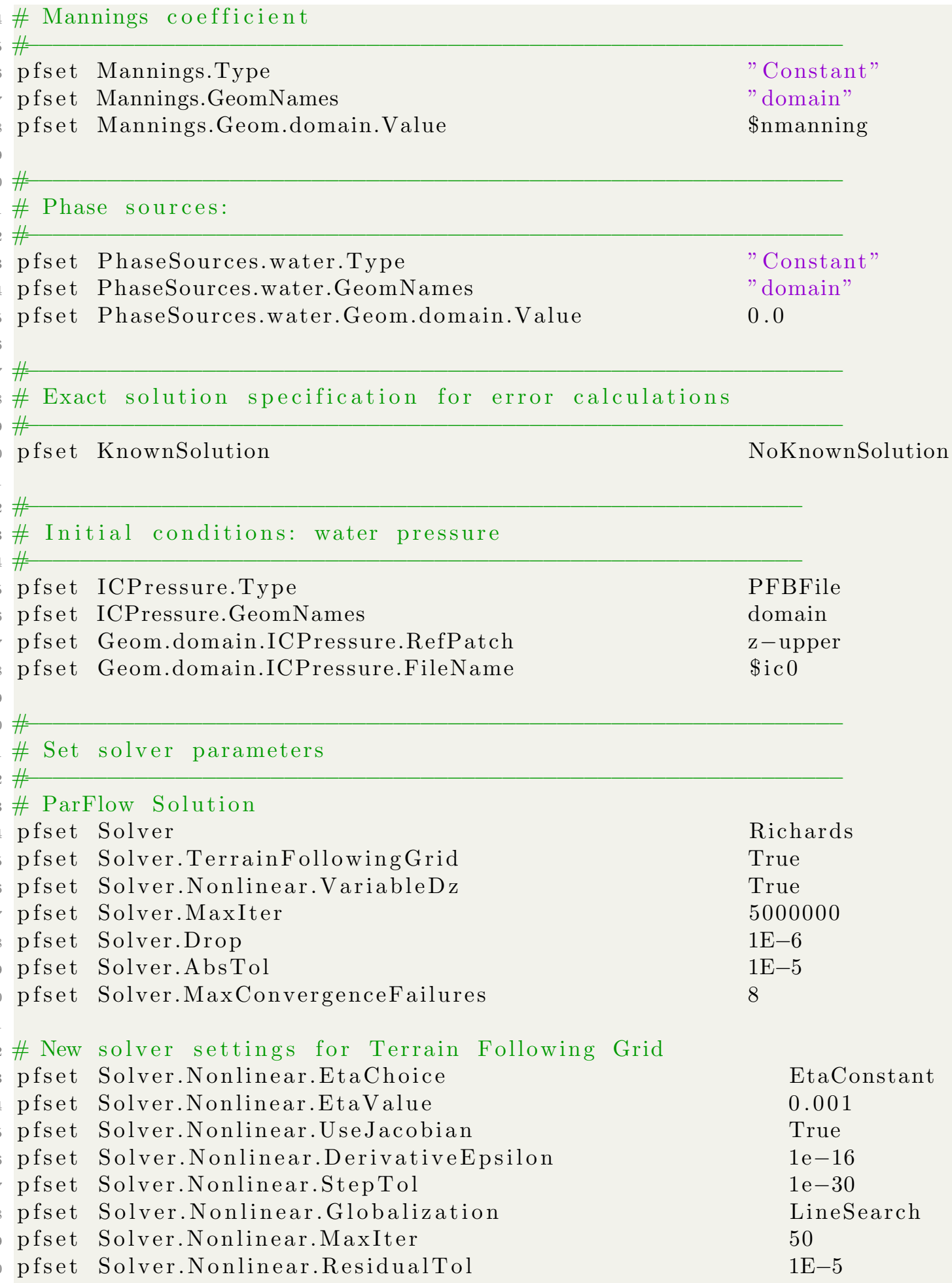




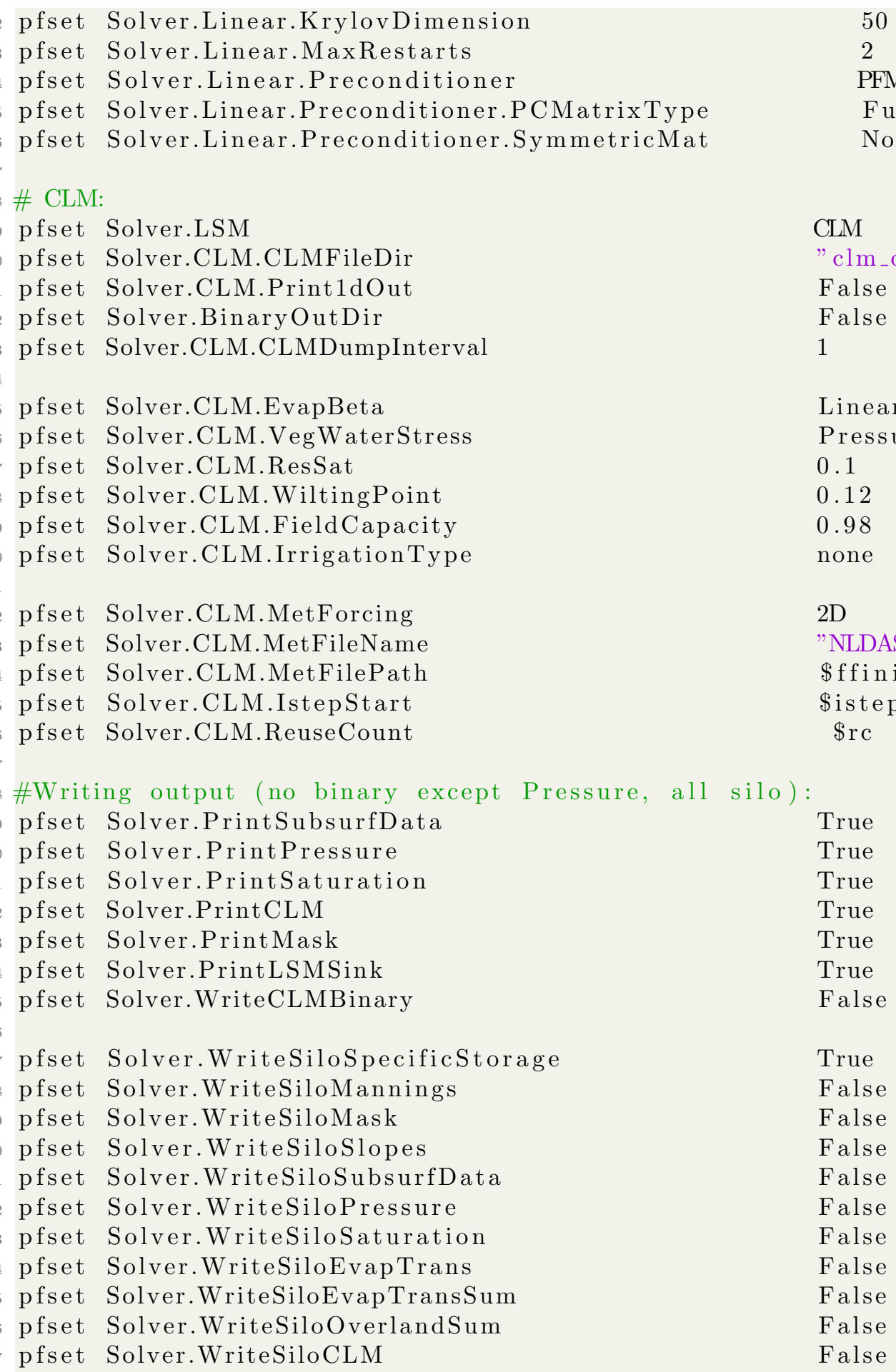


\# \# Run simulation

71 \#

572 puts" "

573 puts "Distributing input files..."

574 pfset ComputationalGrid.NX

575 pfset ComputationalGrid.NY

576 pfset ComputationalGrid.NZ

$\$ n x$

pfdist $\$ s x$

pfdist $\$ s y$

pfset ComputationalGrid.NX \$nx

pfset ComputationalGrid.NY \$ny

pfset ComputationalGrid.NZ \$nz

pfdist $\$$ si

pfdist $\$$ ic0

puts"

puts "Executing pfrun..."

pfrun \$runname

puts" "

\# Undistribute files

3 \#

4 puts "Undistributing files"

pfundist \$runname

pfundist $\$ s x$

pfundist $\$$ sy

pfundist $\$$ si

pfundist $\$$ ic0

600

601 puts "..DONE."

\section{C.2 TCL script to distribute WRF forcing meteorological data}

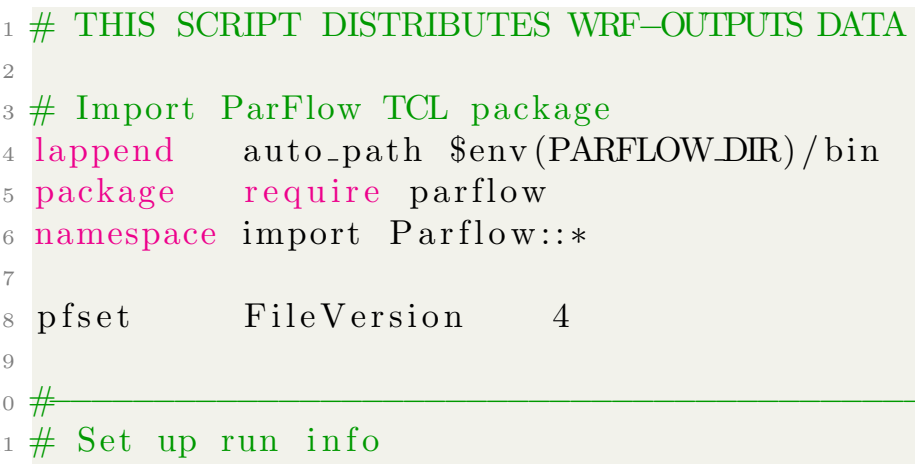




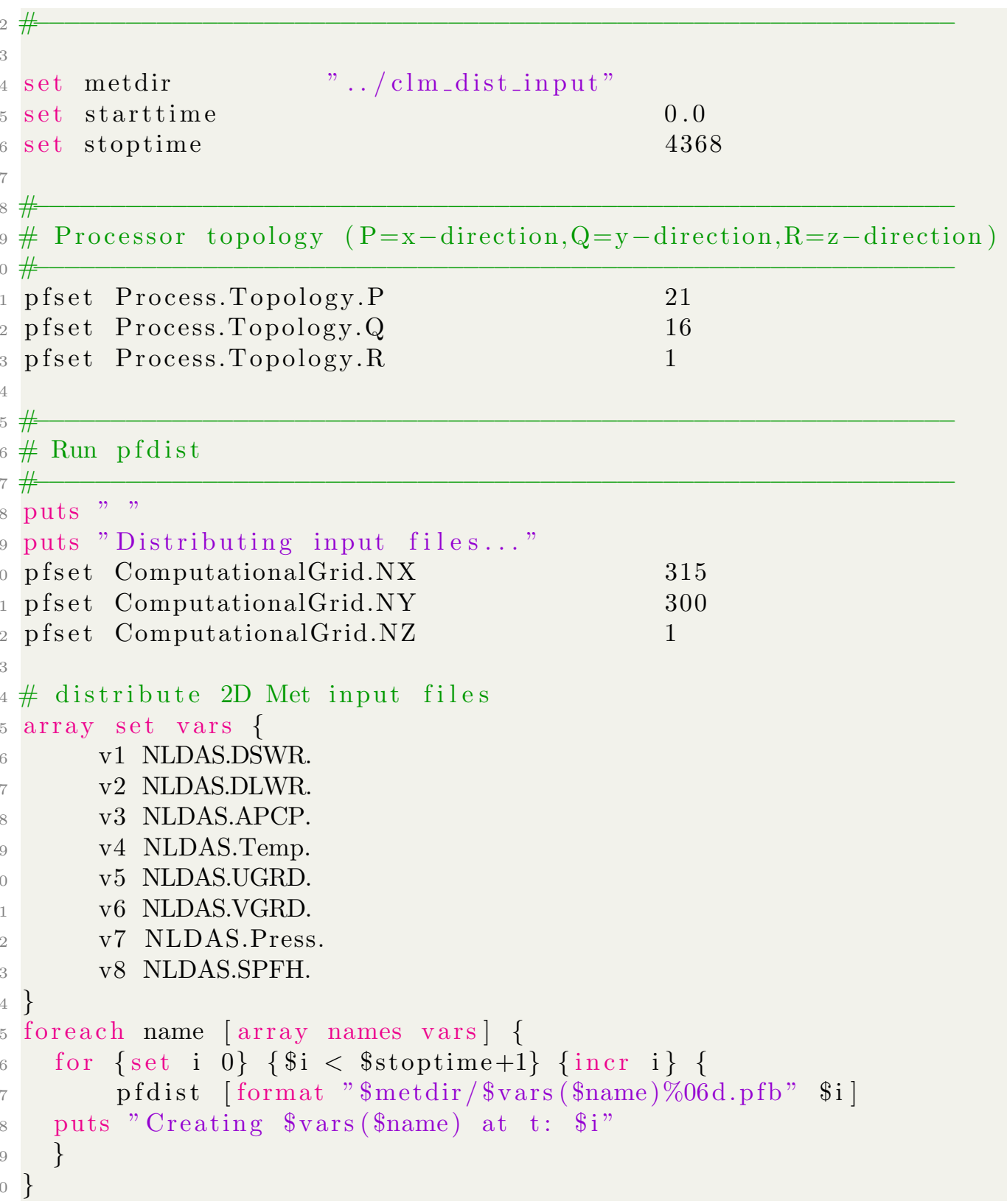




\section{APPENDIX D:}

\section{PARFLOW-CLM POSTPROCESSING SCRIPTS}




\section{D.1 TCL script for streamfow estimation}

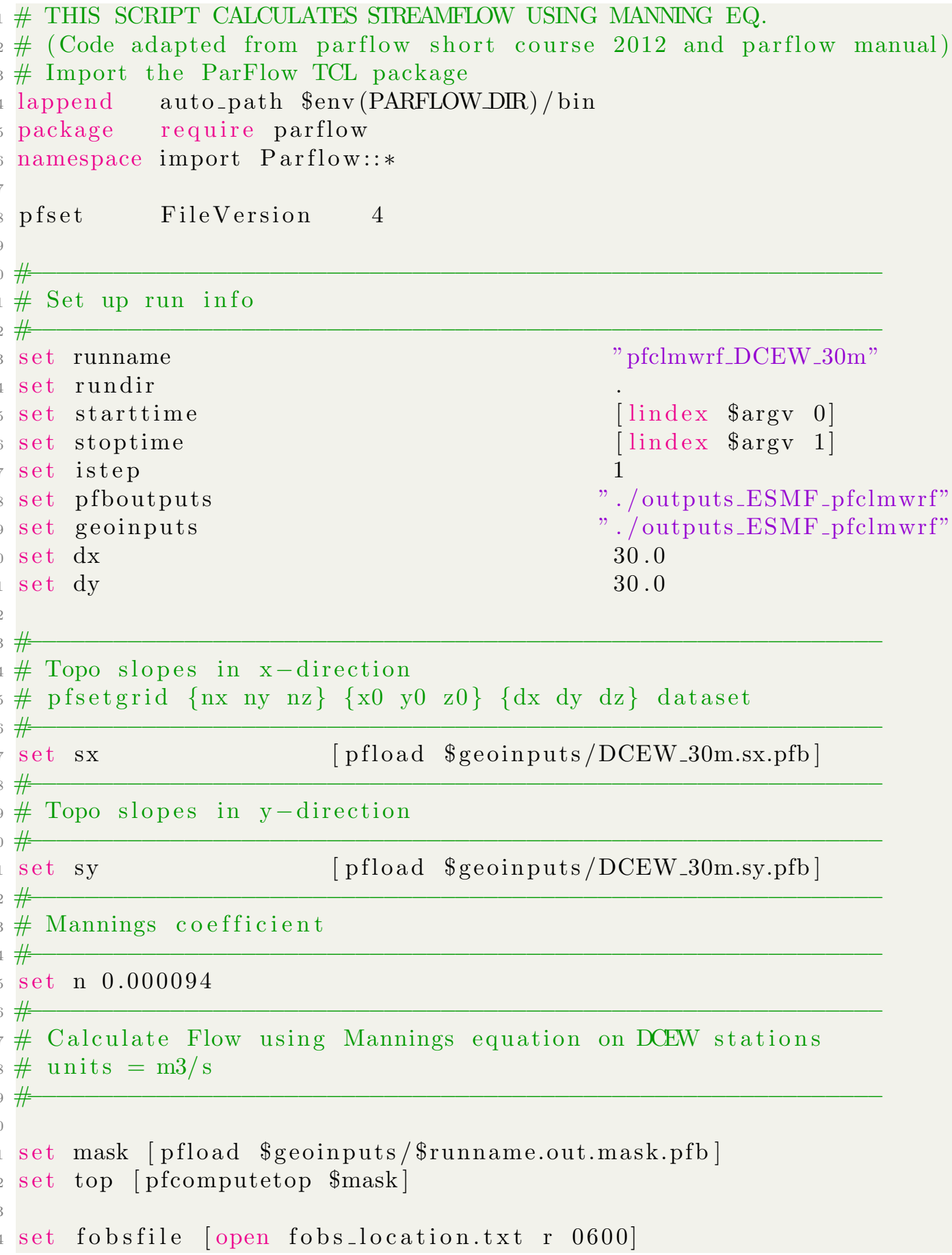




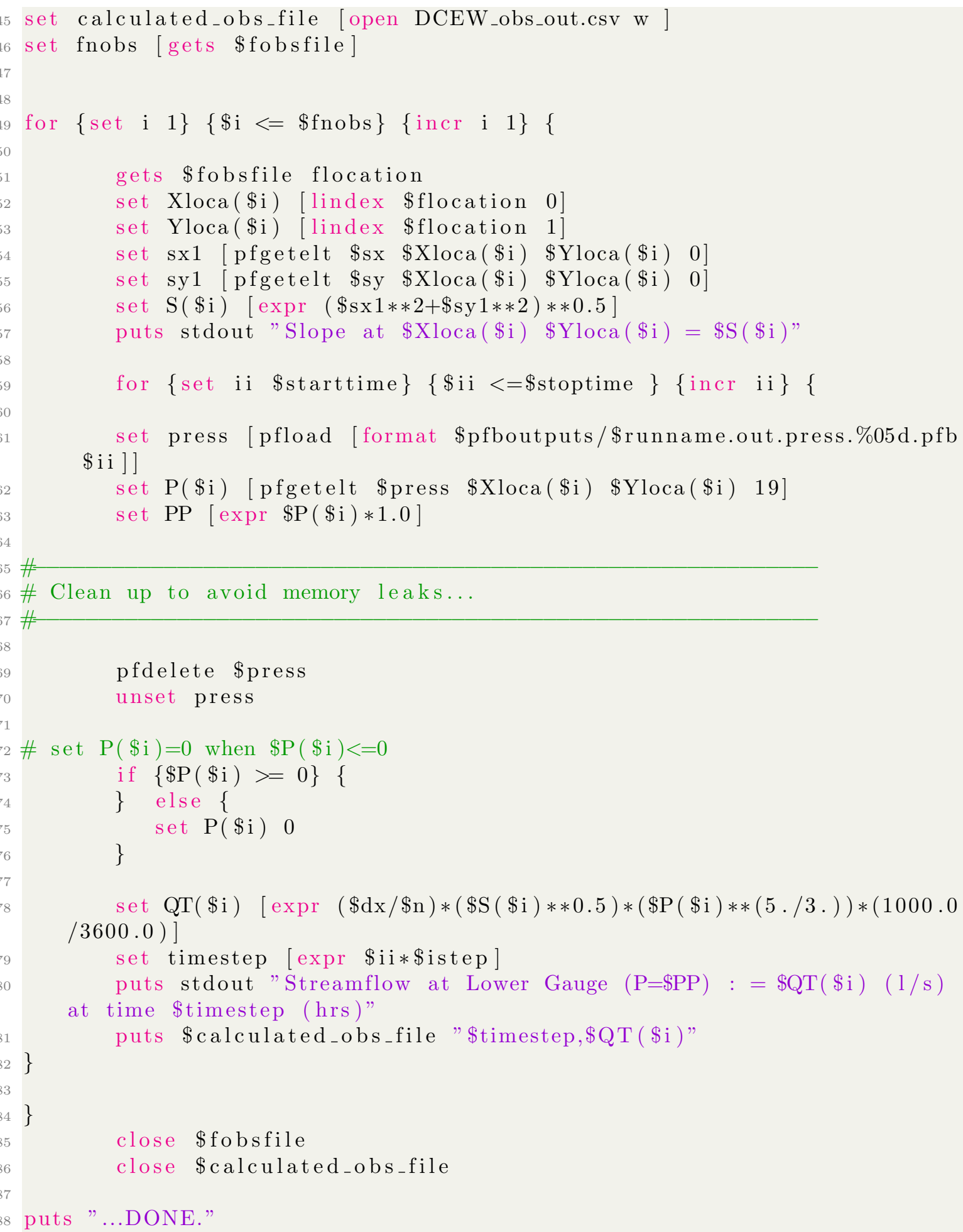




\section{D.2 TCL script to get SWE data at specific points}

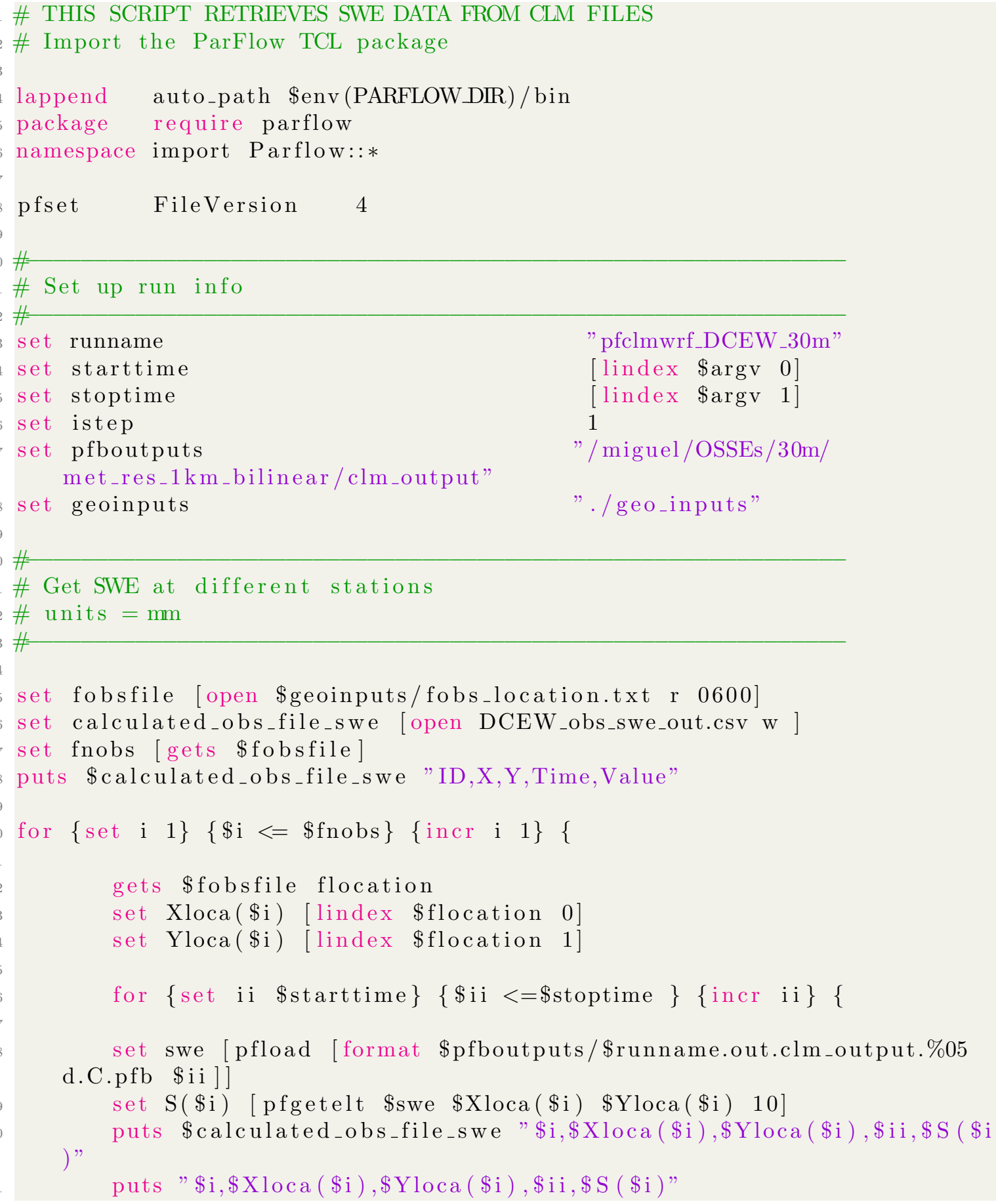




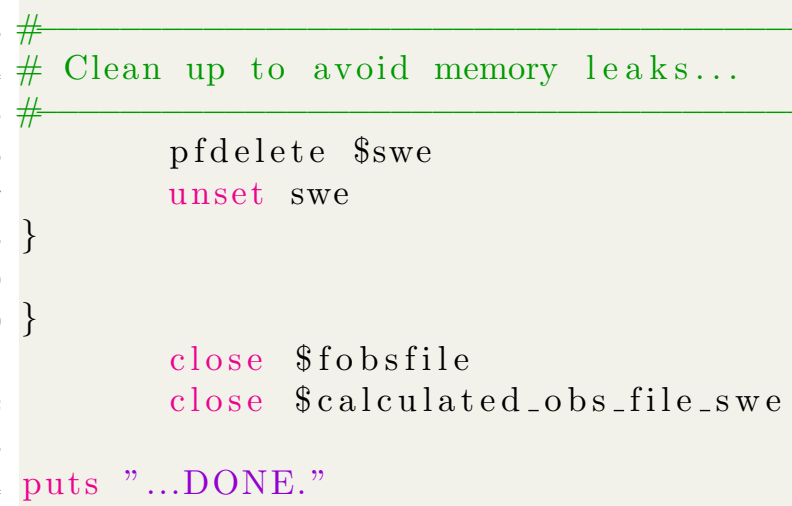

\section{D.3 Python script to convert spatially distributed outputs to vtk format}

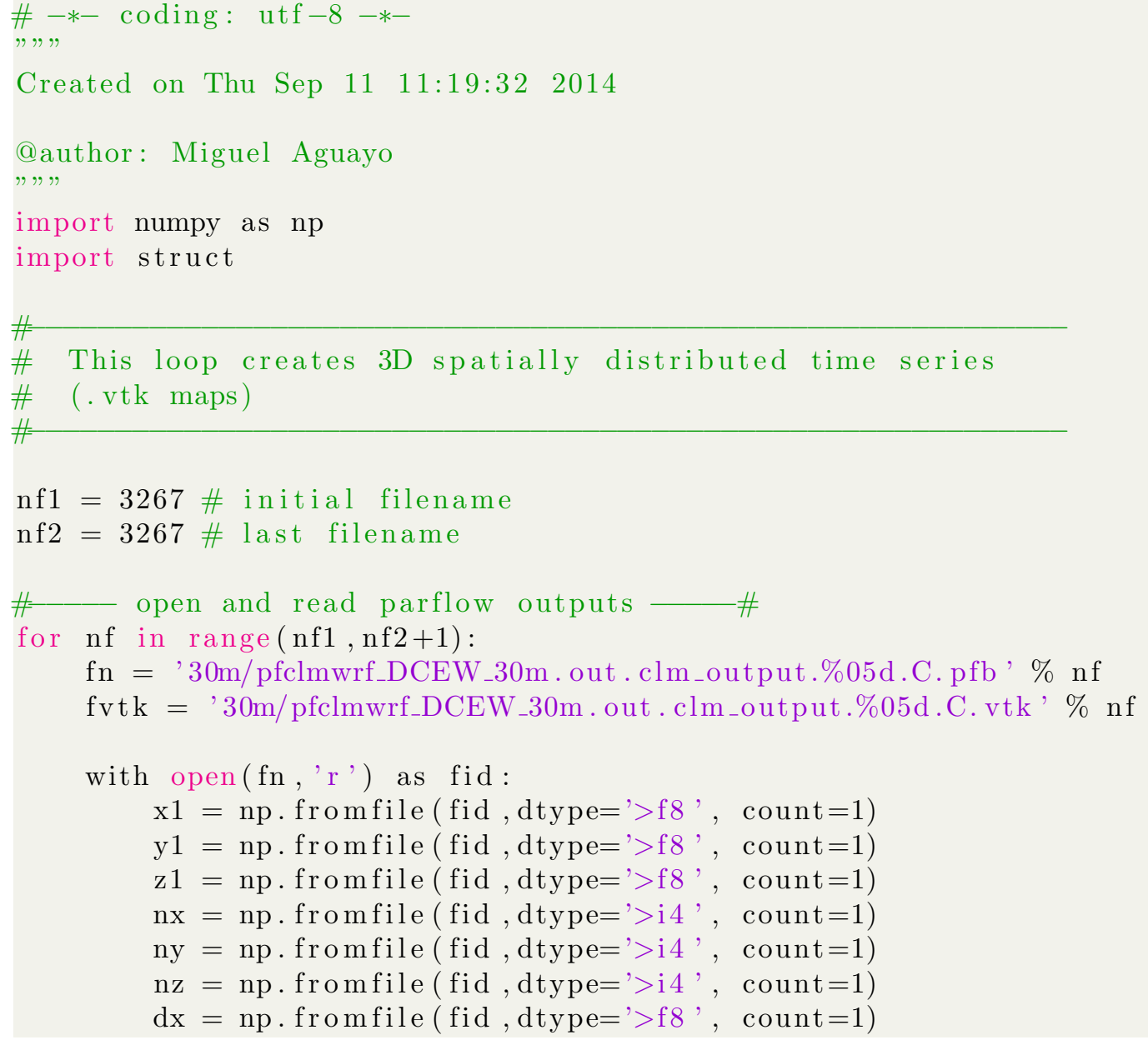




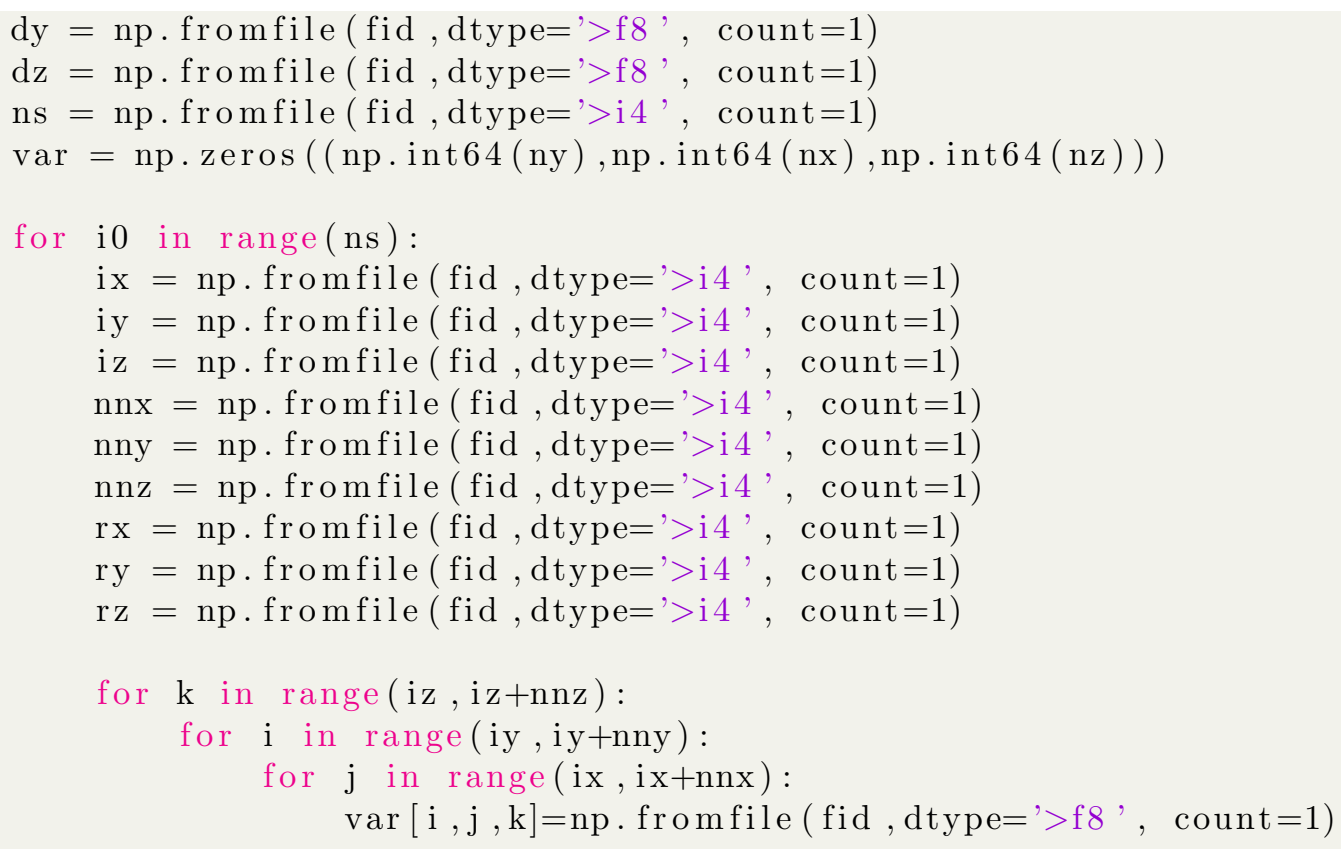




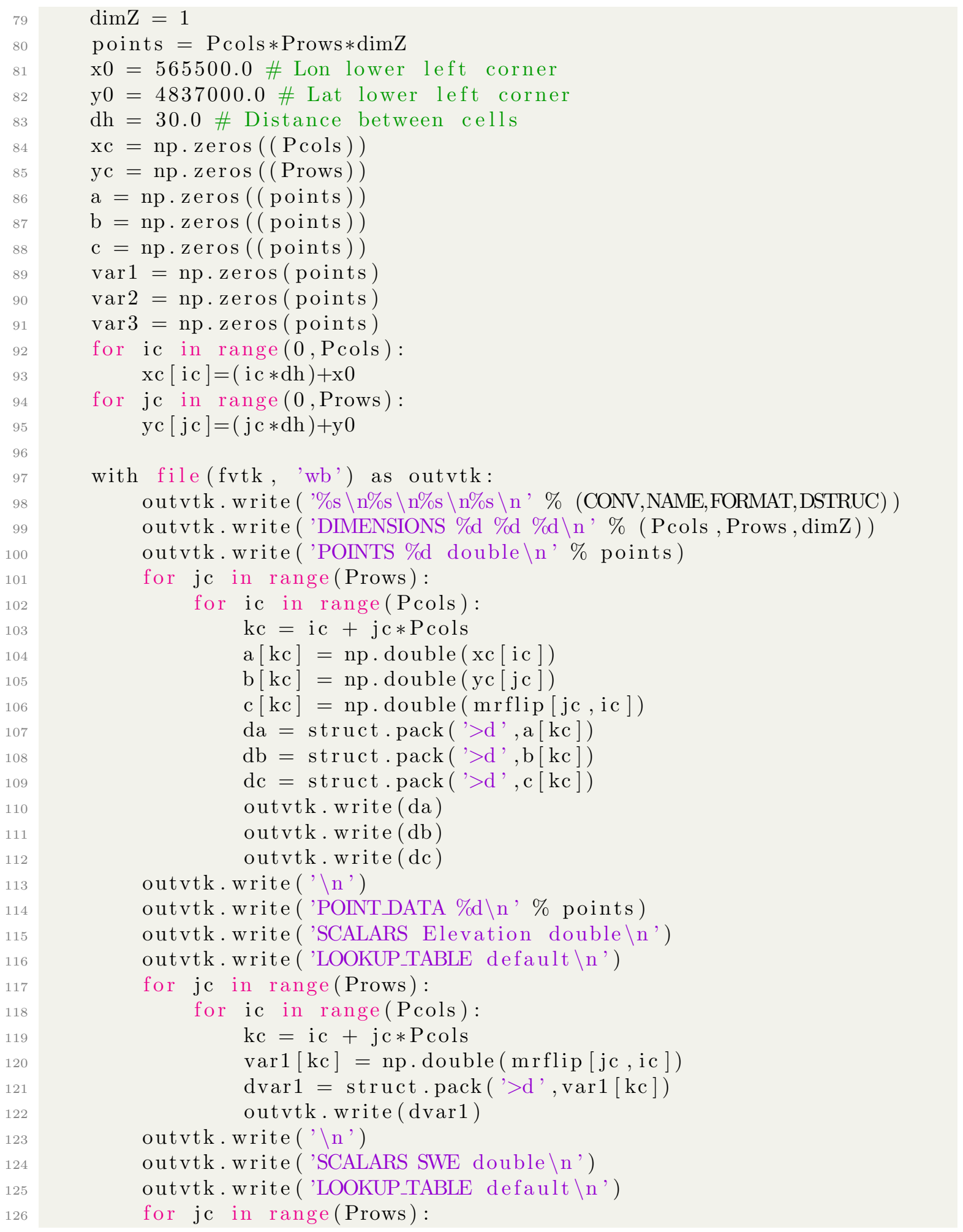




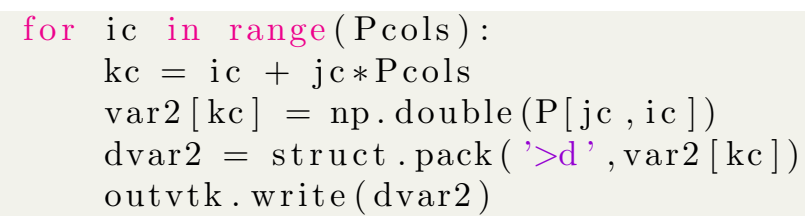

